\title{
ANÁLISE DA COMBUSTÃO EM MOTORES \\ BASEADA NA MEDIÇÃO DE PRESSÃO
}

Dissertação apresentada à Escola

Politécnica da Universidade de São

Paulo para obtenção do título de Mestre em Engenharia.

São Paulo 


\section{CLAYTON BARCELOS ZABEU}

\section{ANÁLISE DA COMBUSTÃO EM MOTORES BASEADA NA MEDIÇÃO DE PRESSÃO}

Dissertação apresentada à Escola Politécnica da Universidade de São Paulo para obtenção do título de Mestre em Engenharia.

Área de Concentração:

Engenharia Mecânica

Orientador:

Francisco Emílio Baccaro Nigro

São Paulo 
À minha família, fonte de permanente incentivo e amparo. 


\section{AGRADECIMENTOS}

Ao grande amigo e orientador Prof. Dr. Francisco Emílio Baccaro Nigro, sempre incansável, pelas importantes lições dadas e estímulo constante.

Ao IPT, por ter a mim propiciado trabalhar com pessoas que deixaram de ser apenas colegas para se tornarem amigas.

A todos que colaboraram para a conclusão deste trabalho. 


\section{SUMÁRIO}

LISTA DE TABELAS

LISTA DE FIGURAS

LISTA DE SÍMBOLOS

RESUMO

"ABSTRACT"

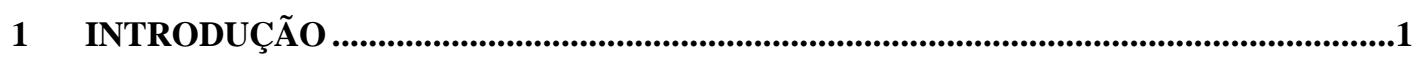

2 OBJETIVO

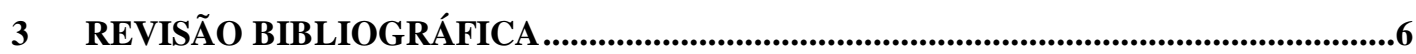

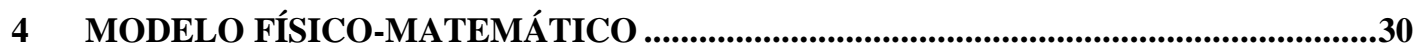

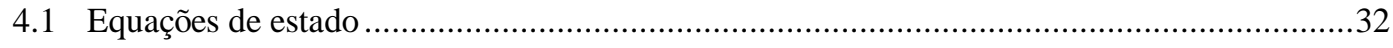

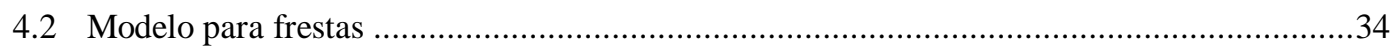

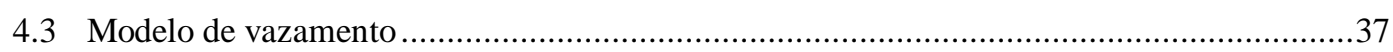

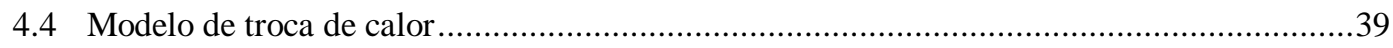

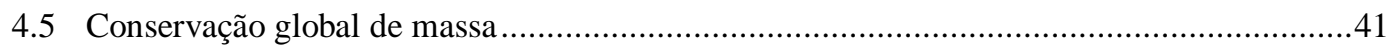

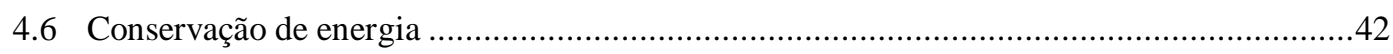

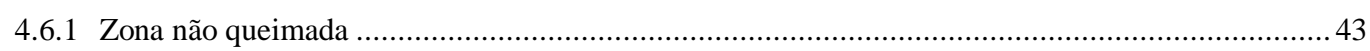

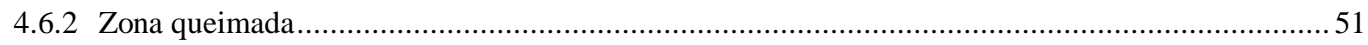

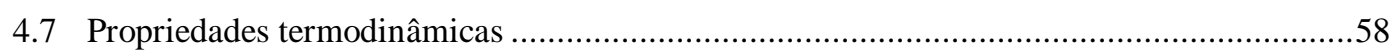

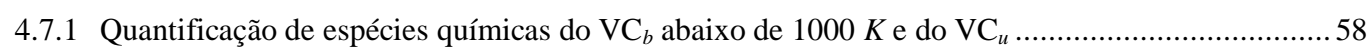

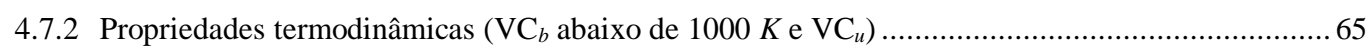

4.7.3 Quantificação de espécies químicas e propriedades termodinâmicas do $\mathrm{VC}_{b}$ acima de $1000 K \ldots . . . .72$

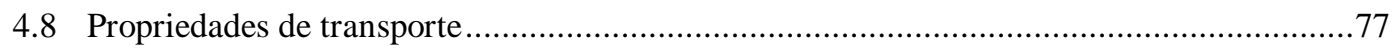

4.8.1 Condutibilidade térmica e viscosidade dinâmica para gases não queimados ................................ 78

4.8.2 Condutibilidade térmica e viscosidade dinâmica para gases queimados .................................... 78

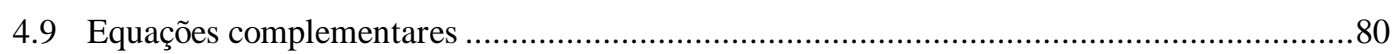

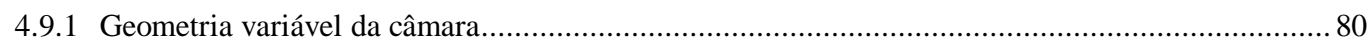

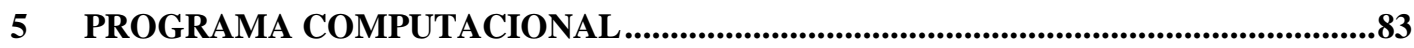

6 MONTAGEM EXPERIMENTAL E DADOS COLETADOS ...................................91

6.1 Instalações e motor utilizados ...........................................................................92

6.2 Sistema de medição de pressão no interior do cilindro ..............................................95

6.3 Sistema de medição de posição angular do virabrequim ..............................................98 
6.4 Sistema de medição de corrente de ignição ………………………………………............99

6.5 Sistema de aquisição de dados .................................................................................99

6.6 Testes para verificação do correto funcionamento do sistema ………………………........104

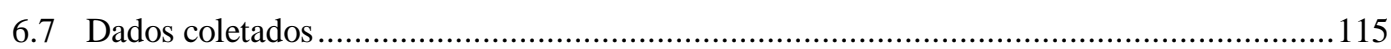

7 RESULTADOS DA ANÁLISE DA COMBUSTÃO ......................................................119

7.1 Verificação do programa contra um simulador ..............................................................119

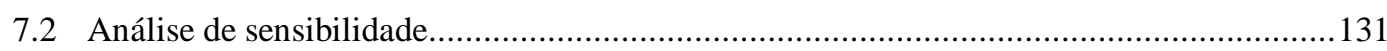

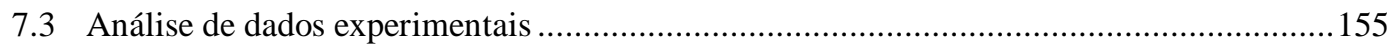

8 CONCLUSÕES E RECOMENDAÇÕES ...........................................................................181

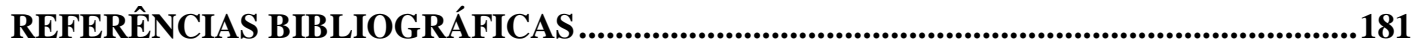

APÊNDICE A

APÊNDICE B 


\section{LISTA DE TABELAS}

Tabela 4.1 - Composição dos gases queimados abaixo de $1740 \mathrm{~K}$. . .62

Tabela 4.2 - Composição dos gases não queimados...................................................................64

Tabela 4.3 - Coeficientes para cálculo de entalpia e calor específico.................................................67

Tabela 4.4 - Coeficientes para cálculo de entalpia e calor específico de combustíveis gasosos. .......69

Tabela 6.1 - Especificações do motor M 366 G................................................................................92

Tabela 6.2 - Especificações do transdutor de pressão..........................................................95

Tabela 6.3- Características da placa de aquisição utilizada.....................................................104

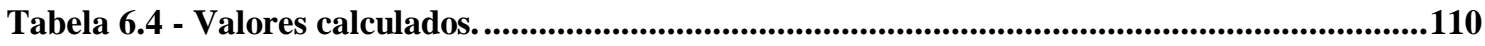

Tabela 6.5 - Valores medidos na bancada dinamométrica. ................................................................110

Tabela 6.6 - Valores de pressão média indicada calculados como média de 32 ciclos.....................112

Tabela 6.7 - Pressões médias indicadas calculadss com um ciclo médio de 32 ciclos......................113

Tabela 6.8 - Pressões médias indicadas...........................................................................................115

Tabela 7.1 - Dados medidos em bancada dinamométrica...........................................................120

Tabela 7.2 - Composição do combustível utilizado. .............................................................120

Tabela 7.3 - Temperaturas das paredes da câmara em regime de potência máxima.......................121

Tabela 7.4 - Valores de consumos resultantes da simulação............................................................122

Tabela 7.5 - Temperaturas das paredes reduzidas para efeito de análise de sensibilidade.............151

Tabela 7.6 - Valores medidos na bancada dinamométrica. ........................................................156

Tabela 7.7 - Consumos calculados a partir dos valores da Tabela 7.6. ......................................156

Tabela 7.8 - Composição do combustível de maior conteúdo energético............................................175

Tabela 7.9 - Valores medidos na bancada dinamométrica. ........................................................175

Tabela 7.10 - Consumos calculados a partir dos valores da Tabela 7.9. .........................................176 


\section{LISTA DE FIGURAS}

Figura 3.1 - Esquema do volume de controle adotado por GATOWSKI. .........................................15

Figura 4.1 - Progressão da frente de chama no interior da câmara de combustão..........................30

Figura 4.2 - Divisão da câmara de combustão em duas zonas. ....................................................33

Figura 4.3 - Superfícies de troca de calor. ...........................................................................40

Figura 4.4 - Curvas de entalpia molar. ...........................................................................................68

Figura 4.5 - Viscosidade dinâmica dos produtos de combustão. (HEYWOOD $\left.{ }^{[20]}\right)$...........................80

Figura 4.6 - Esquema do sistema biela - manivela.............................................................

Figura 5.1 - Fluxograma principal do programa computacional. .....................................................85

Figura 6.1 - Configuração da câmara do motor M 366 G. .........................................................93

Figura 6.2 - Configuração de folgas a frio na região do primeiro anel. .............................................94

Figura 6.3 - "Short term drift" causado por tensões térmicas no diafragma do transdutor. .............96

Figura 6.4 - Efeito do drift na curva de liberação de calor......................................................97

Figura 6.5 - Encoder para medição de posição angular do virabrequim............................................98

Figura 6.6 - Sistema de alta taxa de aquisição de dados integrado ao motor...............................100

Figura 6.7 - Sinais amostrados pelo sistema de aquisição..........................................................101

Figura 6.8 - Exemplo de um ciclo completo adquirido. ..................................................................103

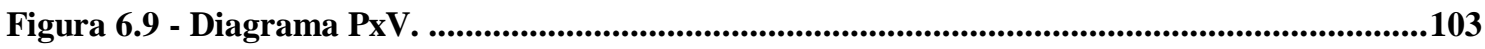

Figura 6.10 - Curvas de pressão do $5^{0}$ cilindro queimando $(25$ ciclos $)$...................................106

Figura 6.11 - Curvas de pressão do $5^{0}$ cilindro arrastado (25 ciclos). ............................................107

Figura 6.12 - Curva de pressão de um ciclo do $5^{0}$ cilindro arrastado. .............................................108

Figura 6.13 - Curva média de pressão do $5^{0}$ cilindro queimando (25 ciclos)...................................108

Figura 6.14 - Curva média de pressão do $5^{0}$ cilindro arrastado (25 ciclos)...................................109

Figura 6.15 - Curva de pressão gerada pelo Indiskop (média de 32 ciclos) a 1300 rpm................114

Figura 6.16 - Curva de pressão gerada pelo Indiskop (média de 32 ciclos) a 2200 rpm...............114

Figura 6.17 - Curva de pressão gerada pelo Indiskop (média de 32 ciclos) a 2800 rpm.................115

Figura 7.1 - Curvas de pressão medida e simulada.....................................................................121

Figura 7.2 - Curvas de fração de massa queimada. ............................................................122 
Figura 7.3 - Fração de massa queimada anterior ao início da combustão.

Figura 7.4 - Fração de massa queimada próximo ao final da combustão.

Figura 7.5 - Valores de $h$ calculados pelo simulador e pelo programa de análise.

Figura 7.6 - Temperaturas das zonas calculadas pelo simulador e pelo programa de análise. ......125

Figura 7.7 - Evolução da frente de chama. .126

Figura 7.8 - Detalhamento Figura 7.7 na região de combustão. .127

Figura 7.9 - Curvas de trabalho, calor e energia interna.

Figura 7.10 - Detalhe da Figura 7.9 na região de combustão.

Figura 7.11 - Taxa de liberação de calor e taxa de variação de pressão. .130

Figura 7.12 - Comparação entre as frações de massa queimada.

Figura 7.13 - Região inicial de queima da Figura 7.12.

Figura 7.14 - Região final de queima da Figura 7.12

Figura 7.15 - Variações na liberação total de calor devidas às defasagens.

Figura 7.16 - Variações da taxa de liberação de calor devidas às defasagens

Figura 7.17 - Comparação entre as temperaturas para as curvas de pressão defasadas.

Figura 7.18 - Efeito das defasagens da curva de pressão na evolução da frente de chama.

Figura 7.19 - Curvas de fração de massa queimada para variação na pressão de referência.........136

Figura 7.20 - Evolução da frente de chama para cada pressão de referência. .137

Figura 7.21 - Variações do calor total liberado em função da pressão de referência. .138

Figura 7.22 - Taxas de liberação de calor em função da pressão de referência.

Figura 7.23 - Temperaturas dos VC em função da pressão de referência. .140

Figura 7.24 - Influência da dissociação química na fração de massa queimada. 141

Figura 7.25 - Temperaturas calculadas não se considerando a dissociação química.

Figura 7.26 - Curvas de liberação de calor não se considerando a dissociação química.

Figura 7.27 - Taxa de liberação de calor considerando-se ou não a dissociação.

Figura 7.28 - Efeito das frestas na fração de massa queimada.

Figura 7.29 - Alteração na evolução da frente de chama devida às frestas. .145

Figura 7.30 - Curvas comparativas de liberação de calor. .146

Figura 7.31 - Detalhe da Figura 7.30. 
Figura 7.32 - Temperaturas calculadas considerando-se as frestas.

Figura 7.33 - Taxa de liberação de calor calculada com efeitos de frestas.

Figura 7.34 - Efeito dos vazamentos na fração de massa queimada

Figura 7.35 - Detalhe da Figura 7.34 na parte inicial da combustão. .149

Figura 7.36 - Detalhe da Figura 7.34 na parte final da combustão. 150

Figura 7.37 - Efeito dos vazamentos na liberação de calor. .150

Figura 7.38 - Evolução da frente de chama considerando blow-by. .151

Figura 7.39 - Impacto da redução de temperaturas das paredes na fração de massa queimada. ..152

Figura 7.40 - Aumento na troca de calor devido à redução das temperaturas das paredes. .153

Figura 7.41 - Temperaturas dos VC calculadas com redução das temperaturas de paredes. .153

Figura 7.42 - Efeito da redução de temperaturas das paredes da câmara na liberação de calor...154

Figura 7.43 - Efeito da redução de temperaturas das paredes na taxa de liberação de calor. .154

Figura 7.44 - Comparação entre as evoluções da frente de chama. .155

Figura 7.45 - Pressões médias de 25 ciclos. .157

Figura 7.46 - Evoluções das frações mássicas (caso A). .158

Figura 7.47 - Curva de liberação de calor (caso A). .158

Figura 7.48 - Evolução do volume queimado e do raio da frente de chama (caso A). 159

Figura 7.49 - Correção de pressão estimada devida ao drift do transdutor. .159

Figura 7.50 - Efeito da correção do drift na fração de massa queimada. .160

Figura 7.51 - Efeito da correção do drift na liberação de calor. .160

Figura 7.52 - Taxa de liberação de calor calculada a cada $0,2^{\circ}$ (caso A). .161

Figura 7.53 - Derivada da pressão calculada com diferenças finitas centradas $\left(0,2^{\circ}\right)$. 162

Figura 7.54 - Derivadas de pressão calculadas a cada $0,2^{\circ}$ e $1,0^{\circ}$. .163

Figura 7.55 - Liberações de calor calculadas com passo de integração de $0,2^{\circ}$ e $1,0^{\circ}$. .163

Figura 7.56 - Taxas de liberação de calor calculadas para os dois passos de integração. .164

Figura 7.57 - Alterações no raio da frente de chama e volume queimado. .164

Figura 7.58 - Temperaturas calculadas com passos de integração iguais a $0,2^{\circ}$ e $1,0^{\circ}$ .165

Figura 7.59 - Efeito da defasagem de $0,5^{\circ}$ na curva de pressão na liberação de calor. .166 
Figura 7.60 - Comparação entre as evoluções da frente de chama.

Figura 7.61 - Comparação entre efeitos da média móvel e passo de integração. .167

Figura 7.62 - Detalhe da Figura 7.61. ....................................................................................168

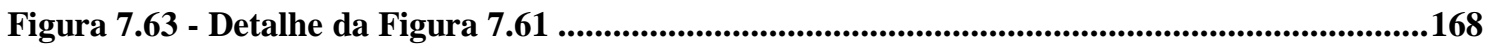

Figura 7.64 - Região inicial das curvas de liberação de calor calculadas. .......................................169

Figura 7.65 - Região final das curvas de liberação de calor calculadas. ........................................169

Figura 7.66 - Taxas de liberação de calor para diferentes passos de integração e média móvel....170

Figura 7.67 - Evoluções da frente de chama para diferentes passos de integração e média móvel.

Figura 7.68 - Frações de massa queimada referentes às condições da Tabela 7.6...........................172

Figura 7.69 - Temperaturas calculadas para as condições A, B e C. ..............................................172

Figura 7.70 - Curvas de liberação de calor para as condições A, B e C.........................................173

Figura 7.71 - Evolução da frente de chama para as condições A, B e C. ......................................174

Figura 7.72 - Taxas de liberação de calor para as condições A, B e C........................................174

Figura 7.73 - Curvas de pressão e suas derivadas para combustíveis I e II. ....................................176

Figura 7.74 - Comparação entre as frações mássicas para os combustíveis I e II.............................177

Figura 7.75 - Evolução das frentes de chama e volumes queimados para os combustíveis I e II. ...178

Figura 7.76 - Taxas de liberação de calor calculada para os combustíveis I e II. ............................179

Figura 7.77 - Curvas de liberação de calor para os combustíveis I e II. .....................................179

Figura 7.78 - Curvas de temperaturas dos VC para os combustíveis I e II.......................................180 


\section{LISTA DE SÍMBOLOS}

$\begin{array}{ll}A & \text { área } \\ B & \text { diâmetro } \\ c, C & \text { calor específico } \\ C_{d} & \text { coeficiente de descarga } \\ C_{m} & \text { velocidade média do pistão } \\ D & \text { diâmetro } \\ e & \text { energia interna específica } \\ E & \text { energia interna } \\ F / A & \text { razão combustível - ar } \\ g & \text { aceleração da gravidade } \\ h & \text { altura, entalpia específica ou coeficiente de película } \\ K & \text { constante de equilíbrio } \\ K_{b b} & \text { constante de vazamento (blow-by) } \\ L & \text { comprimento ou dimensão característica } \\ m, M & \text { massa } \\ n, N & \text { número de moles } \\ p, P & \text { pressão } \\ Q & \text { calor (trocado ou liberado) } \\ r_{c} & \text { razão de compressão } \\ R & \text { constante de gás perfeito ou raio de circunferência } \\ T & \text { temperatura } \\ u & \text { energia interna específica } \\ U & \text { energia interna, número de moléculas triatômicas } \\ v & \text { volume específico } \\ V & \text { velocidade } \\ V & \text { volume } \\ w & \text { velocidade característica } \\ w & \text { relação N-C do combustível } \\ W & \text { trabalho } \\ x, X & \text { fração mássica } \\ y & \text { relação H-C do combustível } \\ y & \text { fração volumétrica } \\ Y & \text { número de moléculas biatômicas } \\ z & \text { cota } \\ z & \text { relação O-C do combustível } \\ & \end{array}$

\section{Símbolos gregos}

$\begin{array}{ll}\delta & \text { função da razão atômica } \mathrm{H}-\mathrm{C} \text { do combustível } \\ \varepsilon & \text { função razão atômica } \mathrm{H}-\mathrm{C} \text { do combustível } \\ \phi & \text { razão de equivalência } \\ \gamma & \text { razão entre calores específicos } \\ \lambda & \text { microescala de Taylor } \\ \mu & \text { viscosidade dinâmica }\end{array}$




$\begin{array}{ll}\theta & \text { ângulo de virabrequim } \\ \rho & \text { massa específica } \\ v & \text { viscosidade cinemática } \\ \omega & \text { umidade absoluta do ar } \\ \psi & \text { razão entre número de átomos de nitrogênio e oxigênio do ar }\end{array}$

Subscritos

$\begin{array}{ll}b & \text { referente aos gases queimados (burned) } \\ b b & \text { referente ao vazamento de gases para o cárter (blow-by) } \\ c h & \text { referente à câmara de combustão (chamber) } \\ c r, \text { crev } & \text { referente às frestas (crevices) } \\ \text { evo } & \text { instante de abertura da válvula de escapamento } \\ i v c & \text { instante de fechamento da válvula de admissão } \\ r e l & \text { relativo à liberação de calor } \\ u & \text { referente aos gases não queimados (unburned) }\end{array}$

Sobrescritos

grandeza em base molar

- $\quad$ derivada em relação à posição angular do virabrequim

- $\quad$ valor médio

' referente ao campo turbulento de velocidades

Números adimensionais

$\begin{array}{ll}\mathrm{Nu} & \text { número de Nusselt } \\ \mathrm{Pr} & \text { número de Prandtl } \\ \mathrm{Re} & \text { número de Reynolds }\end{array}$ 


\section{RESUMO}

Em motores de combustão interna, o entendimento do processo de combustão é de fundamental importância para o desenvolvimento de modelos de queima empregados em simuladores de ciclos termodinâmicos, sendo a curva de pressão medida na câmara uma das principais fontes de informações a respeito deste processo. Além disto, este entendimento fornece subsídios valiosos para o projeto e desenvolvimento de novas câmaras de combustão, de componentes e do próprio motor.

O objetivo deste trabalho é, a partir da medição da pressão na câmara de combustão de motores de ignição por centelha, obter informações a respeito da evolução da combustão, tais como taxa de liberação de calor e fração de massa queimada em função da posição angular do virabrequim. Para tanto, supõe-se a câmara de combustão dividida em três zonas, a saber: a de gases não queimados, composta pela mistura fresca admitida pelo motor e uma fração de gases residuais; a de gases queimados resultantes da combustão e a de gases não queimados contidos em frestas. Uma frente de chama adiabática, com formato esférico e interagindo com as paredes da câmara é admitida como interface entre as zonas queimada e não queimada. São também considerados os efeitos da dissociação química dos produtos da combustão, de troca de calor com as paredes e os de vazamento de gases da câmara para o cárter (blow-by).

O modelo construído a partir destas hipóteses foi traduzido em um código computacional e aplicado a curvas de pressão geradas por um simulador e obtidas experimentalmente em um motor específico. 


\begin{abstract}
Understanding the combustion process in IC engines is very important to develop combustion models used in thermodynamic cycle simulators, and the in-cylinder pressure history is the basic source of information about this process. Besides, this understanding provides valuable knowledge to design and develop new combustion chambers, components and the engine itself.

The purpose of the present work is to obtain information about combustion development in SI engines from in-cylinder pressure measurements, in terms of variables such as heat release and mass fraction burned as a function of crank angle. The combustion chamber is divided into three zones, comprising burned gases, mixture of fresh charge and residual gases, and gases in crevices. A spherical and adiabatic flame front that interacts with the chamber walls is assumed to separate the burned and unburned zones. The proposed model considers chemical dissociation at high temperatures, heat transfer and blow-by as well.

The model built from the assumptions above was implemented as a numerical code and applied to a specific engine, using both cylinder gas pressure data from a cycle simulator and experimentally obtained.
\end{abstract}




\section{INTRODUÇÃO}

O crescimento do uso de computadores, com conseqüente aprimoramento e aumento da utilização de técnicas numéricas de resolução de equações, traz para o campo da engenharia aquilo que sempre se almejou: a possibilidade de simular um fenômeno sem que se tenha de recorrer totalmente a montagens experimentais. No entanto, para que essa simulação possa ser realizada com razoável fidelidade à realidade, o modelo matemático que descreve tal fenômeno deve ser o mais completo possível, fato que nem sempre é fácil de se conseguir, pois muitos fenômenos são demasiadamente complexos para serem representados por meio de algumas equações. Há então que se estabelecer um compromisso entre a complexidade do modelo e a dificuldade de resolução de suas equações.

O trabalho de projeto, construção, teste e avaliação de um motor de combustão interna é um ramo da engenharia no qual a simulação numérica é de importância fundamental, pois as montagens experimentais são caras e demoradas em função do grande número de variáveis envolvidas. Assim, um modelo capaz de prever determinados fenômenos com razoável fidelidade diminui drasticamente o número de ensaios a serem feitos. E, dentre os fenômenos cujo estudo pode refletir em aperfeiçoamento e aumento de rendimento global do motor, estão aqueles envolvidos direta ou indiretamente com a combustão.

A variação de volume durante a combustão, a própria combustão, a fuga de gases para o cárter (blow-by), a troca de calor com as paredes da câmara e os efeitos de frestas (crevices) são fenômenos que trazem como resultado de suas interações a evolução da pressão no interior dos cilindros dos motores de combustão interna. A busca de 
identificação detalhada da forma com que energia devida à combustão é liberada a partir de valores medidos da pressão no interior do cilindro é tradicionalmente designada por análise de liberação de calor. Através da liberação de calor, podem-se obter importantes parâmetros ligados à combustão, como por exemplo: verificar se a taxa de queima é grande ou pequena em um motor operando com determinado combustível; se a combustão se inicia em instante desejado ou não e se termina antes da abertura da válvula de escapamento; o atraso de ignição e a temperatura média dos gases - todos aspectos fundamentais do desenvolvimento de motores com baixa emissão de poluentes.

Assim, no tocante ao diagnóstico do processo de combustão de motores em teste ou em fase de otimização, a análise de liberação de calor pode ser considerada como uma ferramenta que permite que os fenômenos comentados acima tenham seus efeitos identificados separadamente.

Ainda no âmbito da simulação numérica de ciclos termodinâmicos, os resultados da análise de liberação de calor permitem que modelos matemáticos para previsão da taxa de queima do combustível sejam validados, bem como fornecem dados para parametrização da curva de evolução da fração de massa queimada caso se queira obter uma "curva universal de queima" em função da posição angular do virabrequim, como por exemplo a função de Wiebe.

A análise da liberação de calor, pelo fato de possibilitar uma estimativa das temperaturas dos gases no interior da câmara desde o fechamento da válvula de admissão até a abertura da válvula de escapamento e do calor trocado com as paredes, traz resultados muito valiosos para o projeto e desenvolvimento de componentes. Um exemplo típico desse fato é o cálculo estrutural de pistões: para que as tensões térmicas e propriedades físicas (módulo de elasticidade, coeficiente de Poisson, etc.) sejam 
determinadas, é necessário que se conheça a distribuição de temperaturas ao longo de todo o pistão. A medição direta dessas temperaturas do pistão é algo difícil, caro e requer, na maioria das vezes, a instrumentação de um pistão para cada situação a ser medida. Assim, as temperaturas dos gases e coeficientes de película na região de fogo do pistão fornecidos pela análise de liberação de calor são utilizadas como as principais condições de contorno para cálculo da distribuição de tensões por meio da aplicação de métodos de elementos finitos.

Embora existam comercialmente equipamentos de análise de combustão capazes de adquirir os valores de pressão no interior de cilindros de motores para vários ciclos completos, o tratamento analítico desses dados, sob o ponto de vista da liberação de calor, ainda se mostra um tanto quanto simplificado. Mesmo sistemas que fazem uma análise mais completa dos fenômenos, e que têm um custo elevado, apresentam diversas simplificações de modelo que poderiam ser mais elaboradas. Entretanto, por força do fato de serem sistemas fechados (não se permitem muitas interferências do usuário na concepção dos modelos), essas alterações não podem ser realizadas.

O modelo físico-matemático de combustão empregado neste trabalho será aplicado em um sistema aberto de análise de combustão. 


\section{OBJETIVO}

Este trabalho tem como principal meta a elaboração, à luz da Primeira Lei da Termodinâmica, de um modelo físico-matemático capaz de prever, a partir da evolução da pressão no interior de cilindros de motores de combustão interna com ignição por centelha, de que forma a combustão se desenvolve. A verificação do comportamento do modelo é feita por meio da comparação dos resultados oriundos de sua aplicação a um motor específico contra dados fornecidos por um simulador de combustão em motores existente.

Paralelamente à elaboração do modelo matemático, um sistema de alta taxa de aquisição de dados é construído a fim de que a pressão na câmara de combustão de um motor adequadamente instrumentado possa ser medida de forma confiável. A partir então destas curvas de pressão experimentalmente obtidas, o modelo desenvolvido é aplicado para o mesmo motor, sendo os resultados avaliados quanto aos aspectos de balanço global de massa e energia.

O processo de combustão de uma mistura ar - combustível homogênea em um motor de ignição por centelha será aqui representado por um modelo de duas zonas principais: a da mistura combustível - ar - gases residuais não queimada e a de gases queimados, separadas por uma frente de chama admitida esférica e limitada pelas paredes da câmara. Além disso, considera-se o volume das frestas como uma terceira zona que armazena gases não queimados enquanto a pressão na câmara sobe e os libera quando a pressão cai. Admite-se que as propriedades termodinâmicas e de transporte de cada ponto interno à cada zona sejam iguais ao longo de toda a região. Partindo dessas hipóteses, o modelo físico-matemático permitirá calcular, em cada posição do 
virabrequim (enquanto as válvulas de admissão e escapamento estão fechadas), o raio da frente de chama, a fração de mistura queimada, a taxa de liberação de calor, a quantidade de calor trocada com as paredes da câmara, cabeçote e pistão e as temperaturas das duas regiões.

Para complementação do equacionamento, serão utilizados modelos fenomenológicos de troca de calor com as paredes, de "blow-by", equações para cálculo das propriedades termodinâmicas e de transporte dos gases, levando em consideração a dissociação química quando devida, e rotinas para cálculo de parâmetros geométricos da interação da frente de chama com as paredes. 


\section{REVISÃO BIBLIOGRÁFICA}

A busca por melhoria de eficiência nos motores de combustão interna é feita nas mais variadas direções: redução de massa de componentes móveis por meio da utilização de novos materiais; pesquisa e desenvolvimento de novos lubrificantes e combustíveis que, além de almejarem melhoria no desempenho dos motores, buscam atender às cada vez mais restritivas normas mundiais de emissão de poluentes; desenvolvimento de sistemas inteligentes de injeção de combustível bem como utilização de motores multicombustível, etc.

Mas um dos setores que ainda propicia um largo campo de estudo e evolução é o processo que, fundamentalmente, é o núcleo do funcionamento do motor: a combustão. Vários pesquisadores têm-se dedicado ao estudo desse fenômeno ao longo das últimas décadas, tentando melhor compreender o que ocorre no interior do cilindro de um motor desde que a válvula de admissão se fecha e a de escapamento se abre. É um processo complexo que envolve reações químicas, escoamentos de difícil previsão, fuga de massa pelos anéis e frestas, variação de volume, troca de calor, além de outros fatores. E todos esses fenômenos são transitórios, isto é, não são constantes ao longo do tempo. Todos esses fatores não permitem que a modelagem matemática dos processos envolvidos com a combustão seja simples.

Devido a essas dificuldades, a modelagem em motores começou a ser específica, ou seja, começaram a se formar grupos dedicados ao estudo de cada fenômeno ou até subpartes de um fenômeno. Nesse contexto, iniciou-se a tentativa de diagnosticar a combustão em motores.

Desde que foi possível se medir a pressão no interior dos cilindros de motores de 
combustão interna e se levantar a curva de pressão em função de tempo ou posição angular do virabrequim, tal curva passou a ser o principal diagnóstico do processo de combustão dentro dos motores. Uma das primeiras tentativas de obter mais informações a partir da curva de pressão, além da máxima pressão do ciclo ou da taxa de crescimento da pressão, cabe a RASSWEILER e WITHROW ${ }^{[1]}$, que em seu trabalho relataram uma forma de obter a taxa de massa queimada a partir da curva de pressão e assim estabelecer uma indicação sobre a evolução da combustão. Esse trabalho foi posteriormente revisado por SHAYLER et al. ${ }^{[2]}$. A idéia básica do trabalho de RASSWEILER e WITHROW era separar a variação de pressão devida à variação de volume daquela devida à combustão. Por meio de experimentos com bombas de combustão de volume constante, chegaram a duas conclusões:

- a fração de massa queimada $X$ até um estágio $b$ é aproximadamente igual à fração do aumento de pressão total:

$$
X=\frac{m_{b}}{m_{t}}=\frac{P_{b}}{P_{t}}
$$

onde o índice $t$ denota a condição ao final da combustão;

- para uma determinada quantidade de energia liberada na combustão, o aumento de pressão é inversamente proporcional ao volume:

$$
P_{e}=\frac{1}{V}
$$

Essas observações foram aplicadas às condições de operação em um motor de ignição por centelha de forma que a mudança de pressão que ocorre durante uma variação $\Delta \theta$ do ângulo da árvore de manivelas pudesse ser então considerada como resultado da variação de volume e da combustão considerados separadamente. A parte 
de variação de pressão devida à variação de volume foi considerada como compressão / expansão politrópica. Assim a pressão de compressão $P_{p}$ resultante após um giro de $\Delta \theta$ do virabrequim é dada por:

$$
P_{p}=P_{\theta-\Delta \theta} \cdot\left(\frac{\nvdash_{\theta-\Delta \theta}}{\bigvee_{\theta}}\right)^{n}
$$

onde $n$ é o coeficiente politrópico aparente.

A pressão medida no interior do cilindro, quando a posição angular do virabrequim era $\theta$, é denominada de $P_{\theta}$. A diferença entre esse valor e $P_{p}$ resultaria no acréscimo de pressão devido somente à combustão na posição $\theta$, denominado $P_{C}$ :

$$
P_{C}=P_{\theta}-P_{p}
$$

Mas para posição $\theta$, o volume da câmara é diferente. Para que se possa aplicar então as conclusões do experimento da bomba de combustão de volume constante, há que fazer uma redução de $P_{C}$ a um mesmo volume de referência $V^{\prime}$, e através da Eq. 32, pode-se escrever:

$$
P_{C}^{\prime}=\left(P_{\theta}-P_{p}\right) \cdot\left(\frac{V_{\theta}}{V^{\prime}}\right)
$$

SHAYLER et $a l .{ }^{[2]}$ sugerem que o volume $V^{\prime}$ adotado seja o volume da câmara quando o pistão se encontra no PMS, pois sendo este o mínimo volume durante todo o deslocamento do pistão, os aumentos de pressão $P_{C}^{\prime}$ serão maiores e o controle numérico do método se torna mais fácil. Assim, cada aumento de pressão devido à combustão pode ser determinado. E cada aumento na pressão de combustão é resultado de uma pequena fração de combustível queimado. Utilizando a Eq. 3-1, a massa 
queimada até a posição $\theta$, expressa como uma fração da massa total final queimada $X_{\theta}$, é dada por:

$$
X_{\theta}=\frac{\sum_{\theta=\theta_{\text {centelh } a}}^{\theta} P_{C}^{\prime}}{\sum_{\theta=\theta_{\text {centelh } a}}^{F C} P_{C}^{\prime}}
$$

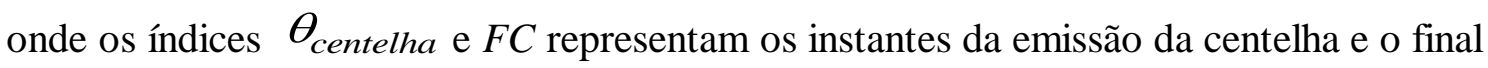
da combustão, respectivamente.

O modelo de RASSWEILER é bastante simples e duas dentre suas principais vantagens estão a fácil implementação e a curva de pressão como único dado de entrada. Embora não considere formalmente a troca de calor com as paredes e a fuga de massa, esses efeitos estão de certa forma embutidos na utilização de um coeficiente politrópico aparente adequado (o coeficiente politrópico $n$ se torna diferente da relação entre os calores específicos $\gamma$ ), o que traz de certo modo alguns resultados com relativa inexatidão. Outro problema a ser resolvido quando se usa esse método diz respeito à determinação do final da combustão. Uma das formas de obter esse instante seria quando o cálculo de $P_{C}^{\prime}$ resultasse em um valor negativo, significando que o aumento de pressão devido à combustão passou por um valor nulo. Esse método de determinação do final da combustão apresenta, por sua vez, alguns problemas associados ao ruído inerente à aquisição do valor da pressão, que por vezes pode oscilar e assim levar a valores de $P_{C}^{\prime}$ alternadamente positivos e negativos. Como desvantagem desse método, ressalta-se a não possibilidade de se identificarem os efeitos de troca de calor e fuga de massa. Mas, adotado como aproximação inicial, esse método se mostra como uma maneira de estimar a fração de massa queimada. 
$\mathrm{Na}$ intenção de melhorar a representação do processo de combustão, surgiram trabalhos mais sofisticados e que não mais se baseavam só na variação de volume e na combustão como causadores da variação de pressão no cilindro. Começaram a surgir modelos fenomenológicos baseados na Primeira Lei da Termodinâmica, os chamados modelos zero-dimensionais, onde a única variável independente é o tempo. Tais modelos não são capazes de fornecer informações suficientes sobre o impacto de alterações de parâmetros de projeto e operação de motores sobre desempenho, eficiência e emissões.

Muito mais complexos que os modelos zero-dimensionais são os multidimensionais. Esses modelos são de grande utilidade na análise de problemas caracterizados pela necessidade de detalhes geométrico-espaciais e interações de vários fenômenos complexos. Entretanto são limitados no tocante a seus submodelos de turbulência, de química da combustão, etc. e necessitam de grandes computadores para que suas inúmeras equações possam ser resolvidas. Tudo isso acaba por dificultar e encarecer a utilização desses modelos.

A terceira categoria de modelos é a denominada quasi-dimensional. Tais modelos incrementam algumas interações geométricas simplificadas e submodelos (escoamentos, combustão, interação de frente de chama com a superfície de câmara, modelo de formação de poluentes, etc.) aos modelos zero-dimensionais de forma que tal representação matemática passa a responder às alterações de projeto e operação e fornece resultados na área de emissões e desempenho, por exemplo.

Assim começaram a surgir trabalhos como o de KRIEGER e BORMAN ${ }^{[3]}$, que apresentaram seu modelo para cálculo da liberação de calor admitindo que, a qualquer instante durante a combustão, o volume da câmara pode ser dividido em uma zona de gases queimados e outra de mistura ar - combustível não queimada, zonas estas 
separadas por uma frente de chama de espessura infinitesimal. Supõem também que cada volume esteja em equilíbrio termodinâmico e que estejam submetidos à mesma pressão em qualquer instante. Em termos matemáticos:

$$
\forall=\forall_{b}+\forall_{u}
$$

onde o subscrito $u$ (unburned) designa o sistema composto por vapor de combustível, ar e gases residuais e o subscrito $b$ (burned), o sistema composto pelos produtos da combustão. $\mathrm{O}$ volume total $V$ é definido pela geometria em função do ângulo $\theta$ do virabrequim.

Adotadas essas hipóteses, é escrita a equação de conservação de massa: a massa total é assumida constante uma vez que efeitos de blow-by e fuga pelas válvulas são negligenciados, resultando:

$$
\begin{aligned}
& M=M_{b}+M_{u} \\
& \dot{M}_{b}=-\dot{M}_{u}
\end{aligned}
$$

Como ambas as zonas estão submetidas à mesma pressão $p$, a equação de estado para cada zona fornece (admitida a hipótese de gás perfeito):

$$
p=\frac{M_{b} \cdot R_{b} \cdot T_{b}}{V_{b}}=\frac{M_{u} \cdot R_{u} \cdot T_{u}}{V_{u}}
$$

onde $R$ representa a constante e $T$ a temperatura absoluta do gás.

Diferenciando a Eq. 3-10 em relação tempo, ou em relação à posição angular do virabrequim já que se supõe sua velocidade de rotação constante, resulta em:

$$
\frac{\dot{p}}{p}=\frac{\dot{M}_{b}}{M_{b}}+\frac{\dot{R}_{b}}{R_{b}}+\frac{\dot{T}_{b}}{T_{b}}-\frac{\dot{\forall}_{b}}{\bigvee_{b}}=\frac{\dot{M}_{u}}{M_{u}}+\frac{\dot{R}_{u}}{R_{u}}+\frac{\dot{T}_{u}}{T_{u}}-\frac{\dot{V}_{u}}{\bigvee_{u}}
$$


Conhecendo-se a curva de pressão, os primeiros membros da Eq. 3-10 e da Eq. 3-11 são valores conhecidos. Aplicando a Primeira Lei da Termodinâmica para os dois volumes de controle, resulta:

$$
\begin{aligned}
& \overrightarrow{M_{u} u_{u}}=-p \dot{V}_{u}+\sum_{i=1}^{n} \dot{Q}_{u i}+h_{u} \dot{M}_{u} \\
& \dot{M_{b} u_{b}}=-p \dot{\forall}_{b}+\sum_{i=1}^{n} \dot{Q}_{b i}+h_{b} \dot{M}_{b}
\end{aligned}
$$

onde os termos têm o seguinte significado:

* $\quad \dot{\overline{M u}}$ : variação da energia interna do volume de controle;

* $\quad p \dot{\forall}$ : incremento de trabalho realizado pelo volume de controle;

* $\sum_{i=1}^{n} \dot{Q}_{i}$ : calor trocado com as superfícies metálicas $i=1$ até $n$, positivo quando entra no volume de controle (assume-se que não há troca de calor pela frente de chama);

* $\quad h \dot{M}$ : fluxo de entalpia para o interior do volume de controle.

Neste ponto cabe salientar um dos motivos dos bons resultados desse método: para que se possam utilizar a Eq. 3-12 e a Eq. 3-13, é necessário que se tenham as propriedades termodinâmicas dos gases avaliadas com grande exatidão. Isso foi obtido por KRIEGER através do uso de dados das tabela JANAF para o cálculo da energia interna de produtos de combustão de $\mathrm{C}_{\mathrm{n}} \mathrm{H}_{2 n}$ em ar. Para a obtenção das propriedades de transporte, KRIEGER interpolou dados originados de trabalhos de outros pesquisadores. Grande parte do paper de KRIEGER e BORMAN é destinado à explicação de como calcular essas propriedades. Para calcular a troca de calor com as superfícies, KRIEGER utiliza a seguintes expressões: 


$$
\dot{Q}_{u i}=\hat{h}_{u} A_{u i}\left(T_{w i}-T_{u}\right)
$$

$$
\dot{Q}_{b i}=\hat{h}_{b} A_{b i}\left(T_{w i}-T_{b}\right)
$$

onde $A_{i}$ é a área de cada uma das superfícies com temperatura $T_{w i}$ através das quais há troca de calor e $\hat{h}$ é o coeficiente de película estimado pela fórmula de EICHELBERG $^{[4]}$, revisada por BORMAN e NISHIWAKI ${ }^{[5]}$, a saber:

$$
\hat{h}=7,67 \cdot 10^{3} \cdot C_{m}^{1 / 3} \cdot(p T)^{1 / 2}
$$

onde $C_{m}$ é a velocidade media do pistão em $\mathrm{m} / \mathrm{s}, p$ é a pressão em $M P a$ e $T$ a temperatura absoluta em $K$. O valor de $\hat{h}$ será expresso então em $k W /\left(m^{2} K\right)$.

Mesmo de posse do coeficiente de película, ainda assim não é possível calcular a troca de calor com as paredes da câmara; resta saber as temperaturas $T_{w i}$ de cada superfície de troca e quais são os valores das áreas $A_{i}$. As temperaturas foram estimadas partindo-se de resultados experimentais. Entretanto, a determinação da fração de cada área de troca a que está exposta a região queimada ou não queimada é algo de difícil realização. Para resolver esse problema, alguma forma de frente de chama deve ser adotada, isto é, deve-se arbitrar um formato de volume queimado. E essa estimativa só é utilizada no cálculo das perdas térmicas.

Para facilidade de cálculo, KRIEGER e BORMAN adotaram apenas cinco superfícies passíveis de trocarem calor com os gases: a cabeça do pistão, a superfície cilíndrica limitada pelo pistão e o cabeçote, o próprio cabeçote e as válvulas de admissão e escapamento. Admitiram também que a fração da área da cabeça do pistão exposta aos gases queimados é igual à fração de volume de gases queimados, ou seja, $V_{b} / V$ e que a 
superfície do cilindro não é tocada pela frente de chama, significando que a área do cilindro estará sempre exposta aos gases não queimados.

A partir da Eq. 3-7 até a Eq. 3-15, foi possível aos pesquisadores resolver o sistema para $T_{u}, T_{b}, M_{u}$ e $M_{b}$ com algumas hipóteses adicionais, como adotar a temperatura inicial dos gases queimados como a temperatura adiabática de chama.

O método de KRIEGER e BORMAN pode ser refinado ao se adotar uma evolução da frente de chama mais realista do que as hipóteses simplificadoras que foram feitas em seu trabalho. A dificuldade em se fazer tal modificação reside na obrigatoriedade de se implementar uma rotina de cálculo de parâmetros geométricos da câmara de combustão.

Um outro trabalho na área de análise de liberação de calor publicado por GATOWSKI et al. ${ }^{[6]}$ trata a câmara de combustão como um só volume, admitido homogêneo, com propriedades termodinâmicas representadas por uma aproximação linear da razão entre os calores específicos $\gamma(T)$. Embora seja um modelo de uma só zona, efeitos de troca de calor, injeção de combustível e resfriamento da mistura em frestas da câmara são considerados, o que acarreta uma melhoria significativa dos métodos de análise de uma só zona.

Aplicando-se a equação da conservação de energia ( $1^{\underline{a}}$ Lei) para um sistema aberto (ou volume de controle), vem:

$$
d U=\delta Q-\delta W-\sum d m_{i} h_{i}
$$

onde $d U$ representa a variação de energia interna da massa contida no volume de controle, $\delta Q$ representa a transferência de calor para o volume de controle, $\delta W$ é o trabalho realizado pelo volume de controle sobre o meio e a somatória significa o fluxo 
de entalpia através da fronteira do volume de controle. A Figura 3.1 mostra esquematicamente o volume de controle adotado por GATOWSKI em seu trabalho.

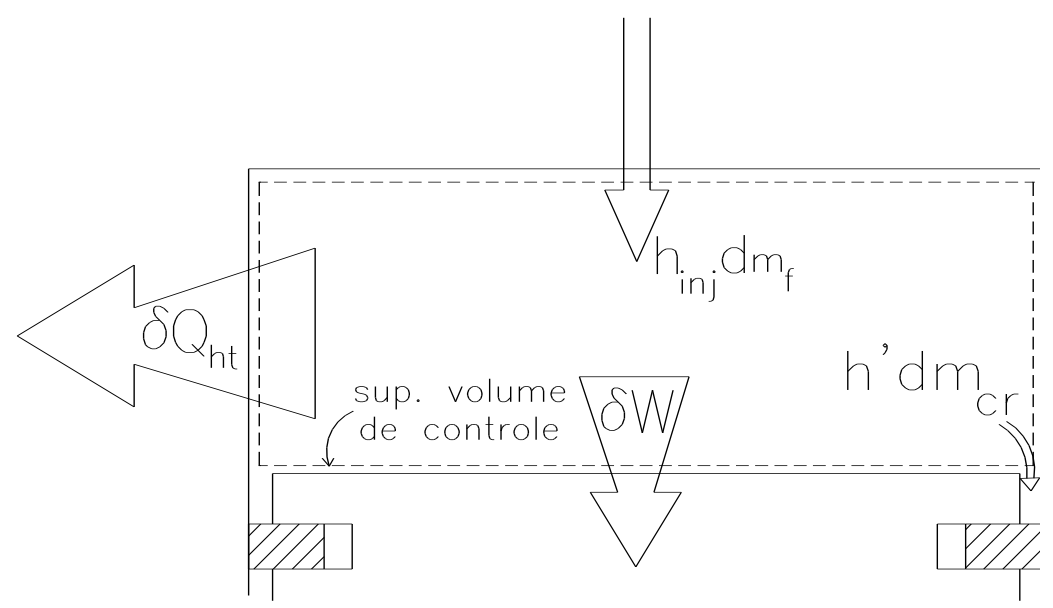

Figura 3.1 - Esquema do volume de controle adotado por GATOWSKI.

Os possíveis fluxos de massa que atravessam a superfície do volume de controle após o fechamento das válvulas são basicamente restritos a três tipos: (i) fuga de massa pelas válvulas de admissão e escapamento; (ii) escoamento de gases para frestas entre o pistão, cilindro e anéis (crevices) e daí, uma fração desses gases, para o cárter (blow-by) e (iii) injeção de combustível diretamente na câmara. O modelo de GATOWSKI despreza o primeiro tipo de fuga, levando em consideração só efeitos de injeção de combustível, efeitos de frestas e blow-by.

O modelo de uma zona, definindo o estado do conteúdo do cilindro em termos de propriedades médias e não distinguindo gases queimados de não queimados, oferece maior simplicidade de tratamento dos fenômenos de troca de calor e efeitos de resfriamentos em frestas em relação aos modelos multizona. A combustão é então encarada como uma "adição separada de calor". Partindo dessas simplificações, rescreve-se a Primeira Lei:

$$
\delta Q_{c h}=d U_{s}+\delta W+\sum h_{i} \cdot d m_{\mathrm{i}}+\delta Q_{h t}
$$


As mudanças de energia interna sensível do sistema são separadas das mudanças devido à variação de composição. O termo $\delta Q_{c h}$ representa a "adição de energia química" devida à combustão. O trabalho $\delta W$ é representado por $p d V$ e o termo $\delta Q_{h t}$ representa a troca de calor com as paredes. A mudança na energia interna sensível é calculada admitindo-se como sendo devida exclusivamente à temperatura média:

$$
U_{s}=m_{c} \cdot u(T)
$$

que derivada fornece:

$$
d U_{s}=m_{c} \cdot d u(T)+d m_{c} \cdot u(T)=m_{c} \cdot c_{v}(T) \cdot d T+d m_{c} \cdot u(T) \quad \text { Eq. } 3-20
$$

onde $m_{c}$ é a massa contida no interior do volume de controle, e $c_{v}$ é o calor específico a volume constante. A temperatura média é determinada admitindo-se comportamento de gás perfeito para os gases contidos no interior do volume de controle, resultando em:

$$
T=\frac{p V}{m_{c} R}
$$

O autor comenta que, embora a forma de cálculo de $d U$ não seja exata, a temperatura média calculada pela equação de gás perfeito é próxima da média das temperaturas ponderadas pelas massas dos reagentes e produtos da combustão. Essa proximidade entre os valores das temperaturas se explica pela semelhança dos pesos moleculares dos reagentes e produtos.

Considerando motores que admitem ar e combustível previamente misturados (sem injeção na câmara), o único fluxo de massa atravessando a fronteira é aquele que se dirige a frestas na câmara, frestas estas que podem ser o volume entre o pistão, anéis e parede do cilindro; a região entre o cabeçote, o bloco e a junta; reentrâncias na vela de ignição e ao redor do transdutor de pressão. 
Denominando $m_{c r}$ a massa contida nesses volumes, a equação de conservação de massa se torna:

$d m_{c}=-d m_{c r}$

Substituindo-se a Eq. 3-20, Eq. 3-21 e Eq. 3-22 na equação Eq. 3-18, vem:

$\delta Q_{c h}=m_{\mathrm{c}} c_{v} d T+\left(h^{\prime}-u\right) \cdot d m_{c r}+p \cdot d V+\delta Q_{h t}$

onde

- $d m_{c r}>0$ quando o escoamento é do volume de controle para as frestas;

- $d m_{c r}<0$ quando o escoamento é das frestas para o volume de controle;

- $h^{\prime}$ : entalpia calculada nas condições (temperatura) do volume de controle quando $d m_{c r}>0$ ou calculada nas condições das frestas quando $d m_{c r}<0$.

Escrevendo a equação utilizando a lei de gás perfeito, vem:

$\delta Q_{c h}=\frac{\gamma}{\gamma-1} p \cdot d \nvdash+\frac{1}{\gamma-1} \forall \cdot \mathrm{d} p+\delta Q_{h t}+R\left[T^{\prime}+\frac{T}{\gamma-1}-\frac{1}{B} \ln \left(\frac{\gamma-1}{\gamma^{\prime}-1}\right)\right] \mathrm{d} m_{\mathrm{c}} \quad$ Eq. 3-24

Para utilização da equação Eq. 3-24, dois pontos devem ser ressaltados:

1) o valor da razão entre calores específicos $\gamma$ foi, depois de várias investigações realizadas por GATOWSKI sobre propriedades termodinâmicas de produtos de combustão, aproximado por uma função linear do tipo $\gamma=\left(R+c_{v}\right) / c_{v}=A+B \cdot T$. Daí o termo $B$ do coeficiente que multiplica o logaritmo da Eq. 3-24. Essa aproximação do coeficiente politrópico é, em última análise, o que dá consistência ao modelo pois, ao contrário do que fez RASSWEILER fixando um valor de $\gamma$ durante todo o período da combustão, essa aproximação traz melhores resultados; 
2) os termos que são marcados com um apóstrofo na equação Eq. 3-24 devem ser calculados nas condições do volume de controle quando o escoamento é do volume para as frestas e, no caso de escoamento reverso, tais termos devem ser calculados nas condições das frestas.

O modelo de transferência de calor utilizado por GATOWSKI é o desenvolvido por WOSCHNI ${ }^{[7]}$. Esse trabalho, que se tornou uma importante ferramenta na análise da transferência de calor em motores, propõe uma correlação do tipo $N u=C \cdot R e^{m}$, admitindo que a troca de calor entre os gases e as superfícies do cilindro a que estão expostos é essencialmente uma convecção turbulenta forçada. A densidade, viscosidade e condutibilidade térmica são expressas em função da temperatura e pressão, o comprimento característico no número de Reynolds adotado por WOSCHNI é o diâmetro do cilindro, e a velocidade característica adotada varia de acordo com a fase em que se encontra o ciclo - explica-se: WOSCHNI efetuou experimentos primeiramente com o motor arrastado, isto é, sem combustão, e derivou expressões do coeficiente de película para o período de troca de gases; posteriormente, realizou testes com o motor queimando combustível e avaliou o incremento da troca de calor devido à combustão.

Esse acréscimo na troca de calor durante a combustão se deve, entre outros fatores como o aumento de temperatura dos gases, a um aumento na velocidade dos gases no interior do cilindro. Em contrapartida, na fase de expansão há uma diminuição da velocidade dos gases em virtude de atritos e conservação do momento angular para motores com algum nível de swirl, e portanto há um decréscimo na troca de calor.

A expressão para transferência de calor formulada por WOSCHNI é, em resumo, $N u=0,035 \cdot R e^{0,8}$. Expandida com o auxílio de expressões empíricas para representar a condutibilidade térmica e a viscosidade cinemática em função da temperatura resulta em: 


$$
h\left[W / m^{2} K\right]=131 C_{1} \cdot D[m]^{0,2} \cdot p[a t m]^{0,8} \cdot T[K]^{-0,53} \cdot w[m / s]^{0,8} \quad \text { Eq. } 3-25
$$

onde $D$ é o diâmetro do cilindro, $p$ é a pressão absoluta e $T$ é a temperatura absoluta média no interior do cilindro. A velocidade característica $w$ é dependente do estágio do ciclo da seguinte forma:

$$
\begin{array}{lr}
w_{s c}=6,18 \cdot c_{m} \text { para o período da troca de gases; } & \text { Eq. 3-26 } \\
w_{\text {comp }}=2,28 \cdot c_{m} \text { para o período de compressão; } & \text { Eq. } 3-27 \\
w_{\text {comb+exaust }}=2,28 \cdot c_{m}+3,24 \cdot 10^{-3} \frac{V_{d i s p}}{V_{i v c}} \frac{p_{f}-p_{m}}{p_{i v c}} \cdot T_{i v c}[K] \text { para o período da } \\
\text { combustão e expansão. } & \text { Eq. 3-28 }
\end{array}
$$

Nas expressões acima, $c_{m}$ designa a velocidade média do pistão, o índice $i v c$ se refere às condições no instante de fechamento da válvula de admissão, $p_{f}$ e $p_{m}$ se referem às pressões com o motor queimando e arrastado, respectivamente e $V_{d i s p}$ é o volume total deslocado pelo pistão. Os coeficientes $C$ (ou $C_{l}$ ) são ajustados de forma a propiciar a melhor sensibilidade do modelo em resposta a dados experimentais.

Ressalte-se que o último termo do segundo membro da equação Eq. 3-28 referese exatamente ao aumento de velocidade dos gases devido à combustão.

Embora o trabalho de WOSCHNI tenha sido desenvolvido para motores de ignição por compressão (diesel), a relação $N u=C \cdot R e^{m}$ tem sido geralmente aplicada a motores de ignição por centelha.

O modelo de GATOWSKI utiliza a Eq. 3-25, a Eq. 3-26, a Eq. 3-27 e a Eq. 328 para a troca de calor e adota a massa contida no volume das frestas como regida pela equação de gás perfeito: 


$$
\begin{aligned}
& m_{c r}=\frac{p V_{c r}}{R T_{w}}, \text { que diferenciada resulta: } \\
& d m_{c r}=\frac{V_{c r}}{R T_{w}} \cdot d p
\end{aligned}
$$

onde o volume das frestas e suas temperaturas são admitidos constantes. Caso se queira incluir efeitos de blow-by, GATOWSKI propõe um modelo de escoamento de gás através de pequenos volumes e restrições em série, representando o escoamento de gases do interior do cilindro para o cárter (à pressão atmosférica), através das regiões acima, atrás e abaixo dos anéis.

Quanto à parte experimental, GATOWSKI reporta os cuidados em posicionar corretamente seu sistema de medição de posição angular. Foram os seguintes os procedimentos para determinação do ponto morto inferior: determinação estática da posição do pistão em cada lado do ponto morto; comparação dinâmica com a marca de ponto morto no volante; determinação da posição de máxima pressão para o motor arrastado e utilização da curva $\log (p)$ em função de $\log (V)$ para o motor arrastado.

Como resultado de seu trabalho, GATOWSKI discute a influência de vários parâmetros na curva de liberação de calor. Uma de suas conclusões diz respeito à determinação da massa no interior do cilindro no final do processo de admissão. Transdutores piezelétricos não apresentam precisão suficiente para determinar a pressão no início do ciclo de compressão. Variações da ordem de $\pm 0,05 \mathrm{~atm}$ em torno da pressão estimada de início de ciclo acarretaram apenas pequenas alterações na curva de calor liberado. O autor sugere, a partir dessa constatação, que a determinação da pressão de início de ciclo deve ser estimada dentro de uma faixa de $\pm 5 \%$. 
Outra observação importante foi que a determinação dos valores de $C$ (ou $C_{I}$ ) e o expoente $m$ do número de Reynolds do modelo de troca de calor foi feita buscando aproximar o valor de calor liberado calculado com o valor da eficiência da combustão. O valor dessa eficiência é a fração do fluxo de entalpia do combustível que é convertida em energia térmica no interior do motor. Para calcular essa eficiência, desconta-se da unidade a fração do fluxo de entalpia do combustível presente nos gases de escapamento.

Ratifique-se o fato de que o modelo de uma só zona proposto por GATOWSKI não permite que sejam feitos cálculos de emissões pois trabalha com uma temperatura média da câmara. Um exemplo de fenômeno que depende muito da temperatura é a formação de óxidos de nitrogênio. BOWMAN ${ }^{[8]}$ cita, em seu artigo, o mecanismo de formação de $\mathrm{NO}_{\mathrm{x}}$ nos motores de combustão interna, denominado mecanismo estendido de Zeldovich. De forma resumida, os óxidos de nitrogênio se formam, segundo esse mecanismo, em condições de altas temperaturas e pressões. A reação direta de $N_{2}+\mathrm{O} \rightarrow \mathrm{NO}+\mathrm{N}$ é estimulada pelas altas temperaturas e pressões presentes na câmara durante a combustão, mas a reação inversa $N O+N \rightarrow N_{2}+O$ é de certa forma “congelada" no período de expansão e escapamento dos gases. Assim, um modelo que não consiga predizer valores de temperatura na câmara próximos aos reais certamente falhará na previsão de emissões.

Um trabalho de comparação entre os modelos de KRIEGER e BORMAN e o de GATOWSKI et al. foi elaborado por CHUN e HEYWOOD ${ }^{[9]}$. Nesse trabalho, os autores comentam que a fração de energia química liberada e a fração de massa queimada durante a combustão podem ser estimadas com exatidão por modelos de uma zona desde que a "razão média de calores específicos $\bar{\gamma}$ " para o conteúdo do cilindro seja adequadamente utilizada. Esses valores de $\bar{\gamma}$ foram obtidos da calibração dos 
resultados originados pelos modelos de zona única pelos resultados gerados por modelos mais rigorosos de duas zonas.

Ainda trabalhando em modelos de uma só zona, CHEUNG e HEYWOOD ${ }^{[10]}$ efetuaram aprofundamentos em testes utilizando o modelo proposto por GATOWSKI e observaram que a análise por meio desse modelo é mais sensível a erros em dados experimentais de entrada (massa inicial e pressão de início de ciclo, por exemplo) do que a alterações em parâmetros dos submodelos como coeficientes de troca de calor e expoente do número de Reynolds, admissão de temperaturas de parede, estimativas de swirl ratio, aproximações do coeficiente politrópico, entre outros.

NIGRO e TRIELLI ${ }^{[11]}$ também realizaram experimentos com a predição da curva de liberação de calor para motores de ignição por compressão (diesel) trabalhando com combustíveis alternativos como ésteres de óleos vegetais. Para tanto, adotaram um modelo de uma zona, com seu conteúdo composto por gás ideal com calor específico constante, percorrendo um ciclo reversível. Para corrigir a curva de pressão medida, levaram em consideração efeitos de perda térmica e vazamento para o cárter: a correção da pressão devida às perdas térmicas emprega uma equação semelhante à de WOSCHNI, modificada, entretanto, para levar em consideração os maiores efeitos de turbulência presentes em motores de ignição por compressão. Já a modelagem de vazamento emprega a hipótese de escoamento laminar de gases distribuído ao longo de uma fração do perímetro dos anéis. Como se tratava de um estudo comparativo de combustíveis, essas simplificações no modelo foram suficientes para gerar resultados aproveitáveis na análise comparativa.

Indo em outra direção quanto à modelagem da combustão, MUELLER et al. ${ }^{[12]}$ propõem um método de calcular a fração de massa queimada baseado em trabalhos 
desenvolvidos por pesquisadores russos na década de 30. O princípio em que se baseia esse método é o da modelagem das complexas reações de hidrocarbonetos no interior da câmara durante a combustão através de uma simples equação:

$$
-\frac{d N}{d t}=n \frac{d N_{p}}{d t}
$$

A equação Eq. 3-31 traz o significado de que o decréscimo do número de moles dos reagentes $N$, em relação ao tempo, é proporcional ao acréscimo do número de moles dos produtos $N_{p}$, onde $n$ é definido apenas como constante de proporcionalidade. Através da equação acima, da definição de uma variável $\rho$ denominada termo de densidade que reflete a evolução da transformação de reagentes em produtos e de várias passagens matemáticas, MUELLER chega a uma expressão capaz de prever a taxa de queima (transformação de reagentes em produtos):

$$
\rho=a \cdot t^{m}
$$

O uso dessa equação, entretanto, seria restrito ao levantamento da constante $m$ que levaria em consideração todos os efeitos de tipo de motor e da geometria de sua câmara de combustão, características de turbulência, propriedades termodinâmicas e químicas do combustível, dos gases queimados e dos não queimados. Isso encerra o fato de que qualquer mudança em alguns desses parâmetros demandaria nova série de experimentos a fim de se determinar o valor dessa constante. É obvio que, em se pretendendo realizar análises de liberação para várias condições de operação e projeto de motores, tal método se mostra um tanto quanto inadequado.

Também utilizando modelos de duas zonas em seu trabalho, POULOS e HEYWOOD $^{[13]}$ se dedicam a estudar a influência do formato da câmara de combustão no desempenho de motores, por meio da utilização de um programa de simulação 
computacional construído como tese de doutorado de POULOS. O modelo que esse programa representa leva em conta a interação da frente de chama com as paredes da câmara de combustão, diferentemente do trabalho de KRIEGER E BORMAN que não considerava explicitamente essa interação. Dessa forma, o modelo de evolução da combustão proposto por POULOS e HEYWOOD é mais fenomenológico. Uma análise mais detalhada desse simulador de motores é realizada no trabalho de NIGRO ${ }^{[14]}$, que trata de todos os aspectos fundamentais envolvidos na construção do modelo de POULOS e HEYWOOD.

Esse programa de simulação se inicia com uma rotina para cálculo de grandezas envolvidas na fase de admissão do ciclo. Uma dessas grandezas é a energia cinética do campo médio de velocidades, valor este que é calculado por meio de um modelo de escoamento unidimensional através da válvula de admissão. Esse valor é utilizado no modelo de conversão de energia cinética do campo médio de velocidades em energia cinética de turbulência e finalmente dissipação (modelo de turbulência) e estes valores são utilizados no modelo de combustão turbulenta.

O modelo de combustão turbulenta empregado no programa de POULOS é o modelo de BLIZARD e $\operatorname{KECK}^{[15]}$, que posteriormente foi estendido por TABACZYNSKI et $a l .{ }^{[16]}$. Resumidamente, esses trabalhos assumem que o campo de escoamento turbulento dentro da câmara seja isotrópico e homogêneo. No início da combustão são calculados, por meio do modelo de turbulência, valores iniciais de intensidade e macroescala de turbulência. Após o começo da combustão, admite-se que os gases não queimados são comprimidos pela frente de chama à uma taxa suficientemente alta para que se possa desprezar a dissipação de energia cinética turbulenta nos grandes vórtices. Assim, desprezada a dissipação nos grandes vórtices, os 
valores de macroescala e intensidade de turbulência podem ser calculados por conservação de quantidade de movimento angular nos grandes vórtices.

A microescala de Taylor $\lambda$ é calculada então a partir dos valores de macroescala e intensidade de turbulência.

A combustão é então tratada como dois processos simultâneos: a "entrada" (entrainment) da mistura não queimada na chama e a queima no interior dos vórtices. A velocidade com que a "entrada" da mistura não queimada na chama ocorre é a soma de um termo convectivo (intensidade de turbulência) com um termo difusivo (velocidade laminar de chama). Tudo se passa como se a turbulência distribuísse pontos de ignição nas periferias dos vórtices e a queima no interior destes se processasse com velocidade laminar.

No submodelo de troca de calor, o programa de POULOS e HEYWOOD utiliza uma relação do tipo $N u=\alpha \cdot \operatorname{Re}^{d} \cdot \operatorname{Pr}^{e}$ para cálculo do coeficiente de película $h$ parecida com a formulação de WOSCHNI, sendo que o comprimento característico a ser utilizado agora no número de Reynolds é a macroescala de turbulência, definida como sendo

$$
L=\frac{\nvdash}{\frac{\pi \cdot B^{2}}{4}}
$$

onde $\forall$ é o volume da câmara de combustão em cada instante e $B$ é o diâmetro do cilindro, com a restrição de que $L \leq \frac{B}{2}$; a velocidade a ser empregada no cálculo de Reynolds é admitida como sendo uma velocidade efetiva devida às contribuições de energia cinética do escoamento médio, do campo turbulento e do movimento do pistão, resultando em: 


$$
V=\sqrt{U^{2}+u^{\prime 2}+\left(\frac{V_{p}}{2}\right)^{2}}
$$

Assim, o valor do coeficiente de película $h$ pode ser calculado separadamente para as duas zonas, com a condutibilidade térmica e viscosidade calculadas de acordo com as condições de cada uma das zonas. Ressalte-se que o comprimento e velocidade característicos no cálculo do número de Reynolds são iguais para as duas zonas e iguais, por sua vez, à macroescala de turbulência $L$ e à velocidade $V$ discriminadas na Eq. 3-33 e na Eq. 3-34.

O simulador de POULOS e HEYWOOD emprega relações matemáticas para quantificação de propriedades termodinâmicas dos gases envolvidos na combustão em motores (para temperaturas abaixo de $1000 \mathrm{~K}$, onde a dissociação química pode ser desprezada) desenvolvidas por HIRES et al. ${ }^{[17]}$, que por sua vez foram baseadas em dados da tabela JANAF. Esse trabalho consiste na elaboração de um simulador de ciclo termodinâmico para motores de ignição por centelha com pré-câmara de carga estratificada cujos principais objetivos eram o cálculo de desempenho e emissões de $\mathrm{NO}_{\mathrm{x}}$. Tal simulador também emprega um modelo de duas zonas (gases queimados e nãoqueimados) para a câmara principal e para a pré-câmara. As hipóteses básicas também contemplam uniformidade de temperatura e composição para cada zona, bem como a não existência de gradiente de pressão em toda a câmara, incluindo a pré. $\mathrm{O}$ modelamento para troca de calor empregado por HIRES é também baseado na relação de WOSCHNI, com cálculo de um coeficiente de película $h$ para cada zona.

Para temperaturas acima de $1000 K$, região de temperatura onde considerável quantidade de dissociação química ocorre nos produtos de combustão, POULOS e HEYWOOD utilizam relações desenvolvidas por MARTIN et al. ${ }^{[18]}$ para reações entre 
hidrocarbonetos e oxigênio do ar. A ocorrência da dissociação tem dois aspectos muito importantes: redução da massa molecular média e aumento do calor específico médio dos gases queimados. Assim, a determinação da temperatura da mistura de gases oxidados seria imprecisa caso se utilizassem as relações obtidas para a reação de combustão sem dissociação, como feita para baixas temperaturas.

Se a hipótese de equilíbrio químico local for considerada, a quantificação de espécies químicas quando há dissociação pode ser obtida pela resolução de um sistema de equações não lineares, equações estas que representam as constantes de equilíbrio para cada reação entre os produtos da combustão. Entretanto, tais cálculos demandam muito tempo de processamento e requerem algoritmos de resolução muito robustos para garantir convergência.

No trabalho de MARTIN são desenvolvidas relações aproximadas para as propriedades termodinâmicas dos produtos de combustão de hidrocarbonetos. Essas relações trazem resultados bastante razoáveis uma vez que foram ajustadas a uma forma funcional adequada a partir da resolução das equações de equilíbrio químico. MARTIN parte de um modelo simples de combustão de carbono com oxigênio do ar sob a forma:

$$
\begin{aligned}
& \phi C+\mathrm{O}_{2}+\psi \mathrm{N}_{2} \Rightarrow \\
& \underbrace{(\phi-2 Y) \mathrm{CO}_{2}+2 Y C O+(1-\phi+Y-U) O_{2}+2 U \mathrm{O}+\psi N_{2}}_{\phi \leq 1} \\
& \underbrace{(2-\phi-2 Y) C O_{2}+2(\phi-1+Y) C O+(Y-U) O_{2}+2 U O+\psi N_{2}}_{\phi>1}
\end{aligned}
$$

onde:

$\phi$ : razão de equivalência;

$\psi$ : razão entre o número de átomos de nitrogênio e oxigênio do ar; 
$Y$ : número extra de moléculas devido à dissociação de moléculas triatômicas em diatômicas;

$U$ : número extra de moléculas devido à dissociação de moléculas diatômicas em monoatômicas.

Admitiu também as seguintes reações de dissociação:

$$
\begin{aligned}
& \mathrm{CO}_{2} \leftrightarrow \mathrm{CO}+\frac{1}{2} \mathrm{O}_{2} \\
& \mathrm{O}_{2} \leftrightarrow 2 \mathrm{O}
\end{aligned}
$$

com as respectivas constantes de equilíbrio $K$ definidas por:

$$
\begin{aligned}
& K_{1}(T)=\frac{P_{\mathrm{CO}_{2}}}{P_{C O} \cdot P_{O_{2}}^{1 / 2}} \\
& K_{2}(T)=\frac{P_{O_{2}}^{1 / 2}}{P_{O}}
\end{aligned}
$$

onde $P_{i}$ designa a pressão parcial do componente $i$. Escrevendo as pressões parciais a partir da Eq. 3-37 e da Eq. 3-38 na Eq. 3-39 e na Eq. 3-40 e conhecendo-se os valores de $K_{1}$ e $K_{2}$ em função da temperatura, é possível resolver as quantidades $Y$ e $U$ e, conseqüentemente, determinar a massa molecular média dos produtos da combustão.

Esse modelamento usado na combustão de carbono é utilizado na combustão de moléculas da forma $C_{c x} H_{h y}$. O autor admite que todas as reações de dissociação que ocorrem na combustão desse tipo de combustível possam ser colocadas sob a forma:

$$
\begin{aligned}
& 2 M_{3} \leftrightarrow 3 M_{2} \\
& M_{2} \leftrightarrow 2 M_{1}
\end{aligned}
$$


onde $M_{3}, M_{2}$ e $M_{1}$ representam todas as possíveis moléculas triatômicas, diatômicas e monoatômicas respectivamente. De maneira análoga ao que foi feito na combustão de carbono em ar, as quantidades $Y$ e $U$ de moléculas originadas pela dissociação podem ser obtidas, agora com valores de $K_{1}(T)$ e $K_{2}(T)$ não mais refletindo o equilíbrio de gás carbônico e oxigênio, mas ajustados adequadamente. E com as quantidades de moléculas diatômicas e monoatômicas calculadas, pode-se inferir a massa molecular média dos produtos bem como sua massa específica.

Já no que se refere ao cálculo de entalpia e calor específico, o autor admite que cada tipo de molécula (tri, di ou monoatômica) contribua para o aumento da entalpia dos produtos com $\frac{\tilde{R}}{2}$ para cada grau de liberdade rotacional ou translacional. Contribuições devidas à vibração molecular devem ser tratadas através de mecânica quântica, mas seu valor máximo é $\widetilde{R}$. E esses acréscimos são computados sobre a entalpia de formação dos produtos da combustão. Com essas hipóteses, o autor chega a uma formulação para cálculo da entalpia específica dos gases de combustão.

A partir da entalpia específica, MARTIN obtém também expressões para avaliação das derivadas parciais da entalpia e massa específica dos gases queimados em relação à temperatura e pressão. 


\section{MODELO FÍSICO-MATEMÁTICO}

A concepção básica do modelo matemático utilizado neste trabalho é aquela de KRIEGER e BORMAN, ou seja, a determinação da evolução da combustão a partir da curva de pressão é baseada na Primeira Lei da Termodinâmica, aliada à formulação de WOSCHNI para quantificação de troca de calor. São empregados ainda submodelos fenomenológicos para consideração de efeitos de frestas e dissociação dos produtos da combustão, bem como a evolução da frente de chama e vazamento de gases parar o cárter (blow-by).

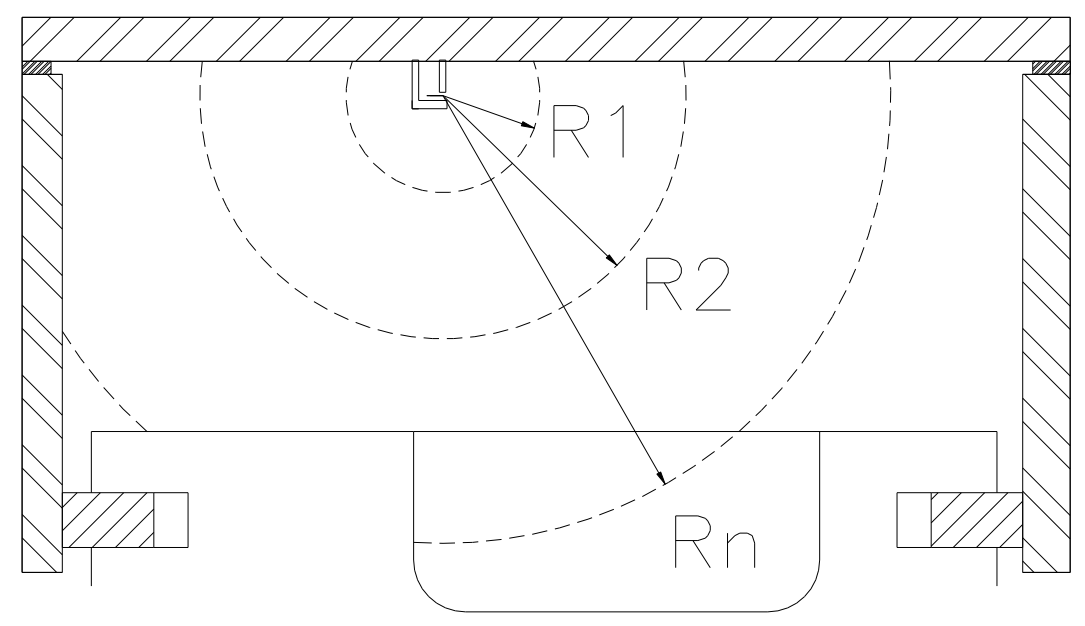

Figura 4.1 - Progressão da frente de chama no interior da câmara de combustão.

O conteúdo do cilindro é dividido em três regiões: uma região dos gases queimados, outra dos gases não queimados e uma terceira região das frestas, todas contendo gases perfeitos. Supõe-se que a frente de chama tenha o formato de uma casca esférica, centrada em um ponto de ignição especificado (usualmente a vela de ignição) e seja adiabática. Também admite-se que haja uniformidade de composição e temperatura dos gases em cada uma das zonas e gradiente de pressão nulo em qualquer ponto da câmara de combustão. A Figura 4.1 mostra esquematicamente a progressão da frente de chama durante a combustão e sua interação com as paredes da câmara. 
Para que se faça então uma análise da evolução da combustão a partir da pressão medida, é necessário que, para cada posição angular do virabrequim, sejam determinados os estados de cada um dos VC, pois assim pode-se inferir a taxa de queima, evolução de frente de chama, calor liberado pela combustão, atraso de ignição, etc. Tal caracterização de estado requer portanto o conhecimento da temperatura e composição dos gases (massa molecular média) adicionalmente à pressão em cada região, uma vez adotado o modelo de gás perfeito.

A determinação da composição dos gases em cada uma das zonas, como será visto adiante, é feita por meio de balanço de espécies químicas envolvidas na reação de combustão, considerando-se efeitos de dissociação nos gases queimados a altas temperaturas. Para as temperaturas, são deduzidas expressões de suas derivadas em relação à posição angular do virabrequim obtidas pela aplicação, basicamente, da equação da continuidade e da Primeira Lei aos volumes de controle.

Boa parte deste capítulo é, pois, dedicada à manipulação das equações fundamentais (estado, continuidade e Primeira Lei) para que se chegue às expressões que permitam calcular a temperatura em cada uma das zonas em cada instante. E, como se objetivava um processo de cálculo que pudesse marchar no tempo, sem reiterações, procurou-se garantir que as expressões das derivadas das temperaturas estivessem sempre em função, de forma explícita, de grandezas cujos valores fossem todos conhecidos em um determinado instante. Essa formulação permite então que a integração numérica dessas expressões seja feita de forma mais simples e rápida.

As passagens matemáticas detalhadas visam mostrar todas as simplificações adotadas na obtenção das duas equações diferenciais de $1^{\mathrm{a}}$ ordem para as temperaturas das duas zonas, em função do ângulo de virabrequim. 
Como dados de entrada do modelo têm-se, além de características geométricas do motor e da curva de pressão na câmara, todos os valores normalmente medidos em bancada dinamométrica, a saber: consumo de ar e combustível e suas temperaturas, pressão no coletor de admissão e escapamento, velocidade angular, etc. Esses valores permitem estabelecer o estado inicial da câmara no instante do fechamento da válvula de admissão, de forma que a integração da equação diferencial da temperatura dos gases não queimados possa se iniciar normalmente. Entretanto, para que a integração da equação diferencial da temperatura dos gases queimados possa começar, é necessário que se estime sua temperatura inicial. É então feita a hipótese de que a combustão do primeiro volume finito a ser queimado ocorre adiabaticamente e sem restrição à expansão de seus gases. Assim a temperatura desse primeiro "pacote" de gases queimados é igualada à temperatura adiabática de chama.

\subsection{Equações de estado}

A hipótese fundamental deste trabalho é que, a qualquer instante entre o fechamento da válvula de admissão e a abertura da válvula de escapamento, pode-se tratar a câmara de combustão como sendo dividida principalmente em um volume de controle com gases não queimados $\left(\mathrm{VC}_{u}\right)$, compostos por mistura ar - combustível não queimada e gases residuais e um outro volume de controle com gases queimados $\left(\mathrm{VC}_{b}\right)$. A fronteira comum desses dois volumes de controle é a frente de chama, considerada adiabática e esférica, centrada na vela de ignição. As demais fronteiras são as paredes do cilindro, cabeçote e pistão. Além desses volumes de controle principais, considera-se também o volume de controle correspondente às frestas, que é admitido constante, e a partir do qual podem ocorrer vazamentos para o cárter. Reiterando, admite-se também 
não haver gradientes de pressão no interior de toda a câmara, bem como supõe-se regime de uniformidade de temperatura e composição em cada um dos VC.

Convencionar-se-á denotar com o subscrito " $u$ " as propriedades relacionadas aos gases da zona não queimada, com o subscrito " $b$ " aquelas relacionadas aos gases da zona queimada e com o subscrito " $c$ " aquelas relacionadas aos gases da zona das frestas. Uma representação esquemática dessa divisão pode ser vista na Figura 4.2. Outra convenção adotada é que todas as derivadas de grandezas designadas por um ponto acima da variável que as representam devem ser tomadas em relação à posição angular do virabrequim, já que para uma condição de velocidade angular constante essas derivadas só diferem das tomadas em relação ao tempo por uma constante multiplicativa.

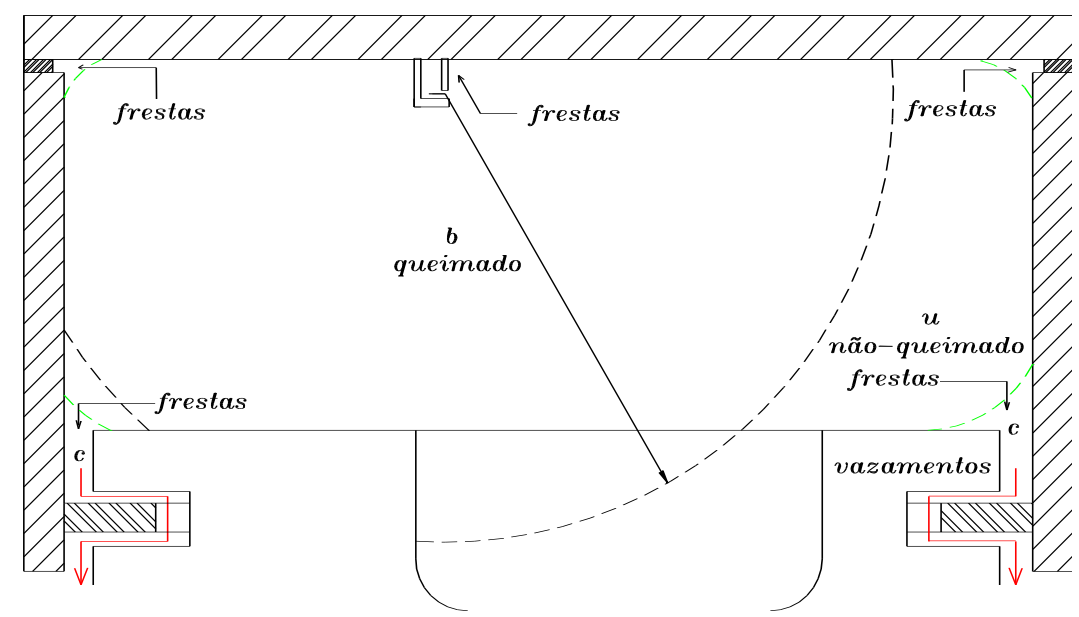

Figura 4.2 - Divisão da câmara de combustão em duas zonas.

Chamando de $M_{c h}$ a massa total contida no cilindro num determinado instante (sem considerar as frestas), para conservação de massa nas duas zonas deve-se ter:

$$
M_{c h}=M_{u}+M_{b}
$$

onde $M_{u}$ e $M_{b}$ representam as massas das zonas não queimada e queimada, respectivamente.

Derivando-se a Eq. 4-1 em relação à posição angular do virabrequim, chega-se a: 


$$
\dot{M}_{c h}=\dot{M}_{u}+\dot{M}_{b}
$$

O volume da câmara $\forall$ (sem considerar o volume das frestas) em cada instante pode ser escrito como a soma dos volumes de controle ocupados pelas duas zonas:

$$
\forall=\forall_{u}+\forall_{b}
$$

onde $\forall$ pode ser calculado através de relações geométricas do motor.

Derivando-se novamente a Eq. 4-3 em relação à posição angular do virabrequim, obtém-se:

$$
\dot{\forall}=\dot{\forall}_{u}+\dot{\forall}_{b}
$$

Admitindo que os gases em ambas as zonas possam ser considerados como perfeitos, suas equações de estado podem ser escritas como segue:

$$
\begin{aligned}
& p \cdot \forall_{u}=M_{u} \cdot R_{u} \cdot T_{u} \\
& p \cdot V_{b}=M_{b} \cdot R_{b} \cdot T_{b}
\end{aligned}
$$

onde $p$ e $T$ se referem à pressão e temperatura absolutas e $R$ é a constante universal dos gases em base mássica, ou seja, $R=\frac{\tilde{R}}{m o l}$ para cada zona. Para efeito de esclarecimento, será utilizado $\tilde{R}=83,145 \frac{\mathrm{bar} \cdot \mathrm{cm}^{3}}{\mathrm{gmol} \cdot \mathrm{K}}$.

\subsection{Modelo para frestas}

Como é sabido, existem várias frestas na câmara de combustão que podem armazenar quantidades consideráveis de gás não queimado durante os períodos de compressão e combustão. Essas frestas compreendem a folga entre o pistão e o cilindro 
logo acima do primeiro anel, região entre os anéis e o pistão (fundo dos canaletes), cavidades em torno da vela de ignição e pequenos interstícios ao longo da junta de cabeçote.

O efeito dessas frestas é significativamente maior em motores onde a mistura do combustível ao ar é feita fora do cilindro, pois essas frestas irão, em determinados períodos, retirar da câmara principal mistura combustível para, posteriormente, devolvêla à câmara. E como a relação área/volume dessas frestas é muito grande, a troca de calor se processa de forma a aproximar a temperatura dos gases nelas contidos à temperatura de suas paredes.

O modelo para frestas a ser empregado neste trabalho parte da hipótese de que todas as frestas podem ter seus efeitos considerados em conjunto, como se seus volumes pudessem ser agrupados em um único denominado $V_{c}$. Admite-se também que a qualquer instante, a pressão reinante na câmara de combustão seja igual àquela presente nas frestas, não havendo, portanto, restrição no fluxo de gases entre as frestas e a câmara de combustão. Esta última hipótese traz como consequiência o fato de que enquanto a pressão é crescente, o fluxo de gases é da câmara para as frestas; a partir do instante em que a pressão começa a cair, o fluxo se reverte, passando a ocorrer das frestas para a câmara.

Cabe aqui salientar que, neste trabalho, a título de simplificação, será considerado somente o fluxo de mistura não queimada entre as frestas e a câmara. Essa hipótese é razoável na medida em que, por ser tratar de regiões relativamente frias e de espessura reduzida, o efeito de apagamento (quenching) faz com que a frente de chama não consiga se propagar para dentro das frestas. Além disso, a região onde se encontram os maiores volumes das frestas está bastante afastada da vela de ignição, de modo que a frente de chama normalmente não deve atingir essa região até que ocorra o pico de 
pressão na câmara. No caso da geometria do motor utilizado neste trabalho para a verificação experimental dos resultados (câmara no pistão e vela praticamente centrada) essa simplificação é plenamente justificada. Em se tratando de motores com câmara de combustão no cabeçote do tipo cunha, em que a vela de ignição fica em uma das extremidades da câmara, o modelo poderia incorporar, na parte que calcula a interação da frente de chama com as superfícies da câmara, um parâmetro que fornecesse a fração das frestas submetida aos gases queimados. Esse aspecto deveria ser considerado se o modelo pretendesse simular também a emissão de hidrocarbonetos não queimados, na qual o volume das frestas ocupa posição primordial.

Vale realçar que, sendo o efeito das frestas secundário na análise de liberação de calor em função do pequeno volume ocupado, uma demasiada sofisticação em seu modelo não se justifica.

Utilizando novamente o modelo de gás perfeito, agora para as frestas, pode-se escrever a massa de gases não queimados contida nas frestas como:

$$
M_{c}=\frac{p \cdot V_{c}}{R_{c} \cdot T_{c}}
$$

onde:

$M_{c}$ : massa de gases contidos nas frestas;

$p$ : pressão nas frestas (igual à da câmara);

$\nvdash_{c}$ : volume total das frestas;

$R_{c}=\frac{\tilde{R}}{M o l_{c}}:$ constante para os gases contidos nas frestas (mistura não queimada);

$T_{c}$ : temperatura absoluta dos gases contidos nas frestas.

Para obter a variação de massa contida nas frestas, basta derivar a Eq. 4-7 em 
relação à posição angular do virabrequim:

$$
\dot{M}_{c}=\frac{\dot{p} \cdot \nvdash_{c}}{R_{c} \cdot T_{c}}
$$

uma vez que $V_{c}, R_{c}$ e $T_{c}$ são considerados constantes.

Essas equações serão empregadas no balanço global de massa.

\subsection{Modelo de vazamento}

O mecanismo de vazamento de gases da câmara de combustão para o cárter de um motor é complexo pois envolve escoamentos blocados em alguns pontos (gaps entre pontas dos anéis), escoamentos através de passagens e folgas entre anéis e pistão e escoamento ao longo de algumas regiões da superfície de contato anel - cilindro. O modelo de vazamento aqui adotado objetiva resolver apenas globalmente a quantidade de massa que vaza para o cárter durante um ciclo completo. Esse modelo se resume no escoamento crítico de gás perfeito desde as frestas até o cárter através de um orifício equivalente a todos os descritos acima.

A vazão mássica no escoamento de um fluido através de um orifício pode ser escrita como:

$$
\frac{d M}{d t}=C_{D} \cdot A \cdot \rho \cdot V
$$

onde:

$\frac{d M}{d t}$ : vazão mássica do fluido;

$C_{D}:$ coeficiente de descarga;

$A$ : área do orifício; 
$\rho:$ massa específica do fluido;

$V$ : componente normal média da velocidade no orifício.

Como em grande parte do período que vai desde o fechamento da válvula de admissão até a abertura da válvula de escapamento a pressão é grande o suficiente para promover um escoamento blocado de gases para o cárter, esse será o regime de escoamento adotado ao longo de todo esse período. Admitindo então que todo o vazamento ocorra sob o regime de escoamento crítico, pode-se reformular a Eq. 4-9 através das relações de escoamento blocado para gás perfeito (VAN WYLEN ${ }^{[19]}$ ) e então escrever o fluxo de massa que escoa das frestas para o cárter como sendo:

$$
\frac{d M}{d t}=\frac{C_{D} \cdot A \cdot p}{\sqrt{R_{c} \cdot T_{c}}} \cdot \gamma^{1 / 2} \cdot\left(\frac{2}{\gamma+1}\right)^{(\gamma+1) / 2(\gamma-1)}
$$

onde $p$ é a pressão de estagnação presente nas frestas e $\gamma$ a relação entre os calores específicos dos gases nelas contidos.

Pelo fato dos termos $C_{D}, A, \gamma, R_{c}$ e $T_{c}$ poderem ser considerados constantes, a Eq. 4-10 pode ser simplificada para:

$$
\dot{M}_{b b}=\left(\frac{d \theta}{d t}\right)^{-1} K_{b b} \cdot p
$$

onde o subscrito $b b$ denota blow-by e o termo $\left(\frac{d \theta}{d t}\right)^{-1}$ foi introduzido para referir o fluxo de massa à posição angular do virabrequim. A constante $K_{b b}$ deverá ser então determinada através de medições de blow-by em um motor específico. 


\subsection{Modelo de troca de calor}

O modelo de troca de calor entre os gases e as paredes da câmara utilizado neste trabalho é baseado nas relações obtidas por WOSCHNI ${ }^{[7]}$ já descritas anteriormente na revisão bibliográfica . Entretanto, o modelo proposto por WOSCHNI foi idealizado para fornecer um coeficiente de troca de calor por convecção médio em toda a câmara. Neste trabalho, é feita a hipótese de que as relações obtidas por WOSCHNI para um coeficiente médio podem ser utilizadas em cada um dos dois VC, sendo que as propriedades termodinâmicas e de transporte utilizadas pela formulação serão avaliadas particularmente em cada uma das zonas.

Assim, a relação entre os adimensionais Nusselt e Reynolds proposta por WOSCHNI $\left(N u=0,035 \cdot R e^{0,8}\right)$, em sua forma expandida:

$$
N u=\frac{h \cdot B}{k}=0,035 \cdot R e^{0,8}=0,035 \cdot\left(\frac{\rho \cdot w \cdot B}{\mu}\right)^{0,8}
$$

onde:

$h:$ coeficiente de troca de calor por convecção;

$B$ : dimensão característica (adotada como sendo o diâmetro do cilindro);

$k$ : condutibilidade térmica do fluido;

$\rho:$ massa específica;

$w$ : velocidade característica (dada pela Eq. 3-26, Eq. 3-27 e Eq. 3-28);

$\mu$ : viscosidade dinâmica,

pode ser particularizada para cada um dos VC, resultando em:

$$
h_{u}=0,035 \cdot\left(\frac{\rho_{u} \cdot w \cdot B}{\mu_{u}}\right)^{0,8} \cdot \frac{k_{u}}{B}
$$




$$
h_{b}=0,035 \cdot\left(\frac{\rho_{b} \cdot w \cdot B}{\mu_{b}}\right)^{0,8} \cdot \frac{k_{b}}{B}
$$

para o $\mathrm{VC}_{u}$ e o $\mathrm{VC}_{b}$ respectivamente.

A taxa de calor trocado entre cada um dos VC e as superfícies da câmara que os delimitam pode ser escrita como mostram a Eq. 3-14 e Eq. 3-15, com os coeficientes de película dados agora pela Eq. 4-13 e pela Eq. 4-14. As temperaturas de cada uma das superfícies são adotadas como valores médios constantes ao longo de todo o ciclo e dependem da condição de operação do motor. Esses valores devem ser estimados a partir de medições realizadas na zona de fogo de pistões, cilindros e cabeçote.

Já a área de troca é calculada da seguinte forma: é construído um "mapa" contendo as áreas de contato de cada um dos VC e as paredes da câmara (pistão, cilindro e cabeçote), bem como seus volumes, para diversas posições do pistão e diversos raios de frente de chama. Esse mapa é gerado a partir da interação de uma casca esférica com as paredes da câmara. Para cada posição angular do virabrequim e, conseqüentemente, para cada posição do pistão a partir do ponto morto superior, ter-seá uma configuração de áreas e volumes como indica esquematicamente a Figura 4.3, onde $\mathrm{A}_{\text {head }}, \mathrm{A}_{c w}$ e $\mathrm{A}_{\text {piston }}$ designam as áreas de contato entre o $\mathrm{VC}_{u}$ (subscrito out) e $\mathrm{VC}_{b}$ (subscrito in) e o cabeçote, paredes do cilindro e pistão, respectivamente.

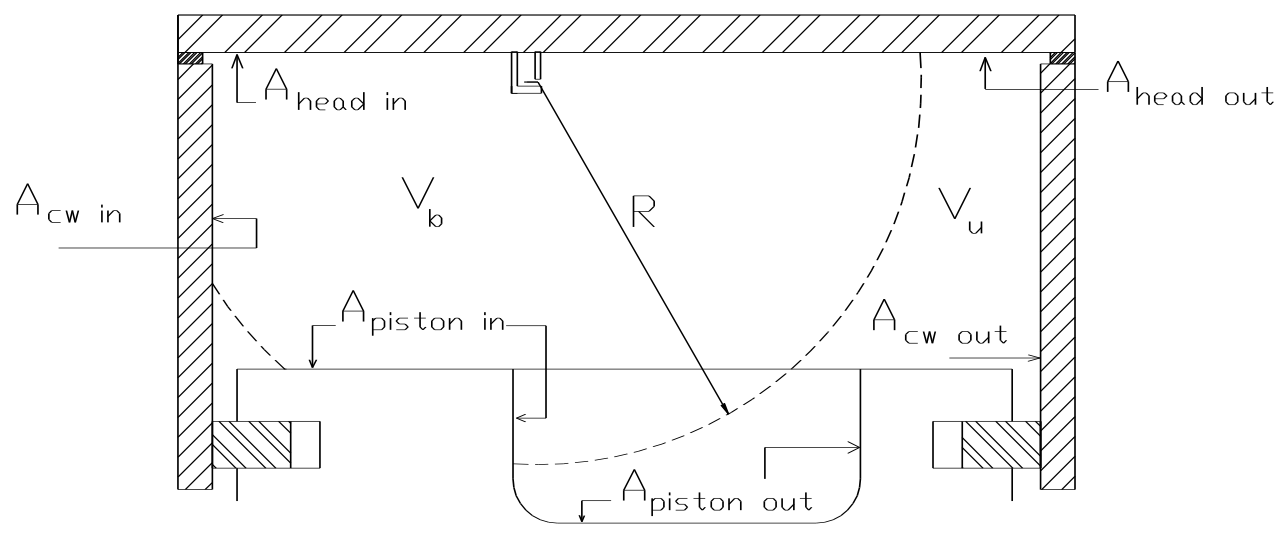

Figura 4.3 - Superfícies de troca de calor. 
Esse mapa é específico para cada geometria de câmara e um código numérico foi escrito para gerá-lo, no caso de a câmara estar contida no pistão. Os mapas das áreas e volumes indicados na Figura 4.3 foram gerados para o motor que foi utilizado na parte experimental deste trabalho e se encontram no Apêndice A.

Durante a resolução das equações de estado e de energia, esse mapa é então utilizado para que, dado um determinado "volume queimado" em uma posição do pistão, seja possível interpolar o raio da frente de chama que, em contato com as paredes da câmara, gera esse volume e as superfícies de contato.

Uma vez determinadas as áreas de troca e adotadas as temperaturas médias de cilindro, pistão e cabeçote, podem-se calcular os coeficientes de película e as taxas de troca de calor em cada superfície como uma função de $T_{u}$ e $T_{b}$ (Eq. 3-14 e Eq. 3-15). Observe-se que a massa específica e viscosidade dinâmica dos gases também são funções de suas temperaturas, como será explicitado posteriormente.

\subsection{Conservação global de massa}

Como será admitida uma terceira "pseudo-zona" das frestas com composição, temperatura e pressão conhecidas e ainda um vazamento de gases não queimados para o cárter, a soma das massas nos volumes de controle dos gases não queimados e queimados não será constante ao longo de todo o período analisado. Para que haja conservação global de massa, a variação da soma das massas nos dois VC deve ser igual ao oposto do fluxo de massa que entra nas frestas, isto é:

$$
\dot{M}_{c h}=\dot{M}_{u}+\dot{M}_{b}=-\dot{m}_{\text {increv }}
$$

onde $\dot{m}_{\text {in crev }}$ representa o fluxo de massa que entra nas frestas provindo da câmara. 
Já a variação da massa contida nas frestas pode ser expressa pela soma algébrica dos fluxos de massa oriundo da câmara e destinado ao cárter, ou seja:

$$
\dot{M}_{c}=\dot{m}_{\text {in crev }}-\dot{m}_{\text {out crev }}
$$

O fluxo de massa que sai das frestas para o cárter é aquele caracterizado pela Eq. 4-11 que, associada à Eq. 4-8, permite rescrever a Eq. 4-16, resultando no fluxo de massa que entra nas frestas:

$$
\dot{m}_{\text {in crev }}=\frac{\dot{p} \cdot \forall_{c}}{R_{u} \cdot T_{c}}+\left(\frac{d \theta}{d t}\right)^{-1} \cdot K_{b b} \cdot p
$$

guardando-se a convenção de que quando $\dot{m}_{\text {in crev }}>0$ massa está entrando no volume de controle das frestas e, conseqüentemente, quando $\dot{m}_{\text {increv }}<0$ massa está saindo das frestas para a câmara.

\subsection{Conservação de energia}

A Primeira Lei da Termodinâmica, ao ser aplicada a um volume de controle com fronteiras móveis, resulta em:

$$
\frac{d Q}{d t}+\sum \frac{d m_{e}}{d t} \cdot\left(h_{e}+\frac{v_{e}^{2}}{2}+z_{e} \cdot g\right)=\frac{d E}{d t}+\sum \frac{d m_{s}}{d t} \cdot\left(h_{s}+\frac{v_{s}^{2}}{2}+z_{s} \cdot g\right)+\frac{d W}{d t} \quad \text { Eq. } 4-18
$$

onde:

$\frac{d Q}{d t}$ : fluxo de calor que atravessa a superfície de controle (positivo quando entra no VC); $\frac{d m_{e}}{d t}, \frac{d m_{s}}{d t}:$ fluxos de massa de entrada e saída que atravessam a superfície de controle;

$\frac{d E}{d t}$ : variação da energia interna do conteúdo do volume de controle (ao se desprezarem as energias cinética e potencial associadas ao volume de 
controle);

$\frac{d W}{d t}$ : potência de eixo e/ou associada ao deslocamento da superfície de controle (positiva quando sai do VC);

$h$ : entalpia específica dos fluxos de massa que cruzam o VC;

$\frac{v^{2}}{2}$ : energia cinética específica dos fluxos de massa que cruzam o VC;

$z \cdot g:$ energia potencial específica dos fluxos de massa que cruzam o VC.

Ao se adotar a mesma referência para valores de entalpia e energia interna para todas as substâncias presentes na mistura combustível e nos produtos da combustão, não é necessário se considerar o calor liberado pela combustão uma vez que esse valor já se encontra incluso no balanço de energias internas e/ou entalpias.

Ao se aplicar a Eq. 4-18 aos volumes de controle de cada uma das zonas, serão desprezadas as parcelas de energia cinética e potencial dos fluxos de massa em função de serem muito pequenas frente à parcela devida à entalpia. A região das frestas, por ter volume, temperatura e composição conhecidos, não necessita de uma equação particular da Primeira Lei para determinação de seu estado. Também podem-se referir todas as derivadas à posição angular do virabrequim no lugar do tempo, uma vez que, como já mencionado anteriormente, supõe-se sua velocidade angular constante.

\subsubsection{Zona não queimada}

Particularizando a Eq. 4-18 para o volume de controle dos gases não queimados, tem-se:

$$
\dot{Q}_{u}+\sum \dot{m}_{e} \cdot h_{e}=\dot{E}_{u}+\sum \dot{m}_{s} \cdot h_{s}+\dot{W}_{u}
$$

Como afirmado anteriormente, neste trabalho somente será considerada a possibilidade de fluxo de gases não queimados entre a câmara e as frestas, ou seja, gases 
queimados não chegam a entrar nas frestas. Assim sendo, existem quatro situações a serem consideradas: enquanto não há queima, só podem ocorrer fluxos de massa de gases não queimados da câmara para as frestas (situação 1) ou das frestas para a câmara (situação 2). Uma vez iniciada a queima, o fluxo de massa dos gases não queimados pode ocorrer do $\mathrm{VC}_{u}$ para o $\mathrm{VC}_{b}$ e para as frestas (situação 3) ou das frestas para o $\mathrm{VC}_{b}$ (situação 4). Nesta última situação, supõe-se que os gases não queimados que venham a sair das frestas em algum instante sejam instantaneamente "queimados" e passem a integrar o $\mathrm{VC}_{b}$. Isto posto, a Eq. 4-19 pode ser rescrita sob quatro formas:

- situação 1 (sem queima):

massa saindo do $\mathrm{VC}_{u}$ e entrando nas frestas $\left(\dot{m}_{\text {in crev }} \geq 0\right)$, com $\sum \dot{m}_{e} \cdot h_{e}=0$. Portanto, tem-se:

$$
\dot{Q}_{u}=\dot{E}_{u}+\dot{m}_{\text {in crev }} \cdot h_{u}+\dot{W}_{u}
$$

- situação 2 (sem queima):

massa saindo das frestas e entrando no $\mathrm{VC}_{u}\left(\dot{m}_{\text {in crev }}<0\right)$, com $\sum \dot{m}_{s} \cdot h_{s}=0$. Portanto, tem-se: $\dot{Q}_{u}-\dot{m}_{\text {in crev }} \cdot h_{c}=\dot{E}_{u}+\dot{W}_{u}$, ou,

$$
\dot{Q}_{u}=\dot{E}_{u}+\dot{m}_{\text {in crev }} \cdot h_{c}+\dot{W}_{u}
$$

Note-se que a única diferença entre a Eq. 4-20 e a Eq. 4-21 se refere à condição em que o cálculo da entalpia do fluxo de massa $\dot{m}_{\text {in crev }}$ deve ser feito. $\mathrm{Na}$ Eq. 4-20, a entalpia $h_{u}$ do fluxo que vai para as frestas deve ser avaliada nas condições dos gases não queimados na câmara, ou seja, basicamente pressão e temperatura reinante na câmara. Já na Eq. 4-21, a entalpia $h_{c}$ do fluxo que vai das frestas para a câmara deve ser avaliada nas condições dos gases não queimados nas 
frestas, ou seja, com a temperatura $T_{c}$. Assim sendo, essas duas equações podem ser agrupadas em uma só, a saber:

$$
\dot{Q}_{u}=\dot{E}_{u}+\dot{m}_{\text {in crev }} \cdot h^{*}+\dot{W}_{u}
$$

com $h^{*}=h_{u}$ quando $\dot{m}_{\text {in crev }} \geq 0$ e $h^{*}=h_{c}$ quando $\dot{m}_{\text {in crev }}<0$.

- situação 3 (com queima):

massa saindo do $\mathrm{VC}_{u}$ entrando nas frestas $\left(\dot{m}_{\text {in crev }} \geq 0\right)$ e no $\mathrm{VC}_{b}, \sum \dot{m}_{e} \cdot h_{e}=0$. Portanto, tem-se:

$$
\dot{Q}_{u}=\dot{E}_{u}+\dot{m}_{\text {in crev }} \cdot h_{u}+\dot{m}_{u \rightarrow b} \cdot h_{u}+\dot{W}_{u}
$$

onde o termo $\dot{m}_{u \rightarrow b}$ significa o fluxo de massa que passa do $\mathrm{VC}_{u}$ para o $\mathrm{VC}_{b}$. Como nessa situação não se tem nenhum outro fluxo entrando no $\mathrm{VC}_{b}$ a não ser a massa que está sendo queimada, vem:

$$
\dot{M}_{b}=\dot{m}_{u \rightarrow b}
$$

Utilizando esta última relação na Eq. 4-23, vem:

$$
\dot{Q}_{u}=\dot{E}_{u}+\left(\dot{m}_{\text {in crev }}+\dot{M}_{b}\right) \cdot h_{u}+\dot{W}_{u}
$$

Da Eq. 4-15, pode-se escrever:

$$
-\dot{M}_{u}=\dot{m}_{\text {increv }}+\dot{M}_{b}
$$

que substituída Eq. 4-25, resulta em:

$$
\dot{Q}_{u}=\dot{E}_{u}-\dot{M}_{u} \cdot h_{u}+\dot{W}_{u}
$$

- situação 4 (com queima):

massa saindo do $\mathrm{VC}_{u}$ e das frestas $\left(\dot{m}_{\text {in crev }}<0\right)$ e entrando no $\mathrm{VC}_{b}, \sum \dot{m}_{e} \cdot h_{e}=0$. 
Portanto, tem-se:

$$
\dot{Q}_{u}=\dot{E}_{u}+\dot{m}_{u \rightarrow b} \cdot h_{u}+\dot{W}_{u}
$$

onde o termo $\dot{m}_{u \rightarrow b}$ significa, novamente, o fluxo de massa que passa do $\mathrm{VC}_{u}$ para o $\mathrm{VC}_{b}$. Como nesta situação a variação de massa do $\mathrm{VC}_{u}$ é unicamente devida ao fluxo $\dot{m}_{u \rightarrow b}$ que está sendo queimado, vem:

$$
\dot{M}_{u}=-\dot{m}_{u \rightarrow b}
$$

Utilizando esta última relação na Eq. 4-28, vem:

$$
\dot{Q}_{u}=\dot{E}_{u}-\dot{M}_{u} \cdot h_{u}+\dot{W}_{u}
$$

que é idêntica à Eq. 4-27. Assim, ambas as situações 3 e 4 são representadas matematicamente pela mesma equação (Eq. 4-27 ou Eq. 4-30) enquanto as situações 1 e 2 também são representadas por uma única equação (Eq. 4-22).

O passo seguinte é expressar a variação da energia interna em função da entalpia específica, propriedade escolhida para caracterizar o estado de cada um dos VC. Da Termodinâmica, sabe-se que:

$$
E=M \cdot u \Rightarrow \frac{d E}{d t}=\frac{d}{d t}(M \cdot u)=\frac{d M}{d t} \cdot u+M \cdot \frac{d u}{d t}
$$

e admitindo que a energia interna específica seja função somente da temperatura e pressão, pode-se escrever:

$$
\frac{d u}{d t}=\frac{\partial u}{\partial T} \cdot \frac{d T}{d t}+\frac{\partial u}{\partial p} \cdot \frac{d p}{d t}
$$

Agrupando a Eq. 4-31 e a Eq. 4-32, e tomando suas derivadas, alternativamente, em relação à posição angular do virabrequim uma vez que sua rotação 
é tomada como constante, vem:

$$
\dot{E}=\dot{M} \cdot u+M \cdot\left(\frac{\partial u}{\partial T} \cdot \dot{T}+\frac{\partial u}{\partial p} \cdot \dot{p}\right)
$$

Supõe-se agora que os gases não queimados não apresentem dissociação (em função da temperatura não tão elevada) e portanto possam ser considerados com composição e massa molar média fixas. Isto implica $\frac{\partial u_{u}}{\partial p}=0$ pois não havendo dissociação, não haverá variação da composição dos gases não queimados ao longo do ciclo devido à pressão. Essa conclusão aplicada à Eq. 4-33, resulta em:

$$
\dot{E}_{u}=\dot{M}_{u} \cdot u_{u}+M_{u} \cdot\left(\frac{\partial u_{u}}{\partial T_{u}} \cdot \dot{T}_{u}\right)
$$

para a variação da energia interna dos gases contidos no $\mathrm{VC}_{u}$.

Tomando novamente as situações 1 e 2 (sem queima) expressas pela Eq. 4-22 e nela substituindo esta última relação, obtém-se:

$$
\dot{M}_{u} \cdot u_{u}+M_{u} \cdot \frac{\partial u_{u}}{\partial T_{u}} \cdot \dot{T}_{u}=\dot{Q}_{u}-\dot{m}_{\text {increv }} \cdot h^{*}-p \cdot \dot{V}_{u}
$$

onde o termo relativo ao trabalho foi substituído por $p \cdot \dot{V}_{u}$ visto que não existe trabalho de eixo, só a movimentação da superfície do volume de controle. Lembrando que a utilização da Eq. 4-22 estava restrita à fase sem queima, o único fluxo que entra ou sai do $\mathrm{VC}_{u}$ é aquele que vai para as frestas. Assim, $-\dot{M}_{u}=\dot{m}_{\text {in crev }}$, que pode ser utilizada na simplificação da Eq. 4-35, resultando em:

$$
\dot{M}_{u} \cdot u_{u}+M_{u} \cdot \frac{\partial u_{u}}{\partial T_{u}} \cdot \dot{T}_{u}=\dot{Q}_{u}+\dot{M}_{u} \cdot h^{*}-p \cdot \dot{\forall}_{u}
$$

que tendo a derivada da temperatura isolada fornece: 


$$
\dot{T}_{u}=\frac{\dot{Q}_{u}+\dot{M}_{u} \cdot\left(h^{*}-u_{u}\right)-p \cdot \dot{V}_{u}}{M_{u} \cdot \frac{\partial u_{u}}{\partial T_{u}}}
$$

Da definição de entalpia específica:

$$
h=u+p \cdot v=u+\frac{p}{\rho}
$$

onde $h$ é a entalpia específica, $u$ a energia interna específica, $p$ a pressão, $v$ o volume específico e $\rho$ é a massa específica. Da Eq. 4-38 tem-se que:

$$
u=h-p \cdot v=h-\frac{p}{\rho}
$$

e pode-se escrever também:

$$
\begin{aligned}
\left.\frac{\partial u}{\partial T}\right|_{p=c t e} & =\left.\frac{\partial\left(h-\frac{p}{\rho}\right)}{\partial T}\right|_{p=c t e}=\left.\frac{\partial h}{\partial T}\right|_{p=c t e}-\left.\frac{\partial\left(\frac{p}{\rho}\right)}{\partial T}\right|_{p=c t e}= \\
& =\left.\frac{\partial h}{\partial T}\right|_{p=c t e}-\left[\left.\frac{1}{\rho} \frac{\partial p}{\partial T}\right|_{p=c t e}-\left.\frac{p}{\rho^{2}} \cdot \frac{\partial \rho}{\partial T}\right|_{p=c t e}\right] \\
\left.\frac{\partial u}{\partial p}\right|_{T=c t e} & =\frac{\partial\left(h-\frac{p}{\rho}\right)}{\partial p}\left|=\frac{\partial h}{\partial p}\right|_{T=c t e}-\left.\frac{\partial\left(\frac{p}{\rho}\right)}{\partial p}\right|_{T=c t e}= \\
= & \left.\frac{\partial h}{\partial p}\right|_{T=c t e}-\left[\frac{1}{\rho}-\left.\frac{p}{\rho^{2}} \cdot \frac{\partial \rho}{\partial p}\right|_{T=c t e}\right]
\end{aligned}
$$

Da lei de gás perfeito, tem-se que:

$$
p=\rho \cdot R \cdot T \Rightarrow \rho=\frac{p}{R \cdot T}
$$




$$
\left.\frac{\partial \rho}{\partial T}\right|_{p=c t e}=-\frac{p}{R \cdot T^{2}}
$$

Substituindo a Eq. 4-42 e a Eq. 4-43 na Eq. 4-40 e observando que

$$
\begin{aligned}
\left.\frac{\partial p}{\partial T}\right|_{p=c t e} & =0, \text { vem: } \\
\frac{\partial u}{\partial T} & =\frac{\partial h}{\partial T}-R
\end{aligned}
$$

Substituindo a Eq. 4-39 e a Eq. 4-44 na Eq. 4-37, ter-se-á:

$$
\dot{T}_{u}=\frac{\frac{\dot{Q}_{u}}{M_{u}}+\frac{\dot{M}_{u}}{M_{u}} \cdot\left(h^{*}-h_{u}\right)+\frac{\dot{M}_{u}}{M_{u}} \cdot \frac{p}{\rho_{u}}-\frac{p \cdot \dot{V}_{u}}{M_{u}}}{\left(\frac{\partial h_{u}}{\partial T_{u}}-R_{u}\right)}
$$

Como $\dot{M}_{u}=\overline{\rho_{u} \cdot \forall_{u}}=\dot{\rho}_{u} \cdot \forall_{u}+\rho_{u} \cdot \dot{\forall}_{u}$ e $\frac{p \cdot V_{u}}{M_{u}}=R_{u} \cdot T_{u}$, a Eq. 4-45 se simplifica para:

$$
\dot{T}_{u}=\frac{\frac{\dot{Q}_{u}}{M_{u}}+\frac{\dot{M}_{u}}{M_{u}} \cdot\left(h^{*}-h_{u}\right)+R_{u} \cdot T_{u} \cdot \frac{\dot{\rho}_{u}}{\rho_{u}}}{\left(\frac{\partial h_{u}}{\partial T_{u}}-R_{u}\right)}
$$

Tomando a derivada total da lei de gás perfeito sob a forma

$$
\frac{\dot{p}}{p}=\frac{\dot{\rho}}{\rho}+\frac{\dot{R}}{R}+\frac{\dot{T}}{T}
$$

e isolando o termo relativo à massa específica para substituí-lo na Eq. 4-46, tem-se: 


$$
\dot{T}_{u}=\frac{\frac{\dot{Q}_{u}}{M_{u}}+\frac{\dot{M}_{u}}{M_{u}} \cdot\left(h^{*}-h_{u}\right)+R_{u} \cdot T_{u} \cdot\left(\frac{\dot{p}}{p}-\frac{\dot{T}_{u}}{T_{u}}\right)}{\left(\frac{\partial h_{u}}{\partial T_{u}}-R_{u}\right)}
$$

uma vez que se considera $\dot{R}_{u}=0$ devido à hipótese de não haver dissociação nos gases não queimados. Rearranjando os termos da Eq. 4-48, ter-se-á:

$$
\dot{T}_{u}=\frac{\frac{\dot{Q}_{u}}{M_{u}}-\frac{\dot{m}_{\text {increv }}}{M_{u}} \cdot\left(h^{*}-h_{u}\right)+\frac{\dot{p}}{\rho_{u}}}{\frac{\partial h_{u}}{\partial T_{u}}}
$$

já que, como equacionado anteriormente, $-\dot{M}_{u}=\dot{m}_{\text {in crev }}$ para essas situações. A Eq. 4-49 é então a expressão que permite avaliar a derivada da temperatura dos gases não queimados em relação à posição angular do virabrequim enquanto não há combustão. Note-se que nesse regime descrito nas situações 1 e 2 mencionadas supra, o único fluxo de massa que entra ou sai do $\mathrm{VC}_{u}$ é aquele que vem ou vai para as frestas $\dot{m}_{\text {increv }}$ (Eq. 417).

Assim sendo, esse fluxo só poderá contribuir na avaliação de $\dot{T}_{u}$ quando seu sentido for das frestas para a câmara, pois nesse caso $h^{*}=h_{c} \neq h_{u}$. Caso contrário, quando o fluxo for da câmara para as frestas, $h^{*}=h_{u}$, e sua contribuição direta na variação de temperatura dos gases não queimados é nula.

Tomando agora as situações 3 e 4 (com queima) expressas pela Eq. 4-27 (ou Eq. 4-30) e nela substituindo a Eq. 4-34, obtém-se:

$$
\dot{M}_{u} \cdot u_{u}+M_{u} \cdot \frac{\partial u_{u}}{\partial T_{u}} \cdot \dot{T}_{u}=\dot{Q}_{u}+\dot{M}_{u} \cdot h_{u}-p \cdot \dot{V}_{u}
$$

que tendo a derivada da temperatura novamente isolada fornece: 


$$
\dot{T}_{u}=\frac{\dot{Q}_{u}+\dot{M}_{u} \cdot\left(h_{u}-u_{u}\right)-p \cdot \dot{V}_{u}}{M_{u} \cdot \frac{\partial u_{u}}{\partial T_{u}}}
$$

Aplicando as mesmas simplificações que foram efetuadas para se obter a Eq. 449 (situações 1 e 2) à Eq. 4-51 (situações 3 e 4), tem-se como resultado:

$$
\dot{T}_{u}=\frac{\frac{\dot{Q}_{u}}{M_{u}}+\frac{\dot{p}}{\rho_{u}}}{\frac{\partial h_{u}}{\partial T_{u}}}
$$

Cabe aqui ressaltar que a diferença entre a Eq. 4-49 e a Eq. 4-52 pode ser explicada pelo seguinte: os fluxos de entalpia associados aos fluxos de massa que atravessam o $\mathrm{VC}_{u}$ só podem influenciar diretamente a temperatura dos gases não queimados quando esses fluxos entram no volume de controle com uma entalpia específica diferente da que existe no seu interior. Quando esses fluxos saem do $\mathrm{VC}_{u}$, não acarretam mudança de temperatura dos gases no volume de controle. Como na situação 3 e 4, por hipótese, não entra massa no $\mathrm{VC}_{u}$ pois os fluxos de massa que saem das frestas são "queimados" diretamente e passam a integrar o $\mathrm{VC}_{b}$, o termo relacionado ao fluxo de entalpia que aparece na Eq. 4-49 não existe na Eq. 4-52.

\subsubsection{Zona queimada}

Particularizando a Eq. 4-18 agora para o volume de controle dos gases queimados, obtém-se:

$$
\dot{Q}_{b}+\sum \dot{m}_{e} \cdot h_{e}=\dot{E}_{b}+\sum \dot{m}_{s} \cdot h_{s}+\dot{W}_{b}
$$

A partir do início da combustão, só duas situações serão contempladas para a região dos gases queimados: o fluxo de massa que entra no $\mathrm{VC}_{b}$ é composto pela massa 
que deixa de integrar $\mathrm{o} \mathrm{VC}_{u}$ para ser queimada e, adicionalmente, pelo fluxo de massa que venha a deixar as frestas (situação 5) ou, queimada toda a massa que se encontrava no interior do $\mathrm{VC}_{u}$, o único fluxo que entra no $\mathrm{VC}_{b}$ é o proveniente das frestas (situação 6). Note-se que não se admite saída de massa do $\mathrm{VC}_{b}$ em qualquer uma das situações.

Assim, a Eq. 4-53 pode ser reformulada para cada caso:

\section{- situação 5:}

massa saindo do $\mathrm{VC}_{u}$ e das frestas $\left(\dot{m}_{\text {increv }}<0\right)$, entrando no $\mathrm{VC}_{b}$, com $\sum \dot{m}_{s} \cdot h_{s}=0$. Portanto, tem-se:

$$
\dot{Q}_{b}+\dot{m}_{u \rightarrow b} \cdot h_{u}-\dot{m}_{\text {increv }} \cdot h_{c}=\dot{E}_{b}+\dot{W}_{b}
$$

- situação 6:

massa saindo das frestas e entrando no $\mathrm{VC}_{u}\left(\dot{m}_{\text {in crev }}<0\right)$, com $\sum \dot{m}_{s} \cdot h_{s}=0$. Portanto, tem-se:

$$
\dot{Q}_{b}-\dot{m}_{\text {increv }} \cdot h_{c}=\dot{E}_{b}+\dot{W}_{b}
$$

Quando $\dot{m}_{\text {increv }} \geq 0$, o termo relativo ao fluxo de entalpia $\dot{m}_{\text {increv }} \cdot h_{c}$ será computado só no $\mathrm{VC}_{u}$, como comentado e equacionado anteriormente.

Como a situação 6 é um caso particular da situação 5, esta última será equacionada em detalhes a seguir. Tomando-se a Eq. 4-54 em conjunto com a Eq. 4-31 e as reorganizando, vem:

$$
\dot{E}_{b}=\dot{M}_{b} \cdot u_{b}+M_{b} \cdot \dot{u}_{b}=\dot{Q}_{b}+\dot{m}_{u \rightarrow b} \cdot h_{u}-\dot{m}_{\text {increv }} \cdot h_{c}-p \cdot \dot{\forall}_{b}
$$

onde novamente o termo relativo ao trabalho foi substituído por $p \cdot \dot{\forall}_{b}$ por não haver trabalho de eixo e sim só a movimentação da superfície do volume de controle.

Como nessa situação o aumento de massa do $\mathrm{VC}_{b}$ é devido aos fluxos de massa 
provenientes do $\mathrm{VC}_{u}$ e das frestas, tem-se que:

$$
\dot{m}_{u \rightarrow b}-\dot{m}_{\text {increv }}=\dot{M}_{b} \Rightarrow \dot{m}_{u \rightarrow b}=\dot{M}_{b}+\dot{m}_{\text {increv }}
$$

Usando o resultado da Eq. 4-57 na Eq. 4-56 e agrupando os termos relacionados, vem:

$$
M_{b} \cdot \dot{u}_{b}=\dot{Q}_{b}+\dot{M}_{b} \cdot\left(h_{u}-u_{b}\right)-\dot{m}_{\text {increv }} \cdot\left(h_{c}-h_{u}\right)-p \cdot \dot{\forall}_{b}
$$

A Eq. 4-39, que relaciona a energia interna e entalpia, aplicada na Eq. 4-58, juntamente com as relações de gás perfeito (Eq. 4-42 e Eq. 4-47), e sabendo que $\dot{M}_{b}=\overline{\rho_{b} \cdot \forall_{b}}=\dot{\rho}_{b} \cdot \forall_{b}+\rho_{b} \cdot \dot{V}_{b}$, resulta em:

$$
\dot{u}_{b}=\frac{\dot{Q}_{b}}{M_{b}}+\frac{\dot{M}_{b}}{M_{b}} \cdot\left(h_{u}-h_{b}\right)+\frac{p}{\rho_{b}} \cdot\left(\frac{\dot{p}}{p}-\frac{\dot{T}_{b}}{T_{b}}-\frac{\dot{R}_{b}}{R_{b}}\right)-\frac{\dot{m}_{\text {increv }}}{M_{b}} \cdot\left(h_{c}-h_{u}\right) \quad \text { Eq. } 4-59
$$

Antes de prosseguir com a dedução para obtenção da derivada $\dot{T}_{b}$, dar-se-á atenção ao termo $\frac{\dot{M}_{b}}{M_{b}}$. Partindo-se da Eq. 4-3 que representa a divisão da câmara em dois volumes, pode-se escrever:

$$
\forall=\forall_{u}+\forall_{b}=\frac{M_{u}}{\rho_{u}}+\frac{M_{b}}{\rho_{b}}
$$

e integrando-se a Eq. 4-15, sabendo-se que no instante do fechamento da válvula de admissão (IVC) a massa no interior do cilindro é $M$, tem-se também:

$$
M_{u}=M-M_{b}-\int_{\theta_{I V C}}^{\theta} \dot{m}_{i n c r e v} \cdot d \theta
$$

Isolando-se o termo $M_{b}$ a partir da Eq. 4-60 e da Eq. 4-61: 


$$
M_{b}=\frac{\forall \cdot \rho_{u}-M+\int_{\theta_{I V C}}^{\theta} \dot{m}_{\text {increv }} \cdot d \theta}{1-\frac{\rho_{b}}{\rho_{u}}} \cdot \frac{\rho_{b}}{\rho_{u}}
$$

Derivando-se a Eq. 4-62 em relação à posição angular do virabrequim, chega-se a:

$$
\begin{aligned}
& \dot{M}_{b}= \frac{\left(\frac{\cdot}{V \cdot \rho_{u}}+\dot{m}_{\text {increv }}\right) \cdot\left(\frac{\rho_{b}}{\rho_{u}}\right)+\left(V \cdot \rho_{u}-M+\int_{\theta_{I V C}}^{\theta} \dot{m}_{\text {increv }} \cdot d \theta\right) \cdot \overline{\left[\frac{\rho_{b}}{\rho_{u}}\right]}}{1-\frac{\rho_{b}}{\rho_{u}}}+ \\
&+\frac{\left(V \cdot \rho_{u}-M+\int_{\theta_{I V C}}^{\theta} \dot{m}_{\text {increv }} \cdot d \theta\right) \cdot\left(\frac{\rho_{b}}{\rho_{u}}\right) \cdot \overline{\left[\frac{\rho_{b}}{\rho_{u}}\right]}}{\left(1-\frac{\rho_{b}}{\rho_{u}}\right)^{2}}
\end{aligned}
$$

Dividindo-se a Eq. 4-63 pela Eq. 4-62 e simplificando-se:

$$
\frac{\dot{M}_{b}}{M_{b}}=\frac{\left(\frac{\cdot}{V \cdot \rho_{u}}+\dot{m}_{\text {increv }}\right)}{\left(\forall \cdot \rho_{u}-M+\int_{\theta_{I V C}}^{\theta} \dot{m}_{\text {in crev }} \cdot d \theta\right)}+\left[\frac{\dot{\rho_{b}}}{\rho_{u}}\right] \cdot\left[\frac{\rho_{u}^{2}}{\rho_{b} \cdot\left(\rho_{u}-\rho_{b}\right)}\right]
$$

onde o termo $\frac{\cdot}{V \cdot \rho_{u}}$ pode ser desenvolvido em:

$$
\begin{aligned}
\frac{\cdot}{V \cdot \rho_{u}} & =\dot{V} \cdot \rho_{u}+V \cdot \dot{\rho}_{u}=\dot{V} \cdot \rho_{u}+V \cdot\left(\frac{p}{R_{u} \cdot T_{u}}\right)= \\
& =\rho_{u} \cdot\left(\dot{V}+V \cdot\left(\frac{\dot{p}}{p}-\frac{\dot{T_{u}}}{T_{u}}\right)\right)
\end{aligned}
$$

uma vez que $\dot{R}_{u}=0$ em virtude de não se considerar dissociação nos gases não queimados. 
Desenvolvendo-se também o termo $\overline{\left[\frac{\rho_{b}}{\rho_{u}}\right]}$ com auxílio das relações de gás perfeito, tem-se:

$$
\overline{\left[\frac{\rho_{b}}{\rho_{u}}\right]}=\frac{\rho_{b}}{\rho_{u}} \cdot\left[\frac{\dot{T}_{u}}{T_{u}}-\frac{\dot{T}_{b}}{T_{b}}-\frac{\dot{R}_{b}}{R_{b}}\right]
$$

Substituindo-se então a Eq. 4-65 e a Eq. 4-66 na Eq. 4-64 e simplificando-se o resultado, chega-se a:

$$
\frac{\dot{M}_{b}}{M_{b}}=\mathbf{A}-\mathbf{B} \cdot\left[\frac{\dot{T}_{b}}{T_{b}}+\frac{\dot{R}_{b}}{R_{b}}\right]
$$

onde

$$
\mathbf{A}=\frac{\rho_{u \cdot}\left(\dot{V}+V \cdot\left(\frac{\dot{p}}{p}-\frac{\dot{T}_{u}}{T_{u}}\right)\right)+\dot{m}_{\text {increv }}}{\left(V \cdot \rho_{u}-M+\int_{\theta_{I V C}}^{\theta} \dot{m}_{\text {increv }} \cdot d \theta\right)}+\frac{\rho_{u}}{\rho_{u}-\rho_{b}} \cdot\left[\frac{\dot{T}_{u}}{T_{u}}\right]
$$

$\mathrm{e}$

$$
\mathbf{B}=\frac{\rho_{u}}{\rho_{u}-\rho_{b}}
$$

Retomando-se então a Eq. 4-59 e nela substituindo-se a Eq. 4-67, vem:

$$
\begin{aligned}
\dot{u}_{b}= & \frac{\dot{Q}_{b}}{M_{b}}+\left(\mathbf{A}-\mathbf{B} \cdot\left[\frac{\dot{T}_{b}}{T_{b}}+\frac{\dot{R}_{b}}{R_{b}}\right]\right) \cdot\left(h_{u}-h_{b}\right)+ \\
& +\frac{p}{\rho_{b}} \cdot\left(\frac{\dot{p}}{p}-\frac{\dot{T}_{b}}{T_{b}}-\frac{\dot{R}_{b}}{R_{b}}\right)-\frac{\dot{m}_{\text {increv }}}{M_{b}} \cdot\left(h_{c}-h_{u}\right)
\end{aligned}
$$

que pode ser simplificada para: 


$$
\begin{aligned}
\frac{\partial u_{b}}{\partial T_{b}} \cdot \dot{T}_{b}+\frac{\partial u_{b}}{\partial p} \cdot \dot{p}= & \frac{\dot{Q}_{b}}{M_{b}}+\mathbf{A} \cdot\left(h_{u}-h_{b}\right)+\frac{\dot{p}}{\rho_{b}}+ \\
& -\left[\mathbf{B} \cdot\left(h_{u}-h_{b}\right)+\frac{p}{\rho_{b}}\right] \cdot\left[\frac{\dot{T}_{b}}{T_{b}}+\frac{\dot{R}_{b}}{R_{b}}\right] \\
& -\frac{\dot{m}_{\text {increv }}}{M_{b}} \cdot\left(h_{c}-h_{u}\right)
\end{aligned}
$$

Diferentemente do que foi feito para os gases não queimados, não será possível fazer $\frac{\partial u_{b}}{\partial p}=0$ pois se admitiu que os gases queimados possam apresentar dissociação química e portanto não podem ser considerados com composição e massa molar média fixas. Utilizando-se então a Eq. 4-47 para substituir o termo $\left[\frac{\dot{T}_{b}}{T_{b}}+\frac{\dot{R}_{b}}{R_{b}}\right]$, a Eq. $4-40$ e a Eq. 4-41 para substituírem, respectivamente, os termos $\frac{\partial u_{b}}{\partial T_{b}}$ e $\frac{\partial u_{b}}{\partial p}$ na Eq. 4-71 e simplificando-se o resultado, vem:

$$
\dot{T}_{b}=\frac{\frac{\dot{Q}_{b}}{M_{b}}+\left[\mathbf{A}-\mathbf{B} \cdot \dot{p} \cdot\left(\frac{1}{p}-\frac{1}{\rho_{b}} \cdot \frac{\partial \rho_{b}}{\partial p}\right)\right] \cdot\left(h_{u}-h_{b}\right)+\dot{p} \cdot\left(\frac{1}{\rho_{b}}-\frac{\partial h_{b}}{\partial p}\right)-\frac{\dot{m}_{\text {increv }}}{M_{b}} \cdot\left(h_{c}-h_{u}\right)}{\frac{\partial h_{b}}{\partial T_{b}}-\mathbf{B} \cdot \frac{\left(h_{u}-h_{b}\right)}{\rho_{b}} \cdot \frac{\partial \rho_{b}}{\partial T_{b}}}
$$

que é a equação que fornece a derivada da temperatura dos gases queimados em relação à posição angular do virabrequim enquanto ainda há massa na região dos gases não queimados, com A e B dados pela Eq. 4-68 e pela Eq. 4-69 respectivamente.

Para a situação 6, representada pela Eq. 4-55, na qual se pressupõe finda a massa da região dos gases não queimados $\left(\dot{m}_{u \rightarrow b}=0\right)$, a equação que fornece a derivada da temperatura dos gases queimados é gerada de forma análoga à empregada na obtenção da Eq. 4-72, resultando em: 


$$
\dot{T}_{b}=\frac{\frac{\dot{Q}_{b}}{M_{b}}+\dot{p} \cdot\left(\frac{1}{\rho_{b}}-\frac{\partial h_{b}}{\partial p}\right)-\frac{\dot{m}_{\text {increv }}}{M_{b}} \cdot\left(h_{c}-h_{b}\right)}{\frac{\partial h_{b}}{\partial T_{b}}}
$$

Assim, foram explicitadas duas equações diferenciais para as temperaturas das regiões não queimada e queimada $\left(\dot{T}_{u}\right.$ e $\left.\dot{T}_{b}\right)$ em cada situação que, integradas em função do ângulo do virabrequim, fornecem as temperaturas dos dois VC em cada instante. Para que se possa determinar o volume e massa de cada um dos VC em cada posição angular $\theta$ do virabrequim, serão utilizadas as equações de estado (Eq. 4-5 e Eq. 4-6) e a equação de conservação de massa (Eq. 4-61) que, escritas de forma conveniente, resultam em:

$$
\begin{aligned}
& \forall_{u}=\frac{M-\int_{\theta_{I V C}}^{\theta} \dot{m}_{\text {increv }} \cdot d \theta-\rho_{b} \cdot \forall}{\rho_{u}-\rho_{b}} \\
& \forall_{b}=\forall-\forall_{u} \\
& M_{u}=\rho_{u} \cdot \forall_{u} \\
& M_{b}=\rho_{b} \cdot \forall_{b}
\end{aligned}
$$

Dessa forma, partindo-se desse conjunto de equações, aliadas a relações que permitam avaliar propriedades como $h, \frac{\partial h}{\partial T}, \frac{\partial h}{\partial p}, \rho, \frac{\partial \rho}{\partial T}, \frac{\partial \rho}{\partial p}$ para o conteúdo de cada um dos VC em função da temperatura e pressão correspondente e, utilizando-se o modelamento proposto para estimar a troca de calor com as paredes da câmara, podem ser calculados parâmetros como evolução da fração de massa queimada, duração total de queima (bem como suas parciais), taxa de liberação de calor, etc. O "formato" da curva 
da evolução da fração de massa queimada (ou da taxa de liberação de calor) em função da posição angular do virabrequim pode ser parametrizado e posteriormente utilizado em simuladores que empreguem taxa de queima predeterminada.

\subsection{Propriedades termodinâmicas}

Como comentado anteriormente, a resolução das equações diferenciais nas temperaturas requer que sejam conhecidas certas propriedades termodinâmicas dos gases contidos nos VC. Como cada VC contém várias espécies gasosas, inicialmente deve-se identificar e quantificar esses componentes.

Para temperaturas abaixo de $1000 \mathrm{~K}$, a dissociação nos produtos de combustão pode ser desprezada, de forma que a quantificação dos componentes do $\mathrm{VC}_{b}$ é feita de forma simplificada, como é feita também para $\mathrm{o} \mathrm{VC}_{u}$ e $\mathrm{VC}_{c}$ (onde se admitiu não ocorrer dissociação).

Para temperaturas superiores a $1000 K$, onde a dissociação química é considerável, serão utilizadas aqui as relações apresentadas no trabalho de MARTIN ${ }^{[18]}$, brevemente comentado no capítulo da revisão bibliográfica.

\subsubsection{Quantificação de espécies químicas do $\mathrm{VC}_{b}$ abaixo de $1000 \mathrm{~K}$ e do $\mathrm{VC}_{u}$}

Supondo-se que a composição molar mínima do combustível possa ser expressa por $\mathrm{CH}_{y} \mathrm{O}_{z} N_{w}$ com $y$ representando a relação $\mathrm{H} / \mathrm{C}, z$ a relação $\mathrm{O} / \mathrm{C}$ e $w$ a relação N/C do combustível, a equação química de sua combustão com o oxigênio do ar pode ser escrita como (HEYWOOD $\left.{ }^{[20]}\right)$ :

$$
\begin{aligned}
& \mathrm{CH}_{y} \mathrm{O}_{z} \mathrm{~N}_{w}+\frac{1}{\phi} \cdot\left(1+\frac{y}{4}-\frac{z}{2}\right)\left(\mathrm{O}_{2}+\psi \mathrm{N}_{2}\right) \rightarrow \\
& n_{\mathrm{CO}_{2}}^{\prime} \mathrm{CO}_{2}+n_{\mathrm{H}_{2} \mathrm{O}}^{\prime} \mathrm{H}_{2} \mathrm{O}+n_{\mathrm{CO}}^{\prime} \mathrm{CO}+n_{\mathrm{H}_{2}}^{\prime} \mathrm{H}_{2}+n_{\mathrm{O}_{2}}^{\prime} \mathrm{O}_{2}+n_{\mathrm{N}_{2}}^{\prime} \mathrm{N}_{2}
\end{aligned}
$$


onde $\psi$ é a relação entre as frações molares do nitrogênio e do oxigênio na atmosfera (valor típico $=3,76$ ) e $n_{i}^{\prime}$ é o número de moles da espécie $i$ produzido pela combustão de um mol de $\mathrm{CH}_{y} \mathrm{O}_{z} N_{w}$ com uma razão de equivalência combustível - ar $\phi$. Colocando-se agora o primeiro membro da Eq. 4-78 em função de cada mol de $O_{2}$ proveniente do ar, pode-se escrever:

$$
\begin{gathered}
\phi \varepsilon C+2 \phi \cdot\left(1-\varepsilon+\frac{z \varepsilon}{2}\right) H_{2}+\left(\frac{\phi z \varepsilon}{2}\right) O_{2}+\left(\psi+\frac{\phi \varepsilon w}{2}\right) N_{2}+O_{2} \rightarrow \\
n_{\mathrm{CO}_{2}} \mathrm{CO}_{2}+n_{\mathrm{H}_{2} \mathrm{O}} \mathrm{H}_{2} \mathrm{O}+n_{\mathrm{CO}} \mathrm{CO}+n_{\mathrm{H}_{2}} \mathrm{H}_{2}+n_{\mathrm{O}_{2}} \mathrm{O}_{2}+n_{\mathrm{N}_{2}} \mathrm{~N}_{2}
\end{gathered}
$$

com $\varepsilon$ dado por:

$$
\varepsilon=\frac{1}{1+\frac{y}{4}-\frac{z}{2}}
$$

e os valores $n_{i}$ agora representando o número de moles de cada espécie por mol de $\mathrm{O}_{2}$.

Dependendo da razão de equivalência $\phi$, têm-se três restrições quanto aos produtos a considerar:

1. misturas pobres ou estequiométricas $(\phi \leq 1) \rightarrow$ excesso de oxigênio $\therefore$ quantidades de $\mathrm{CO}$ e $\mathrm{H}_{2}$ nos produtos desprezíveis; Assim, um balanço de espécies químicas na Eq. 4-79, resulta nas seguintes quantidades dos produtos da reação: 


$$
\begin{array}{lc}
\mathrm{CO}_{2} & \phi \varepsilon \\
\mathrm{H}_{2} \mathrm{O} & 2 \phi \cdot\left(1-\varepsilon+\frac{z \varepsilon}{2}\right) \\
\mathrm{CO} & 0 \\
\mathrm{H}_{2} & 0 \\
\mathrm{O}_{2} & (1-\phi) \\
\mathrm{N}_{2} & \left(\psi+\frac{\phi \varepsilon w}{2}\right)
\end{array}
$$

total $\phi \cdot\left(1-\varepsilon+z \varepsilon+\frac{w \varepsilon}{2}\right)+1+\psi$

2. misturas ricas $(\phi>1) \rightarrow$ escassez de oxigênio

$\therefore$ quantidade de $\mathrm{O}_{2}$ nos produtos desprezível;

3. misturas ricas $\rightarrow$ pode-se considerar que a reação

$$
\mathrm{CO}_{2}+\mathrm{H}_{2} \Leftrightarrow \mathrm{CO}+\mathrm{H}_{2} \mathrm{O}
$$

esteja em equilíbrio com a seguinte constante:

$$
K(T)=\frac{n_{\mathrm{H}_{2} \mathrm{O}} \cdot n_{\mathrm{CO}}}{n_{\mathrm{CO}_{2}} \cdot n_{\mathrm{H}_{2}}}
$$

Em tese, essa constante de equilíbrio é função da temperatura. Entretanto, como uma simplificação usual em produtos de combustão em motores, utiliza-se $K$ com um valor fixo e igual a 3,5, correspondendo a uma temperatura de $1740 K\left(\mathrm{HEYWOOD}^{[20]}\right)$.

Chamando de $c$ a quantidade de $\mathrm{CO}$ oriunda da transformação de $\mathrm{CO}_{2}$ segundo a Eq. 4-82, um balanço de espécies químicas na Eq. 4-79 com as restrições para mistura rica resulta nas seguintes quantidades dos produtos da reação de combustão: 


$$
\begin{array}{lc}
\mathrm{CO}_{2} & \phi \varepsilon-c \\
\mathrm{H}_{2} \mathrm{O} & 2 \cdot(1-\varepsilon \phi)+z \varepsilon \phi+c \\
\mathrm{CO} & c \\
\mathrm{H}_{2} & 2 \cdot(\phi-1)-c \\
\mathrm{O}_{2} & 0 \\
\mathrm{~N}_{2} & \left(\psi+\frac{\phi \varepsilon w}{2}\right)
\end{array}
$$

$$
\text { total } \phi \cdot\left(2-\varepsilon+z \varepsilon+\frac{w \varepsilon}{2}\right)+\psi
$$

Substituindo-se as quantidades de $\mathrm{CO}_{2}, \mathrm{H}_{2} \mathrm{O}, \mathrm{CO}$ e $\mathrm{H}_{2}$ acima na Eq. 4-83 lembrando que foi adotado $n_{C O}=c$, vem:

$$
(1-K) \cdot c^{2}+\{2 \cdot(1-\not \phi)+K[2 \cdot(\phi-1)+\not \phi]+z \not \phi\} \cdot c+2 K \not \phi \cdot(1-\phi)=0
$$

onde se pode colocar:

$$
\begin{aligned}
& \alpha=(1-K) \\
& \beta=\{2 \cdot(1-\not \phi)+K[2 \cdot(\phi-1)+\varepsilon \phi]+z \varepsilon \phi\} \\
& \gamma=2 K \varepsilon \phi \cdot(1-\phi)
\end{aligned}
$$

e resolver a quantidade $c$ de moles de $C O$. 


\begin{tabular}{|c|c|c|}
\hline & \multicolumn{2}{|c|}{$\frac{n_{i} \text { moles }}{\text { mol de } \mathrm{O}_{2} \text { do ar }}$} \\
\hline Espécie & $\phi \leq 1$ & $\phi>1$ \\
\hline $\mathrm{CO}_{2}$ & $\phi \varepsilon$ & $\phi \varepsilon-c$ \\
\hline $\mathrm{H}_{2} \mathrm{O}$ & $2 \phi \cdot\left(1-\varepsilon+\frac{z \varepsilon}{2}\right)$ & $2 \cdot(1-\not \phi)+z \not \phi+c$ \\
\hline $\mathrm{CO}$ & 0 & $c$ \\
\hline$H_{2}$ & 0 & $2 \cdot(\phi-1)-c$ \\
\hline $\mathrm{O}_{2}$ & $(1-\phi)$ & 0 \\
\hline$N_{2}$ & $\left(\psi+\frac{\phi \varepsilon w}{2}\right)$ & $\left(\psi+\frac{\phi \varepsilon w}{2}\right)$ \\
\hline Total & $\phi \cdot\left(1-\varepsilon+z \varepsilon+\frac{w \varepsilon}{2}\right)+1+\psi$ & $\phi \cdot\left(2-\varepsilon+z \varepsilon+\frac{w \varepsilon}{2}\right)+\psi$ \\
\hline
\end{tabular}

Tabela 4.1 - Composição dos gases queimados abaixo de $1740 \mathrm{~K}$.

A Tabela 4.1 resume a quantidade molar de cada espécie química presente nos gases queimados por mol de $\mathrm{O}_{2}$ do oxidante (ar).

Chamando de $c x$ o número de átomos de carbono presentes em uma molécula do combustível, vê-se que a quantidade de moles de combustível por mol de $O_{2}$ do ar é $\frac{\varepsilon \phi}{c x}$.

E, como sempre há uma fração de gases queimados presente na mistura fresca (provinda de EGR ou de gases residuais), há que se considerar essa fração na composição dos gases não queimados para a completa identificação das espécies do $\mathrm{VC}_{u}$. Sendo resfrk essa fração (em base molar) de gases queimados residuais presentes na mistura não queimada, pode-se escrever a composição da mistura não queimada como sendo: 


$$
\begin{aligned}
& (1-\text { resfrk }) \cdot\left(\frac{c \phi}{c x} \text { molécula de combustível }+\mathrm{O}_{2}+\psi \mathrm{N}_{2}\right)+ \\
& \text { resfrk } \cdot\left(n_{\mathrm{CO}_{2}} \mathrm{CO}_{2}+n_{\mathrm{H}_{2} \mathrm{O}} \mathrm{H}_{2} \mathrm{O}+n_{\mathrm{CO}} \mathrm{CO}+n_{\mathrm{H}_{2}} \mathrm{H}_{2}+n_{\mathrm{O}_{2}} \mathrm{O}_{2}+n_{\mathrm{N}_{2}} \mathrm{~N}_{2}\right)
\end{aligned}
$$

Eq. $4-87$

onde os valores $n_{i}$ estão relacionados na Tabela 4.1. Agrupando as quantidades molares de $\mathrm{O}_{2}$ e $\mathrm{N}_{2}$, os componentes da mistura combustível-ar-gases residuais podem ser quantificados como mostra a Tabela 4.2.

Sabendo-se que a massa total dos produtos (que é igual à dos reagentes) por mol de $\mathrm{O}_{2}$ do ar é dada por:

$$
\begin{gathered}
\not \phi\left(\mathrm{mol}_{C}+y \cdot \mathrm{mol}_{H}+z \cdot \mathrm{mol}_{O}+w \cdot \mathrm{mol}_{N}\right)+\left(\mathrm{mol}_{\mathrm{O}_{2}}+\psi \cdot \mathrm{mol}_{N_{2}}\right)= \\
\& \phi(12+y \cdot 1+z \cdot 16+w \cdot 14)+(32+\psi \cdot 28)
\end{gathered}
$$

conclui-se que a massa molecular média dos gases contidos no $\mathrm{VC}_{b}$ é:

$$
M W_{b}=\frac{\varepsilon \phi(12+y \cdot 1+z \cdot 16+w \cdot 14)+(32+\psi \cdot 28)}{n_{b t o t a l}}
$$

com $n_{\text {btotal }}$ sendo o número total de moles dos produtos da combustão por mol de $\mathrm{O}_{2}$, explicitado na última linha da Tabela 4.1. 


\begin{tabular}{|c|c|c|}
\hline & \multicolumn{2}{|c|}{$\frac{n_{i} \text { moles }}{\text { mol de } \mathrm{O}_{2} \text { do } a r}$} \\
\hline Espécie & $\phi \leq 1$ & $\phi>1$ \\
\hline $\mathrm{CO}_{2}$ & resfrk $\cdot \phi \varepsilon$ & resfrk $\cdot(\phi \varepsilon-c)$ \\
\hline $\mathrm{H}_{2} \mathrm{O}$ & resfrk $\cdot 2 \phi \cdot\left(1-\varepsilon+\frac{z \varepsilon}{2}\right)$ & resfrk $\cdot(2 \cdot(1-\not \phi)+z \not \phi+c)$ \\
\hline $\mathrm{CO}$ & 0 & resfrk $\cdot c$ \\
\hline $\mathrm{H}_{2}$ & 0 & resfrk $\cdot(2 \cdot(\phi-1)-c)$ \\
\hline $\mathrm{O}_{2}$ & $(1-\operatorname{resfrk} \cdot \phi)$ & $(1-r e s f r k)$ \\
\hline$N_{2}$ & $\left(\psi+\right.$ resfrk $\left.\cdot \frac{\phi \varepsilon w}{2}\right)$ & $\left(\psi+\right.$ resfrk $\left.\cdot \frac{\phi \varepsilon w}{2}\right)$ \\
\hline combustível & $(1-r e s f r k) \cdot\left(\frac{\phi \varepsilon}{c x}\right)$ & $(1-r e s f r k) \cdot\left(\frac{\phi \varepsilon}{c x}\right)$ \\
\hline Total & $\begin{array}{c}\phi \cdot \text { resfrk } \cdot\left[1+\varepsilon \cdot\left(z-1-\frac{1}{c x}+\frac{w}{2}\right)\right] \\
+\frac{c \phi}{c x}+1+\psi\end{array}$ & $\begin{array}{c}\phi \cdot \text { resfrk } \cdot\left[1+\varepsilon \cdot\left(z-1-\frac{1}{c x}+\frac{w}{2}\right)\right] \\
+\frac{c \phi}{c x}+1+\psi+\operatorname{resfrk} \cdot(\phi-1)\end{array}$ \\
\hline
\end{tabular}

Tabela 4.2 - Composição dos gases não queimados.

Também pode-se determinar a massa molecular média dos gases contidos no $\mathrm{VC}_{u}$ a partir da Eq. 4-87, resultando em:

$$
M W_{u}=\frac{\varepsilon \phi(12+y \cdot 1+z \cdot 16+w \cdot 14)+(32+\psi \cdot 28)}{n_{\text {utotal }}}
$$

com $n_{\text {utotal }}$ sendo o número total de moles presentes no $\mathrm{VC}_{u}$ por mol de $\mathrm{O}_{2}$ (contando com gases residuais) discriminado na última linha da Tabela 4.2. Notar que as massas moleculares médias $M W_{b}$ e $M W_{u}$ calculadas pela Eq. 4-89 e Eq. 4-90 são expressas em gmol. 
Conhecendo-se a massa molecular média dos gases contidos nos VC, é possível que suas massas específicas sejam determinadas a partir de suas temperaturas e pressões, como indicado pelas equações de estado dadas pela Eq. 4-5 e pela Eq. 4-6. Em termos mais explícitos:

$$
\begin{gathered}
\rho_{u}=\frac{p}{R_{u} \cdot T_{u}}=\frac{p \cdot M W_{u}}{\widetilde{R} \cdot T_{u}} \\
\rho_{b}=\frac{p}{R_{b} \cdot T_{b}}=\frac{p \cdot M W_{b}}{\widetilde{R} \cdot T_{b}}
\end{gathered}
$$

Uma observação pode ser aqui feita: como a massa molar média dos gases queimados a baixas temperaturas e a dos não queimados são muito próximas, a fração de gases residuais em base molar resfrk se confunde com a fração em base mássica.

A partir das quantidades molares de cada espécie química contida no $\mathrm{VC}_{b}$ ou $\mathrm{VC}_{u}$ expressas na Tabela 4.1 e na Tabela 4.2 respectivamente, e do número total de moles em cada um dos VC, as frações molares $X_{i}$ de cada substância podem ser determinadas:

$$
X_{i}=\frac{n_{i}}{n_{\text {total }}}
$$

\subsubsection{Propriedades termodinâmicas $\left(\mathrm{VC}_{b}\right.$ abaixo de $1000 \mathrm{~K}$ e $\left.\mathrm{VC}_{u}\right)$}

De posse das frações molares de cada substância nos volumes de controle, é possível se determinar a entalpia e calor específicos da mistura de gases em cada caso, a partir das entalpias específicas dos componentes.

HIRES et al. ${ }^{[17]}$, no apêndice A de seu trabalho, apresentam curvas de entalpia específica molar em função da temperatura $\tilde{h}(T)$ para várias substâncias. As curvas são fornecidas pela expressão: 


$$
\tilde{h}_{i}(T)=a f_{i, 1} \cdot S T+\frac{a f_{i, 2} \cdot S T^{2}}{2}+\frac{a f_{i, 3} \cdot S T^{3}}{3}+\frac{a f_{i, 4} \cdot S T^{4}}{4}-\frac{a f_{i, 5}}{S T}+a f_{i, 6} \quad \text { Eq. } 4-94
$$

onde $S T=\frac{T(K)}{1000}$ e os coeficientes $a f_{i}$ são dados de forma que a entalpia molar da substância $i$ seja expressa em $\mathrm{kcal} / \mathrm{mol}$. O estado de referência adotado para essas curvas é $\mathrm{O}_{2}, \mathrm{~N}_{2}$ e $\mathrm{H}_{2}$ gasosos e $\mathrm{C}$ grafite sólida a $0 \mathrm{~K}$.

Da definição de calor específico a pressão constante, vem:

$$
\tilde{C}_{p}=\left.\frac{\partial \tilde{h}}{\partial T}\right|_{p=c t e}
$$

Como para um gás perfeito a entalpia é função unicamente da temperatura (VAN WYLEN $^{[19]}$, tem-se:

$$
\tilde{C}_{p}=\frac{d \tilde{h}}{d T}
$$

Assim, o calor específico molar a pressão constante pode ser obtido a partir da derivação da Eq. 4-94 em relação à temperatura, resultando em:

$$
\tilde{C}_{p, i}(T)=a f_{i, 1}+a f_{i, 2} \cdot S T+a f_{i, 3} \cdot S T^{2}+a f_{i, 4} \cdot S T^{3}+\frac{a f_{i, 5}}{S T^{2}}
$$

que fornece o calor específico em $\frac{\mathrm{cal}}{\mathrm{mol} \cdot \mathrm{K}}$.

Os coeficientes então utilizados neste trabalho são mostrados na Tabela 4.3, onde $a$ e $b$ se referem às faixas de temperatura para as quais os ajustes dos coeficientes foram feitos, a saber:

faixa $a: 500 K \leq T \leq 6000 K$ - faixa $b: 100 K \leq T<500 K$. 


\begin{tabular}{|c|c|c|c|c|c|c|c|}
\hline \multirow[b]{2}{*}{ Espécie } & \multirow[b]{2}{*}{$\begin{array}{c}\text { Faixa de } \\
\text { temperatur } \\
\text { a }\end{array}$} & \multicolumn{6}{|c|}{ Coeficientes } \\
\hline & & $a f_{1}$ & $a f_{2}$ & $a f_{3}$ & $a f_{4}$ & $a f_{5}$ & $a f_{6}$ \\
\hline \multirow{2}{*}{$\mathrm{CO}_{2}$} & $\mathrm{a}$ & 11,94033 & 2,088581 & $-0,47029$ & 0,037363 & $-0,589447$ & 97.1418 \\
\hline & $\mathrm{b}$ & 4,737305 & 16,65283 & $-11,23249$ & 2,828001 & 0,00676702 & $-93,75793$ \\
\hline \multirow{2}{*}{$\mathrm{H}_{2} \mathrm{O}$} & $\mathrm{a}$ & 6,139094 & 4,60783 & $-0,9356009$ & 0,06669498 & 0,0335801 & $-56,62588$ \\
\hline & $\mathrm{b}$ & 7,809672 & $-0,2023519$ & 3,418708 & $-1,179013$ & 0,00143629 & $-57,08004$ \\
\hline \multirow{2}{*}{$\mathrm{CO}$} & $\mathrm{a}$ & 7,099556 & 1,275957 & $-0,2877457$ & 0,022356 & $-0,1598696$ & $-27,73464$ \\
\hline & $\mathrm{b}$ & 6,97393 & $-0,8238319$ & 2,942042 & $-1,176239$ & 0,0004132409 & $-27,19597$ \\
\hline \multirow{2}{*}{$\mathrm{H}_{2}$} & $\mathrm{a}$ & 5,555680 & 1,787191 & $-0,2881342$ & 0,01951547 & 0,1611828 & 0,76498 \\
\hline & $\mathrm{b}$ & 6,991878 & 0,1617044 & $-0,2182071$ & 0,2968197 & $-0,01625234$ & $-0,118189$ \\
\hline \multirow{2}{*}{$\mathrm{O}_{2}$} & $\mathrm{a}$ & 7,865847 & 0,6883719 & $-0,031944$ & $-0,00268708$ & $-0,2013873$ & $-0,893455$ \\
\hline & $\mathrm{b}$ & 6,295715 & 2,388387 & $-0,0314788$ & $-0,3267433$ & 0,00435925 & 0,103637 \\
\hline \multirow{2}{*}{$N_{2}$} & $\mathrm{a}$ & 6,807771 & 1,453404 & $-0,328985$ & 0,02561035 & $-0,1189462$ & $-0,331835$ \\
\hline & $\mathrm{b}$ & 7,092199 & $-1,295825$ & 3,20688 & $-1,202212$ & $-0,0003457938$ & $-0,013967$ \\
\hline
\end{tabular}

Tabela 4.3 - Coeficientes para cálculo de entalpia e calor específico.

A Figura 4.4 mostra graficamente as curvas de entalpia em função da temperatura calculadas a partir dos coeficientes da Tabela 4.3.

Então, a entalpia específica, em base molar, dos gases contidos nos volumes de controle podem ser computadas através de médias ponderada das entalpias específicas molares de cada substância componente, utilizando-se suas frações molares em cada VC como pesos.

$$
\begin{aligned}
& \tilde{h}_{u}(T)=\sum_{i}\left(X_{u, i} \cdot \tilde{h}_{i}(T)\right) \\
& \tilde{h}_{b}(T)=\sum_{j}\left(X_{b, j} \cdot \tilde{h}_{j}(T)\right)
\end{aligned}
$$

onde $i$ designa cada um dos componentes presentes no $\mathrm{VC}_{u}$ e $j$ os presentes no $\mathrm{VC}_{b}$. 


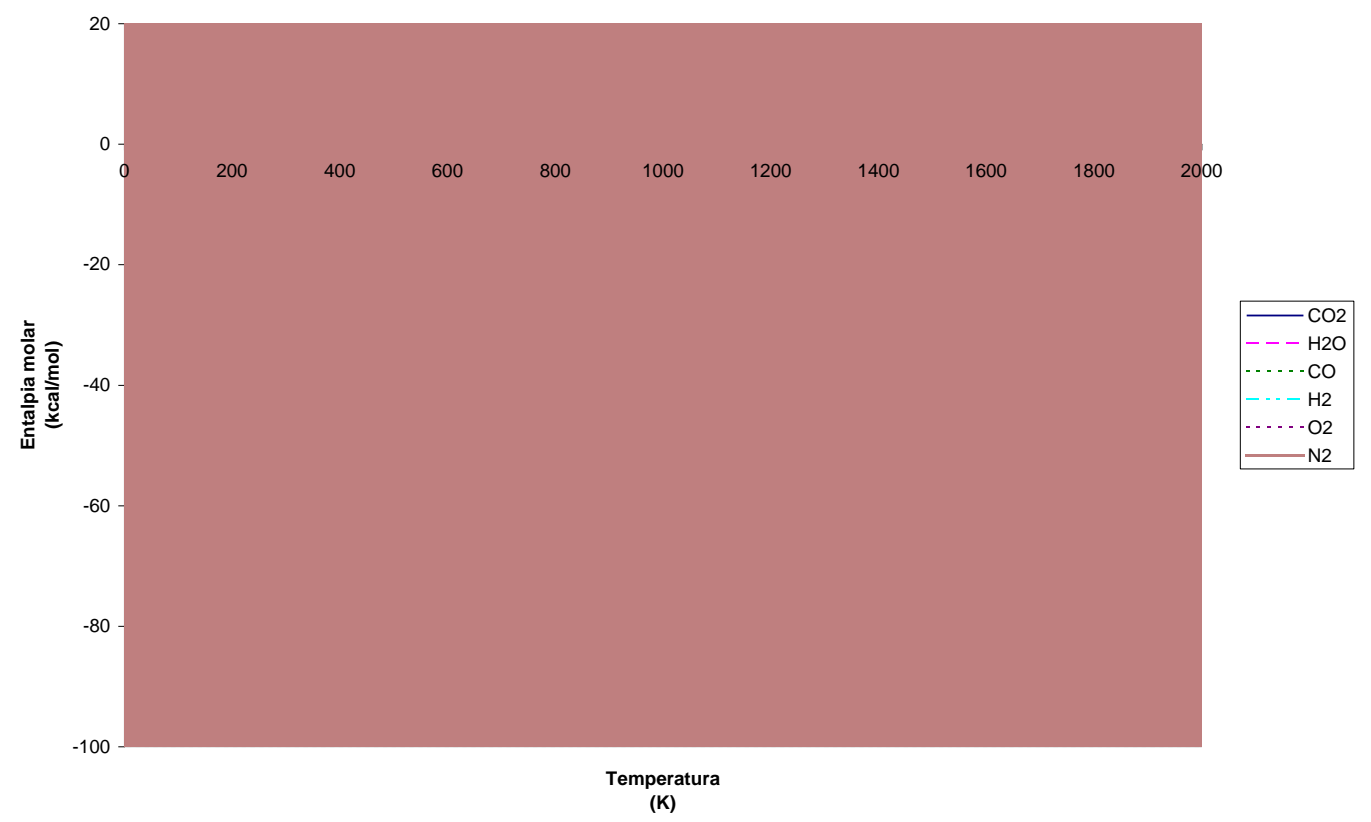

Figura 4.4 - Curvas de entalpia molar.

Essa diferenciação é feita em virtude de haver combustível na forma de vapor somente no $\mathrm{VC}_{u}$ e não no $\mathrm{VC}_{b}$. Portanto há que se determinar também os coeficientes af mantendo-se a convenção de entalpia zero para $\mathrm{O}_{2}, \mathrm{~N}_{2}$ e $\mathrm{H}_{2}$ gasosos e $\mathrm{C}$ grafite sólida a $0 \quad K$. HEYWOOD ${ }^{[20]}$ fornece esses coeficientes para alguns combustíveis (metano, butano e isooctano) e explica a forma através da qual foram obtidos. Para os demais combustíveis apresentados na Tabela 4.4, os coeficientes foram obtidos através da integração das expressões de $\tilde{C}_{p}$ para cada gás fornecidas por VAN WYLEN ${ }^{[19]}$ aliada à determinação da entalpia de formação referida a $0 K$. Encontram-se nesta tabela também os valores dos poderes caloríficos inferiores dor respectivos combustíveis, expressos em $M J / k g$. 


\begin{tabular}{|c|c|c|c|c|c|c|c|}
\hline & \multicolumn{6}{|c|}{ Coeficientes } & \multirow{2}{*}{$\frac{\mathrm{PCI}}{\mathrm{MJ} / \mathrm{kg}}$} \\
\hline Espécie & $a f_{1}$ & $a f_{2}$ & $a f_{3}$ & $a f_{4}$ & $a f_{5}$ & $a f_{6}$ & \\
\hline $\mathrm{CH}_{4}$ & $-0,29149$ & 26,327 & $-10,610$ & 1,5656 & 0,16573 & $-14,031$ & 50,00 \\
\hline $\mathrm{C}_{2} \mathrm{H}_{6}$ & 1,648 & 41,24 & $-15,3$ & 1,74 & 0 & $-15,8507$ & 47,49 \\
\hline $\mathrm{C}_{3} \mathrm{H}_{8}$ & $-1,4867$ & 74,339 & $-39,0649$ & 8,05426 & 0,0121948 & $-18,4611$ & 46,40 \\
\hline$C_{4} H_{10}$ & 0,945 & 88,73 & $-43,8$ & 8,36 & 0 & $-22,8735$ & 45,74 \\
\hline $\mathrm{C}_{8} H_{18}$ & $-0,55313$ & 181,62 & $-97,787$ & 20,402 & $-0,03095$ & $-40,519$ & 44,39 \\
\hline $\mathrm{H}_{2}$ & 5,555680 & 1,787191 & $-0,2881342$ & 0,01951547 & 0,1611828 & 0,76498 & 120,00 \\
\hline
\end{tabular}

Tabela 4.4 - Coeficientes para cálculo de entalpia e calor específico de combustíveis gasosos.

Para um combustível composto, como por exemplo o gás natural (formado basicamente por metano - a maior parte em volume, etano, propano, butano e hidrocarbonetos superiores, e gás carbônico, nitrogênio e hidrogênio em menores frações), os coeficientes af da mistura combustível são obtidos por médias dos af de cada componente, ponderadas pelas respectivas frações molares.

Como pode ser observado durante a quantificação dos componentes do $\mathrm{VC}_{u}$, não foi incluída a umidade do ar de admissão no balanço de espécies químicas. Entretanto, neste trabalho, esta umidade é computada como sendo uma fração do combustível. Segue então a quantificação dessa fração de vapor de água no combustível de modo a trazer a mesma umidade absoluta no ar de admissão do motor.

Seja $\omega$ o valor conhecido da umidade absoluta do ar atmosférico. Pode-se então escrever a relação entra a vazão mássica de vapor de água e a de ar seco admitidas pelo motor:

$$
\dot{m}_{\text {vapor }}=\omega \cdot \dot{m}_{\text {arseco }}
$$


que pode ser colocada sob a forma

$$
\dot{m}_{\text {vapor }}=\omega \cdot \frac{\dot{m}_{c o m b}}{\left(\frac{F}{A}\right)} \Rightarrow \frac{\dot{m}_{\text {vapor }}}{\dot{m}_{c o m b}}=\frac{\omega}{\left(\frac{F}{A}\right)}
$$

com

$\dot{m}_{\text {vapor }}$ : vazão mássica de vapor de água admitida pelo motor;

$\dot{m}_{a r \text { seco }}$ : vazão mássica de ar seco admitida pelo motor;

$\dot{m}_{\text {comb }}$ : vazão mássica de combustível admitida pelo motor;

$\left(\frac{F}{A}\right)$ : razão combustível - ar da mistura.

Colocando a Eq. 4-101 em base volumétrica, vem:

$$
\frac{\omega}{\left(\frac{F}{A}\right)}=\frac{\dot{m}_{\text {vapor }}}{\dot{m}_{\text {comb }}}=\frac{y_{\text {vapor }} \cdot \mathrm{mol}_{\text {vapor }}}{y_{\text {comb }} \cdot \mathrm{mol}_{\text {comb }}}
$$

onde

$y_{\text {vapor }}$ : fração volumétrica de vapor de água na mistura combustível+vapor;

$y_{\text {comb }}$ : fração volumétrica de combustível na mistura combustível+vapor $\left(=1-y_{\text {vapor }}\right)$;

$m_{\text {vapor }}$ : massa molecular do vapor d'água $(18 \mathrm{~g} / \mathrm{mol})$;

mol $_{\text {comb }}$ : massa molecular do combustível.

Rearranjando os termos na Eq. 4-102, tem-se:

$$
y_{\text {vapor }}=\frac{\frac{\omega}{\left(\frac{F}{A}\right)} \cdot \mathrm{mol}_{\text {comb }}}{18+\frac{\omega}{\left(\frac{F}{A}\right)} \cdot \mathrm{mol}_{\text {comb }}}
$$


Lembrando que se partiu de uma fórmula mínima do combustível $\mathrm{CH}_{y} \mathrm{O}_{z} \mathrm{~N}_{w}$ e com $c x$ representando o número de átomos de carbono por molécula, a razão combustível - ar estequiométrica pode ser escrita como:

$$
\left(\frac{F}{A}\right)_{e s t e q}=\frac{\frac{\varepsilon}{c x} m l_{c o m b}}{32+\psi \cdot 28} \Rightarrow m o l_{c o m b}=\frac{c x}{\varepsilon} \cdot\left(\frac{F}{A}\right)_{e s t e q} \cdot(32+\psi \cdot 28) \quad \text { Eq. } 4-104
$$

com $\varepsilon$ dado pela Eq. 4-80. Substituindo a Eq. 4-104 na Eq. 4-103, vem:

$$
y_{\text {vapor }}=\frac{\frac{\omega}{\phi} \cdot \frac{c x}{\varepsilon} \cdot(32+\psi \cdot 28)}{18+\frac{\omega}{\phi} \cdot \frac{c x}{\varepsilon} \cdot(32+\psi \cdot 28)}
$$

já que da definição de razão de equivalência:

$$
\phi=\frac{\left(\frac{F}{A}\right)}{\left(\frac{F}{A}\right)_{e s t e q}}
$$

Assim o combustível "seco" é transformado num combustível "úmido" com a fração volumétrica de vapor dada pela Eq. 4-105. Todas as propriedades do novo combustível são então recalculadas para refletir a inclusão do vapor d'água na sua composição - desde o número de átomos de carbono, hidrogênio, oxigênio e nitrogênio até o poder calorífico, os coeficientes af para cálculo da entalpia e a razão combustível - ar estequiométrica. Esta última é obtida através da inclusão de vapor de água na reação descrita pela Eq. 4-79 $\operatorname{com} \phi=1$ e recalculando as massas envolvidas, resultando em:

$$
\left(\frac{F}{A}\right)_{\text {esteq }}^{\text {úmido }}=\left(\frac{F}{A}\right)_{\text {esteq }}^{\sec o}+\frac{\omega}{\phi}
$$

Note-se que se todas as propriedades do combustível forem recalculadas como 
exposto acima, a razão de equivalência permanece inalterada para o combustível "seco" e "úmido".

Tendo-se então caracterizadas as composições e propriedades termodinâmicas dos volumes de controle a baixas temperaturas, resta determiná-las para o $\mathrm{VC}_{b}$ quando há dissociação química. E é sobre isto que trata o próximo tópico.

\subsubsection{Quantificação de espécies químicas e propriedades termodinâmicas do $\mathrm{VC}_{b}$ acima de $1000 \mathrm{~K}$}

Como relatado no início do subcapítulo, a determinação das propriedades termodinâmicas para os gases sujeitos à dissociação química oriundos da combustão de hidrocarbonetos neste trabalho é feita por meio de relações desenvolvidas por $\operatorname{MARTIN}^{[18]}$.

Uma breve explanação desses conceitos pode ser encontrada no capítulo de revisão bibliográfica. O equacionamento de MARTIN aqui utilizado permitiu então a quantificação de espécies químicas genéricas (moléculas diatômicas e monoatômicas geradas a partir da dissociação de tri e diatômicas) e, conseqüentemente, o cálculo da massa molecular média dos produtos $M W_{b}$ e sua massa específica $\rho_{b}$. Serão empregadas aqui, adicionalmente, as expressões para avaliação de $\frac{\partial h_{b}}{\partial T_{b}}, \frac{\partial h_{b}}{\partial p}, \frac{\partial \rho_{b}}{\partial T_{b}}, \frac{\partial \rho_{b}}{\partial p}$ (valores utilizados na integração de $\dot{T}_{b}$ dada pela Eq. 4-72), desenvolvidas por MARTIN a partir do cálculo da entalpia específica. Segue uma transcrição das principais equações desenvolvidas por MARTIN, partindo da seguinte reação de combustão:

$$
\begin{aligned}
& \phi \eta C+2 \cdot(1-\eta) \cdot \phi \cdot H_{2}+O_{2}+\psi N_{2} \Rightarrow \\
& \underbrace{[(2-\eta) \cdot \phi-2 Y] M_{3}+[1-\phi+3 Y-U+\psi] M_{2}+2 U \cdot M_{1}}_{\phi \leq 1}
\end{aligned}
$$




$$
\underbrace{[(2-\eta \cdot \phi)-2 Y] M_{3}+[2 \cdot(\phi-1)+3 Y-U+\psi] M_{2}+2 U \cdot M_{1}}_{\phi>1}
$$

com $\eta$ definido como:

$$
\eta=\frac{4 \delta}{1+4 \delta}
$$

onde:

$\delta$ : razão entre número de átomos de $C$ e de $H$ do combustível;

$\phi$ : razão de equivalência;

$\psi$ : razão entre o número de átomos de nitrogênio e oxigênio do ar;

$Y$ : número extra de moléculas devido à dissociação de moléculas triatômicas $\left(M_{3}\right)$ em diatômicas $\left(M_{2}\right)$;

$U$ : número extra de moléculas devido à dissociação de moléculas diatômicas $\left(M_{2}\right)$ em monoatômicas $\left(M_{1}\right)$.

Admitiu também que as reações de dissociação pudessem ser consideradas em equilíbrio da seguinte forma:

$$
\begin{aligned}
& 2 M_{3} \leftrightarrow 3 M_{2} \\
& M_{2} \leftrightarrow 2 M_{1}
\end{aligned}
$$

Eq. $4-112$

com as constantes de equilíbrio (ajustadas a partir de dados experimentais) dadas respectivamente por:

$$
\begin{aligned}
& K_{1}(T)=5,819 \cdot 10^{-6} \cdot e^{\left(0.96747+\frac{35810}{T}\right)} \\
& K_{2}(T)=2,961 \cdot 10^{-5} \cdot e^{\left(2,5937+\frac{28980}{T}\right)}
\end{aligned}
$$


com $T$ dado em $K$.

Escrevendo as pressões parciais dos componentes formados pelas moléculas tri, di e monoatômicas a partir das respectivas frações molares na Eq. 4-108 ou na Eq. 4109 e utilizando as constantes de equilíbrio, de maneira análoga ao que foi feito com a combustão do carbono (vide revisão bibliográfica), é possível explicitar os termos $Y$ e $U$, resultando em:

$$
\begin{aligned}
& U=\frac{(2-\eta+\psi) \cdot(\eta-2 \chi)}{4 \cdot P \cdot K_{1} \cdot K_{2} \cdot \chi} \\
& Y=\frac{\chi}{\sqrt{1+\frac{2}{3} \cdot z+\frac{4}{3} \cdot(1-\phi)}} \\
& \underbrace{}_{\phi \leq 1} \\
& Y=\frac{\chi}{1+\frac{2}{3} \cdot z+\frac{1}{3} \cdot z^{2}-\frac{2}{3} \cdot(\phi-1)}
\end{aligned}
$$

com as seguintes variáveis auxiliares:

$$
\begin{aligned}
& \chi=\frac{A \cdot \eta \cdot\left(3 \cdot C_{5}+A \cdot C_{6}\right)}{3 \cdot(1+2 \cdot A) \cdot C_{5}+2 \cdot C_{6} \cdot A^{2}} \\
& A=\left(\frac{C_{5}}{4 \cdot P \cdot K_{1}^{2} \cdot \eta}\right)^{\frac{1}{3}} \operatorname{com} P \text { em atm } \\
& C_{5}=2-\eta+\psi \\
& C_{6}=\eta+2 \cdot C_{5}
\end{aligned}
$$

Eq. $4-121$ 


$$
z=\frac{|1-\phi|}{\chi}
$$

Eq. $4-122$

Admitindo que a entalpia específica dos produtos da combustão seja composta pela entalpia de formação dos compostos acrescentada dos termos devidos aos graus de liberdade das moléculas (translacional, vibracional e rotacional), MARTIN chega à seguinte formulação:

$$
h(P, T)=\frac{\tilde{R}}{2 \cdot m_{c p}}\left(C_{1} \cdot T+C_{2} \cdot \bar{T}_{v}+\bar{h}_{f}\right)
$$

onde $m_{c p}$ representa a massa dos produtos da combustão por mol de $O_{2}$ do ar, $\frac{\tilde{R} \cdot \bar{h}_{f}}{2 \cdot m_{c p}}$ representa sua entalpia específica média de formação e o termo $\frac{\tilde{R} \cdot C_{1} \cdot T}{2 \cdot m_{c p}}$ está associado aos graus de liberdade translacional e rotacional das moléculas, $\frac{\tilde{R} \cdot C_{2} \cdot \bar{T}_{v}}{2 \cdot m_{c p}}$ ao vibracional e $\tilde{R}$ é a constante universal dos gases perfeitos. Note-se que a unidade em que a entalpia específica calculada pela Eq. 4-123 depende das unidades de $\tilde{R}$. O valor de $m_{c p}$ é dado por:

$$
m_{c p}=(8 \cdot \eta+4) \cdot \phi+32+28 \cdot \psi
$$

e, por conseguinte, a massa molecular média dos produtos da combustão se torna:

$$
\begin{aligned}
& \underbrace{M W_{c p}=m_{c p} \cdot(1+(1-\eta) \cdot \phi+\psi+Y+U)}_{\phi \leq 1} \\
& \underbrace{M W_{c p}=m_{c p} \cdot((2-\eta) \cdot \phi+\psi+Y+U)}_{\phi>1}
\end{aligned}
$$


com $M W_{c p}$ dada em gmol. A massa específica dos produtos da combustão é então calculada pela lei de gás perfeito:

$$
\rho=\frac{M \cdot P}{\widetilde{R} \cdot T}
$$

As constantes $C_{1}$ e $C_{2}$ que aparecem na Eq. 4-123 são expressas por:

$$
\begin{aligned}
& \underbrace{C_{1}=7+(9-8 \cdot \eta) \cdot \phi+7 \cdot \psi+5 \cdot Y+3 \cdot U}_{\phi \leq 1} \\
& \underbrace{C_{1}=2+2 \cdot(7-4 \cdot \eta) \cdot \phi+7 \cdot \psi+5 \cdot Y+3 \cdot U}_{\phi>1} \\
& \underbrace{C_{2}=2 \cdot(1+(5-3 \cdot \eta) \cdot \phi+\psi-3 \cdot Y-U)}_{\phi \leq 1} \\
& \underbrace{C_{2}=2 \cdot(4+(2-3 \cdot \eta) \cdot \phi+\psi-3 \cdot Y-U)}_{\phi>1}
\end{aligned}
$$

O termo $\bar{T}_{v}$ está associado a uma temperatura $T_{v}$ característica ajustada para refletir a energia associada à vibração molecular. $T_{v}$ é um valor também dependente da composição do combustível e é dada, em $K$, por:

$$
T_{v}=\frac{3256-2400 \cdot \eta+300 \cdot \psi}{1-0,5 \cdot \eta+0,09 \cdot \psi}
$$

e o valor de $\bar{T}_{v}$ é o resultado de :

$$
\bar{T}_{v}=\frac{T_{v}}{e^{\frac{T_{v}}{T}}-1}
$$

O termo relativo à entalpia de formação na Eq. 4-123 é calculado, dependendo da razão de equivalência, por: 


$$
\begin{aligned}
& \underbrace{\bar{h}_{f}=C_{3} \cdot Y+C_{4} \cdot U+(20372 \cdot \eta-114942) \cdot \phi}_{\phi \leq 1} \quad \text { Eq. 4-134 } \\
& \underbrace{\bar{h}_{f}=C_{3} \cdot Y+C_{4} \cdot U+134390-6500 \cdot\left(\frac{\phi-1}{\eta}\right)+(20372 \cdot \eta+194482) \cdot \phi}_{\phi>1} \quad \text { Eq. 4-135 }
\end{aligned}
$$

onde foram mantidas as convenções de referência de $\mathrm{O}_{2}, \mathrm{~N}_{2}, \mathrm{H}_{2}$ e $\mathrm{C}$ como grafite sólida com entalpia nula a $0 \mathrm{~K}$. As constantes $C_{3}$ e $C_{4}$ são:

$$
\begin{aligned}
& C_{3}=10^{3} \cdot(121,5+29,59 \cdot \eta) \\
& C_{4}=117,5 \cdot 10^{3}
\end{aligned}
$$

Uma vez que as expressões que fornecem a entalpia e a massa específica dos produtos de combustão estejam formuladas (Eq. 4-123 e Eq. 4-127), suas derivadas em relação à temperatura e pressão $\left(\frac{\partial h_{b}}{\partial T_{b}}, \frac{\partial h_{b}}{\partial p}, \frac{\partial \rho_{b}}{\partial T_{b}}, \frac{\partial \rho_{b}}{\partial p}\right)$ podem ser obtidas diretamente pela aplicação da regra da cadeia.

Tendo como calcular todas as propriedades termodinâmicas necessárias à integração das expressões de $\dot{T}_{u}$ e $\dot{T}_{b}$, resta explicitar as propriedades de transporte do conteúdo dos dois principais VC.

\subsection{Propriedades de transporte}

Para cálculo da troca de calor como modelado em capítulo anterior, é necessário que se conheçam a condutibilidade térmica e viscosidade dinâmica dos gases contidos no $\mathrm{VC}_{u}$ e no $\mathrm{VC}_{b}$. Este capítulo é dedicado a esclarecer quais expressões são utilizadas para avaliar estas propriedades nos dois principais VC. 


\subsubsection{Condutibilidade térmica e viscosidade dinâmica para gases não queimados}

Como hipótese simplificadora, admite-se que as propriedades de transporte da mistura não queimada possam ser aproximadas pelas do ar. HEYWOOD ${ }^{[20]}$ traz a seguinte expressão para cálculo da viscosidade dinâmica do ar:

$$
\mu_{a r}=3,3 \cdot 10^{-7} \cdot T^{0,7}
$$

com $\mu_{a r}$ expressa em $\mathrm{kg} /(\mathrm{m} . \mathrm{s})$ e $T$ em $K$, ressaltando que essa viscosidade é praticamente independente da pressão.

Ajustando-se um polinômio de $5^{\underline{0}}$ grau para os valores de condutibilidade térmica $k_{a r}$ fornecidos por HOLMAN ${ }^{[21]}$ em função da temperatura, tem-se:

$$
\begin{aligned}
k_{a r}= & 6,14285 \cdot 10^{-18} \cdot T^{5}-3,65700 \cdot 10^{-14} \cdot T^{4}+8,92558 \cdot 10^{-11} \cdot T^{3}- \\
& 1,11515 \cdot 10^{-7} \cdot T^{2}+1,23362 \cdot 10^{-4} \cdot T-2,55184 \cdot 10^{-3}
\end{aligned}
$$

com a temperatura $T$ expressa em $K$ e o valor de $k_{a r}$ expresso em $\frac{W}{m \cdot K}$. Faz-se então $\mu_{u}=\mu_{a r}$ e $k_{u}=k_{a r}$.

\subsubsection{Condutibilidade térmica e viscosidade dinâmica para gases queimados}

HEYWOOD $^{[20]}$ fornece relações para a condutibilidade térmica $k$ e viscosidade dinâmica $\mu$ oriundas de um programa computacional escrito pela NASA "Thermodynamic and Transport Properties of Complex Chemical Systems". Essas relações são utilizadas na determinação dessas grandezas para o presente trabalho.

A viscosidade dinâmica dos produtos de combustão de hidrocarbonetos em ar, para uma faixa de temperatura entre 500 e $4000 \mathrm{~K}$, pressões entre 1 e $100 \mathrm{~atm}$ e razão de equivalência entre 0 e 4,0, é mostrada na Figura 4.5. O autor comenta que pelo fato de 
as viscosidades desses produtos serem muito próximas à do ar, que pode ser expressa pela Eq. 4-138, pode ser feita uma aproximação do tipo:

$$
\mu_{b}=\frac{\mu_{a r}}{1+0,027 \cdot \phi}=\frac{3,3 \cdot 10^{-7} \cdot T^{0,7}}{1+0,027 \cdot \phi}
$$

para corrigir a viscosidade dinâmica dos gases $\mu_{b}$ queimados em função da razão de equivalência $\phi$. Ressalte-se, novamente, que essa viscosidade é praticamente independente da pressão.

Para obter o valor da condutibilidade térmica dos gases queimados, HEYWOOD inicialmente apresenta relações que trazem o número de Prandtl em função da razão entre os calores específicos $\gamma_{b}$, temperatura $T_{b}$ e razão de equivalência $\phi$, quais sejam:

$$
\begin{aligned}
& \underbrace{\operatorname{Pr}_{b}=0,05+4,2 \cdot\left(\gamma_{b}-1\right)-6,7 \cdot\left(\gamma_{b}-1\right)^{2}}_{\phi \leq 1} \\
& \underbrace{\operatorname{Pr}_{b}=\frac{0,05+4,2 \cdot\left(\gamma_{b}-1\right)-6,7 \cdot\left(\gamma_{b}-1\right)^{2}}{1+0,015 \cdot 10^{-6}\left(\phi \cdot T_{b}\right)^{2}}}_{1<\phi \leq 4}
\end{aligned}
$$

com $T_{b}$ novamente expresso em $K$. Faz-se uma ressalva quanto à utilização da Eq. 4142: embora sua aplicação estivesse dirigida a misturas com razão de equivalência maior que a unidade, a utilização dessa relação ainda se mostra razoável para produtos de combustão de misturas pobres com temperatura acima de $1500 \mathrm{~K}$. 


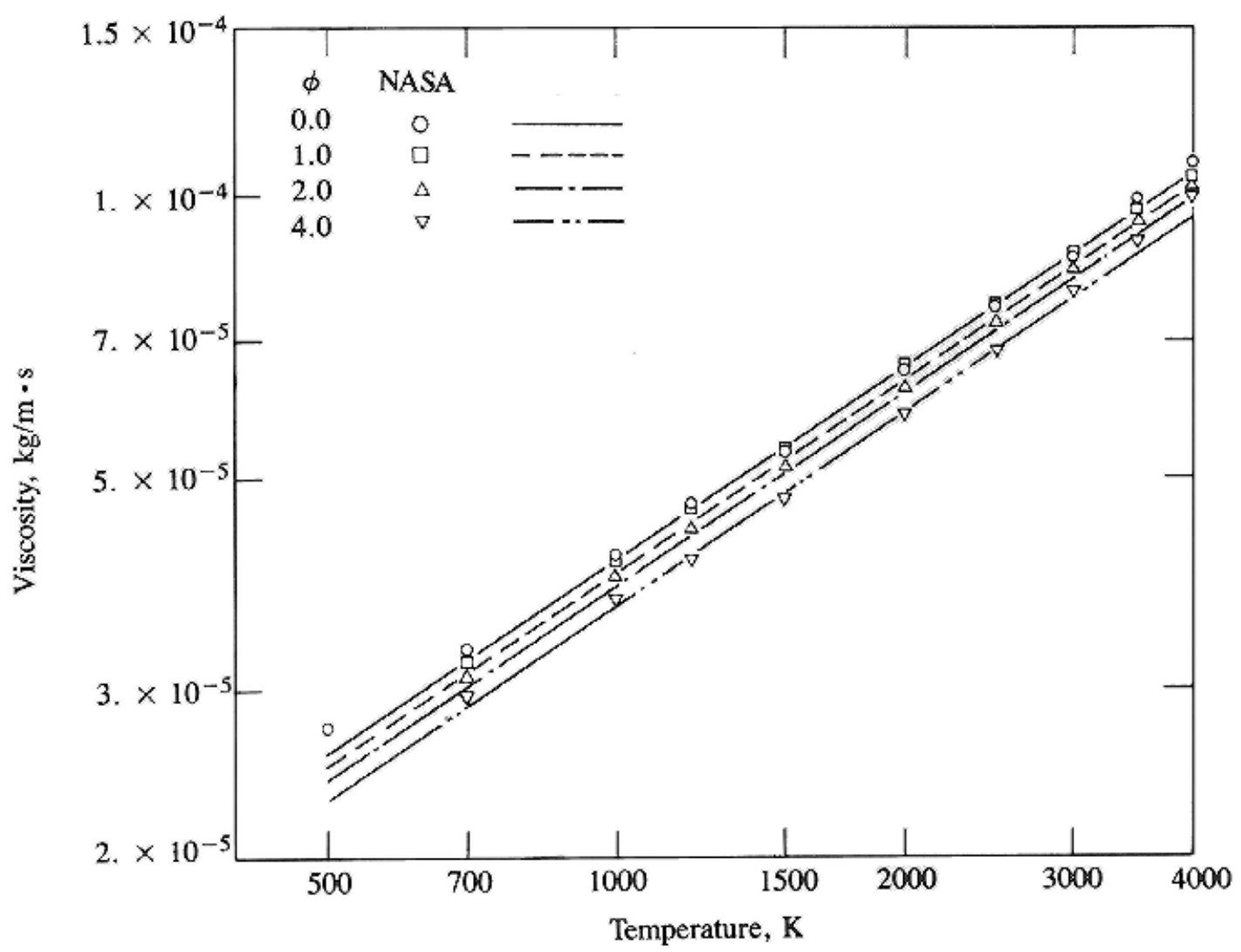

Figura 4.5 - Viscosidade dinâmica dos produtos de combustão. (HEYWOOD ${ }^{[20]}$ )

Uma vez determinado o número de Prandtl, a condutibilidade térmica $k_{b}$ pode ser obtida por:

$$
\operatorname{Pr}_{b}=\frac{\mu_{b} \cdot c_{p, b}}{k_{b}} \rightarrow k_{b}=\frac{\mu_{b} \cdot c_{p, b}}{\operatorname{Pr}_{b}}
$$

conhecido o calor específico a pressão constante dos gases queimados $c_{p, b}$.

\subsection{Equações complementares}

Para que a integração numérica das equações diferenciais das temperaturas possa ser então realizada, algumas equações adicionais devem ser formuladas.

\subsubsection{Geometria variável da câmara}

A Figura 4.6 traz esquematicamente a disposição de pistão, biela e virabrequim 
em um motor, onde $L$ designa o comprimento da biela, $R$ o raio do virabrequim, $h_{0}$ a distância mínima equivalente entre o topo do pistão e o cabeçote, $B$ o diâmetro do cilindro e $\theta$ a posição angular do virabrequim.

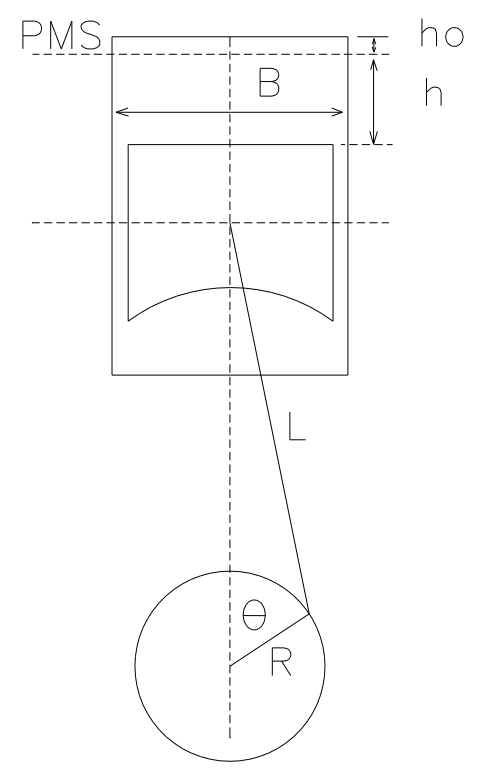

Figura 4.6 - Esquema do sistema biela - manivela.

A partir de considerações geométricas, pode-se escrever:

$$
h=(R+L)-R \cdot \cos (\theta)-\sqrt{L^{2}-R^{2} \cdot \operatorname{sen}^{2}(\theta)}
$$

Eq. 4-144

onde $h$ é a distância entre o topo do pistão e o ponto morto superior (PMS). Também é possível se escrever o volume total da câmara em função da posição angular do virabrequim:

$$
\forall=\left(h+h_{0}\right) \cdot \frac{\pi \cdot B^{2}}{4}
$$

onde $h_{0}$ (a distância mínima equivalente entre o topo do pistão e o cabeçote) pode ser calculada em função da razão de compressão do motor $r_{c}$ :

$$
h_{0}=\frac{2 \cdot R}{r_{c}-1}
$$


A Eq. 4-144, quando derivada em função da posição angular do virabrequim, fornece a velocidade do pistão:

$$
\frac{d h}{d \theta}=R \cdot \operatorname{sen}(\theta) \cdot\left[1+\frac{\cos (\theta)}{\sqrt{L^{2}-R^{2} \cdot \operatorname{sen}^{2}(\theta)}}\right]
$$

Assim, a taxa de variação do volume da câmara em função da posição angular do virabrequim é:

$$
\dot{V}=\frac{\pi}{4} \cdot B^{2} \cdot R \cdot \operatorname{sen}(\theta) \cdot\left[1+\frac{\cos (\theta)}{\sqrt{L^{2}-R^{2} \cdot \operatorname{sen}^{2}(\theta)}}\right]
$$

A Eq. 4-146 e a Eq. 4-148 são utilizadas no cálculo da variável auxiliar A na Eq. 4-68. 


\section{PROGRAMA COMPUTACIONAL}

Uma vez explicitadas todas as equações que levam à determinação dos estados dos volumes de controle, construiu-se um programa computacional em FORTRAN capaz de integrar as equações e fornecer resultados como evolução da fração de massa queimada, taxa de liberação de calor, evolução da frente de chama no interior da câmara, volumes, massas, temperaturas dos VC em cada posição angular do virabrequim, atraso de ignição, etc. A seguir são relacionados os dados necessários à execução do programa, direta ou indiretamente.

1. dados geométricos e operacionais do motor:

- velocidade angular do virabrequim;

- tipo do combustível:

metano, etano, propano, butano, hidrogênio puros ou combinados com frações volumétricas determinadas; isoctano;

- razão de equivalência;

- número de cilindros do motor;

- diâmetro do cilindro;

- curso do pistão;

- comprimento da biela;

- $\quad$ taxa de compressão;

- distância mínima equivalente do pistão ao cabeçote;

- diâmetro e altura da cavidade cilíndrica no pistão, bem como sua excentricidade em relação ao cilindro (caso haja a cavidade); 
- posições angulares de fechamento da válvula de admissão e da abertura da válvula de escapamento;

- posição angular do instante de ignição;

- $\quad$ temperaturas médias do topo do pistão, cabeçote e paredes do cilindro;

- volume total e temperatura média das frestas;

- constante de vazamento de gases para o cárter;

- fração molar de gases residuais;

- consumo volumétrico, temperatura, pressão e umidade absoluta do ar de admissão;

- curva de pressão em função da posição angular do virabrequim.

2. Dados de controle sobre a execução do programa:

- número de pontos utilizados na média para determinação da pressão inicial do ciclo;

- número de pontos utilizados na média móvel da curva de pressão a fim de reduzir ruídos de medição;

- passo de integração;

- mínima e máxima fração de massa queimada para reconhecimento do início da combustão e esgotamento da massa do $\mathrm{VC}_{u}$;

- opção de cálculo da entalpia dos gases queimados (com ou sem dissociação química);

- fatores de correção:

- da massa inicial do ciclo devido à não uniformidade de distribuição entre os cilindros do motor;

- da pressão (ganho, valor de referência e deslocamento do sinal de PMS). 
A integração das equações diferenciais de $1^{\underline{a}}$ ordem das temperaturas é integrada pelo método de Euler. Segue um fluxograma indicativo da seqüência de cálculo empregada:

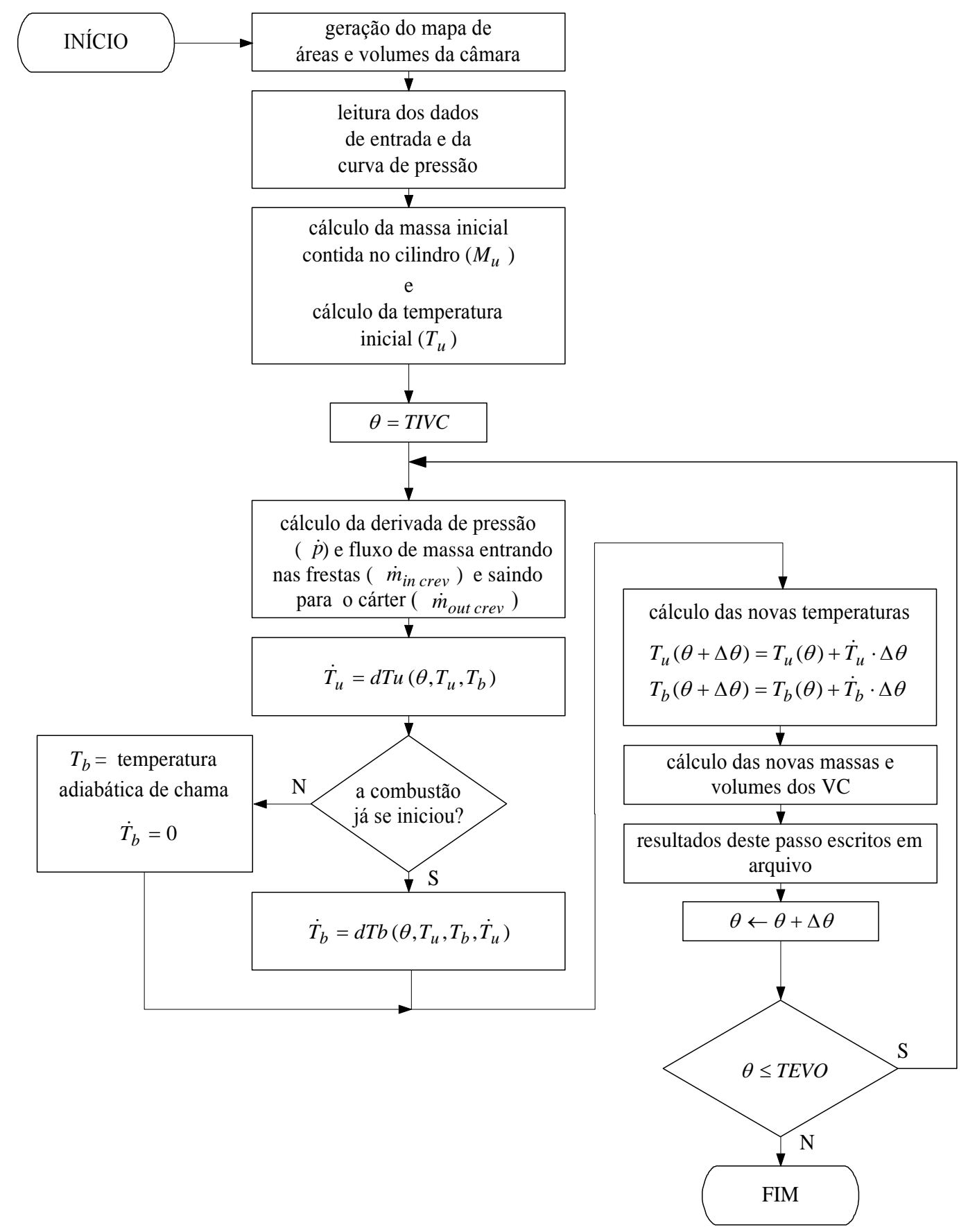

Figura 5.1 - Fluxograma principal do programa computacional.

Alguns comentários sobre o roteiro de cálculos vêm a seguir:

- a geração do mapa de geometria não necessariamente deve ser realizada cada 
vez que o programa é executado, a não ser que alguma característica puramente geométrica do motor tenha se alterado;

- a leitura da curva de pressão pressupõe pontos igualmente espaçados, cujo espaçamento deve ser fornecido junto aos dados de entrada. Convencionouse também que o ponto morto superior do tempo de admissão seja a referência para a curva de pressão e as demais curvas geradas pelo programa. Assim, $0^{\circ}$ de virabrequim está relacionado ao PMS da admissão bem como $360^{\circ}$ marca o PMS da compressão/combustão;

- conhecendo-se a vazão volumétrica do ar de admissão do motor, bem como a pressão e temperatura do mesmo onde está sendo medida a vazão, é possível calcular a vazão mássica de ar por meio da equação de estado (gás perfeito). Conhecendo-se também o número de cilindros e a rotação do motor, é possível então obter a massa de ar que, misturado ao combustível (com razão de equivalência conhecida), entra em cada cilindro por ciclo. Esse valor, dessa forma calculado, só é realista para motores onde o cruzamento de válvulas é relativamente pequeno pois, caso contrário, poder-se-ia estar medindo uma quantidade acima da verdadeira devido à fuga de carga fresca pela válvula de escapamento durante o período de admissão.

- a partir da massa de ar e combustível fornecida a cada cilindro e da fração de gases residuais, é possível então se determinar a massa total no cilindro $M_{u}$ no instante do fechamento da válvula de admissão, aqui denominado TIVC. YUN e MIRSKY ${ }^{[23]}$ fornecem uma forma prática de se estimar esta fração molar de gases residuais a partir da curva de pressão e dos instantes de abertura e fechamento da válvula de escapamento, considerando uma expansão 
politrópica. A fração de gases residuais resfrk pode ser dada pela expressão:

resfrk $=\frac{V_{e v c}}{V_{e v o}} \cdot\left(\frac{p_{e v c}}{p_{e v o}}\right)^{\frac{1}{n}}$

onde $V_{e v c}$ e $V_{\text {evo }}$ designam os volumes da câmara nos instantes de fechamento e abertura da válvula de escapamento, bem como $p_{\text {evc }}$ e $p_{\text {evo }}$ os valores de pressão correspondentes, e n o expoente politrópico.

- para essa mistura de gases, com composição representada pela Tabela 4.2, massa molecular média dada pela Eq. 4-90, massa, volume (Eq. 4-145) e pressão conhecidos, é possível calcular sua temperatura $T_{u}$ pela Eq. 4-5. Caso a vazão mássica de ar não seja medida (e portanto desconhecida), uma estimativa da temperatura inicial do ciclo permite calculá-la;

- a partir da posição angular do fechamento da válvula de admissão, é calculada a derivada da pressão em relação à posição angular do virabrequim. Esse valor é obtido por meio de diferenças finitas dos valores de pressão lidos no início do programa. São também calculados os valores dos fluxos de massa que entram nas frestas (Eq. 4-17) e que vazam para o cárter (Eq. 4-11);

- para cálculo de $\dot{T}_{u}$, utiliza-se a Eq. 4-49 enquanto a combustão não se iniciou e a Eq. 4-52 quando já houver combustão. Note-se que os termos referentes à troca de calor, às propriedades termodinâmicas e aos fluxos de massa que aparecem nos segundos membros dessas equações são todos conhecidos, direta ou indiretamente (por meio dos modelos já detalhados), em um determinado passo de integração;

- já para cálculo de $\dot{T}_{b}$, após o início da combustão, utiliza-se a Eq. 4-72 
enquanto ainda existem gases no $\mathrm{VC}_{u}$ a serem oxidados. Uma vez finda a massa contida na região dos gases não queimados, emprega-se a Eq. 4-73 para cálculo de $\dot{T}_{b}$. Entretanto, enquanto a combustão não se inicia, admitese que o primeiro "pacote" a ser queimado apresente a temperatura adiabática de chama, como comentado anteriormente. O cálculo dessa temperatura é feito em uma subrotina que, de maneira iterativa, obtém um valor de temperatura $T_{b}$ que conduza a um valor de entalpia específica dos gases que seriam produzidos pela combustão igual à dos gases contidos no $\mathrm{VC}_{u}$, naquele passo de integração;

- tendo-se os valores de $\dot{T}_{u}$ e $\dot{T}_{b}$ calculados, é possível integrar numericamente as temperaturas para o passo seguinte. Para isso, é utilizado o método de Euler uma vez que, para a pressão dada a cada $0,2^{\circ}$, métodos mais sofisticados (Runge-Kutta, por exemplo) não trouxeram grande variação nos resultados;

- com as novas temperaturas das duas zonas, é possível calcular os volumes das duas zonas principais através da Eq. 4-74 e da Eq. 4-75, bem como suas massas através da Eq. 4-76 e da Eq. 4-77. Nesse ponto, é verificado se já se iniciou a combustão ou se os gases do $\mathrm{VC}_{u}$ já foram todos queimados para que no próximo passo possam ser utilizadas as equações apropriadas para cálculo de $\dot{T}_{u}$ e $\dot{T}_{b}$. Essa verificação é feita comparando-se as derivadas da frações de massa $\dot{X}_{b}=\frac{\dot{M}_{b}}{M}$ e $\dot{X}_{u}=\frac{\dot{M}_{u}}{M}$ com valores de controle fornecidos na entrada de dados. Caso $\dot{X}_{b}$ seja inferior ao limite dado, admite-se que a combustão não tenha se iniciado e, caso $\dot{X}_{u}$ ultrapasse um limite superior, 
admite-se que todo o conteúdo do $\mathrm{VC}_{u}$ tenha sido queimado;

- são escritos em um arquivo de saída os seguintes valores para os volumes de controle: massa, volume, massa específica, temperatura, massa molecular média, coeficiente e áreas de troca de calor, quantidade de calor trocado e entalpia, bem como a taxa de liberação de calor;

- a integração pára uma vez atingido o instante de abertura da válvula de escapamento (TEVO). Nesse ponto, são também escritos no arquivo de saída valores de intervalos de ângulo de virabrequim para fração de massa queimada de 0 a $10 \%, 10 \%$ a $50 \%, 50 \%$ a $90 \%$ e atraso de ignição.

Uma observação importante deve ser feita: embora seja fornecida a posição angular da emissão da centelha, não é esse valor que força o disparo do processo de integração da equação de $\dot{T}_{b}$, mas sim o valor de uma mínima derivada da fração de massa queimada. Entretanto, se for permitido que a integração de $\dot{T}_{b}$ seja efetuada desde o fechamento da válvula de admissão, ruídos normalmente encontrados nos valores de pressão medida (principalmente na região de baixa pressão do ciclo), que geram grandes valores de $\dot{p}$ alternadamente positivos e negativos, ocasionam a falsa detecção do início da combustão, levando a erros de execução do programa. Assim, optou-se por restringir o intervalo onde se habilita a integração de $\dot{T}_{b}$ a partir do instante da emissão da centelha, região onde a pressão na câmara já está elevada e a derivada da pressão deixa de flutuar erraticamente.

O tempo de execução do programa gerado, para passo de integração de $0,2^{\circ}$, é da ordem de $10 s$ em um microcomputador pessoal com processador PENTIUM 133 MHz. Pode-se executá-lo a partir de um software de gerenciamento de planilhas eletrônicas (MS Excel), com os arquivos gerados sendo automaticamente transferidos 
para planilhas-modelo, de forma a automatizar a exibição de gráficos e demais resultados. 


\section{MONTAGEM EXPERIMENTAL E DADOS COLETADOS}

O potencial de aplicação e limitações do modelo e programa computacional desenvolvidos foram avaliados por meio da análise da combustão de um motor real.

Inicialmente, procedeu-se à implementação de um sistema capaz de medir adequadamente a pressão no interior de cilindros de motores. Poder-se-ia argüir porque não utilizar dados apresentados em trabalhos de outros pesquisadores, mas a resposta para essa questão se encerra no fato de que é relativamente difícil obter dados de pressão no interior de cilindros acompanhados de dados detalhados de geometria da câmara, consumos de ar e combustível, vazamento de gases para o cárter e composição dos gases de escapamento.

Assim optou-se por implementar um sistema próprio capaz de medir a pressão de forma desejada. Os outros valores mencionados podem ser levantados por meio de medidores normalmente disponíveis em bancadas de testes de motores. Em conjunto com a equipe técnica do Agrupamento de Motores do Instituto de Pesquisas Tecnológicas do Estado de São Paulo, foi elaborado um sistema de aquisição de dados que permite que os valores de posição angular da árvore, pressão na câmara e tensão no circuito secundário de ignição pudessem ser medidos com a resolução necessária. Testes desse sistema foram realizados a fim de garantir que os dados obtidos fossem confiáveis pois, como veremos mais adiante, uma das principais fontes de erro, no tipo de análise a que este trabalho se propõe, é a incerteza na medição da pressão em função da posição do pistão.

Os próximos subcapítulos trazem a descrição detalhada do conjunto de sistemas de medição e técnicas utilizadas na obtenção de dados para análise. 


\subsection{Instalações e motor utilizados}

A parte experimental deste trabalho foi desenvolvida no Laboratório de Motores do IPT, onde, desde 1994, vem sendo realizado um projeto de pesquisa com o auxílio da FAPESP entitulado "Redução das emissões em motores de ignição por centelha operando com gás natural", projeto este que contou com a participação do autor desde que começou seu programa de mestrado. Em virtude dessa participação, foi possível utilizarem-se as instalações do laboratório para instrumentar o motor empregado para a realização dos ensaios previstos no projeto temático, de forma a coletar dados experimentais necessários ao desenvolvimento deste trabalho. O motor utilizado foi fabricado pela Mercedes-Benz do Brasil, modelo M $366 \mathrm{G}$, com as seguintes características:

\begin{tabular}{|l|l|}
\hline Número e disposição dos cilindros & 6 em linha \\
\hline Tipo de ciclo & $\begin{array}{l}4 \text { tempos, ignição por centelha, mistura } \\
\text { homogênea, aspiração natural, baixo } \\
\text { "swirl" }\end{array}$ \\
\hline Combustível & gás natural \\
\hline Sistema de alimentação de combustível & $\begin{array}{l}\text { redutor de pressão e dosador controlado } \\
\text { por venturi }\end{array}$ \\
\hline Sistema de ignição & eletrônico com bobina e distribuidor \\
\hline Diâmetro dos cilindros & $97,5 \mathrm{~mm}$ \\
\hline Curso dos pistões & $133,0 \mathrm{~mm}$ \\
\hline Comprimento das bielas & $230,0 \mathrm{~mm}$ \\
\hline Volume deslocado por cilindro & $993 \mathrm{~cm}$ \\
\hline Taxa de compressão & $12: 1$ \\
\hline Abertura da válvula de admissão & $15^{\circ} \mathrm{APMS}$ \\
\hline Fechamento da válvula de admissão & $45^{\circ} \mathrm{DPMI}$ \\
\hline Abertura da válvula de escapamento & $67^{\circ} \mathrm{APMI}$ \\
\hline Fechamento da válvula de escapamento & $13^{\circ} \mathrm{DPMS}$ \\
\hline Potência nominal & $120 \mathrm{~kW} @ 2800 \mathrm{rpm}$ \\
\hline Torque nominal & $420 \mathrm{Nm}$ @ $1300 \mathrm{rpm}$ \\
\hline
\end{tabular}

Tabela 6.1 - Especificações do motor M 366 G.

A configuração da câmara de combustão com a localização da vela de ignição e a cavidade no interior do pistão pode ser observada na Figura 6.1. 


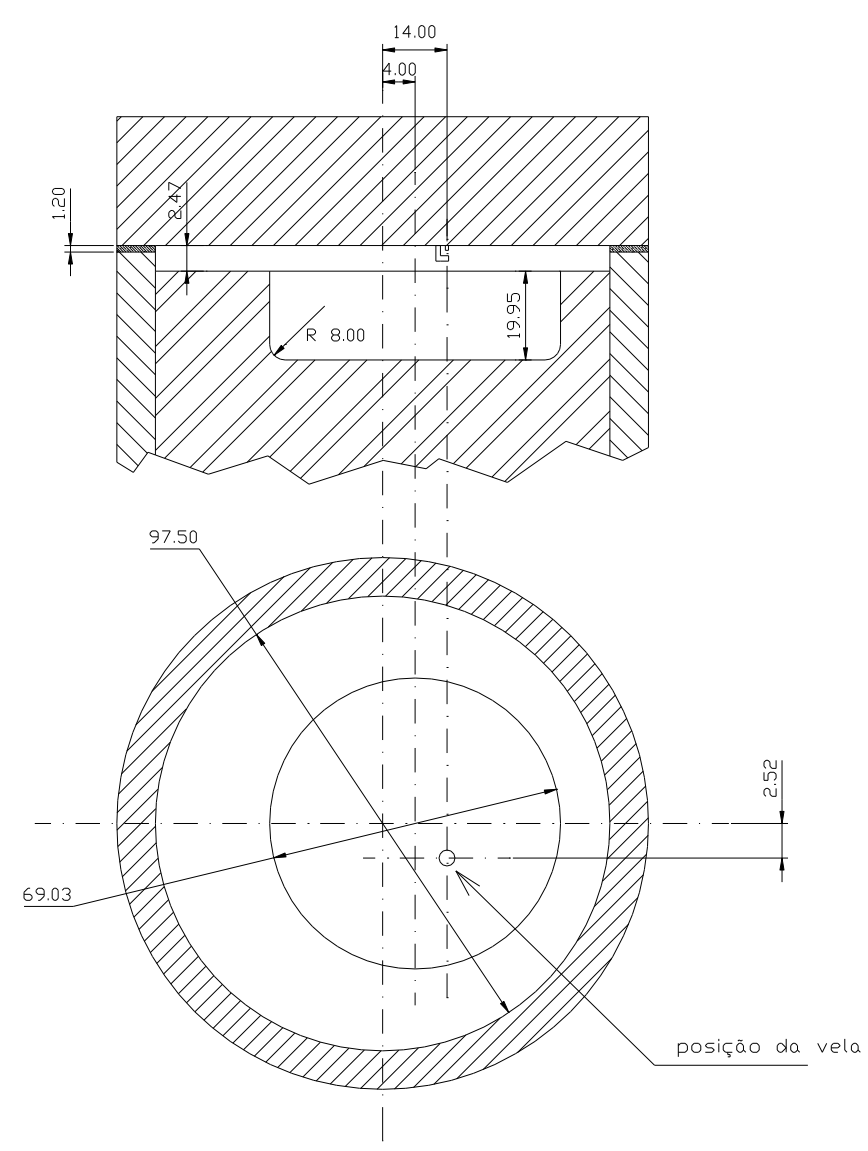

Figura 6.1 - Configuração da câmara do motor M 366 G.

Por meio de informações obtidas junto ao fabricante do pistão empregado nesse motor, a folga radial média entre um pistão novo e o cilindro na região de fogo (acima do primeiro anel) é de $236 \mu m$ a frio e da ordem de $70 \mu m$ a quente (plena potência. A altura da zona de fogo é de $16,4 \mathrm{~mm}$. Assim, o volume $V 1$ entre o pistão e o cilindro acima do primeiro anel é de cerca de $0,35 \mathrm{~cm}^{3}$ a $1,18 \mathrm{~cm}^{3}$ a quente e a frio, respectivamente.

As dimensões a frio das folgas na região do primeiro anel são mostradas na Figura 6.2. Considerando-se que o volume da câmara desse motor é de $90,27 \mathrm{~cm}^{3}$, o volume da fresta acima do primeiro anel corresponderia a 0,4 a 1,3\% do volume da câmara. 


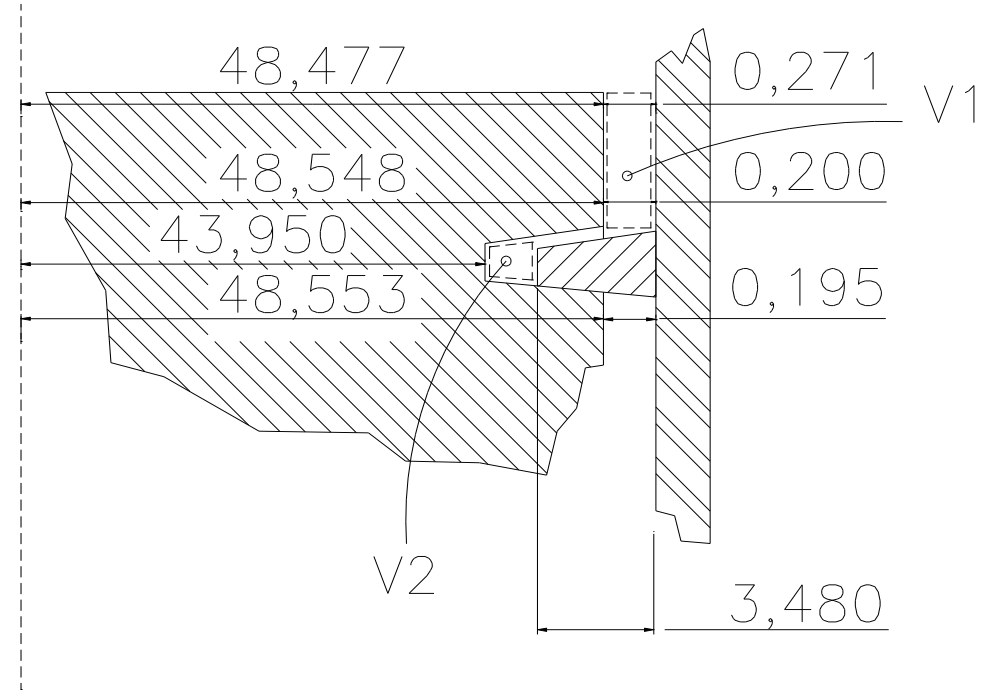

Figura 6.2 - Configuração de folgas a frio na região do primeiro anel.

Segundo dados provenientes da empresa que fornece o pacote de anéis para esse motor, a altura do primeiro anel é de 2,50 $\mathrm{mm}$, e a diferença média entre os diâmetros externo e interno do anel ("radial" do anel) é de 3,48 $\mathrm{mm}$. Assim, a folga radial a frio entre o anel e o fundo do primeiro canalete é de $1,32 \mathrm{~mm}$, quando o diâmetro do fundo do canalete é de 87,90 $\mathrm{mm}$. Dessa forma, o volume V2 contido atrás do primeiro anel é aproximadamente igual a $0,67 \mathrm{~cm}^{3}$ a frio. A quente, estima-se que esse volume caia para 0,47 $\mathrm{cm}^{3}$. Estimando ainda que a junta do cabeçote esteja recuada cerca de $0,3 \mathrm{~mm}$ em relação ao diâmetro do cilindro, o volume das frestas próximas à junta é de $0,1 \mathrm{~cm}^{3}$.

Somando-se todos os volumes das frestas considerados acima, tem-se um volume total variando entre 0,92 e 1,95 $\mathrm{cm}^{3}$, o que representaria 1,02 a 2,15\% do volume da câmara com o pistão no PMS. Esses dados estão muito próximos daqueles reportados na literatura (GATOWSKY et al. ${ }^{[6]}$, KYOUNGDOUG et al. ${ }^{[22]}$ ). Para este trabalho, será admitido que esse volume seja igual a $1,0 \mathrm{~cm}^{3}$ (1,1\% do volume da câmara).

Esse motor, que opera com mistura ligeiramente pobre, estava instalado na cela dinamométrica $\mathrm{n}^{\mathrm{o}} 4$ durante a realização dos ensaios, acoplado a um dinamômetro 
hidráulico marca Schenck, modelo D 360 1-E, teve o cabeçote devidamente usinado para acomodar o transdutor de pressão no cilindro $\mathrm{n}^{\mathrm{o}} 5$ e foi instrumentado para registrar as seguintes grandezas:

- rotação;

- carga;

- temperaturas: ar de admissão, gases de escapamento, líquido de arrefecimento, óleo lubrificante e combustível;

- pressões: ar de admissão, no coletor de admissão após borboleta, no coletor de escapamento e óleo lubrificante;

- umidade relativa do ar de admissão;

- consumos: de ar de admissão e combustível;

- composição dos gases de escapamento: $\mathrm{CO}, \mathrm{O}_{2}, \mathrm{CO}_{2}, \mathrm{NO}_{\mathrm{x}}, \mathrm{CH}_{4}$ e hidrocarbonetos totais;

\subsection{Sistema de medição de pressão no interior do cilindro}

Para a medição da pressão no interior do cilindro foi utilizado um transdutor de pressão piezelétrico marca Kistler, modelo 6123 A2. Esse transdutor tem suas especificações mostradas na Tabela 6.2.

\begin{tabular}{|l|l|l|}
\hline Faixa de operação & bar & $0 \ldots 250$ \\
\hline Sobrecarga & bar & 300 \\
\hline Sensibilidade & $p C / b a r$ & $-16,9$ \\
\hline Linearidade & $\%$ FS & $\leq \pm 0,5$ \\
\hline Faixa de temperatura de operação & ${ }^{\circ} \mathrm{C}$ & $-50 \ldots 350$ \\
\hline
\end{tabular}

Tabela 6.2 - Especificações do transdutor de pressão.

A grande vantagem de sua utilização foi a sua razoavelmente fácil instalação no cabeçote visto que, por não utilizar refrigeração própria, é um transdutor mais compacto 
do que aqueles que demandam refrigeração e conseguiu-se colocar sua face de medição diretamente em contato com a câmara de combustão, evitando assim efeitos indesejados de ressonância em pré-câmara.

Em contrapartida, esse tipo de transdutor apresenta um "short term drift" maior do que os refrigerados. Esse drift é causado por tensões térmicas induzidas no diafragma do transdutor que está exposto aos gases na câmara. Pelo fato de a temperatura dos gases na câmara variar desde $\sim 60{ }^{\circ} \mathrm{C}$ a $\sim 2000^{\circ} \mathrm{C}$ em um único ciclo do motor, essas tensões podem causar (e geralmente causam) erros na medição de pressão. Esse drift pode ser positivo ou negativo, dependendo das características do transdutor. Caso a temperatura na face de medição seja medida e características mais específicas do transdutor sejam conhecidas, uma correção dos valores medidos pode ser efetuada, o que não foi possível neste trabalho. KURATLE e MÄRKI ${ }^{[24]}$ trazem em seu trabalho uma curva típica de correção de pressão devida a este drift, que pode ser observada na Figura 6.3.

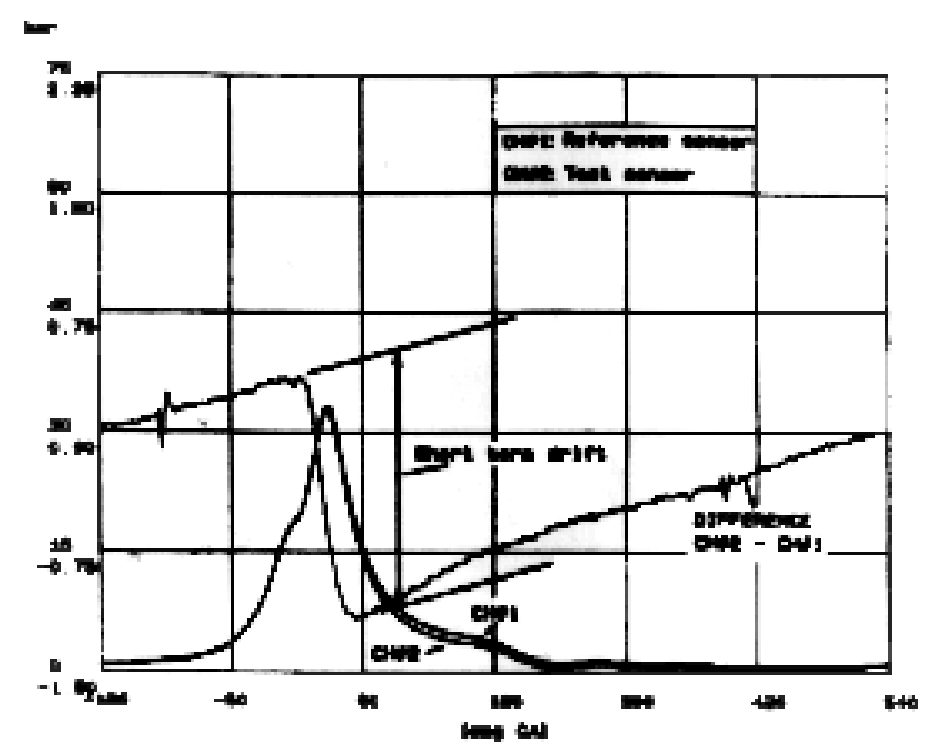

Figura 6.3 - "Short term drift" causado por tensões térmicas no diafragma do transdutor.

O impacto deste drift será notado quando da análise de liberação de calor a partir 
das curvas de pressão medidas. Um exemplo mostrado por KURATLE e MÄRKI ${ }^{[24]}$ do efeito deste drift na curva de liberação de calor pode ser visto na Figura 6.4.

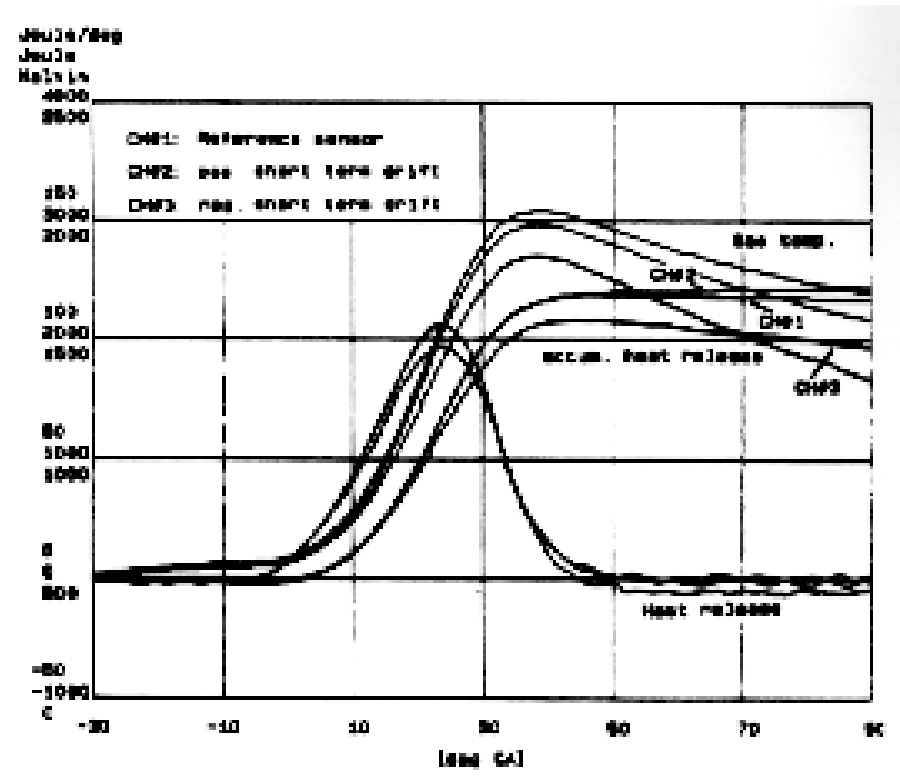

Figura 6.4 - Efeito do drift na curva de liberação de calor.

Como todo transdutor do tipo piezelétrico, esse transdutor gera uma quantidade de carga elétrica proporcional à variação de pressão a ele aplicada. Entretanto, a medição da pressão por meio da medição direta de pequenas cargas elétricas não é algo prático. Assim, para esse tipo de transdutores, são utilizados amplificadores de carga que, resumidamente, são capacitores de alta qualidade e isolação que, ao armazenar essas cargas elétricas em suas armaduras, produzem uma diferença de potencial entre as mesmas. Essa diferença de potencial pode ser amplificada para ser manipulada de forma mais prática. No presente caso, o ganho total do conjunto composto pelo transdutor e pelo amplificador de carga foi fixado em $10 \mathrm{bar} / \mathrm{V}$, tendo sido tal conjunto calibrado no Laboratório de Metrologia do IPT antes de seu uso.

Cabe ressaltar que, como anteriormente dito, transdutores piezelétricos respondem a variações de pressão e não a pressões constantes a eles aplicadas. Assim é necessário estabelecer um valor de referência na curva de pressão medida. Esse valor 
será posteriormente exposto quando se descrever o sistema de medida da pressão em função de ângulo de árvore de manivelas.

\subsection{Sistema de medição de posição angular do virabrequim}

Para que se pudesse medir a posição do virabrequim com a resolução necessária à aplicação do modelo de liberação de calor, foi utilizado um transdutor de posição angular do tipo "encoder", marca AVL e modelo 360C/600, disponível no Laboratório de Motores do IPT. Esse encoder conta com duas trilhas, sendo que uma delas gera 600 pulsos por volta e a outra apenas um pulso por volta. O sinal de 600 pulsos por volta é tratado por um circuito eletrônico que defasa esse sinal em $120^{\circ}$ e $240^{\circ}$ de forma que, para uma volta do virabrequim, são gerados 1800 pulsos padrão TTL, resultando em uma resolução de $0,2^{\circ}$. O outro pulso TTL gerado pelo encoder funciona como sinal de referência da posição angular do eixo de manivelas. A Figura 6.5 mostra o encoder com as suas duas trilhas: a externa com 600 marcas e a interna com uma só marca.

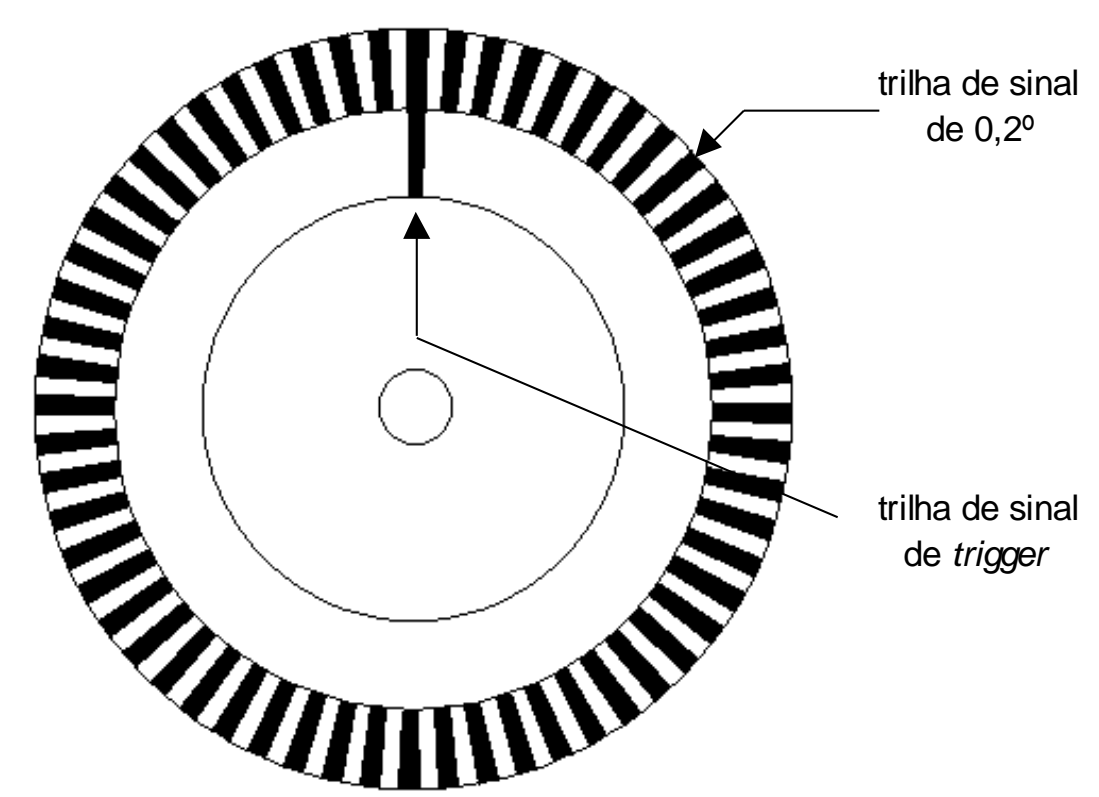

Figura 6.5 - Encoder para medição de posição angular do virabrequim. 


\subsection{Sistema de medição de corrente de ignição}

Sabe-se que a tensão aplicada no circuito secundário de ignição pode chegar a alguns milhares de volts em instantes próximos à ocorrência da centelha. Foi então necessário construir um dispositivo que possibilitasse registrar o instante da faísca e que operasse com tensões reduzidas de forma a não danificar os registradores. Concebeu-se e implantou-se, após vários testes, uma bobina colocada junto à linha secundária de ignição do $5^{\circ}$ cilindro de forma que a tensão induzida nessa bobina, quando da passagem da corrente de ignição, não ultrapassasse o valor de $10 \mathrm{~V}$ (valor máximo admitido pelo sistema de aquisição de dados descrito adiante).

\subsection{Sistema de aquisição de dados}

O sistema de aquisição rápida de dados do Laboratório de Motores do IPT foi concebido de modo a permitir obter os valores de posição angular da árvore de manivelas, pressão no cilindro e tensão no circuito secundário de ignição simultaneamente para posições angulares de até $0,2^{\circ}$ de árvore de manivelas. Além disso, o sistema deveria ser flexível para permitir alterações futuras como, por exemplo, sua aplicação em motores de ignição por compressão onde, em vez de haver a necessidade de se registrar a tensão no circuito secundário de ignição, necessita-se obter valores da pressão na linha de injeção de combustível bem como levantamento da agulha do injetor. O "lay-out" do sistema que é composto por transdutor de pressão piezelétrico, amplificadores de carga, encoder da posição angular, placa de amostragem simultânea, placa de aquisição e computador é detalhado na Figura 6.6. 


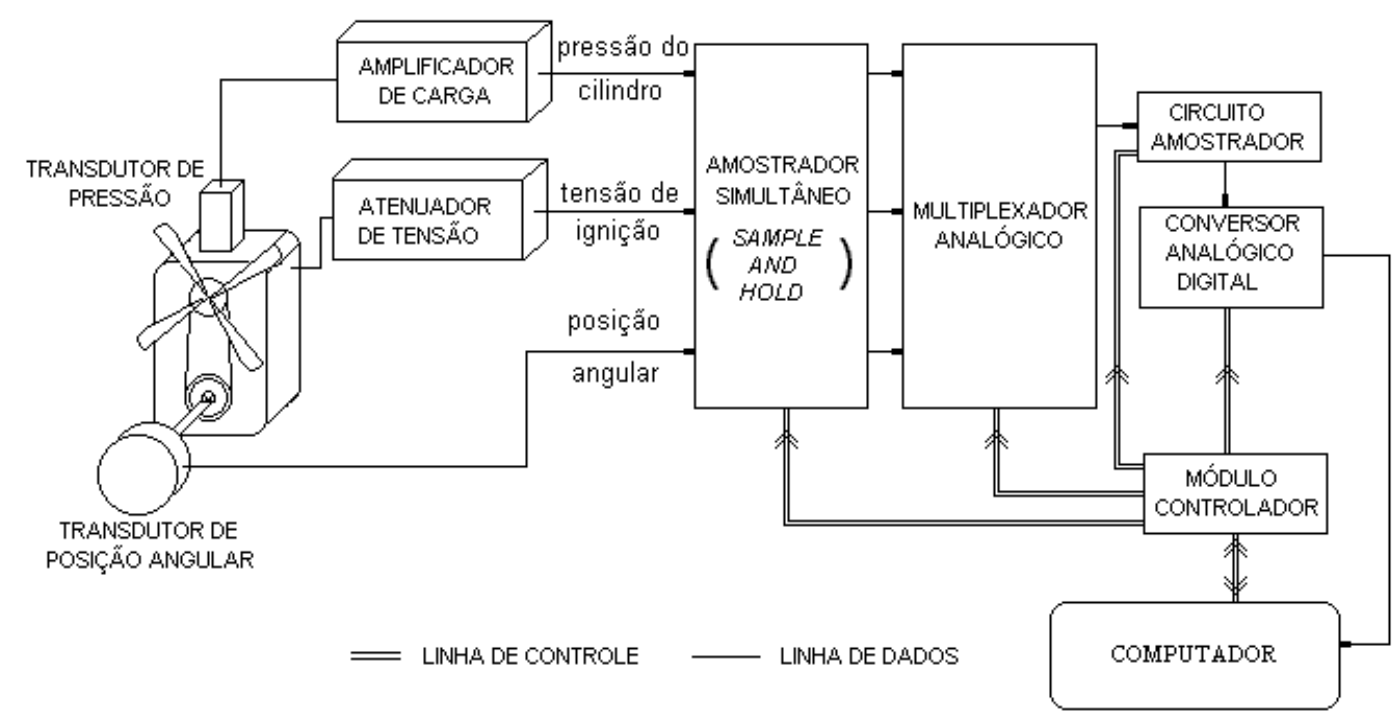

Figura 6.6 - Sistema de alta taxa de aquisição de dados integrado ao motor.

Foram também definidos os circuitos e componentes auxiliares para integração desses elementos, como por exemplo o atenuador de tensão para aquisição do instante de ignição (descrito acima) e um sistema de aterramento de todos os elementos do sistema de forma a minimizar a influência de ruídos pois, como já comentado, o transdutor de pressão gera baixas quantidades de cargas elétricas que podem ser influenciadas por ruídos externos, alterando então o valor de pressão medido.

O sinal de 1800 pulsos/volta, daqui em diante denominado simplesmente sinal de clock, sincroniza a aquisição das tensões dos outros canais enquanto o outro sinal, denominado trigger, disparara a aquisição. A Figura 6.7 mostra de que forma os sinais de pressão e ignição são amostrados as cada $0,2^{\circ}$ do virabrequim a partir do sinal de trigger. A menos do sinal de ignição, os demais sinais não estão sujeitos a aliasing em virtude de a taxa de aquisição ser muito maior do que as freqüências correspondentes. 


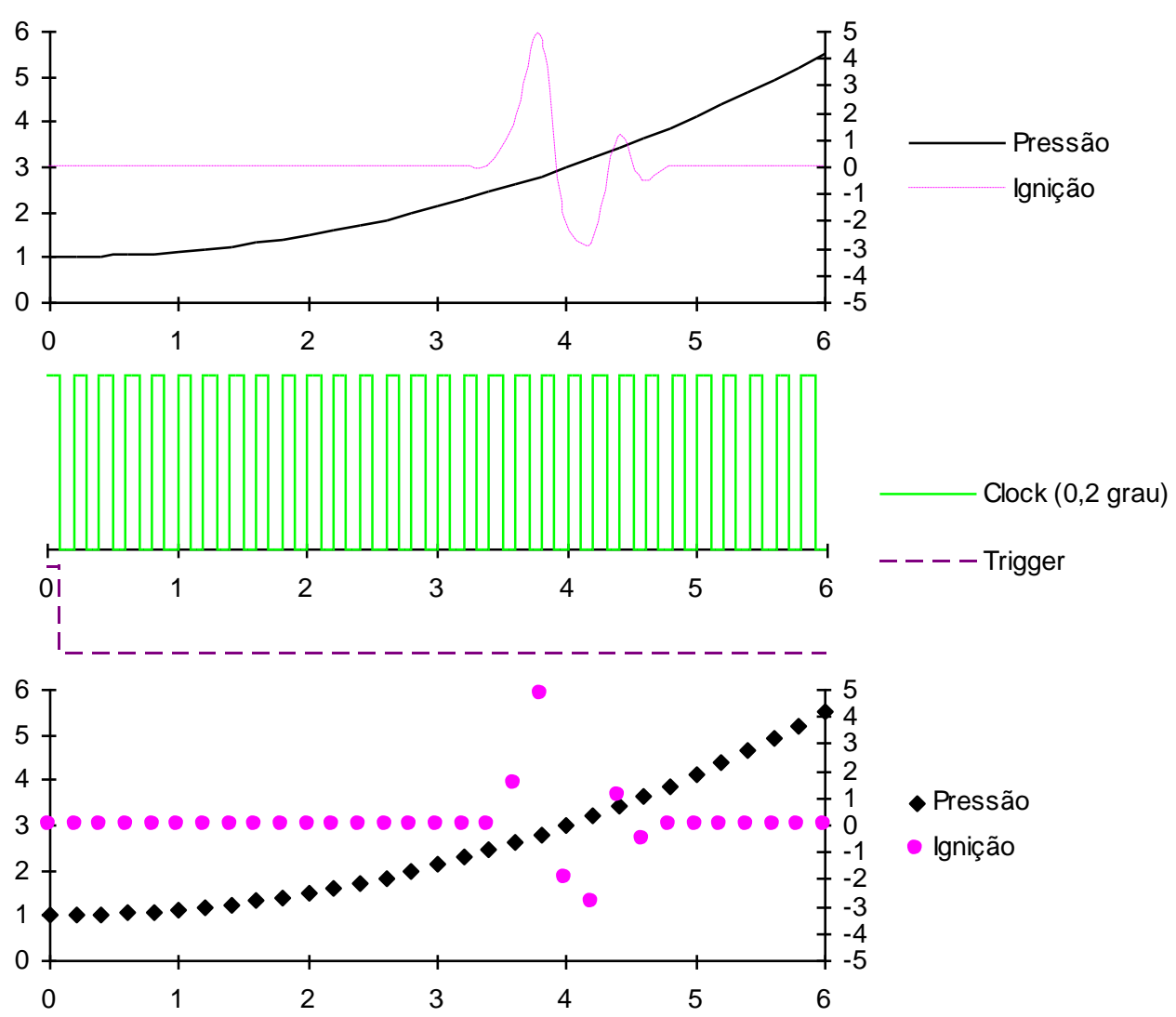

Figura 6.7 - Sinais amostrados pelo sistema de aquisição.

Embora não esteja explicitado na figura acima, o sinal de trigger também é amostrado para se poder conferir, posteriormente à aquisição, se não houve "perda ou ganho" de pulsos, isto é, entre dois sinais consecutivos de trigger deverá haver 1800 amostras; caso isso não ocorra, o sistema amostrou mais ou menos pontos do que deveria e o ciclo deve então ser descartado.

A necessidade de um sistema com alta taxa de amostragem se fez evidente na medida em que se pretendia obter os valores de posição angular da árvore de manivelas, pressão no cilindro e tensão no circuito secundário de ignição para, em caso extremo, um motor trabalhando a $6000 \mathrm{rpm}(100 \mathrm{~Hz})$ com a resolução de aquisição de $0,2^{\circ}$ da árvore. Isso significa que devem ser amostrados três sinais simultaneamente, sincronizados pelo sinal de trigger, a 1800 aquisições $\left(360^{\circ} / 0,2^{\circ}\right)$ por volta e a $6000 \mathrm{rpm}$. Levando em 
conta que é necessário um pulso do clock interno da placa controladora de aquisição para perfazer a amostragem simultânea de todos os canais (sinal para o sample and hold) e um pulso de clock interno da placa para realizar a conversão analógico-digital de cada canal amostrado, no caso de se amostrarem três canais (sinal de ponto morto superior, pressão no cilindro e tensão de ignição), são necessários 4 pulsos de clock interno da placa para aquisição de um conjunto desses dados. Foi então necessário adquirir uma placa que permitisse uma freqüência de amostragem de, no mínimo, $\frac{4 \text { pulsos }}{\text { amostra }} \cdot \frac{1800 \text { amostras }}{\text { volta }} \cdot \frac{100 \text { voltas }}{s}=\frac{720000 \text { pulsos }}{s}$. Prevendo a possibilidade de se ter que registrar um ou mais sinais no futuro além desses mencionados, foi adquirida uma placa com capacidade de efetuar até 1 milhão de aquisições por segundo, marca Keithley - Metrabyte, modelo DAS-58, com entrada de até 8 sinais analógicos de 0 a $10 \mathrm{~V}$, entrada de trigger e clock de aquisição externos, circuito amostrador simultâneo (sample and hold) e conversor A/D de 12 bits. Tal placa ainda apresenta a possibilidade de armazenar até um milhão de amostras em região de memória própria, liberando assim o computador no qual se processa a aquisição para outras tarefas enquanto um ciclo está sendo amostrado. A Tabela 6.3 resume as características desta placa de aquisição.

Após implantação de toda a parte de hardware e realização de testes funcionais, passou-se para a geração do programa que gerencia a aquisição. Foi construído um código em linguagem $C$ que comanda a placa de aquisição (disparo, parada, reinicialização, etc.), analisa se houve ou não perda de pulsos durante a aquisição de um ciclo completo (entenda-se por ciclo completo 2 voltas do virabrequim contadas a partir da fase de admissão), exibe alguns ciclos amostrados no monitor do computador para verificação do andamento da aquisição e, por fim, gera arquivos em disco rígido dos dados coletados. Um exemplo dos gráficos gerados para cada ciclo adquirido pode ser 
visto através da Figura 6.8 (onde são mostradas as curvas de pressão, sinal de ignição e sinal de ponto morto superior) e da Figura 6.9 (diagrama pressão versus volume).

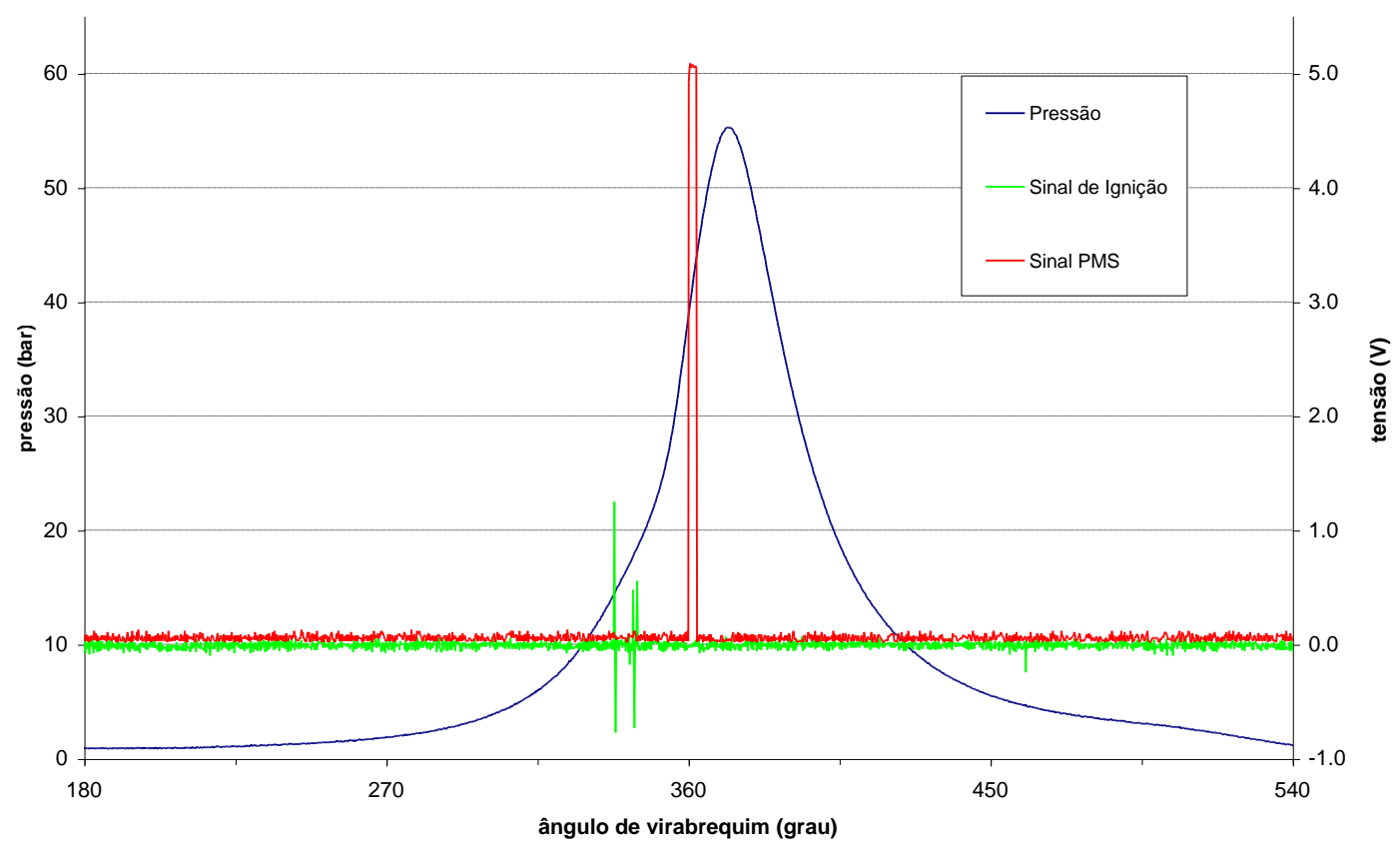

Figura 6.8 - Exemplo de um ciclo completo adquirido.

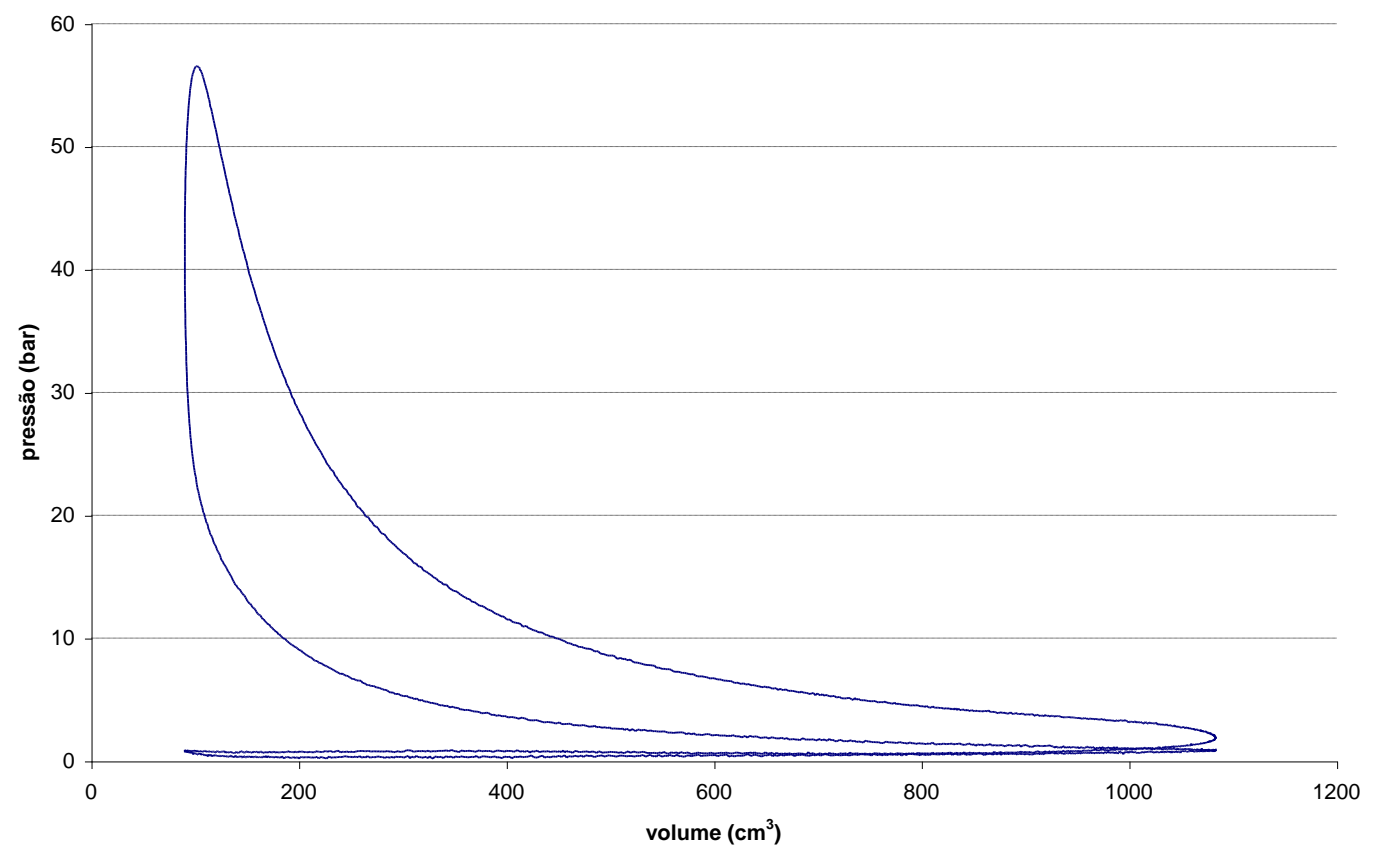

Figura 6.9 - Diagrama PxV. 


\begin{tabular}{|c|c|c|}
\hline \multicolumn{3}{|c|}{ placa de aquisição } \\
\hline \multicolumn{2}{|c|}{ número de canais de entrada } & 8 \\
\hline \multicolumn{2}{|l|}{ impedância } & $1 M \Omega$ \\
\hline \multicolumn{2}{|l|}{ capacitância } & $50 p F$ \\
\hline \multicolumn{2}{|c|}{ taxa de aquisição } & até $1 \mathrm{MHz}$ \\
\hline \multicolumn{2}{|c|}{ memória on-board (16 bit) } & $1 \mathrm{MB}$ \\
\hline \multicolumn{2}{|c|}{ conversor A/D } & 12 bits \\
\hline \multicolumn{2}{|c|}{ precisão global } & 2 LSB máx. \\
\hline \multirow[t]{2}{*}{ faixas } & unipolar & \\
\hline & bipolar & \\
\hline \multicolumn{3}{|c|}{ simultaneous sample \& hold } \\
\hline \multicolumn{2}{|l|}{ ganho } & $0,5 \pm 0,15 \%$ \\
\hline \multicolumn{2}{|l|}{ impedância } & $10 M \Omega$ \\
\hline \multicolumn{2}{|l|}{ capacitância } & $20 p F$ \\
\hline
\end{tabular}

Tabela 6.3- Características da placa de aquisição utilizada.

Este código de controle da aquisição de pressão foi gerado de forma modularizada no intuito de integrá-lo ao programa de análise. Esta integração, então, torna o conjunto de aquisição de pressão e análise da combustão uma ferramenta de utilização simples e transparente para emprego direto em laboratórios motores.

\subsection{Testes para verificação do correto funcionamento do sistema}

Para que se pudesse verificar o correto funcionamento do sistema, foram efetuados ajustes e testes que se iniciaram com a determinação do ponto morto superior (PMS) do $5^{\circ}$ cilindro, onde se encontrava instalado o transdutor de pressão. Para tanto, a vela de ignição desse cilindro foi retirada e em seu alojamento foi aparafusada uma guia através da qual uma haste podia se deslocar tocando a superfície da cabeça do pistão. Com o auxílio de um relógio comparador (resolução de $0,01 \mathrm{~mm}$ ), foi levantada a curva de posição do pistão em função de posição angular do eixo de manivelas, tomando-se o cuidado de deslocar o pistão sempre no sentido do PMS durante as medições de modo a 
minimizar o efeito das folgas e forças de atrito.

Através da análise dessa curva, que deve ser simétrica em relação ao PMS, determinou-se, estaticamente, a posição do PMS do $5^{\text {o }}$ cilindro, e se fez uma marca de referência na polia dianteira do motor. O disco do encoder foi ajustado de forma que o sinal de trigger por ele gerado coincidisse com a marca feita na polia. Um lampejo de uma lâmpada estroboscópica, comandado pelo sinal de trigger, permitiu verificar a coincidência do ponto marcado na polia e o sinal gerado pelo encoder. A repetibilidade da posição do PMS obtida com o procedimento descrito foi estimada em cerca de $0,1^{\circ}$.

Uma forma de verificar o funcionamento global do sistema de aquisição (inclusive calibração do transdutor e posição do PMS) foi a de calcular o trabalho líquido indicado do $5^{\mathrm{o}}$ cilindro e compará-lo com o valor medido indiretamente na bancada. Isso foi realizado da seguinte maneira:

1) fixou-se o regime de operação do dinamômetro para rotação constante e igual a 2800 rpm, ou seja, a aplicação de freio pelo dinamômetro ao motor deu-se de forma necessária e suficiente para que a rotação se estabilizasse em 2800 rpm;

2) com o motor em regime estável, à plena carga e a $2800 \mathrm{rpm}$, foi feita a aquisição dos sinais para 25 ciclos completos, pois como em todo motor de ignição por centelha a variação ciclo a ciclo é grande, há que se efetuar uma média de um número razoável de ciclos para então compará-la com valores medidos na bancada dinamométrica. Enquanto a aquisição se processava, anotaram-se os valores lidos de rotação, carga, consumo de ar, consumo de combustível, temperatura do ar de admissão, temperatura dos gases de escapamento, temperatura de óleo lubrificante, temperatura no medidor de vazão de ar e pressão no coletor de admissão; 
3) desligou-se a ignição do $5^{\circ}$ cilindro por um intervalo de tempo suficiente para que o motor tivesse sua rotação estabilizada novamente em 2800 rpm e uma nova aquisição foi efetuada, anotando-se também os novos valores das grandezas mencionadas acima. Isso foi feito com o intuito de se calcular a potência de bombeamento do cilindro em questão;

4) com a ignição do $5^{\underline{0}}$ cilindro religada, verificou-se se a carga anotada no item 2 se restabeleceu.

As curvas de pressão do motor trabalhando com o $5^{\circ}$ cilindro queimando e sem ignição podem ser vistas na Figura 6.10 e na Figura 6.11, respectivamente.

Vale mencionar que a variação aparentemente grande da pressão medida para o cilindro arrastado (cerca de 1 bar durante os tempos de admissão e escapamento) é decorrente da imprecisão da determinação da pressão de referência do ciclo, do nível de ruído elétrico no sistema de aquisição e no resfriamento gradual das superfícies da câmara para o $5^{\mathrm{o}}$ cilindro arrastado.

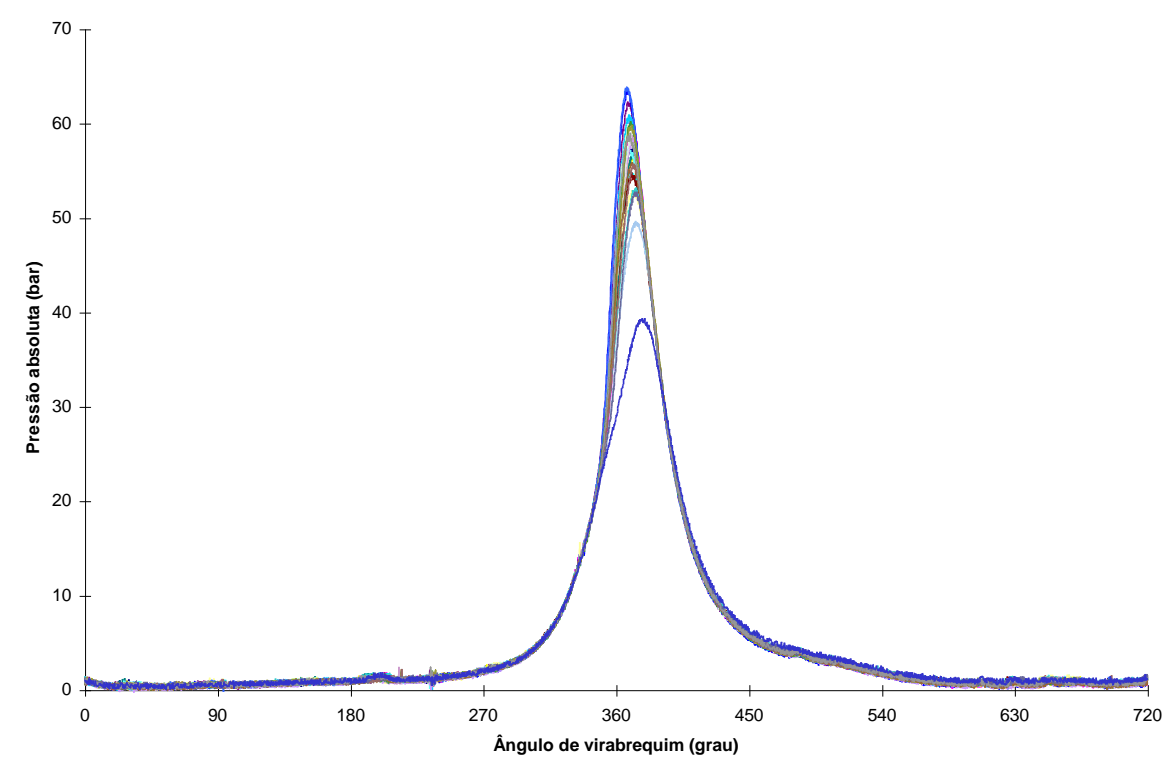

Figura 6.10 - Curvas de pressão do $5^{\circ}$ cilindro queimando (25 ciclos). 


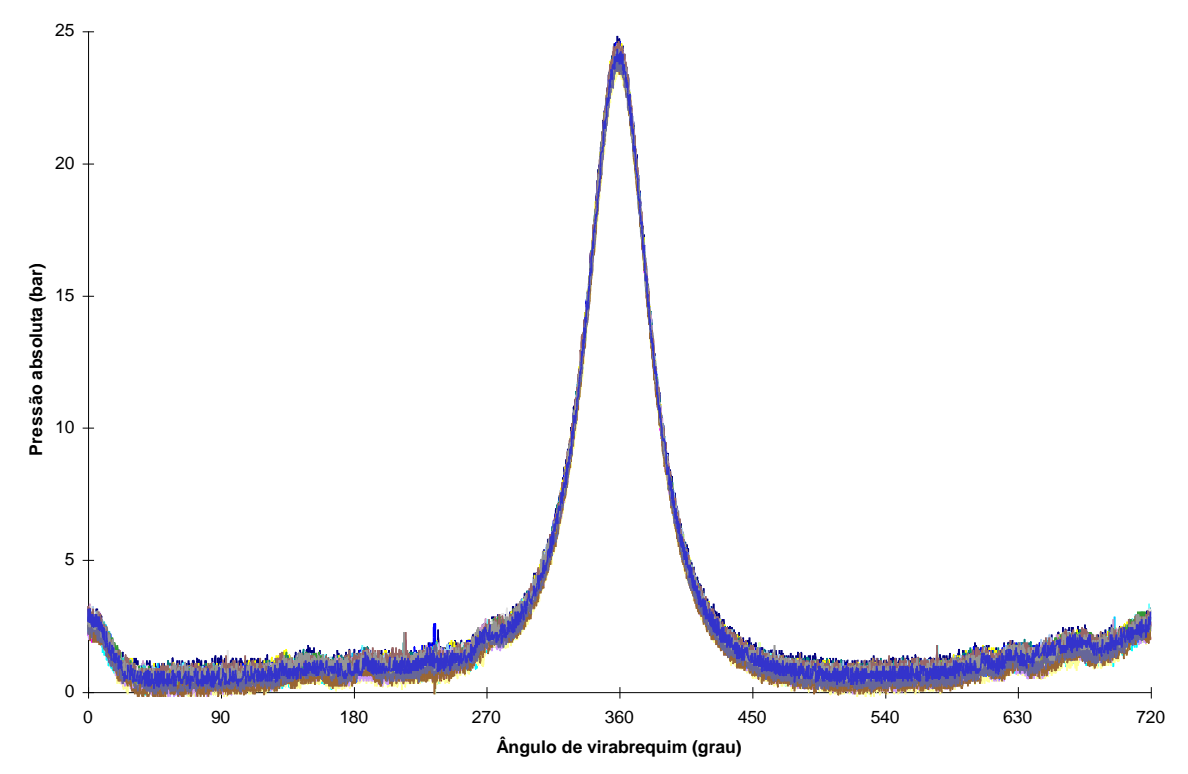

Figura 6.11 - Curvas de pressão do $5^{\underline{0}}$ cilindro arrastado (25 ciclos).

A determinação da pressão de referência do ciclo foi feita da seguinte forma: durante o intervalo que vai de $180^{\circ}$ a $185^{\circ}$ da árvore de manivelas (onde a velocidade do pistão é quase nula e portanto a perda de carga na válvula de admissão é baixa), fez-se uma média dos 25 valores de pressão adquiridos nesse intervalo para cada ciclo. Impôsse que o resultado dessa média fosse igual à pressão absoluta medida no coletor de admissão (660 mmHg neste caso). A diferença entre a média das pressões nesse intervalo e o valor de $660 \mathrm{mmHg}$ foi subtraída de todos os valores de pressão adquiridos no ciclo inteiro a fim de reduzir o efeito do drift ao longo da aquisição dos 25 ciclos e determinar a pressão de referência do ciclo.

Ressalte-se também que os dados apresentados na Figura 6.10 e na Figura 6.11 não foram submetidos a nenhum ajuste ou filtragem pois houve a intenção de se mostrar o nível de ruído nesse sistema de medição de pressão. Para permitir uma melhor visualização desse ruído, a Figura 6.12 mostra um único ciclo do conjunto de ciclos apresentados na Figura 6.11. 


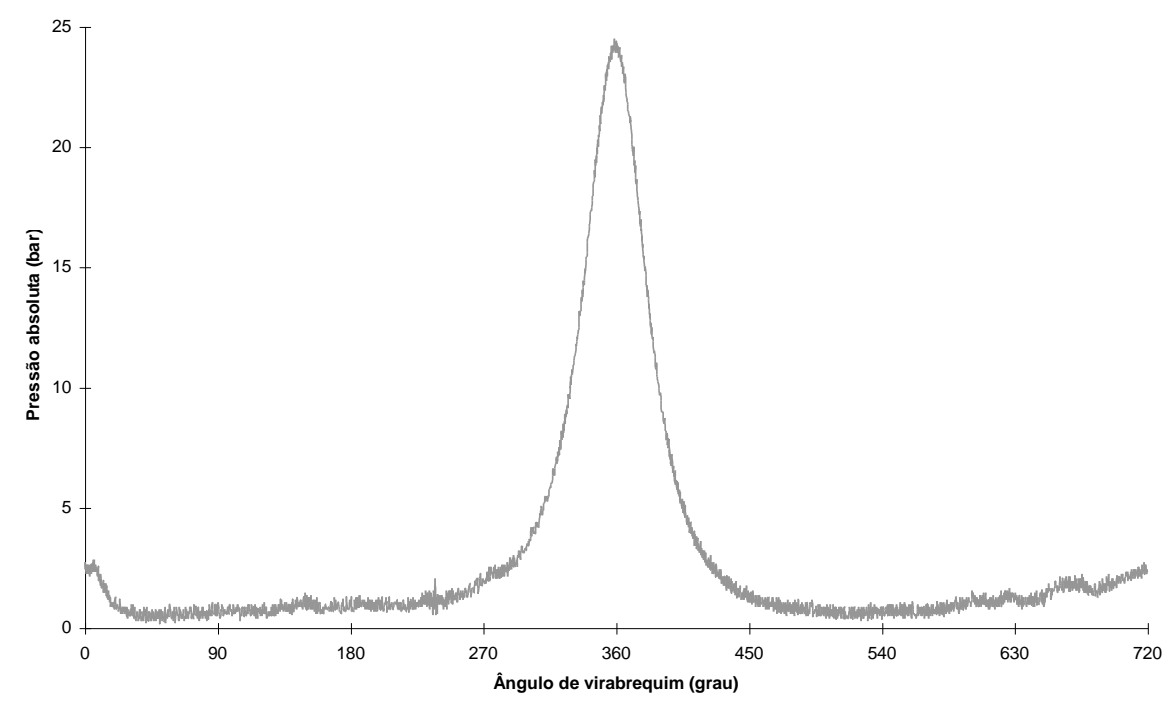

Figura 6.12 - Curva de pressão de um ciclo do $5^{\circ}$ cilindro arrastado.

São.

A Figura 6.13 e a Figura 6.14 mostram as curvas médias de pressão dos 25 ciclos com e sem combustão, respectivamente. Por serem curvas médias de 25 ciclos, atenuam os efeitos dos ruídos e as flutuações que se apresentam são variações sistemáticas da pressão. As causas das flutuações sistemáticas da pressão no interior do cilindro são, entre outras, os efeitos dinâmicos dos escoamentos nos coletores de admissão e escapamento.

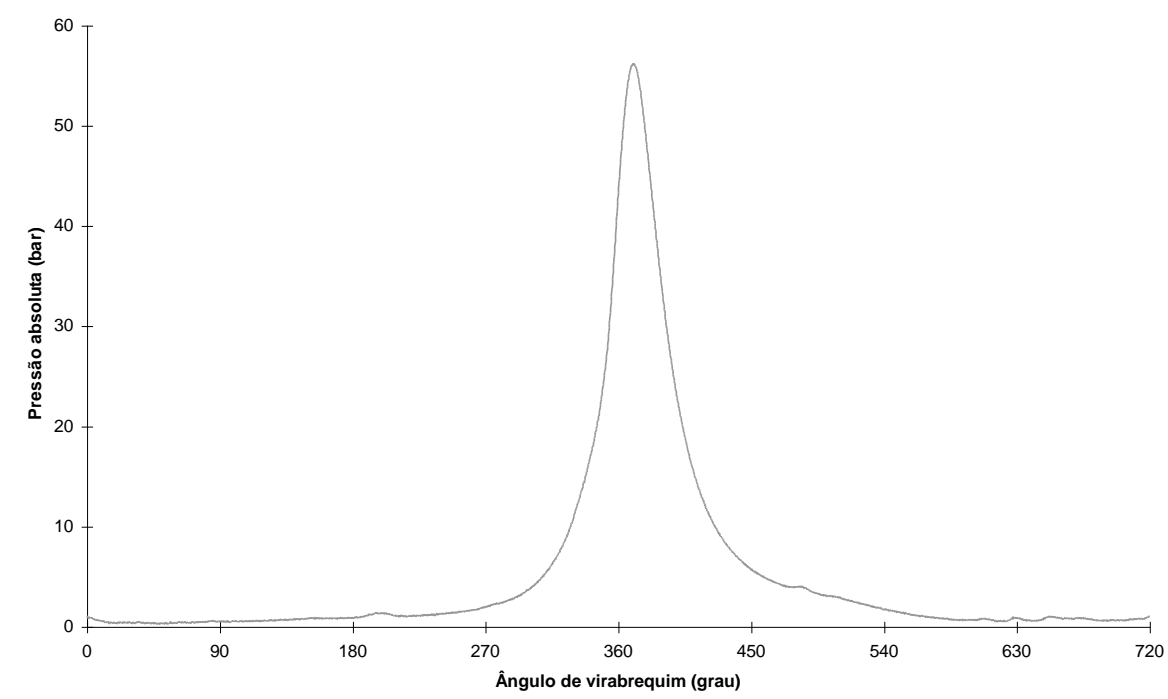

Figura 6.13 - Curva média de pressão do $5^{\circ}$ cilindro queimando ( 25 ciclos). 


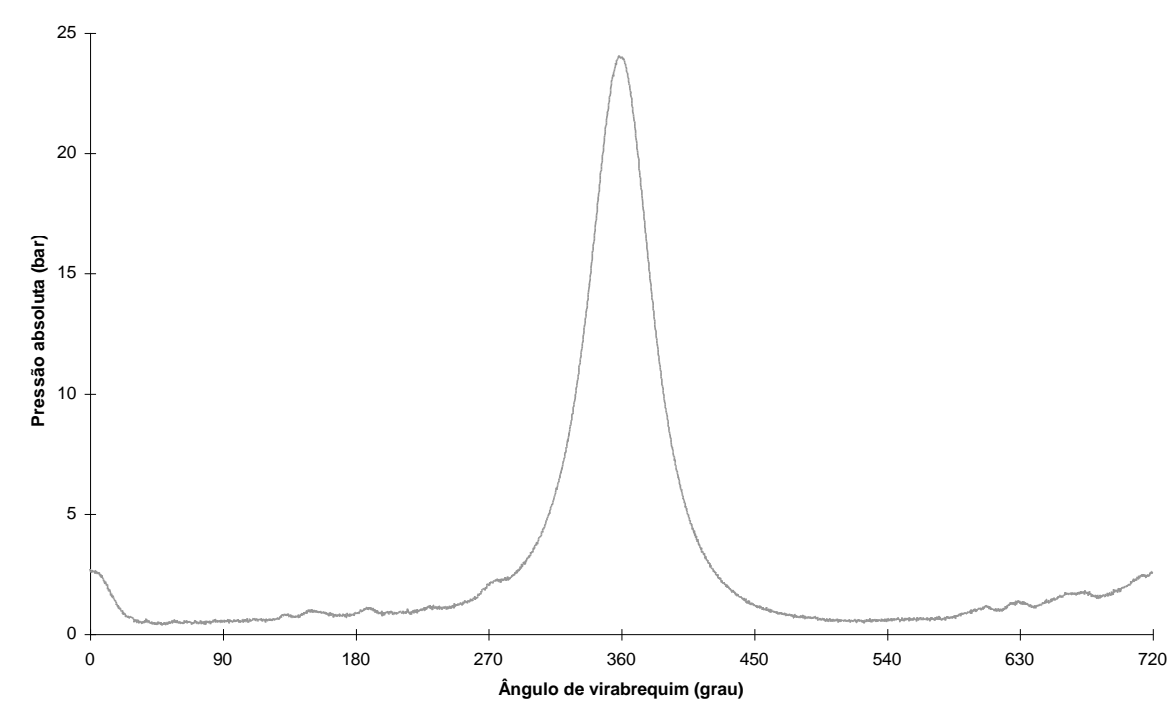

Figura 6.14 - Curva média de pressão do $5^{0}$ cilindro arrastado (25 ciclos).

Também pode ser notado o sinal de abertura da válvula de escapamento, por volta de $470^{\circ}$ do virabrequim, na Figura 6.13. O aumento de pressão no ciclo de escapamento do cilindro sem combustão mostrado na Figura 6.14 é devido às ondas de pressão geradas no coletor de escapamento quando da abertura das válvulas de escapamento de cilindros vizinhos.

Os valores da somatória $\sum(p \cdot \Delta V)$ calculados para cada ciclo, em cada regime, são mostrados na Tabela 6.4.

A média dos trabalhos indicados líquidos por ciclo, entendendo-se por trabalho indicado líquido como sendo o trabalho realizado sobre o pistão durante o ciclo

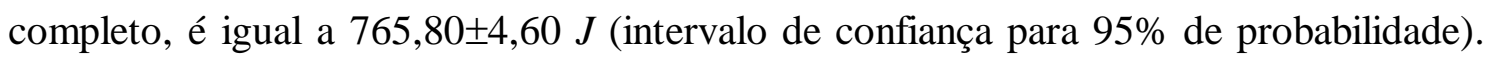
Já o trabalho de bombeamento total para o cilindro arrastado pode ser determinado pela média dos trabalhos calculados com o cilindro operando sem ignição e é igual a $119,88 \pm 2,20 \mathrm{~J}$. O trabalho que deixou de ser efetuado quando a ignição foi desligada é igual a $(765,80 \pm 4,60)-(-119,88 \pm 2,20)=885,68 \pm 5,10 J$ e portanto a potência que

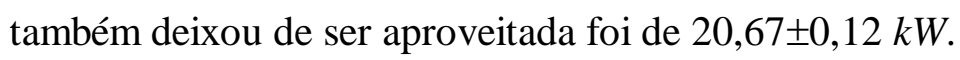




\begin{tabular}{|c|c|c|}
\hline & \multicolumn{2}{|c|}{$\sum_{\left(b a r \times c m^{3}\right)}(p \cdot \Delta V)$} \\
\hline ciclo & $\begin{array}{c}5_{-}^{0} \text { cilindro } \\
\text { com combustão }\end{array}$ & $\begin{array}{c}5_{-}^{0} \text { cilindro } \\
\text { sem combustão }\end{array}$ \\
\hline 1 & 7636.7 & -1123.2 \\
\hline 2 & 7744.8 & -1150.7 \\
\hline 3 & 7680.7 & -1169.2 \\
\hline 4 & 7577.3 & -1142.4 \\
\hline 5 & 7574.6 & -1106.7 \\
\hline 6 & 7586.3 & -1260.5 \\
\hline 7 & 7588.6 & -1249.4 \\
\hline 8 & 7684.7 & -1240.8 \\
\hline 9 & 7721.7 & -1157.6 \\
\hline 10 & 7761.8 & -1224.5 \\
\hline 11 & 7649.9 & -1214.9 \\
\hline 12 & 7592.4 & -1075.5 \\
\hline 13 & 7555.0 & -1151.1 \\
\hline 14 & 7822.0 & -1178.6 \\
\hline 15 & 7808.7 & -1214.9 \\
\hline 16 & 7596.5 & -1265.1 \\
\hline 17 & 7692.4 & -1178.1 \\
\hline 18 & 7663.7 & -1228.9 \\
\hline 19 & 7638.5 & -1229.8 \\
\hline 20 & 7868.8 & -1266.8 \\
\hline 21 & 7760.4 & -1219.2 \\
\hline 22 & 7610.0 & -1221.9 \\
\hline 23 & 7649.3 & -1189.4 \\
\hline 24 & 7677.7 & -1254.4 \\
\hline 25 & 7306.8 & -1257.3 \\
\hline Média & 7658.0 & -1198.8 \\
\hline Desvio Padrão & 111.5 & 53.4 \\
\hline COV & $1.46 \%$ & $4.45 \%$ \\
\hline
\end{tabular}

Tabela 6.4 - Valores calculados.

Os valores anotados da bancada dinamométrica são mostrados na Tabela 6.5:

\begin{tabular}{|l|c|r|r|}
\hline \multicolumn{1}{|c|}{ grandeza } & unidade & $\begin{array}{r}5_{-}^{\circ} \text { cilindro } \\
\text { sem combustão }\end{array}$ & $\begin{array}{r}5_{-}^{\circ} \text { cilindro } \\
\text { com combustão }\end{array}$ \\
\hline rotação & $r p m$ & 2800 & 2800 \\
\hline carga & $\mathrm{N}^{*}$ & $270 \pm 1$ & $345 \pm 1$ \\
\hline temperaturas & & 25 & 24 \\
\hline ar admissão & ${ }^{\circ} \mathrm{C}$ & 669 & 721 \\
\hline escapamento & ${ }^{\circ} \mathrm{C}$ & 122 & 119 \\
\hline lubrificante & ${ }^{\circ} \mathrm{C}$ & 24 & 23 \\
\hline roots & ${ }^{\circ} \mathrm{C}$ & 367,4 & 371,3 \\
\hline consumo de ar & $\mathrm{m}^{3} / \mathrm{h}$ & 20,31 & 20,52 \\
\hline consumo comb. & $\mathrm{kg} / \mathrm{h}$ & & -40 \\
\hline pressão & & -40 & \\
\hline coletor & $\mathrm{mmHg}$ & &
\end{tabular}

Tabela 6.5 - Valores medidos na bancada dinamométrica. 
Para efeito de esclarecimento, ressalta-se que a carga indicada no dinamômetro é um valor que foi calibrado para que, ao se multiplicar diretamente o valor de carga indicado pela rotação em rpm e dividindo-se o resultado por 10000, o valor obtido seja a potência expressa em $k W$. Como a variação da carga indicada foi de $(345 \pm 1)-(270 \pm 1)$ $=75 \pm 1,4 \quad N^{*}$, houve uma diminuição na potência de eixo de $\frac{(75 \pm 1,4) N * \cdot 2800 \mathrm{rpm}}{10000}=21,0 \pm 0,4 \mathrm{~kW}$. Comparando esse valor com o valor de $20,67 \pm 0,12 k W$ obtido através do cálculo a partir da curva de pressão, pode-se aceitar a operação global do sistema como satisfatória, em particular a determinação da posição do ponto morto superior.

Deve-se mencionar que a correta determinação da posição do PMS afeta significativamente o trabalho indicado, pois quando as curvas de pressão originais foram adiantadas em $0,4^{\circ}$ a título de investigação, o resultado dos novos trabalhos indicados líquidos calculados com essas curvas defasadas aumentou cerca de 2,0\%.

Ainda como uma última forma de verificação dos resultados fornecidos pelo sistema de aquisição de dados, foi realizada uma série de testes comparativos entre o próprio sistema e o equipamento denominado Indiskop 647, marca AVL, destinado a efetuar a aquisição de pressões no interior de cilindros bem como de outras grandezas. Esse equipamento, que nos foi gentilmente emprestado pela Mercedes-Benz do Brasil para esses testes no final de dezembro de 96, além de realizar a aquisição dos dados, tem a capacidade de tratá-los estatisticamente. A idéia foi a de, configurando o sistema de aquisição de dados e o Indiskop da mesma maneira (mesma resolução de amostragem de $0,2^{\circ}$, mesmos sinais de clock e trigger, mesmo sinal de pressão oriundo do mesmo transdutor de pressão e amplificador de carga), adquirir um número de ciclos na mesma 
situação de operação do motor nos dois sistemas e confrontar as curvas de pressão e os valores de pressão média indicada por eles fornecidos.

Entretanto, embora o Indiskop possuísse a opção de registrar os ciclos adquiridos em disquete, a formatação em que esses dados eram gravados não permitia que fossem lidos em um PC. Dessa forma, a única forma de registrar os dados era sob a forma de gráficos "plotados" para cada ciclo. Mas, sob um ponto de vista prático, plotar cerca de 30 gráficos para cada condição de operação não era algo desejável. A alternativa foi utilizar o recurso de ciclo médio que é oferecido pelo Indiskop. Esse recurso permite que vários ciclos sejam amostrados para que seja gerado um ciclo médio. A desvantagem desse método é que, pelo fato de se realizar uma média das pressões para cada $0,2^{\circ}$, os efeitos de variação ciclo a ciclo são "camuflados", uma vez que a variação ciclo a ciclo se manifesta principalmente como a variação das pressões de pico. Já quanto ao efeito da variação ciclo a ciclo no valor da pressão média indicada, sabe-se não ser fator de grande influência.

Para confirmar esse fato, procedeu-se ao seguinte:

1) o Indiskop foi inicialmente configurado para adquirir 32 ciclos completos (número máximo de ciclos permitido) e calcular a pressão média indicada de cada um destes ciclos. Para o motor operando de maneira estável à plena carga, os valores médios e os respectivos desvios padrão foram os seguintes:

\begin{tabular}{|c|c|c|}
\hline Rotação & $\begin{array}{c}\text { Média das 32 pressões } \\
\text { médias indicadas } \\
(\text { bar })\end{array}$ & Desvio padrão \\
$(\mathrm{rpm})$ & 7,43 & 0,08 \\
\hline 1300 & 7,63 & 0,10 \\
\hline 2200 & 7,59 & 0,09 \\
\hline 2800 &
\end{tabular}

Tabela 6.6 - Valores de pressão média indicada calculados como média de 32 ciclos. 
2) posteriormente, configurou-se o Indiskop para que gerasse ciclos médios partindo de 32 ciclos adquiridos. Os valores da pressão média indicada para cada ciclo médio podem ser vistos na Tabela 6.7.

Desse teste foi possível verificar que as diferenças entre os valores calculados a partir dos 32 ciclos e o valores calculados a partir do ciclo médio de 32 ciclos, quando existem, são desprezíveis, confirmando a tese inicial que, para efeitos de cálculo de pressão média indicada, pode-se utilizar um ciclo médio em vez dos 32 ciclos.

\begin{tabular}{|c|c|}
\hline $\begin{array}{c}\text { Rotação } \\
(\mathrm{rpm})\end{array}$ & $\begin{array}{c}\text { Pressões médias } \\
\text { indicadas do ciclo médio } \\
(\text { bar })\end{array}$ \\
\hline 1300 & 7,42 \\
\hline 2200 & 7,63 \\
\hline 2800 & 7,59 \\
\hline
\end{tabular}

Tabela 6.7 - Pressões médias indicadas calculadss com um ciclo médio de 32 ciclos.

Para confrontar os resultados do sistema de aquisição de dados e do Indiskop, foram adquiridos, durante o mesmo intervalo de tempo em que o motor operava em regime estável de plena carga a nas rotações discriminadas acima, 25 ciclos pelo sistema de aquisição de dados e 32 ciclos pelo Indiskop, sendo que para estes foi habilitada a opção de geração de ciclo médio. Novamente, as demais configurações permaneceram inalteradas para ambos os sistemas (mesma resolução de amostragem de $0,2^{\circ}$, mesmos sinais de clock e trigger, mesmo sinal de pressão oriundo do mesmo transdutor de pressão e amplificador de carga).

As curvas médias gerada pelo Indiskop para cada rotação estão indicadas na Figura 6.15, na Figura 6.16 e na Figura 6.17. Ressalte-se que existe um recurso no Indiskop para filtragem dos sinais, executando uma "média móvel" dos valores adquiridos e indicando na tela um resultado mais regular (smoothed). Isso é necessário para que no cálculo da liberação de calor não ocorram valores demasiadamente altos da derivada da pressão em relação à posição angular, valores esses induzidos pelos ruídos. 
Os resultados de pressão média indicada fornecidos pelo Indiskop e pelo sistema de aquisição podem ser vistos na Tabela 6.8.

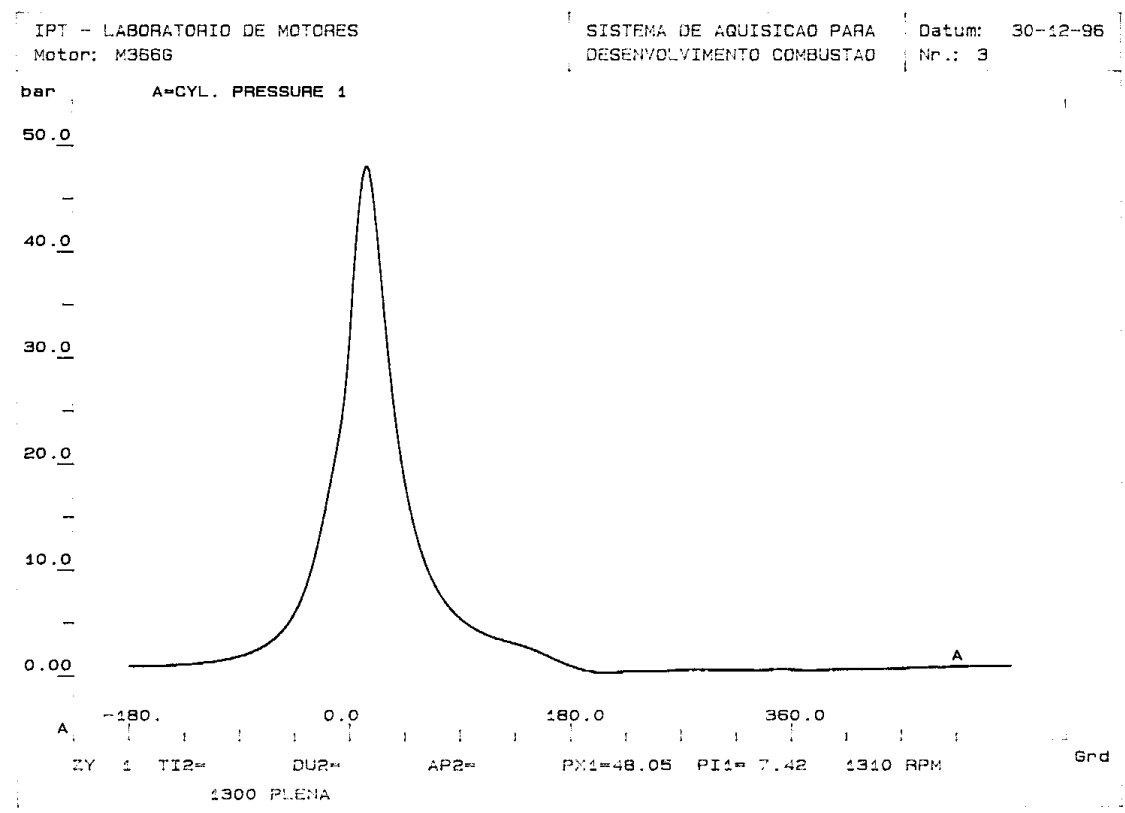

Figura 6.15 - Curva de pressão gerada pelo Indiskop (média de 32 ciclos) a 1300 rpm.

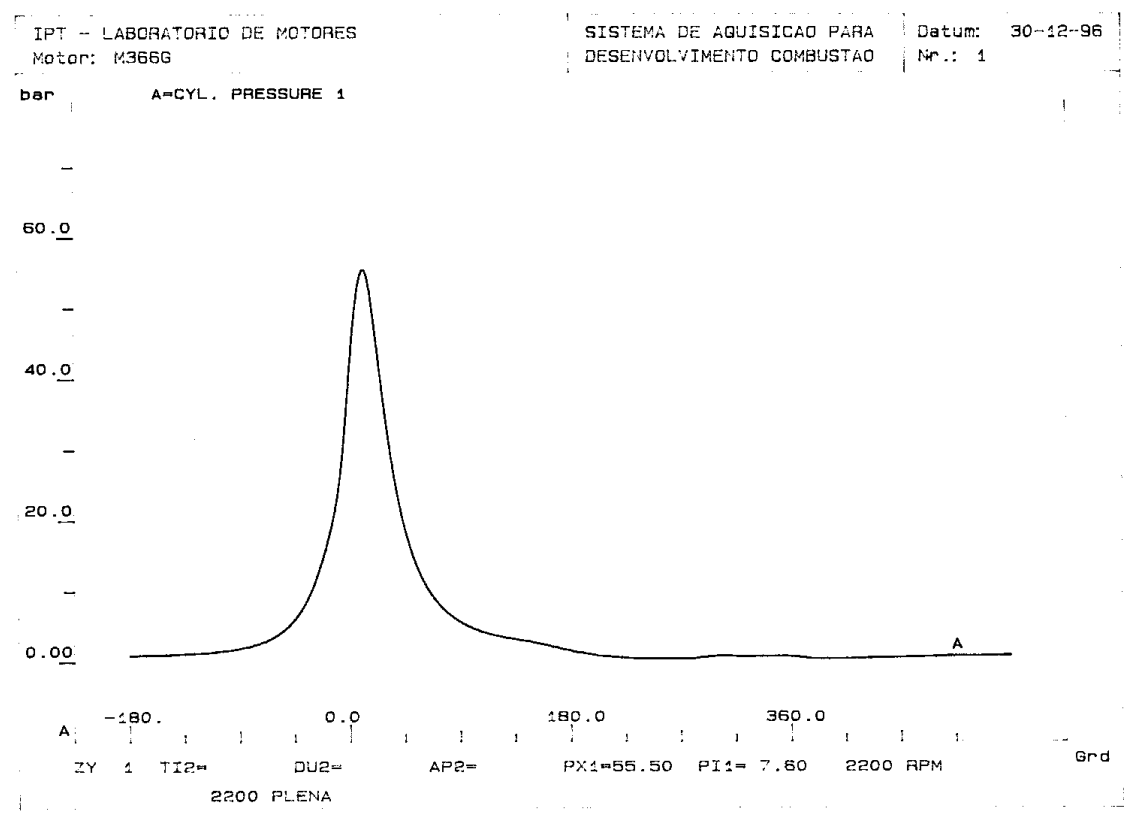

Figura 6.16 - Curva de pressão gerada pelo Indiskop (média de 32 ciclos) a $2200 \mathrm{rpm}$. 


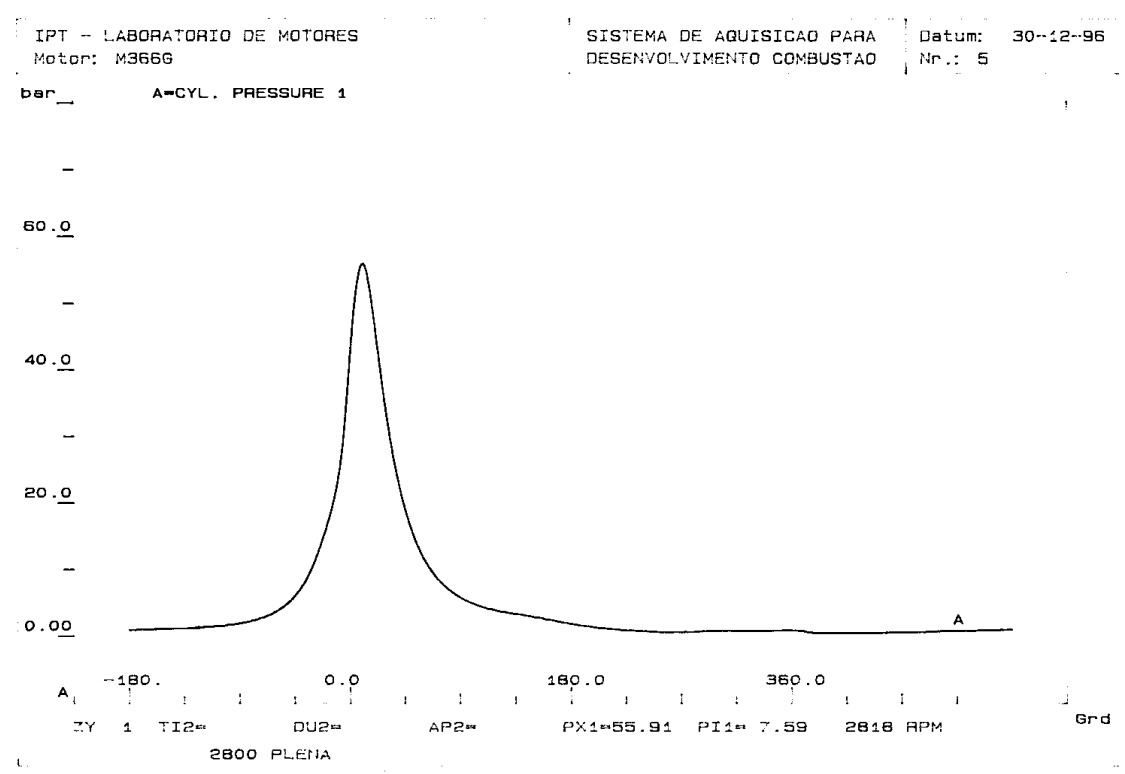

Figura 6.17 - Curva de pressão gerada pelo Indiskop (média de 32 ciclos) a $2800 \mathrm{rpm}$.

\begin{tabular}{|c|c|c|c|c|c|c|c|c|c|c|}
\hline \multirow[t]{2}{*}{$\begin{array}{r}\text { rotação } \\
(\mathrm{rpm}) \\
\end{array}$} & \multicolumn{5}{|c|}{$\begin{array}{c}\text { pressão média } \\
\text { indicada Indiskop } \\
(\text { bar })\end{array}$} & \multicolumn{5}{|c|}{$\begin{array}{c}\text { pressão média } \\
\text { indicada sist. aquis. } \\
(\text { bar })\end{array}$} \\
\hline & média & desvio padrão & no ciclos & $\begin{array}{c}\text { intervalo de } \\
\text { confiança } \\
(p / 95 \%)\end{array}$ & resultado & média & desvio padrão & no ciclos & $\begin{array}{c}\text { intervalo de } \\
\text { confiança } \\
(\mathrm{p} / 95 \%)\end{array}$ & resultado \\
\hline 1300 & 7,43 & 0,08 & 32 & 0,03 & $7,40-7,46$ & 7,49 & 0,08 & 25 & 0,03 & $7,46-7,52$ \\
\hline 2200 & 7,63 & 0,10 & 32 & 0,04 & $7,59-7,67$ & 7,66 & 0,10 & 24 & 0,04 & $7,62-7,70$ \\
\hline 2800 & 7,59 & 0,09 & 32 & 0,03 & $7,56-7,62$ & 7,6 & 0,08 & 23 & 0,03 & $7,57-7,63$ \\
\hline
\end{tabular}

Tabela 6.8 - Pressões médias indicadas.

A comparação entre os valores médios fornecidos pelo sistema de aquisição de dados e pelo Indiskop, considerando-se os intervalos de confiança para uma probabilidade de $95 \%$, indica que a aquisição de dados do sistema implantado fornece resultados confiáveis.

\subsection{Dados coletados}

Uma vez tendo sido o sistema de aquisição de pressão calibrado e testado, vários ensaios foram realizados com o motor M 366 G para verificar o efeito da variação da composição do gás combustível na combustão, no nível de emissões e no funcionamento global do motor. 
$\mathrm{Na}$ fase de ensaios do projeto de pesquisa temático mencionado no começo do subcapítulo 6.1 Instalações e motor utilizados, pressões da câmara de combustão foram medidas em algumas condições específicas a fim de que se pudesse analisar o impacto da alteração do combustível na liberação de calor. A seguir é relatado o procedimento utilizado nos ensaios realizados para desenvolvimento do projeto temático.

Os ensaios com gases de diferentes composições compreendiam três fases: levantamento da curva de desempenho do motor regulado conforme a especificação do fabricante; ensaio de emissões baseado na norma ABNT NBR10813 - "Determinação da emissão do gás de escapamento emitido por motor Diesel" ${ }^{, 25]}$ (ensaio de treze modos); e ensaio para determinação da margem de avanço para a detonação.

A avaliação do nível de emissões do referido motor era baseada em uma norma de ensaio de emissões para motor Diesel em virtude de ainda não existir norma brasileira para motores a gás natural à época. Entretanto, os coeficientes de conversão das concentrações dos gases em base seca para base úmida foram modificados, levando-se em consideração a estequiometria do gás natural de composição mais freqüente em São Paulo.

O procedimento de ensaio utilizado para cada uma das diferentes composições era o seguinte:

- levantava-se a curva de desempenho do motor à pleno acelerador, iniciando-se pela rotação máxima e determinando-se também a rotação de torque máximo;

- utilizando-se os valores medidos de torque à plena carga a 2800 e 1680 rpm como referência, calculavam-se os pontos para o ensaio de emissões.

- realizava-se o ensaio conforme a norma NBR10813 (treze modos), adquirindo-se as curvas de pressão de combustão, conforme comentado a seguir, no sexto, oitavo e 
décimo pontos, correspondendo aos regimes de $1680 \mathrm{rpm}$ plena carga, $2800 \mathrm{rpm}$ e plena carga (potência máxima) e $2800 \mathrm{rpm}$ com meia carga $\left(6^{\circ}, 8^{\underline{o}}\right.$ e $10^{\circ}$ pontos $)$. Em cada condição de operação foram medidas, além das grandezas usuais (torque, rotação, 7 temperaturas e 5 pressões), a vazão em massa do combustível utilizandose um medidor tipo Coriolis, a vazão de ar de admissão com um medidor tipo Roots, e a emissão de THC, NMHC, $\mathrm{CO}$, e $\mathrm{NO}_{\mathrm{x}}$.

- terminado o ensaio de emissões, eram desligados os sistemas de condicionamento do ar de admissão e de ventilação da sala de dinamômetro, e forçava-se o motor a aspirar o ar da sala. Mantendo-se o motor à plena potência, aguardava-se a elevação da temperatura do ar de admissão até $35^{\circ} \mathrm{C}$, e da sala até cerca de $50^{\circ} \mathrm{C}$. Observavase continuamente o traço da curva de pressão na tela do osciloscópio (acoplado paralelamente ao sistema de aquisição de pressão), atrasando-se a ignição do motor, se necessário, de modo a evitar a ocorrência de detonação;

- determinava-se o ângulo de avanço de ignição para ocorrência de detonação incipiente, conforme o traço da curva de pressão de combustão visto na tela do osciloscópio;

As aquisições de pressão eram efetuadas com o motor em regime estável de operação em cada condição. Foram coletados valores de pressão de 25 ciclos completos com uma resolução de $0,2^{\circ}$ de virabrequim. A partir destas curvas individuais, foram geradas curvas médias de pressão de forma a reduzir a influência das variações de pressão ciclo-a-ciclo na análise de liberação de calor.

Do conjunto de ensaios realizados, foram selecionados aqueles nos quais os combustíveis utilizados apresentaram o mínimo e máximo número de Wobbe (parâmetro relacionado ao poder calorífico do combustível em base volumétrica) para ilustrar a 
aplicação do sistema de análise de combustão desenvolvido. Os valores coletados durante os ensaios (consumo de ar e combustível, potência e torque observados, emissões específicas) correspondentes são apresentados no Apêndice B. 


\section{RESULTADOS DA ANÁLISE DA COMBUSTÃ̃}

Antes que se passasse a analisar os dados coletados, uma verificação funcional do programa foi feita a fim de que se constatasse a consistência do modelo e a não ocorrência de erros de lógica e/ou numéricos. Esta verificação foi feita da seguinte forma: simulou-se uma condição de operação do motor M 366 G utilizando-se o simulador de POULOS e HEYWOOD, comentado na revisão bibliográfica. Este é um simulador quasi-dimensional de duas zonas e que também leva em consideração a interação da frente de chama com as paredes da câmara. A curva de pressão gerada pelo simulador, bem como todos os parâmetros pertinentes como consumo de ar e combustível e fração de gases residuais se transformaram em dados de entrada do programa de análise da combustão, sendo então os resultados fornecidos por este último comparados com aqueles do simulador. Este procedimento, pelo fato de não envolver erros devidos à medição de pressão, verifica de fato a consistência do modelo independentemente do processo de medição de pressão.

A partir da curva de pressão gerada pelo simulador também foram feitos estudos de sensibilidade relativos à posição angular de referência da curva de pressão, ao valor de pressão do início do ciclo, ao efeito da dissociação química dos produtos da combustão, efeitos de frestas, blow-by, e temperatura das paredes.

Após esta verificação, passou-se então a analisar alguns dados coletados em bancada dinamométrica para demostrar a aplicabilidade do sistema de análise.

\subsection{Verificação do programa contra um simulador}

Utilizando-se o simulador de POULOS e HEYWOOD, foi simulada uma 
condição de operação, ajustando-se os parâmetros de seu modelo de turbulência, de forma a tentar reproduzir a curva de pressão que foi de fato medida na bancada. A Tabela 7.1 traz os valores das grandezas que foram medidas no motor e que também foram dados de entrada para o simulador:

\begin{tabular}{|l|l|l|}
\hline rotação & 2800 & $\mathrm{rpm}$ \\
\hline pressão no coletor de admissão & 0,8619 & $\mathrm{bar}$ \\
\hline pressão no coletor de escapamento & 0,9102 & $\mathrm{bar}$ \\
\hline razão de equivalência & 0,7833 & \\
\hline temperatura da mistura fresca admitida & 302 & $\mathrm{~K}$ \\
\hline umidade absoluta do ar de admissão & 0,012 & $\begin{array}{l}\mathrm{kg} \text { vapor d'água / } \\
\mathrm{kg} \text { ar seco }\end{array}$ \\
\hline avanço de ignição & 24,5 & ${ }^{\circ} \mathrm{APMS}$ \\
\hline
\end{tabular}

Tabela 7.1 - Dados medidos em bancada dinamométrica.

Esta condição representava a máxima potência do motor. O combustível utilizado nesta condição era basicamente metano. A sua composição mais detalhada está apresentada na Tabela 7.2.

\begin{tabular}{|c|c|}
\hline espécie & fração volumétrica \\
\hline $\mathrm{CH}_{4}$ & $98,0 \%$ \\
\hline $\mathrm{C}_{2} \mathrm{H}_{6}$ & $0,1 \%$ \\
\hline $\mathrm{C}_{3} \mathrm{H}_{8}$ & $0,1 \%$ \\
\hline $\mathrm{C}_{4} \mathrm{H}_{10}$ e superiores & $0,1 \%$ \\
\hline $\mathrm{CO}_{2}$ & $0,0 \%$ \\
\hline $\mathrm{N}_{2}$ & $1,7 \%$ \\
\hline $\mathrm{H}_{2}$ & $0,0 \%$ \\
\hline
\end{tabular}

Tabela 7.2 - Composição do combustível utilizado.

Para esta condição, estimaram-se as temperaturas médias para as paredes da câmara, com base em dados fornecidos pelo fabricante de pistões. Estas temperaturas estão relacionadas na Tabela 7.3.

A Figura 7.1 traz as curvas de pressão na câmara simulada e medida, entendendose por curva medida a curva média de 25 ciclos adquiridos. 


\begin{tabular}{|c|c|}
\hline parede & temperatura $(K)$ \\
\hline topo do pistão & 520 \\
\hline cilindro & 460 \\
\hline cabeçote & 420 \\
\hline
\end{tabular}

Tabela 7.3 - Temperaturas das paredes da câmara em regime de potência máxima.

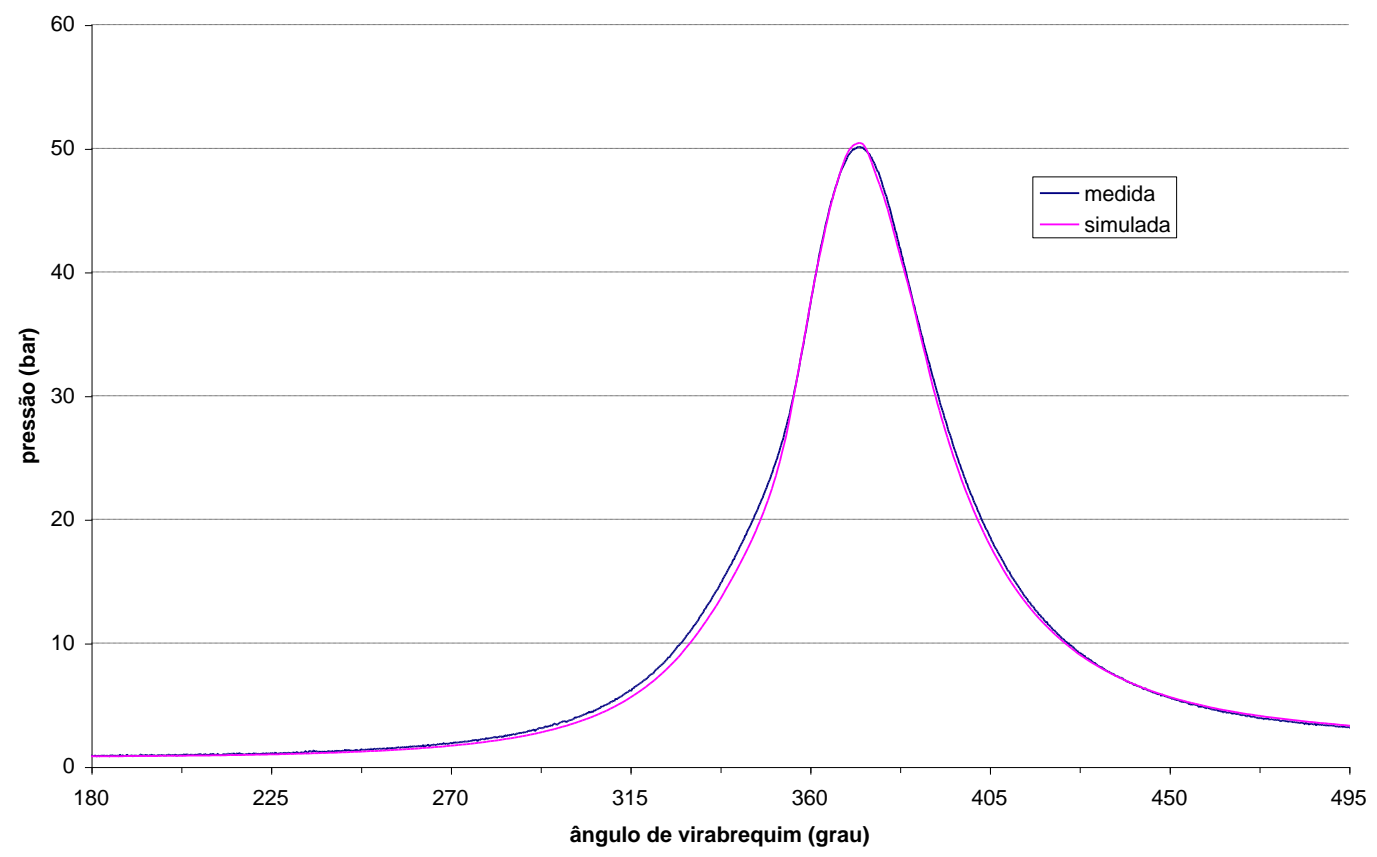

Figura 7.1 - Curvas de pressão medida e simulada.

A Tabela 7.4 traz os valores de consumo obtidos da simulação para esta condição de funcionamento. Estes valores foram então fornecidos ao programa de análise de combustão, juntamente com o mapa da geometria da câmara construído e utilizado na simulação. Não foram considerados nesta análise o volume das frestas e vazamento para o cárter, uma vez que o simulador não contempla estes efeitos. Uma observação: como o simulador não fornecia pontos igualmente espaçados na curva de pressão, um interpolação por splines cúbicos de $0,2^{\circ}$ de virabrequim foi aplicada à curva gerada pelo simulador para só depois passá-la ao programa de análise da combustão. 


\begin{tabular}{|l|c|c|}
\hline consumo de combustível & 0,036 & $\mathrm{~g} /$ ciclo \\
\hline consumo de ar seco & 0,765 & $\mathrm{~g} /$ ciclo \\
\hline consumo de vapor de água & 0,0095 & $\mathrm{~g} /$ ciclo \\
\hline fração molar de gases residuais & 0,048 & \\
\hline
\end{tabular}

Tabela 7.4 - Valores de consumos resultantes da simulação.

A Figura 7.2 traz então a comparação entre a fração de massa queimada gerada pelo simulador e a calculada pelo programa de análise. Note-se que há, de maneira geral, uma boa aderência entre as curvas.

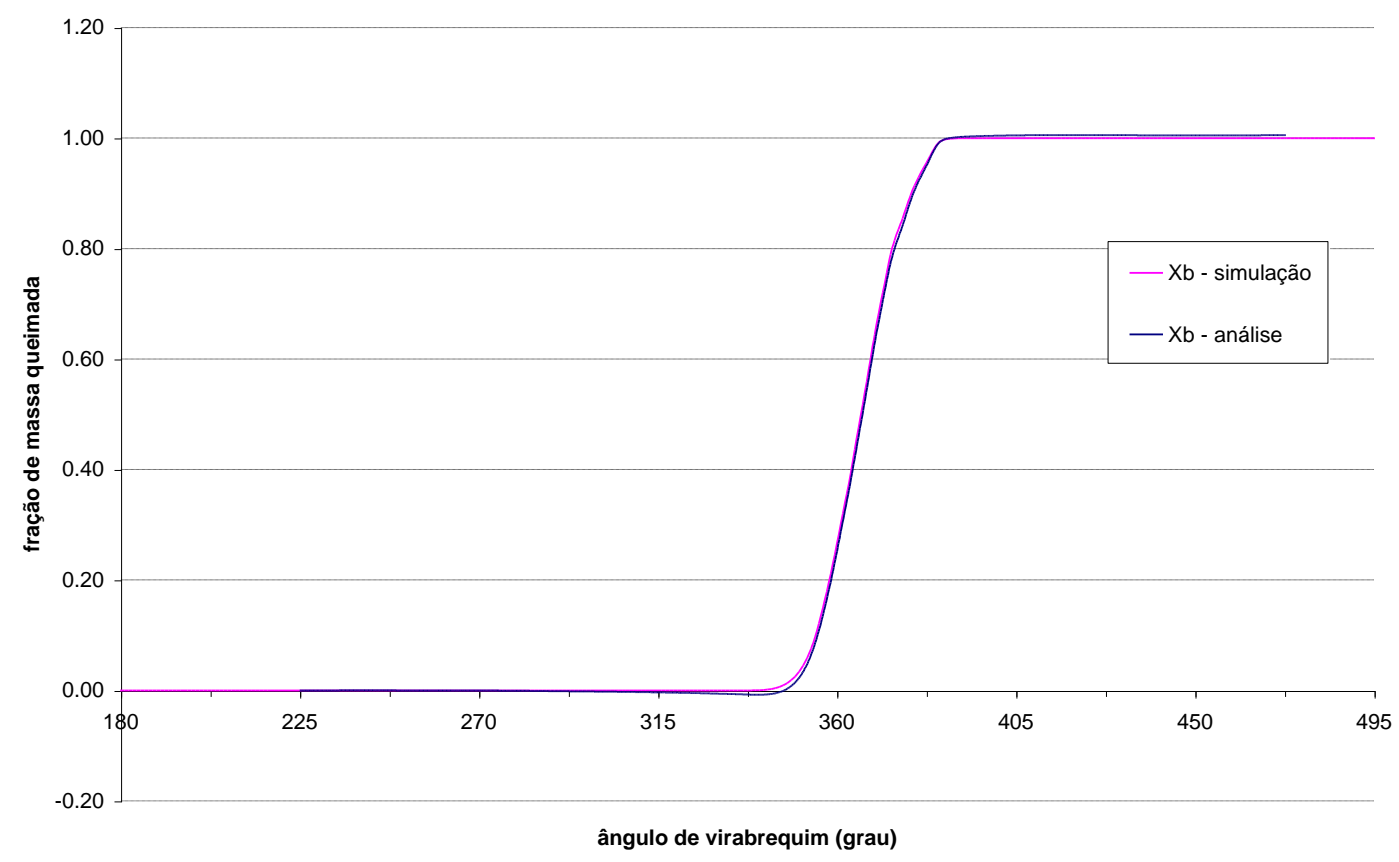

Figura 7.2 - Curvas de fração de massa queimada.

Excertos mais detalhados desta curva na região da combustão, como na Figura 7.3 e na Figura 7.4, mostram que há fração de massa queimada negativa em torno de $0,8 \%$ antes do início da combustão e acima da unidade em $0,5 \%$ finda a queima. Estas pequenas discrepâncias podem ser explicadas pelos diferentes modelos de troca de calor empregados no simulador e no presente trabalho. 


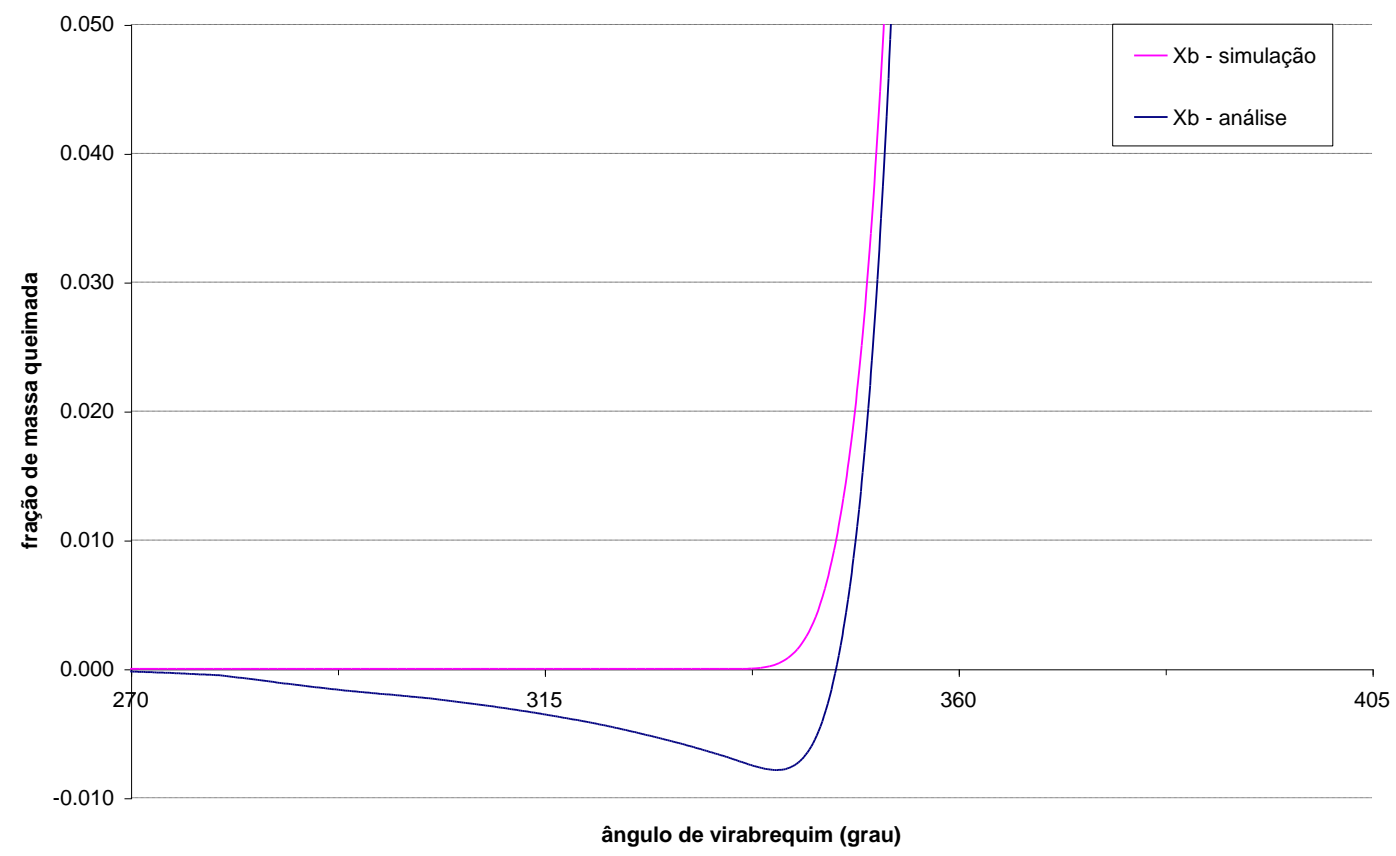

Figura 7.3 - Fração de massa queimada anterior ao início da combustão.

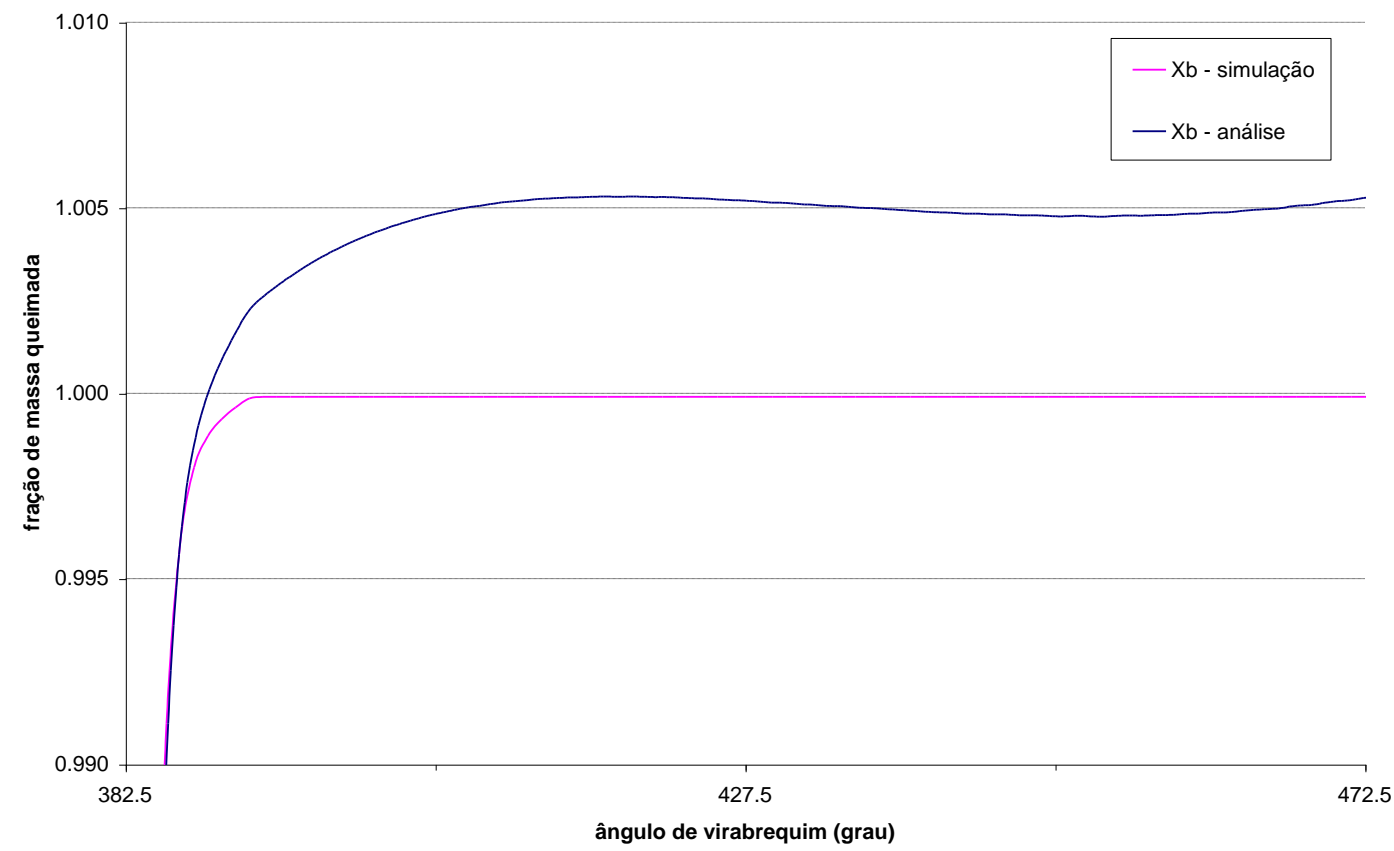

Figura 7.4 - Fração de massa queimada próximo ao final da combustão.

O simulador, embora utilize também uma relação do tipo $N u=C \cdot R e^{m}$, emprega como comprimento característico a macroescala de turbulência e a velocidade característica está baseada na soma das velocidades do campo médio e turbulento, como 
comentado no capítulo da revisão bibliográfica. No presente trabalho, utiliza-se a formulação de WOSCHNI diretamente, onde o comprimento característico é o diâmetro do cilindro e a velocidade característica é baseada na velocidade do pistão aliada a um termo devido à combustão. Estas diferenças se traduzem nos valores do coeficiente de película calculados em cada caso, como mostra a Figura 7.5.

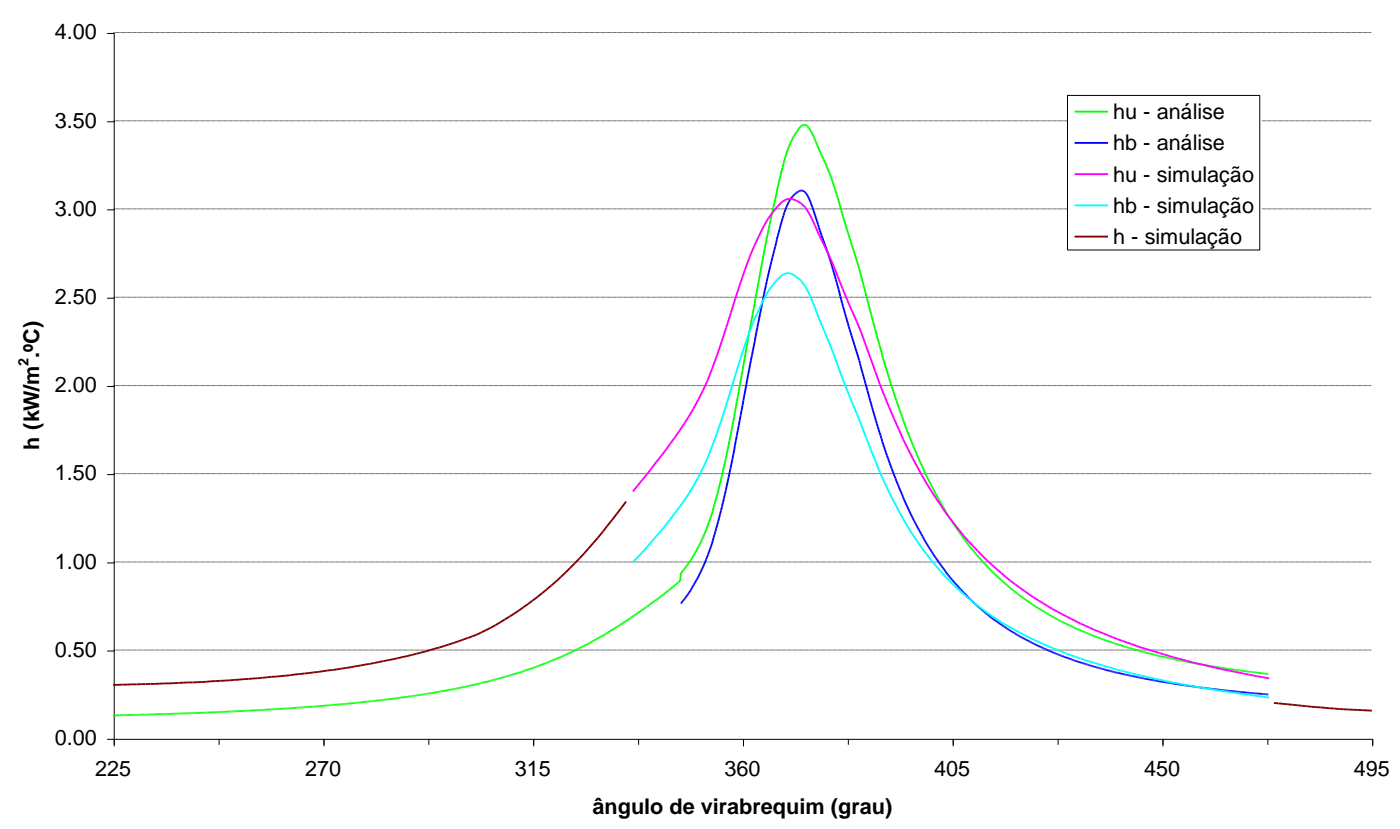

Figura 7.5 - Valores de $h$ calculados pelo simulador e pelo programa de análise.

Vê-se que, na região que vai desde o fechamento da válvula de admissão $\left(225^{\circ}\right)$ até próximo do PMS, o programa de análise da combustão está subestimando o valor do coeficiente de película em relação ao calculado pelo simulador. Deste ponto até próximo de $400^{\circ}$, o valor de $h$ dado pelo programa de análise suplanta aquele fornecido pelo simulador em ambas as regiões. Daí até a abertura da válvula de escapamento $\left(473^{\circ}\right)$, os valores de $h$ se tornam muito próximos. Estas diferenças explicam a alteração causada na curva de fração de massa queimada, uma vez que a maior perda de calor calculada pelo simulador durante o tempo de compressão é vista pelo analisador como uma fração negativa de massa queimada. Entretanto, observa-se que o impacto dessas diferenças de 
troca de calor na precisão geral do simulador é pequena, já que as diferenças entre as temperaturas de cada uma das zonas calculadas pelos dois programas não são maiores do que $25 K$ para a região dos gases não queimados e $10 K$ para a região dos gases queimados, como mostra a Figura 7.6.

É importante ressaltar que a simulação subestimou o valor de pressão em relação à pressão medida, conforme pode ser visto na Figura 7.1, justamente na região onde o valor do coeficiente de película está maior do que aquele calculado pelo programa de análise da combustão - um forte indício de que o simulador está de fato superestimando a troca de calor nesta região.

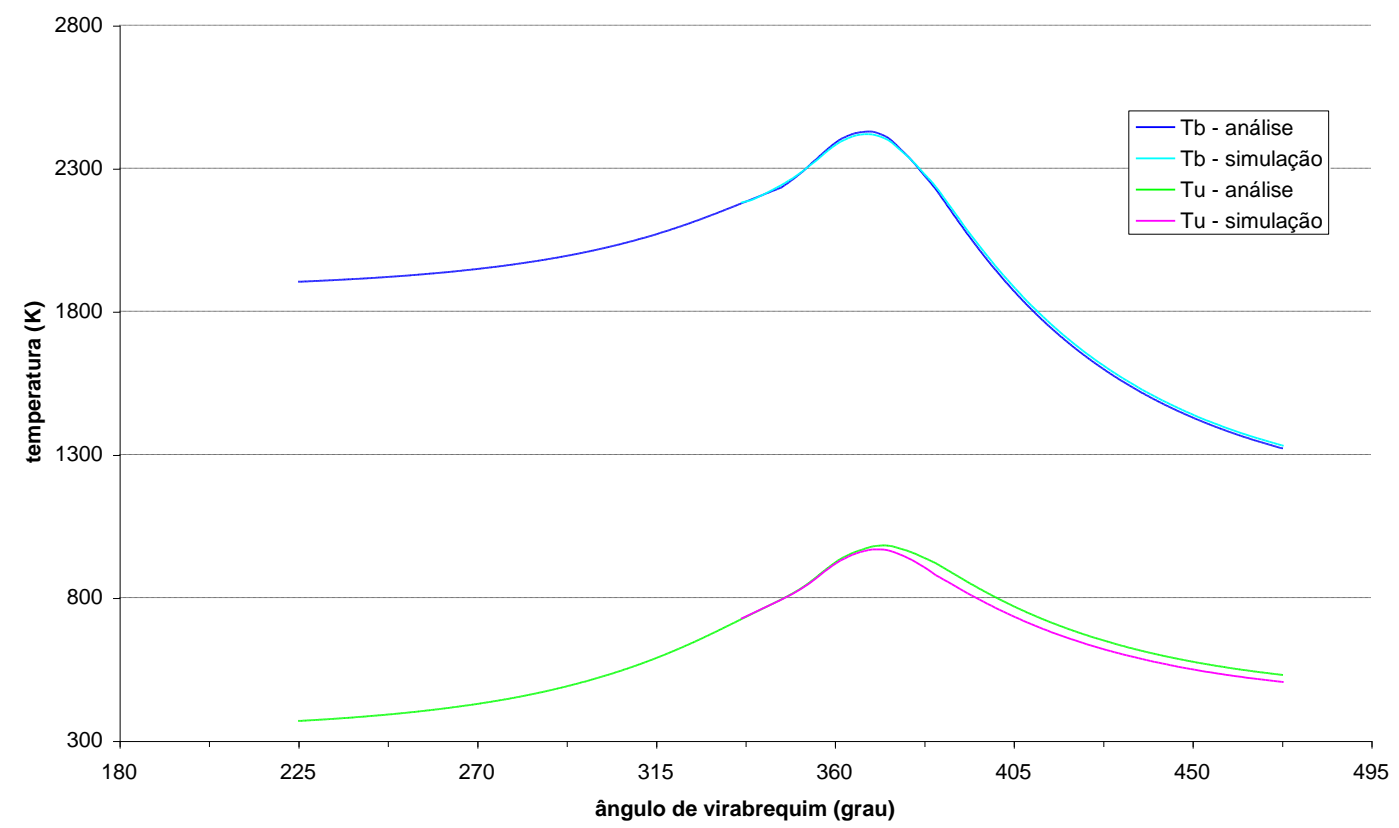

Figura 7.6 - Temperaturas das zonas calculadas pelo simulador e pelo programa de análise.

Uma outra observação: optou-se por permitir que tanto a fração de massa queimada quanto a fração de massa dos gases não queimados se tornassem maior do que a unidade e menor do que zero respectivamente durante a execução do programa por serem estas ocorrências um forte indicador da obtenção do balanço de energia. Assim, se 
a massa dos queimados cai abaixo de zero antes do início da combustão tem-se uma indicação de que as quantidades de energia sob a forma de trabalho, energia interna e troca de calor não são suficientes para que o balanço de energia se estabeleça, sendo necessário que uma "queima negativa" ocorra. Da mesma forma uma fração de massa queimada maior que a unidade indica que é necessário que a massa queimada seja maior que a massa inicial do ciclo para que o balanço de energia seja estabelecido.

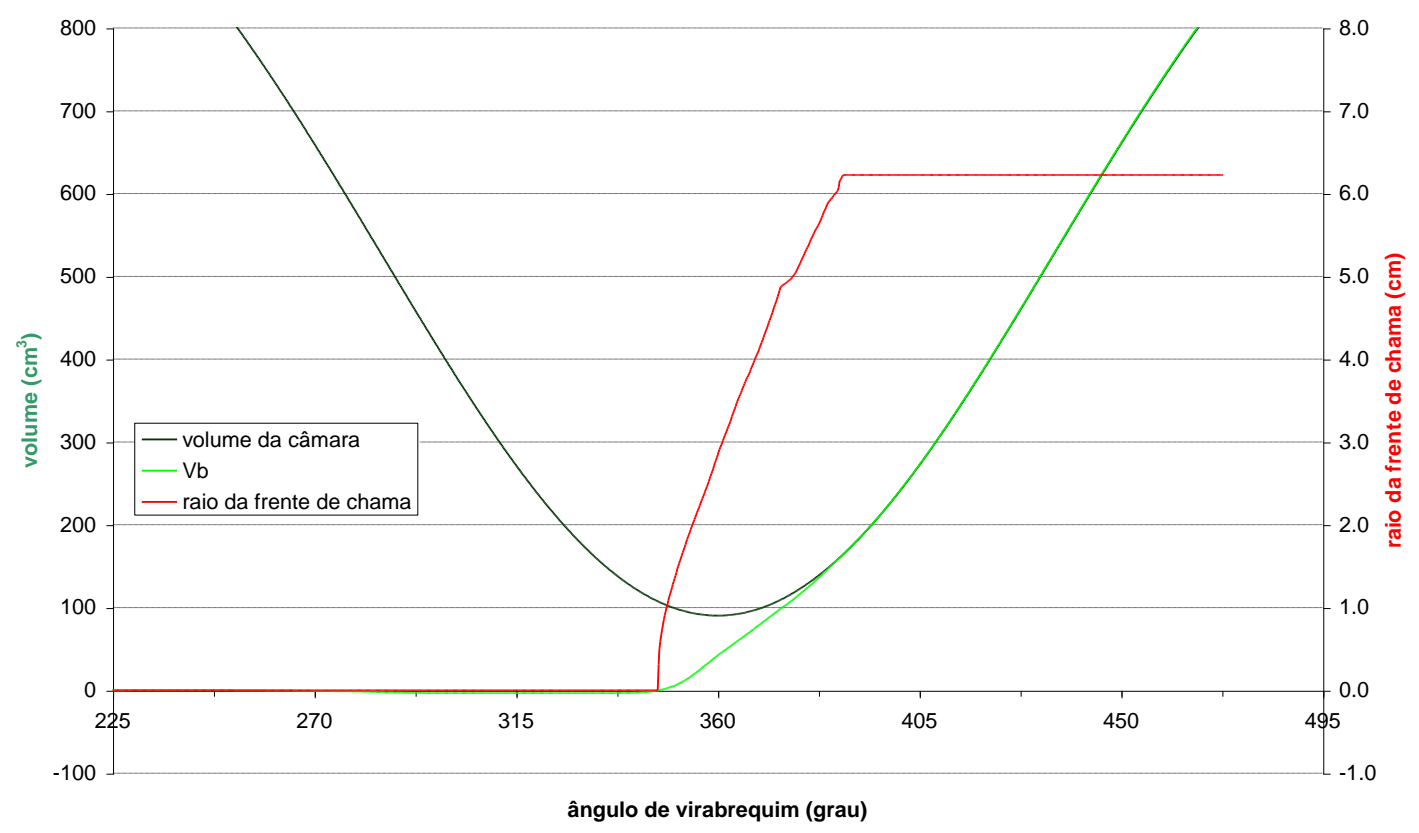

Figura 7.7 - Evolução da frente de chama.

Complementando a exposição de resultados para este caso, a Figura 7.7 traz a evolução da frente de chama, com seu raio e o volume contido em seu interior em função da posição angular do virabrequim, juntamente com o volume total da câmara em cada instante. Um detalhamento da região de combustão é dado pela Figura 7.8. As pequenas perturbações observadas na curva de evolução do raio da frente de chama são devidas a variações abruptas na superfície dessa frente em função da geometria da câmara de combustão. 


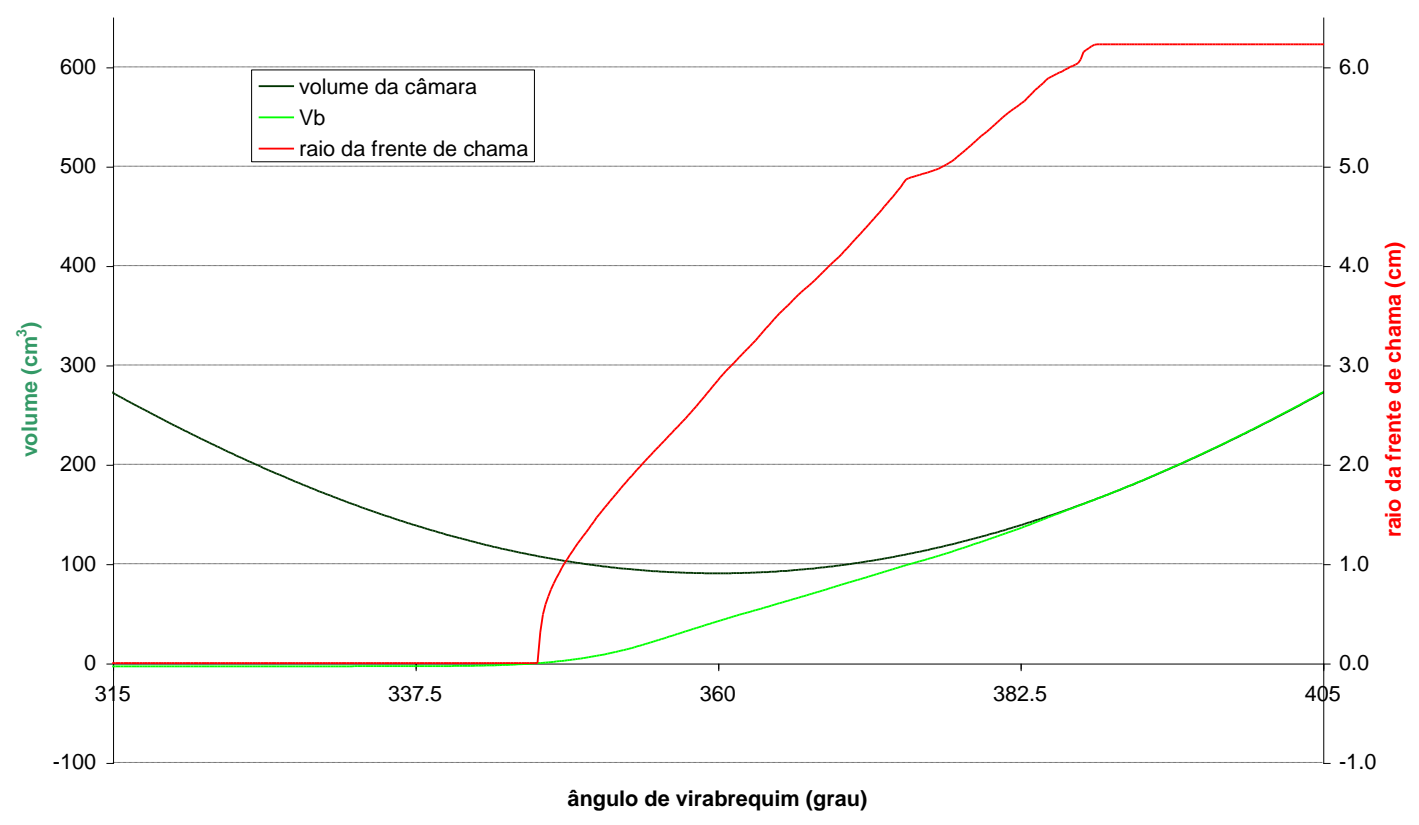

Figura 7.8 - Detalhamento Figura 7.7 na região de combustão.

Para apreciar melhor o balanço energético que ocorre durante a combustão, foi construída a Figura 7.9 que traz as curvas de trabalho líquido e calor total trocado com as paredes da câmara desde o fechamento da válvula de admissão. Adicionalmente, mostra-se a variação de energia interna calculada como se os gases não queimados passassem para a região dos queimados porém sem que ocorresse a combustão (ciclo ar - combustível). Isto é feito pois, em termos rigorosos, não haveria sentido em se falar em liberação de calor para modelos de duas zonas, uma vez que a energia "liberada" pela combustão já está implícita no cálculo das energias internas dos VC. Então, para que se possam comparar os resultados oriundos de modelos de uma só zona com aqueles obtidos através do modelo aqui empregado, uma curva equivalente de liberação de calor é calculada. Para tanto, toma-se agora a câmara toda como um só volume de controle sem variação de composição (ou seja, sem combustão) e se aplica a $1^{\underline{a}}$ Lei:

$$
\left.Q\right|_{1} ^{2}=\left.\Delta E\right|_{1} ^{2}+\left.\sum \dot{m}_{i} \cdot h_{i}\right|_{1} ^{2}+\left.W\right|_{1} ^{2}
$$


onde:

$\left.Q\right|_{1} ^{2}$ : calor total adicionado ao volume de controle desde o estado 1 até o estado 2;

$\left.\Delta E\right|_{1} ^{2}$ : variação da energia interna do volume de controle desde o estado 1 até o estado 2 (desprezam-se as variações de energia cinética e potencial);

$\left.\sum \dot{m}_{i} \cdot h_{i}\right|_{1} ^{2}$ : somatória dos fluxos de entalpia que deixam o volume de controle desde o estado 1 até o estado 2;

$\left.W\right|_{1} ^{2}$ : trabalho realizado pelo volume de controle desde o estado 1 até o estado 2.

A troca de calor total é entendida, neste caso, como a soma do calor trocado com as paredes a uma parcela adicionada "externamente" que refletiria a quantidade de energia liberada pela combustão. Assim, a Eq. 7-1 pode ser reescrita como:

$$
\left.Q_{r e l}\right|_{1} ^{2}=\left.\Delta E\right|_{1} ^{2}+\left.\sum \dot{m}_{i} \cdot h_{i}\right|_{1} ^{2}+\left.W\right|_{1} ^{2}-\left.Q_{w}\right|_{1} ^{2}
$$

com $\left.Q_{\text {rel }}\right|_{1} ^{2}$ representando a quantidade de energia que deveria ser adicionada ao volume de controle (sem combustão) para que as mesmas temperaturas em cada uma das zonas fossem atingidas, o mesmo trabalho fosse realizado e a mesma troca de calor com as paredes $\left.Q_{w}\right|_{1} ^{2}$ ocorresse. Assim, a curva cor-de-rosa $\left(Q_{r e l}\right)$ na Figura 7.9, é a soma das curvas que representam o trabalho, o calor trocado com as paredes e a variação de energia interna dos gases sem combustão (não há fluxos de entalpia saindo da câmara neste caso).

Ainda na Figura 7.9 são apresentadas as curvas que representam a fração de combustível queimada multiplicada pelo seu poder calorífico inferior (Mcomb* $\left.\mathrm{Xb}^{\star} \mathrm{PCl}\right)$ e a massa total de combustível na câmara multiplicada pelo PCI (McombPCl). Nota-se que há uma grande proximidade entre os valores de liberação de energia calculados via 
variação de energia interna dos gases sem combustão e via poder calorífico inferior, o que explica o motivo de muitos pesquisadores adotarem esta última forma de explicitar a liberação de calor em modelos de duas zonas (HEYWOOD ${ }^{[20]}$ ). A Figura 7.10 mostra melhor a diferença entre as curvas mencionadas, ocasionada principalmente pela ocorrência da dissociação química nos gases queimados.

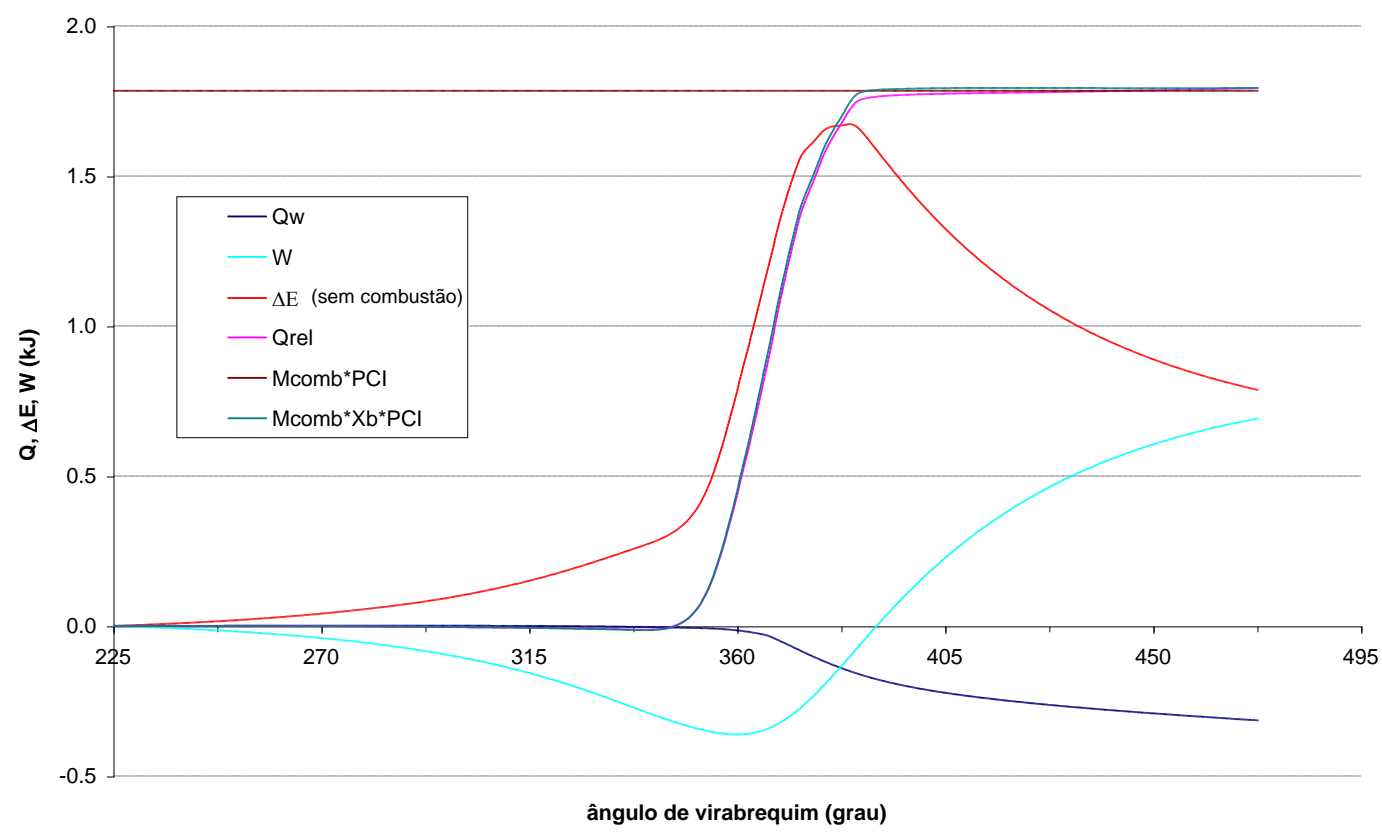

Figura 7.9 - Curvas de trabalho, calor e energia interna.

Um gráfico que traz mais informações a respeito da evolução da combustão é a taxa de liberação de calor. A Figura 7.11 traz a taxa de liberação de calor partindo-se das curvas acumuladas de calor liberado da Figura 7.9. Os pequenos "degraus" que aparecem nas curvas de liberação são causados pelas variações abruptas na curva da derivada da pressão, que também pode ser vista na Figura 7.11. Novamente aqui, pode-se notar que as taxas de liberação de calor calculadas pela variação de energia interna ou pela fração de combustível queimado multiplicada pelo PCI são muito próximas. 


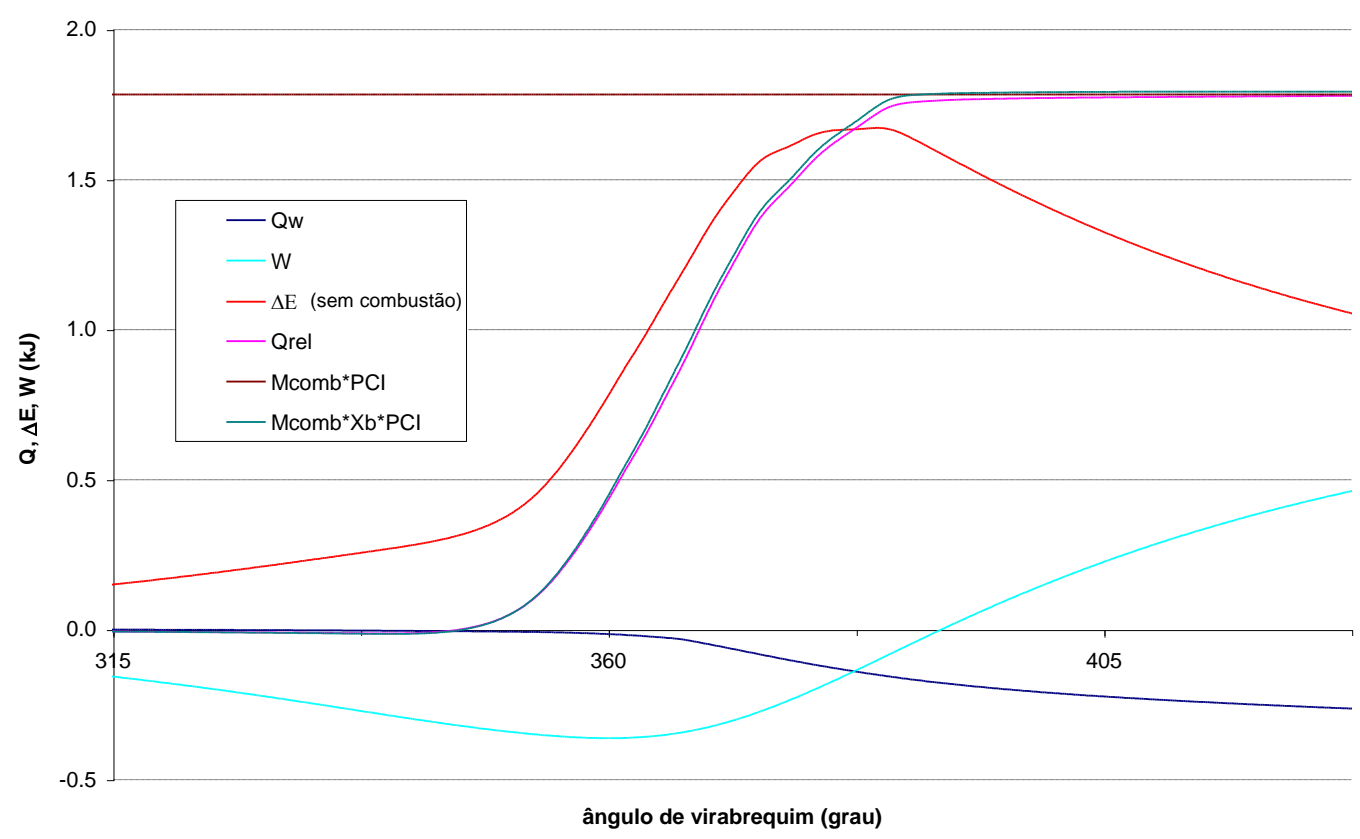

Figura 7.10 - Detalhe da Figura 7.9 na região de combustão.

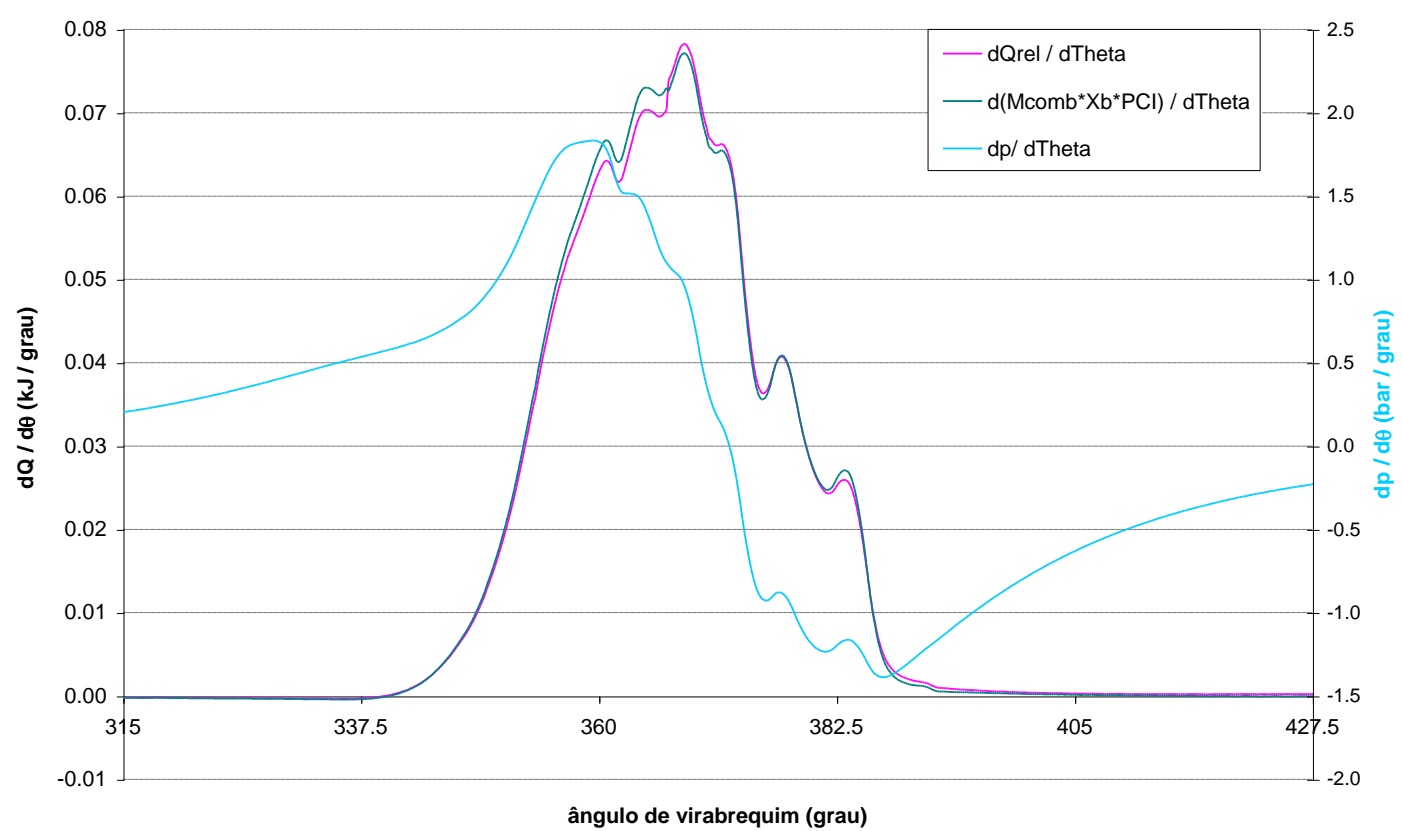

Figura 7.11 - Taxa de liberação de calor e taxa de variação de pressão.

Estas variações abruptas na curva da derivada da pressão são explicadas, por sua vez, pela forma com que o simulador de POULOS calcula a progressão da combustão: seu modelo emprega uma frente de chama de espessura finita onde a combustão se 
processa ("entrainment model"), como comentado na revisão da literatura. Desta forma, o cálculo da progressão da combustão está fortemente ligado à área da frente de chama e qualquer erro numérico resultante do cálculo desta área se reflete diretamente na curva de $\frac{d p}{d \theta}$. Como o código que gera a geometria da câmara o faz de forma discreta, erros numéricos estão presentes e são estes erros ocasionadores dos saltos de pressão na curva simulada.

Perante todos estes resultados, pode-se dizer que o modelo desenvolvido e o programa computacional que o implementa estão fornecendo resultados coerentes.

\subsection{Análise de sensibilidade}

Para que se ganhassem maiores conhecimentos envolvendo a análise acima exposta, um processo de variação de parâmetros foi efetuado a fim de quantificar as suas influências no cálculo da liberação de calor, ainda utilizando a curva de pressão gerada pelo simulador como entrada para o programa de análise da combustão.

O primeiro parâmetro estudado foi a posição de referência da curva de pressão. Para que sua influência fosse realçada, a curva de pressão gerada pelo simulador foi adiantada $0,2^{\circ}$ e $0,5^{\circ}$ em relação à sua posição original. A Figura 7.12 traz a evolução da fração de massa queimada para as curvas de pressão original, adiantada $0,2^{\circ}$ e adiantada $0,5^{\circ}$

Detalhando-se as regiões inicial e final de queima nas curvas da Figura 7.12, conforme pode ser visto na Figura 7.13 e na Figura 7.14, pode-se observar que as defasagens de $0,2^{\circ}$ e $0,5^{\circ}$ ocasionaram variações totais na fração de massa queimada em relação à curva original da ordem de $1,5 \%$ e $2,5 \%$ respectivamente. 


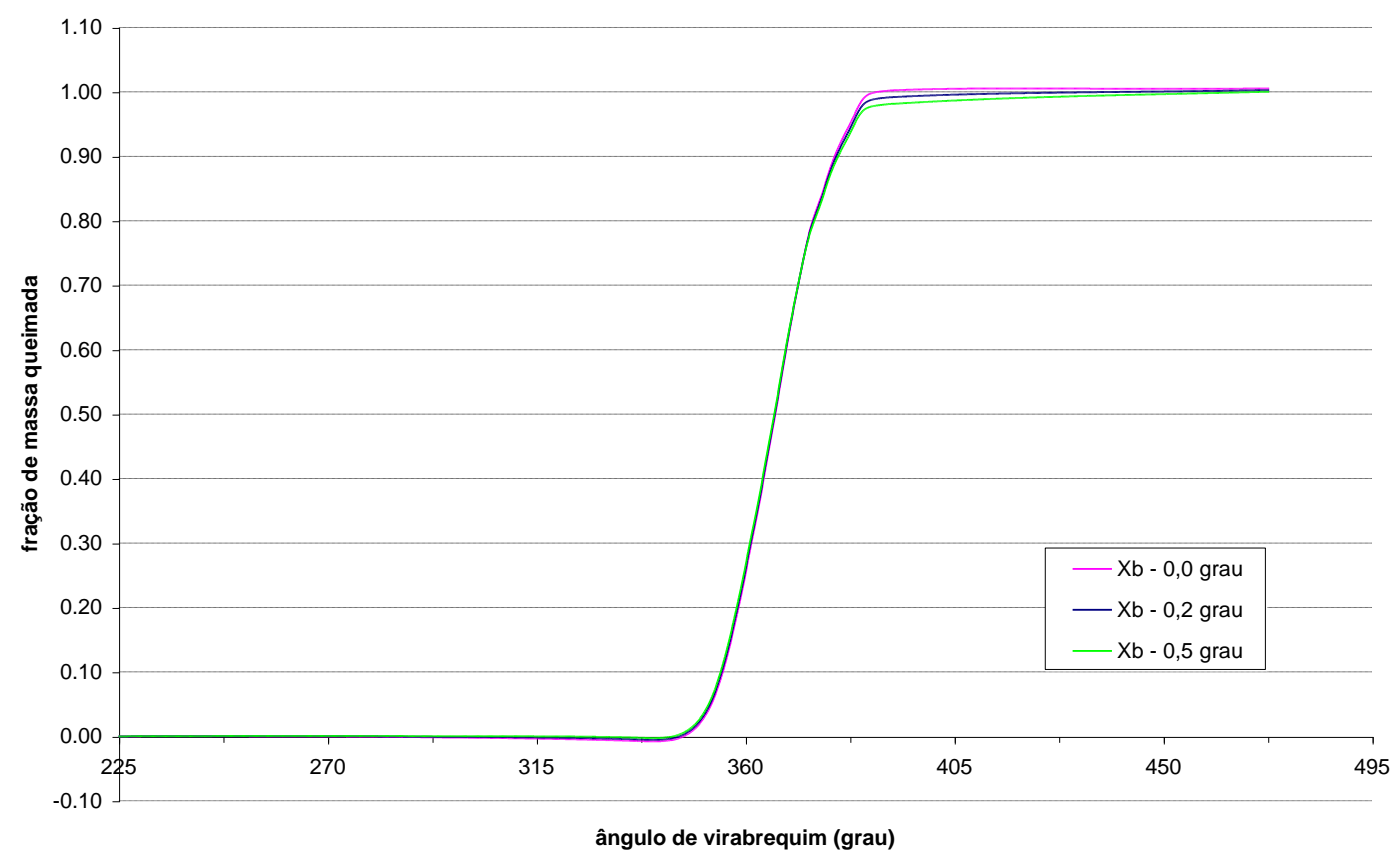

Figura 7.12 - Comparação entre as frações de massa queimada.

As mesmas defasagens de $0,2^{\circ}$ e $0,5^{\circ}$ causam variações de $1,5 \%$ e $2,5 \%$, respectivamente, na liberação total de calor, como mostra a Figura 7.15, bem como também ocasionam uma redução da ordem de 1,3 e 2,7 \% no valor máximo da taxa de liberação de calor em relação à curva de pressão não defasada (Figura 7.16).

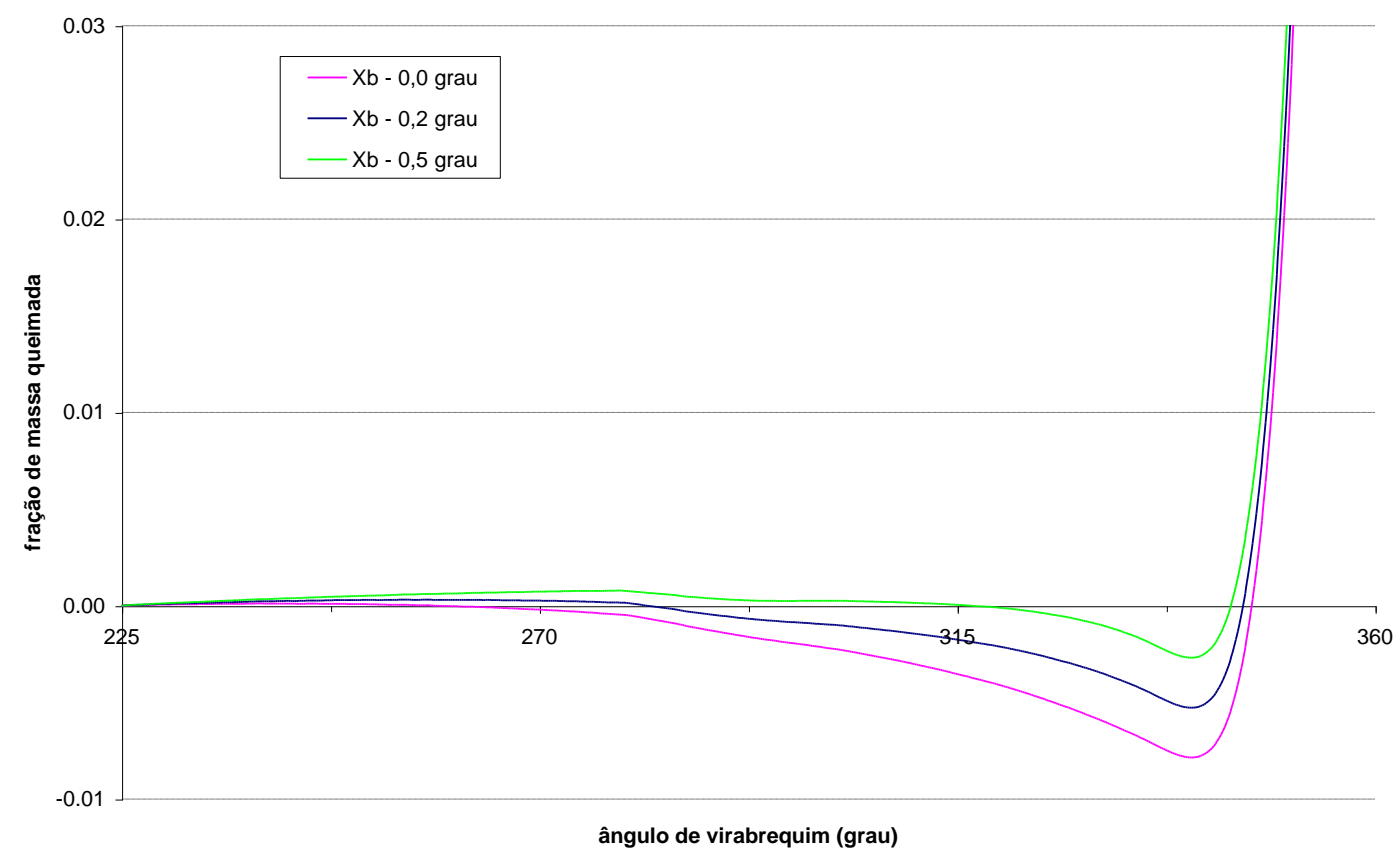

Figura 7.13 - Região inicial de queima da Figura 7.12. 


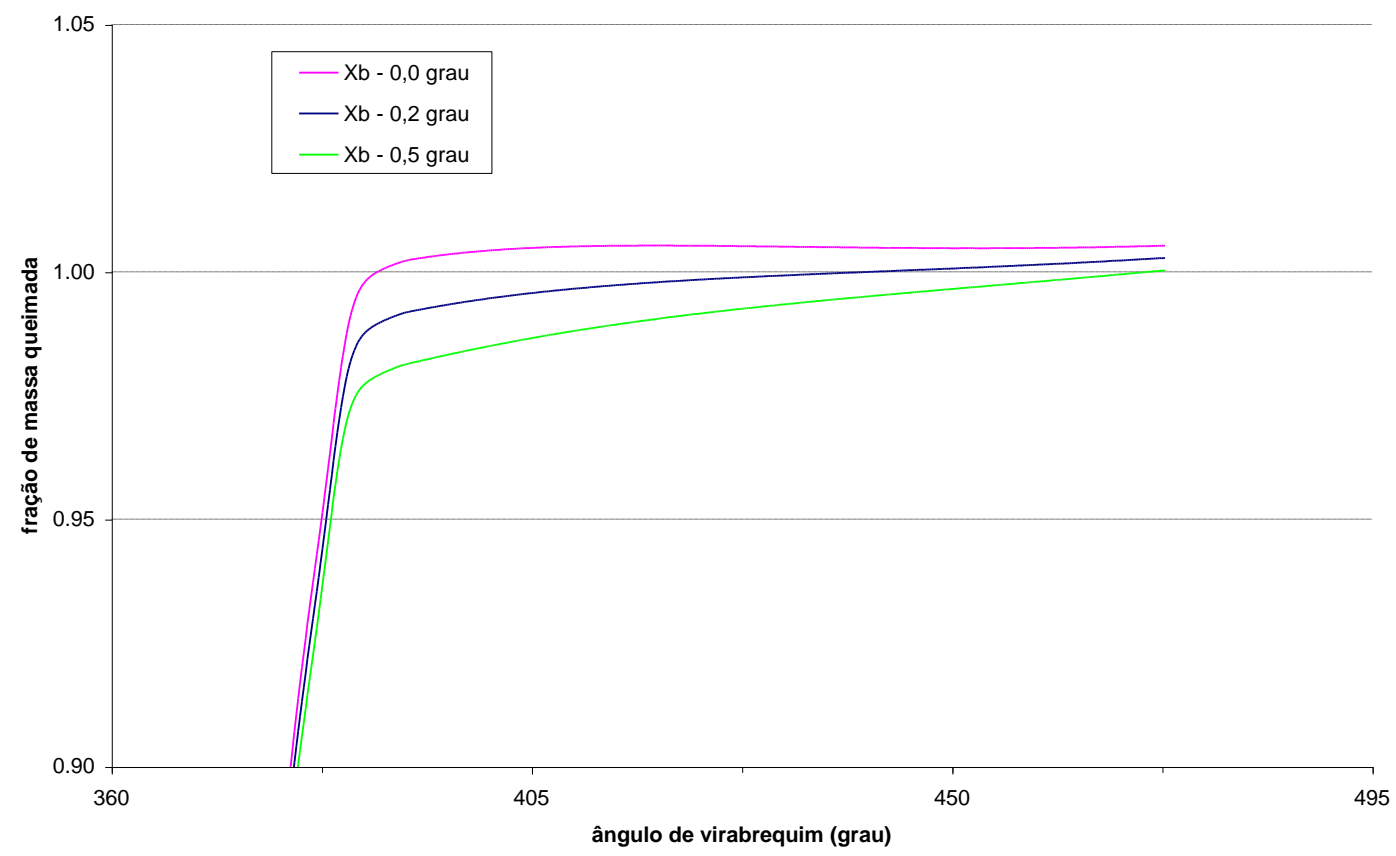

Figura 7.14 - Região final de queima da Figura 7.12

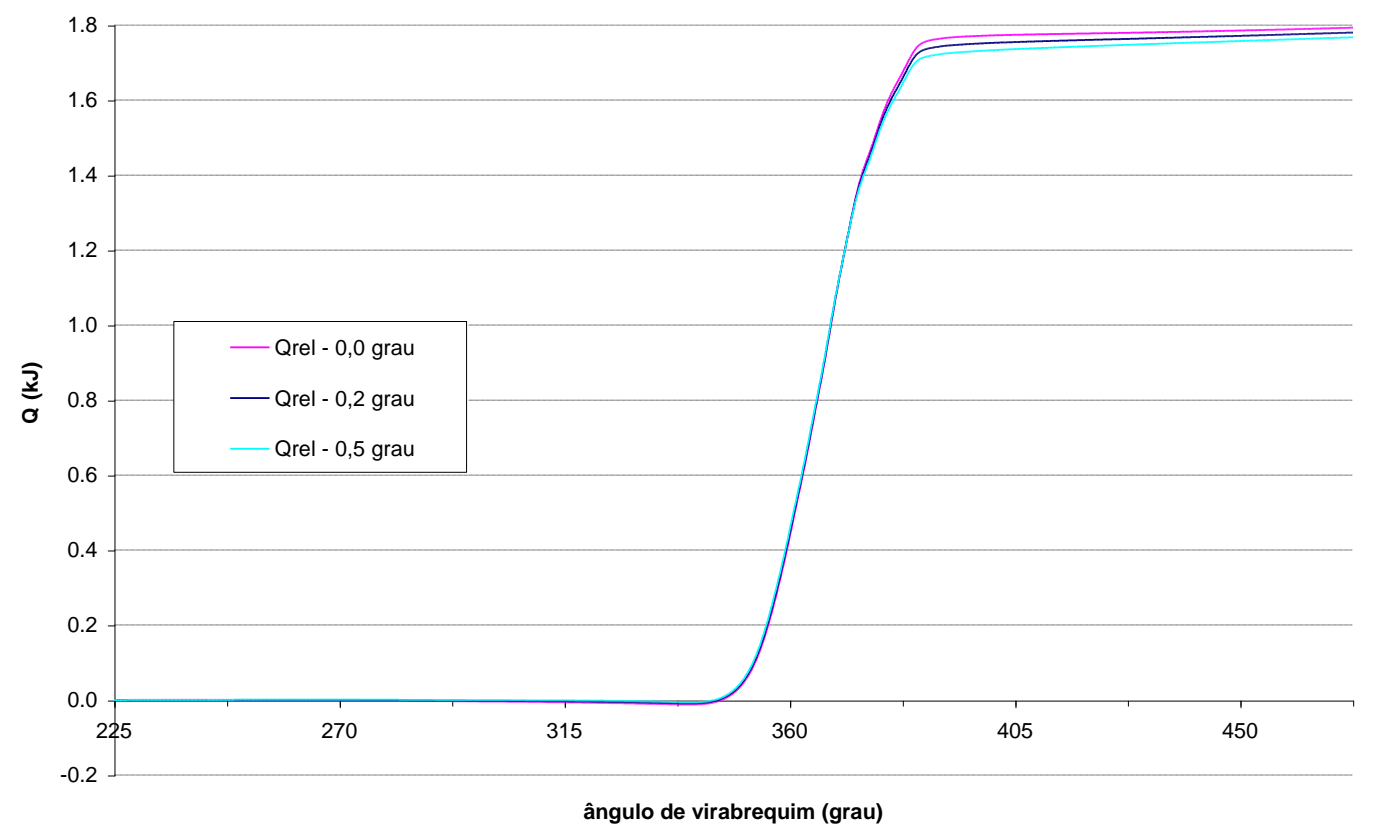

Figura 7.15 - Variações na liberação total de calor devidas às defasagens.

Figura 7.17 traz a comparação entre as temperaturas calculadas para os gases contidos nos dois volumes de controle, novamente considerando as curvas de pressão original e as adiantadas $0,2^{\circ}$ e $0,5^{\circ}$. Pode-se notar que o efeito da defasagem nas 
temperaturas não é tão significativo quanto na curva de fração de massa queimada ou quanto na curva de liberação de calor.

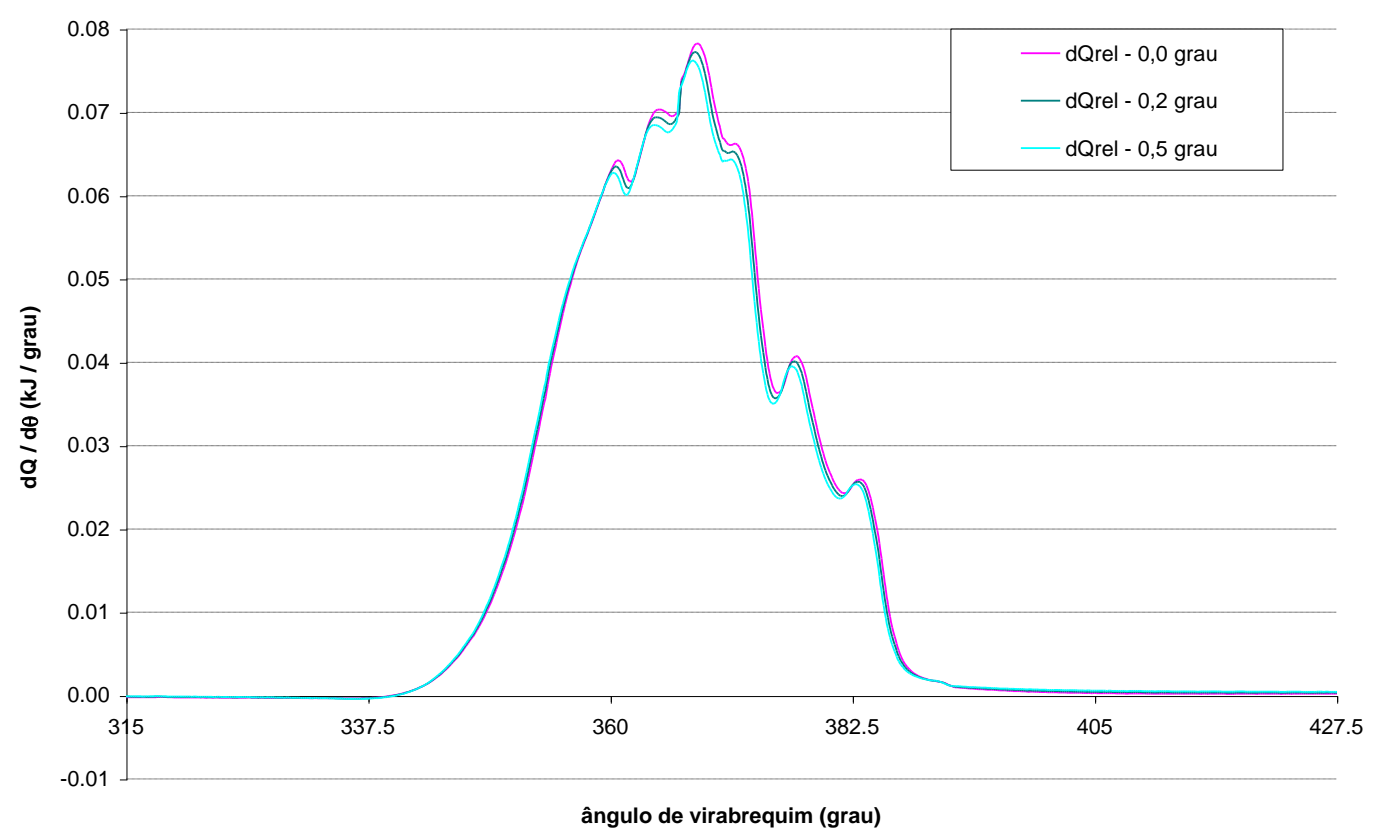

Figura 7.16 - Variações da taxa de liberação de calor devidas às defasagens.

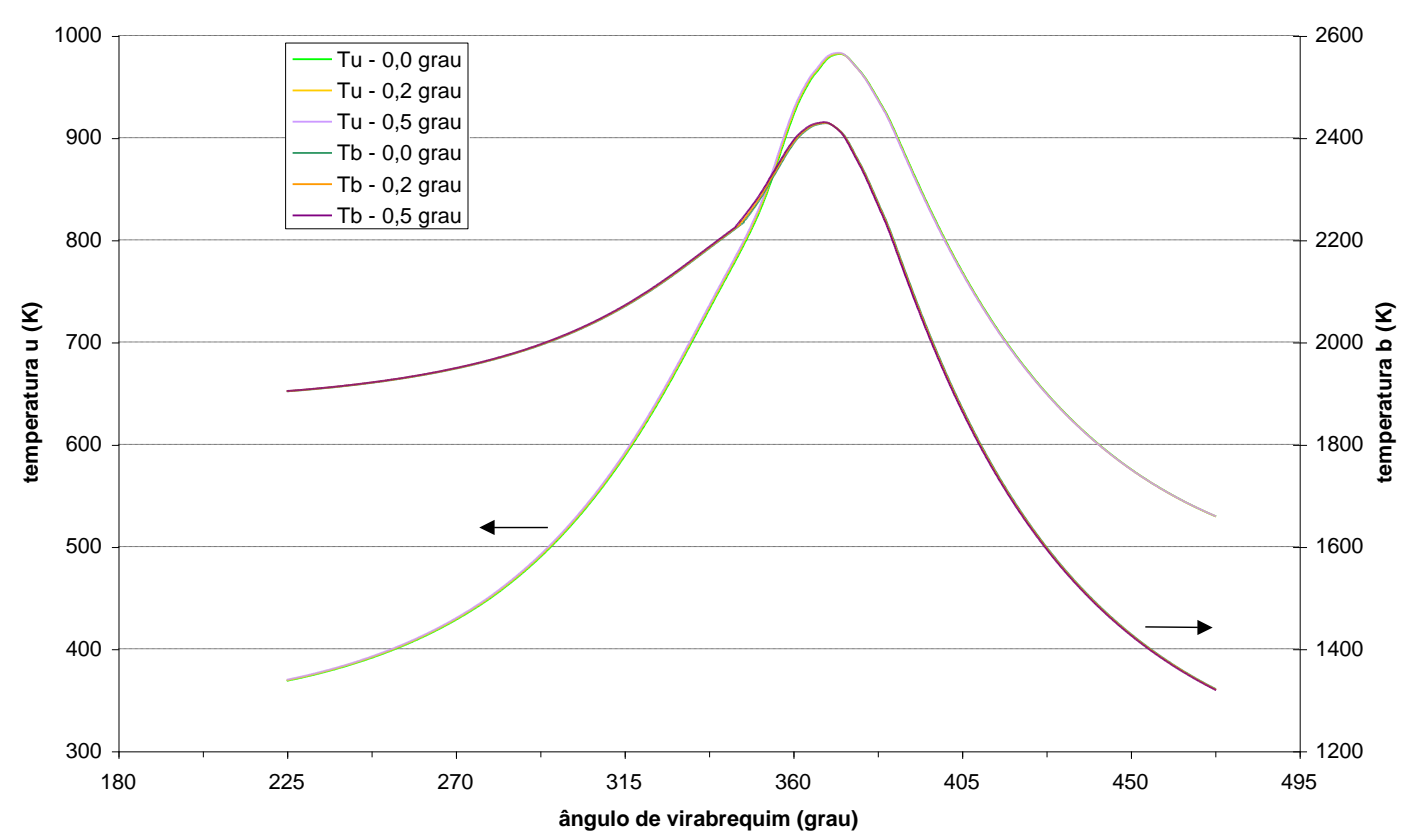

Figura 7.17 - Comparação entre as temperaturas para as curvas de pressão defasadas. 
A Figura 7.18 mostra o efeito das defasagens nos raios da frente de chama calculados. Como era de se esperar, o adiantamento da curva de pressão faz com que o programa de análise "entenda" que a combustão se inicie mais cedo, e se prolongue no final.

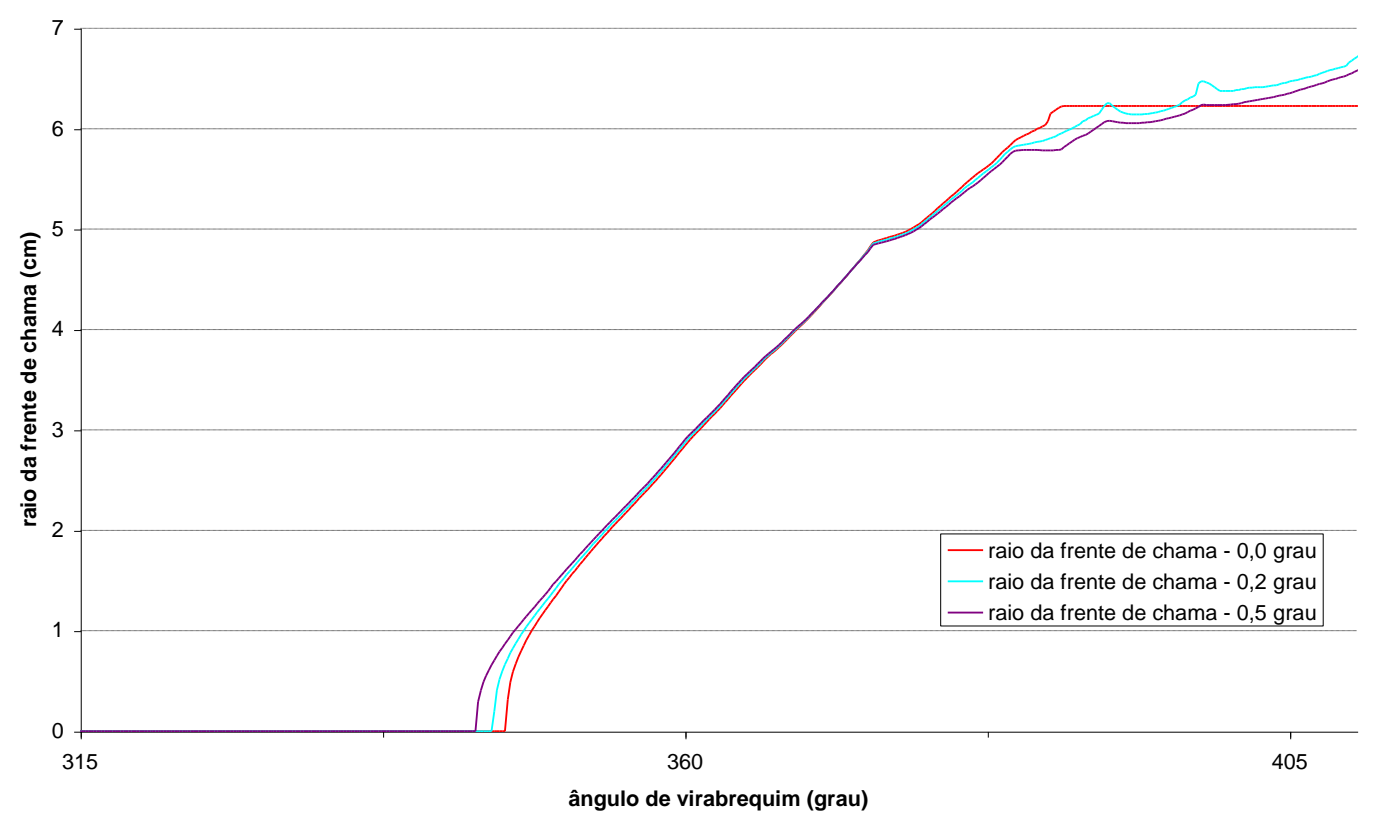

Figura 7.18 - Efeito das defasagens da curva de pressão na evolução da frente de chama.

Todos estes exemplos confirmam um fato largamente comentado na literatura: a referência de posição angular para a curva de pressão é uma das principais fontes de incerteza na análise de liberação de calor em motores. Pequenos erros em sua determinação geram grandes diferenças no cálculo da fração de massa queimada e quantidade de calor liberado.

Um segundo parâmetro que teve sua influência avaliada para a análise da combustão foi o valor de referência da curva de pressão. Assim, somou-se e subtraiu-se um valor de 0,05 bar à curva de pressão gerada pelo simulador e os resultados podem ser vistos a seguir. 


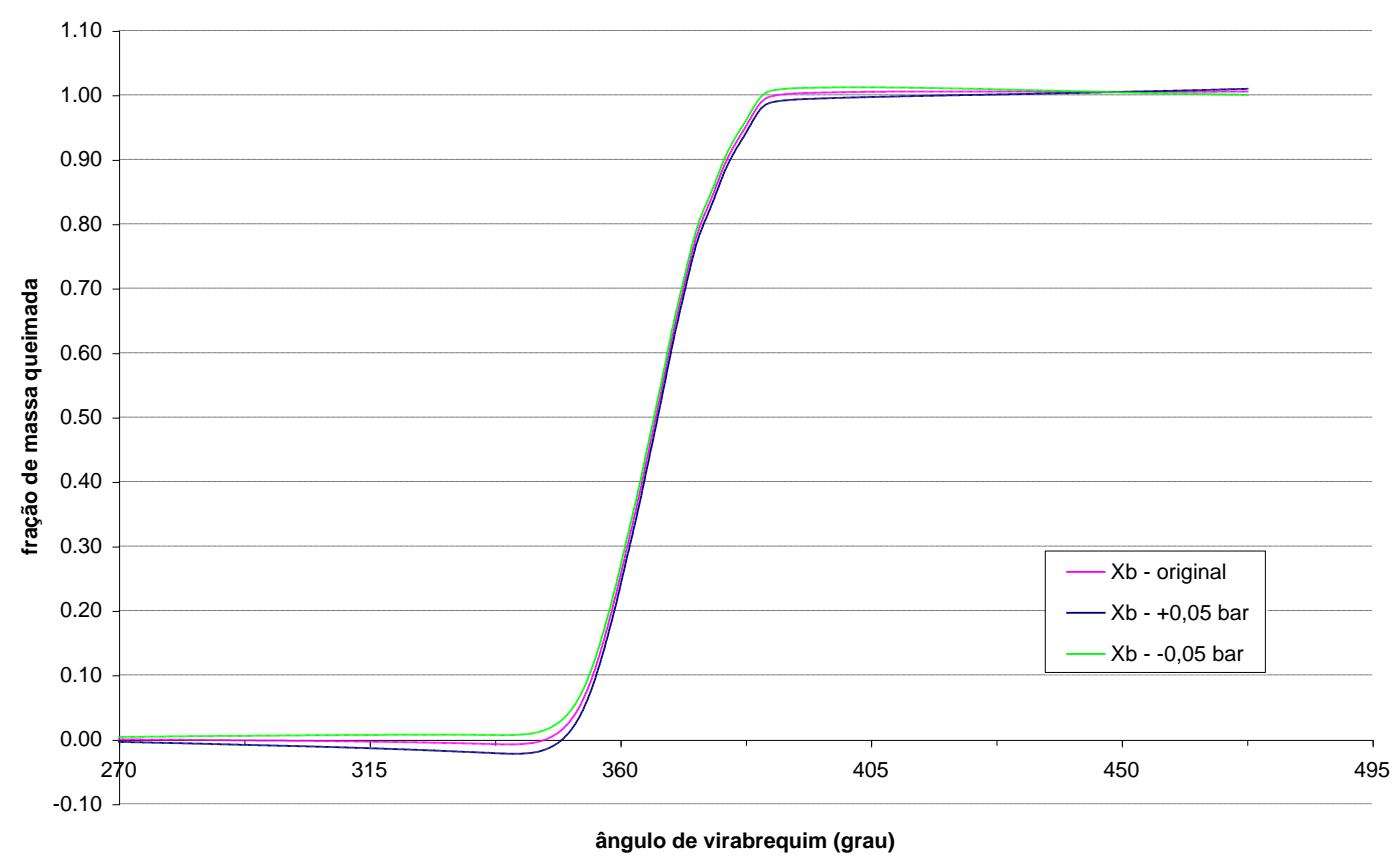

Figura 7.19 - Curvas de fração de massa queimada para variação na pressão de referência.

A Figura 7.19 traz a comparação entre as curvas de fração de massa queimada calculadas a partir da curva original de pressão e das curvas acrescida e reduzida de 0,05 bar. Vê-se que esta variação na pressão de referência causa uma variação na fração de massa queimada da ordem de $\pm 1,5 \%$ no início e no final da combustão em relação ao valor calculado com base na curva original de pressão. No entanto, esta variação ocorre no mesmo sentido, ou seja, para a curva de pressão acrescida de 0,05 bar, a queima "começa" mais tarde e "termina" mais tarde do que a curva original; no caso da pressão reduzida de 0,05 bar, a queima "começa" mais cedo e também "termina" mais cedo. Note-se que este comportamento é inverso àquele apresentado para o caso de defasagem da curva de pressão, onde a defasagem fazia com que as curvas de massa queimada representassem uma queima que se iniciava antecipadamente e terminava posteriormente ao caso original. Isto pode ser confirmado através da evolução do raio da frente de chama para os três casos, como mostra a Figura 7.20. 


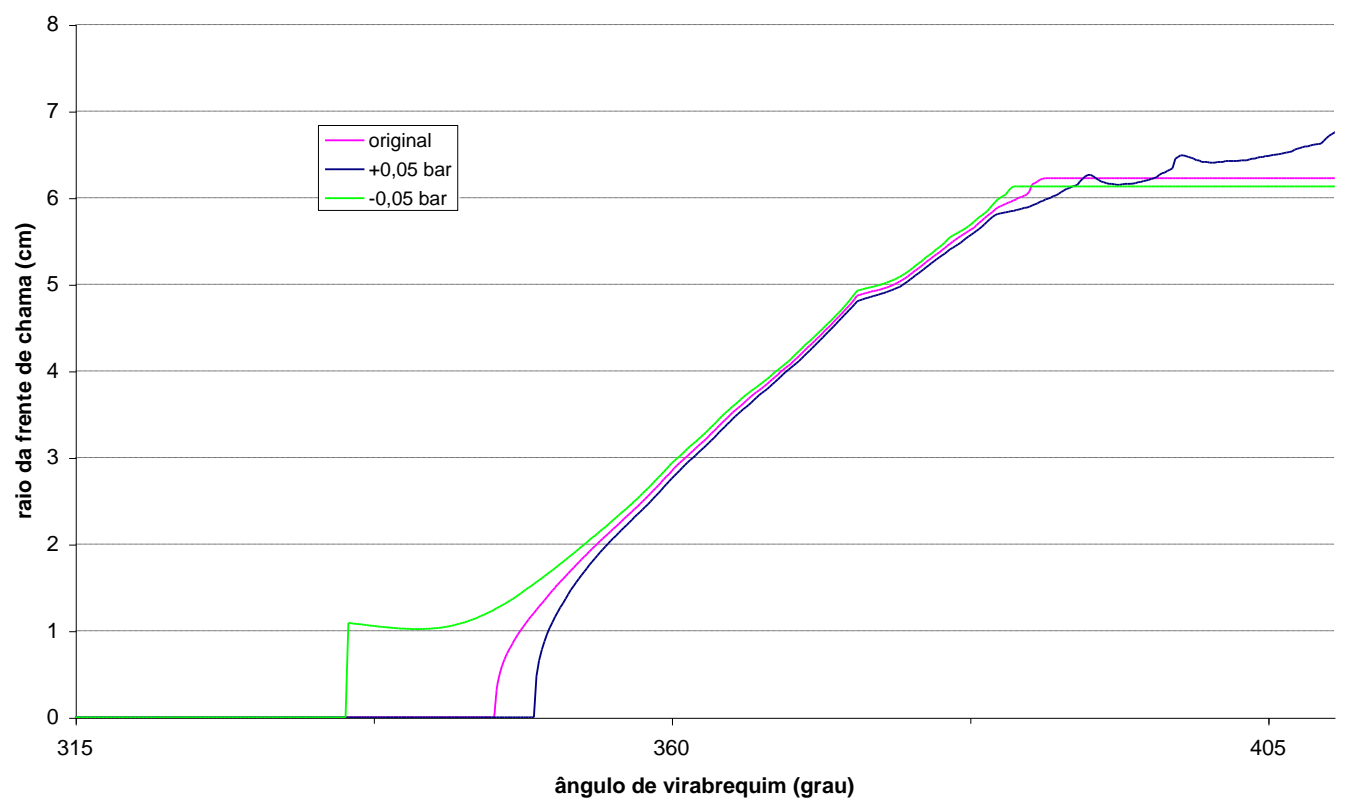

Figura 7.20 - Evolução da frente de chama para cada pressão de referência.

O salto que aparece no raio da frente de chama calculado a partir da curva de pressão com offset negativo de 0,05 bar é causado pela forma com que o programa detecta o início da combustão. Quando o valor de $\frac{d X_{b}}{d \theta}$ ultrapassa um valor de controle, admite-se que a combustão tenha-se iniciado, desde que este instante seja posterior à emissão da centelha. E, no caso, o offset faz com que esta derivada então ultrapasse este valor de controle muito mais cedo que as demais e antes de $335,5^{\circ}$, quando é emitida a centelha, com pode ser visto através da Figura 7.19. Assim, nesta situação, é o instante de emissão da centelha que está disparando a integração de $\dot{T}_{b}$, ocasionando um salto tanto no raio da frente de chama como na temperatura dos gases queimados, como será mostrado adiante.

Embora a quantidade de calor liberado total apresente as mesmas características da curva de massa queimada (Figura 7.21), a taxa de liberação de calor sofre muito pouca influência da pressão de referência, nesta faixa de variação, como mostrado pela 
Figura 7.22. Isto é esperado na medida em que a adição ou subtração de um valor constante à curva de pressão não altera o valor de $\dot{p}$. Como a derivada da pressão em função da posição angular do virabrequim tem grande influência no cálculo da taxa de liberação de calor, esta se manteve praticamente inalterada.

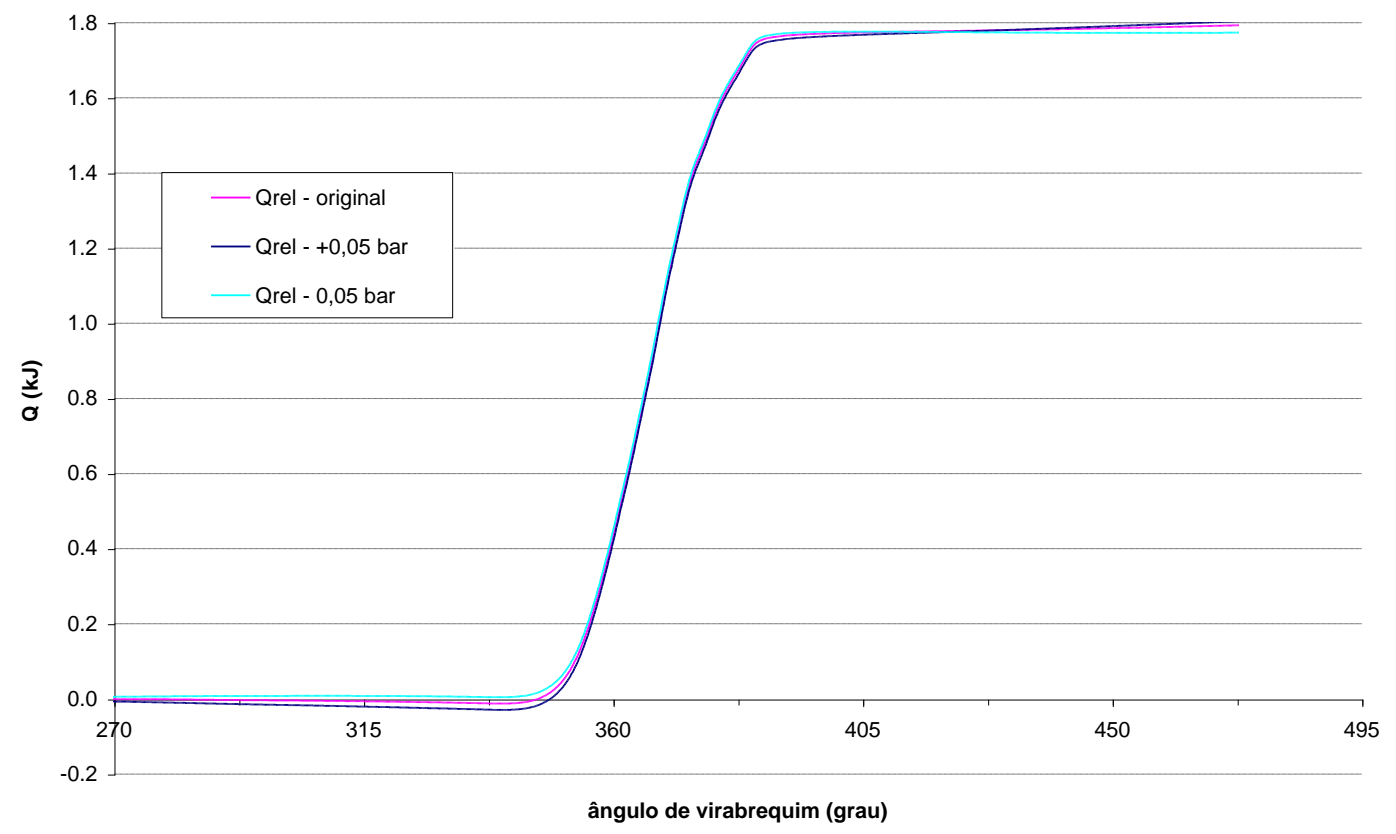

Figura 7.21 - Variações do calor total liberado em função da pressão de referência. 


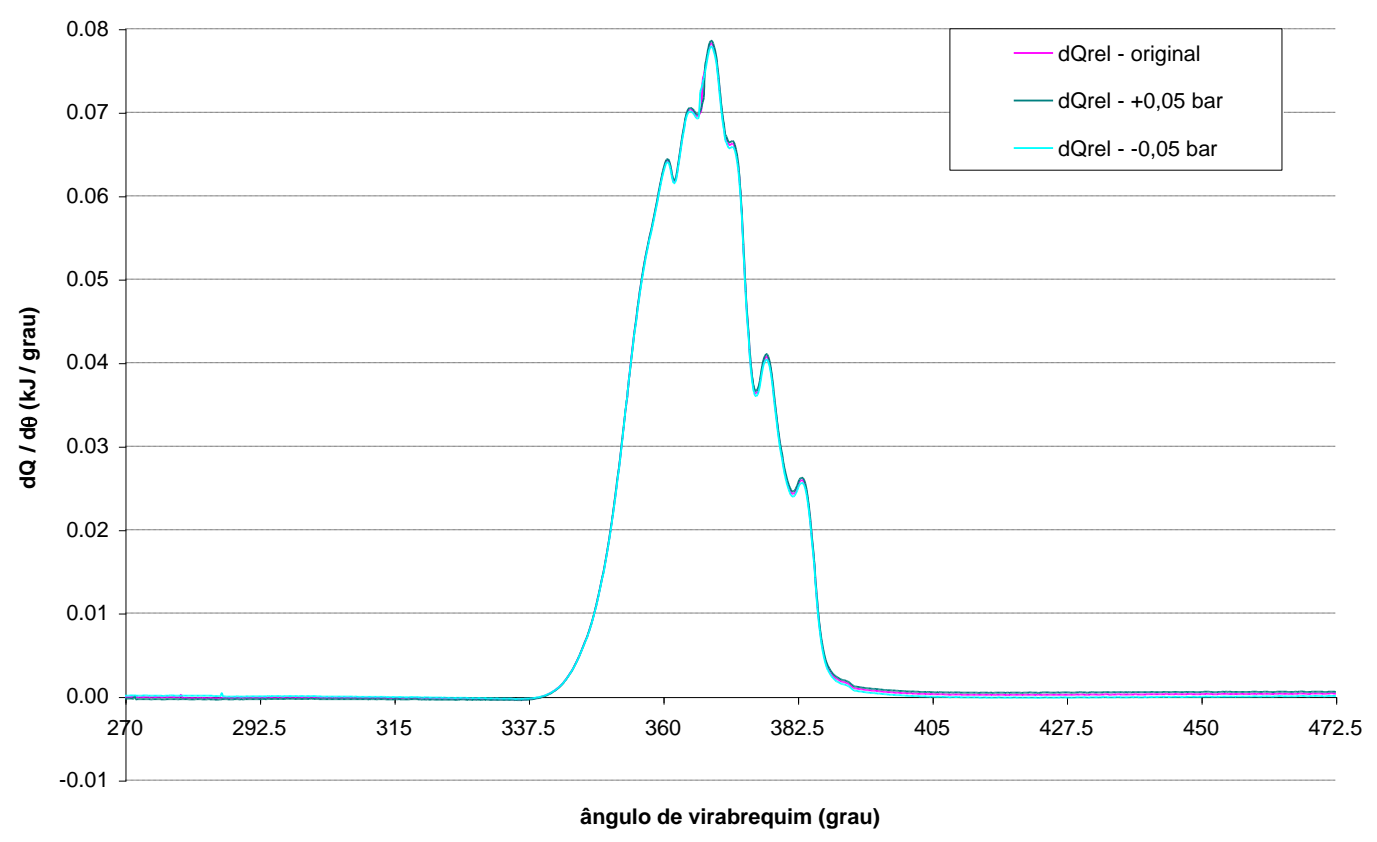

Figura 7.22 - Taxas de liberação de calor em função da pressão de referência.

Deve-se notar que o maior efeito dos "offsets" das curvas de pressão está no cálculo das temperaturas dos dois volumes de controle. A Figura 7.23 mostra as temperaturas calculadas para as curvas de pressão elevadas ou rebaixadas de 0,05 bar. Há uma variação máxima da ordem de $\pm 30 K$ na temperatura dos gases não queimados e $\pm 15 K$ na dos queimados.

É importante esclarecer que um acréscimo na pressão de referência tem efeito análogo à subestimação da massa total contida no cilindro no início do ciclo. Isto pode ser entendido observando-se a lei de gás perfeito: enquanto a pressão guarda uma relação de proporcionalidade direta com a temperatura, a massa apresenta a relação inversa. 


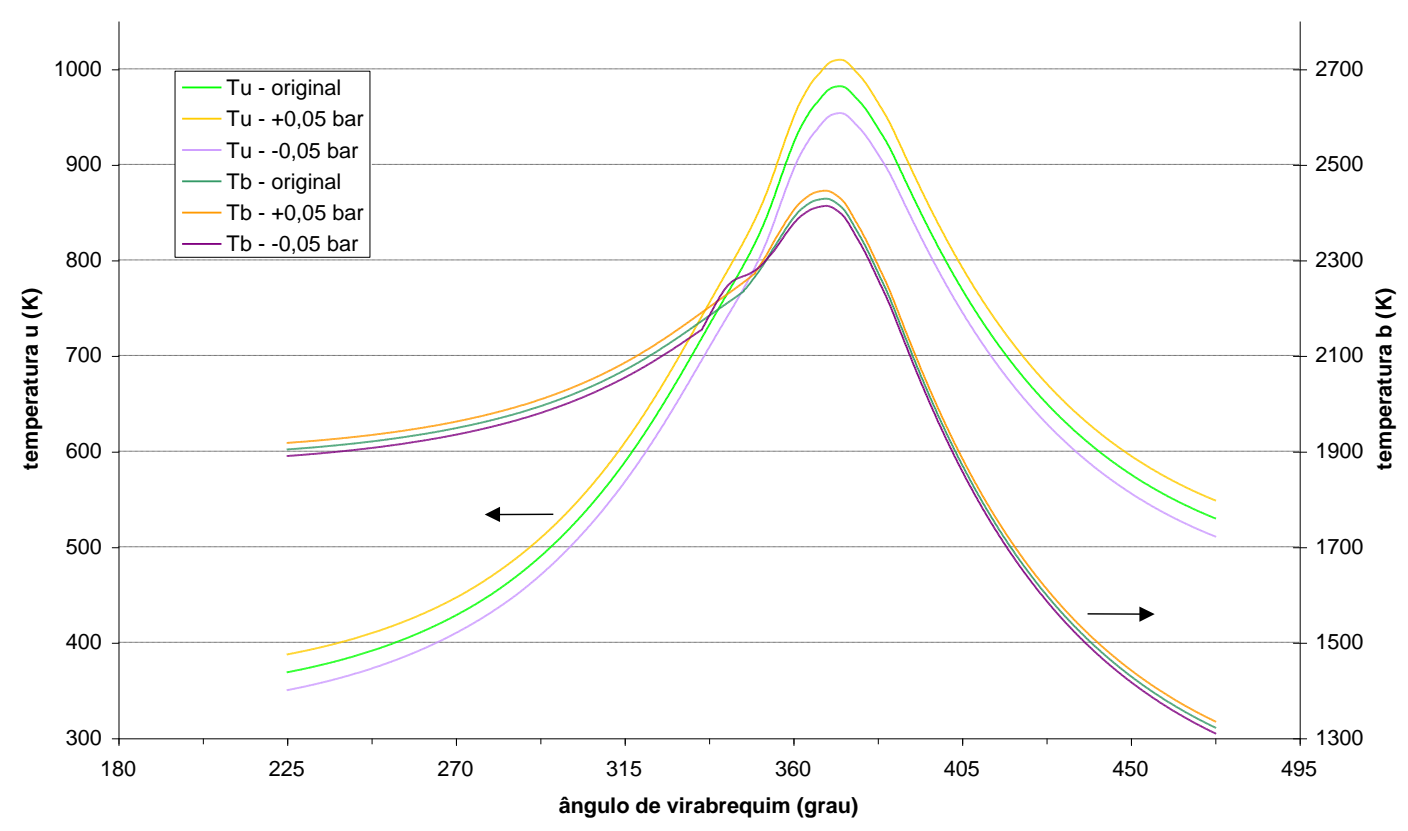

Figura 7.23 - Temperaturas dos VC em função da pressão de referência.

Um estudo sobre a influência da dissociação química no cálculo da liberação de calor e evolução da fração de massa queimada também foi realizado. Isto foi possível desabilitando-se a rotina que calcula a entalpia e massa específica para produtos de combustão acima de $1000 \mathrm{~K}$ segundo o trabalho de MARTIN ${ }^{[18]}$, impondo-se a derivada $\frac{\partial h_{b}}{\partial p}$ igual a zero e quantificando-se os produtos da combustão segundo a Tabela 4.1, de forma que a massa molecular média dos produtos da combustão $M W_{b}$ ficasse constante.

A Figura 7.24 mostra que a diferença causada na fração de massa queimada pela não consideração da dissociação química dos produtos da combustão, neste caso, vai de 4,0 a 3,3\%, sendo que, como esperado, só se manifestou após a combustão ter-se iniciado. 


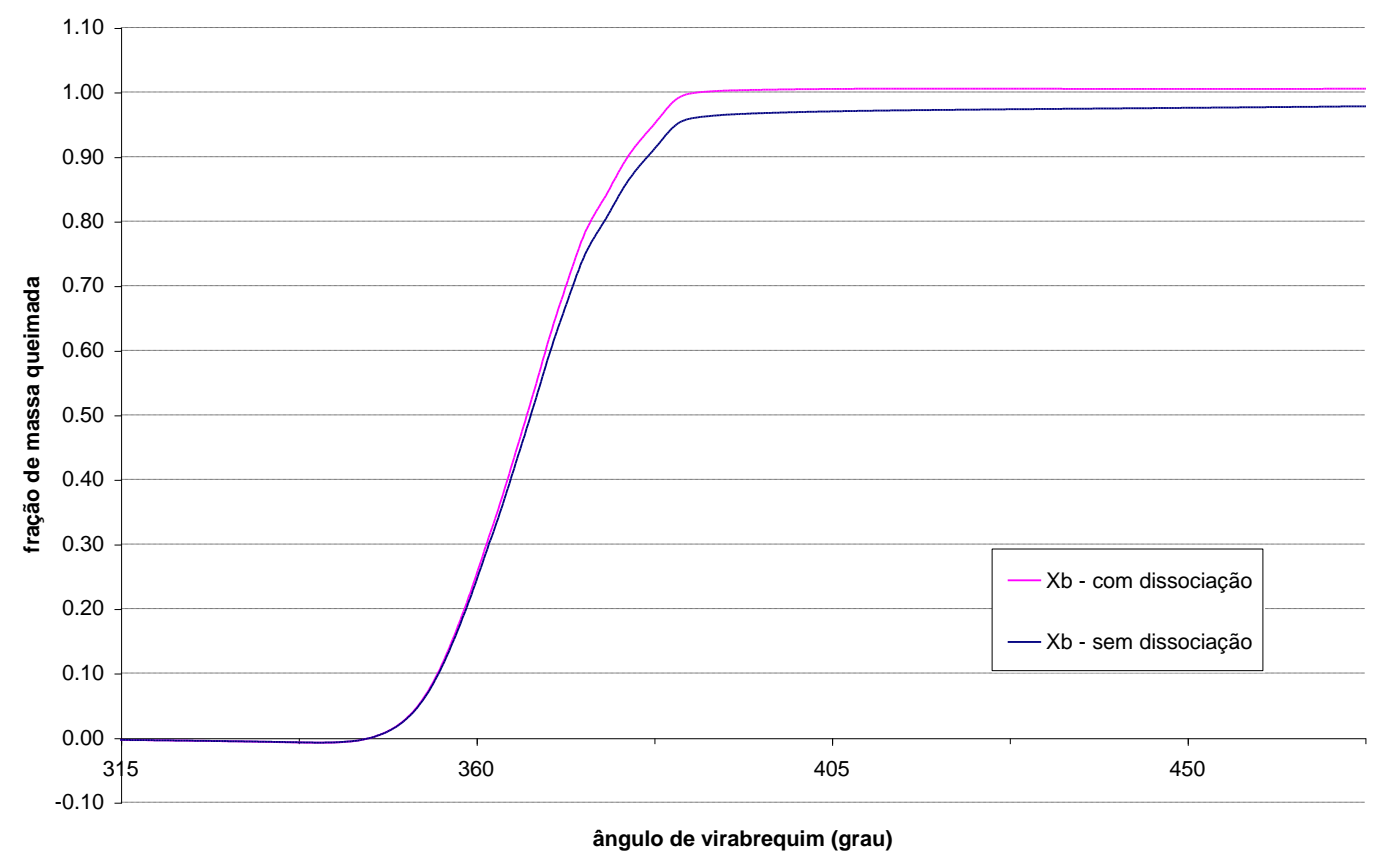

Figura 7.24 - Influência da dissociação química na fração de massa queimada.

O aumento causado na temperatura calculada dos gases queimados também é significativo já que, ao não se considerar a dissociação química, está-se admitindo que os produtos da combustão sejam totalmente oxidados e tenham um valor de entalpia (ou energia interna) específica menor do que de fato apresentam. Como a pressão está fixada, esta menor energia interna específica se traduz numa maior temperatura dos gases queimados para que a conservação de energia seja mantida, como pode ser visto na Figura 7.25. 


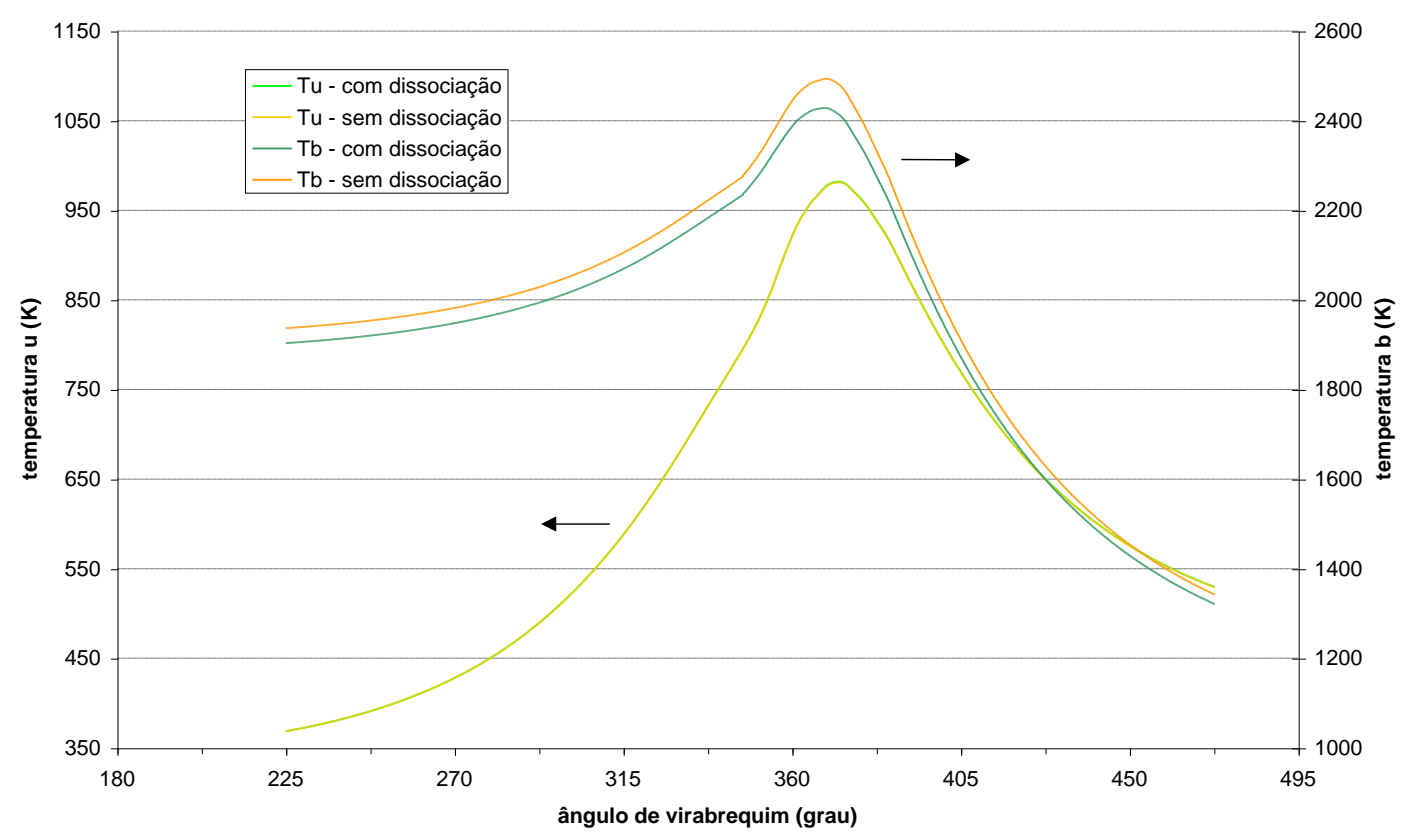

Figura 7.25 - Temperaturas calculadas não se considerando a dissociação química.

Note-se que, embora tenha havido um aumento na temperatura máxima dos gases queimados de $2427 K$ para $2493 K$, a temperatura dos gases não queimados praticamente não se alterou em função de se considerar a frente de chama adiabática.

A mesma explicação acima se aplica à diferença entre as curvas de liberação de calor calculadas considerando-se ou não a dissociação química, como pode ser visto através da Figura 7.26. Ou seja, a menor energia interna específica dos produtos da combustão para o caso sem dissociação em relação à situação onde a dissociação é considerada faz com que menos combustível "necessite ser queimado" para que se atinja a conservação de energia, uma vez fixadas as variações de pressão e volume $(\therefore$ trabalho) e a troca de calor. Assim, a fração de massa queimada não chega à unidade bem como a liberação de calor se torna menor.

É perceptível também a redução na taxa de liberação de calor na fase final da combustão, como mostra a Figura 7.27. 


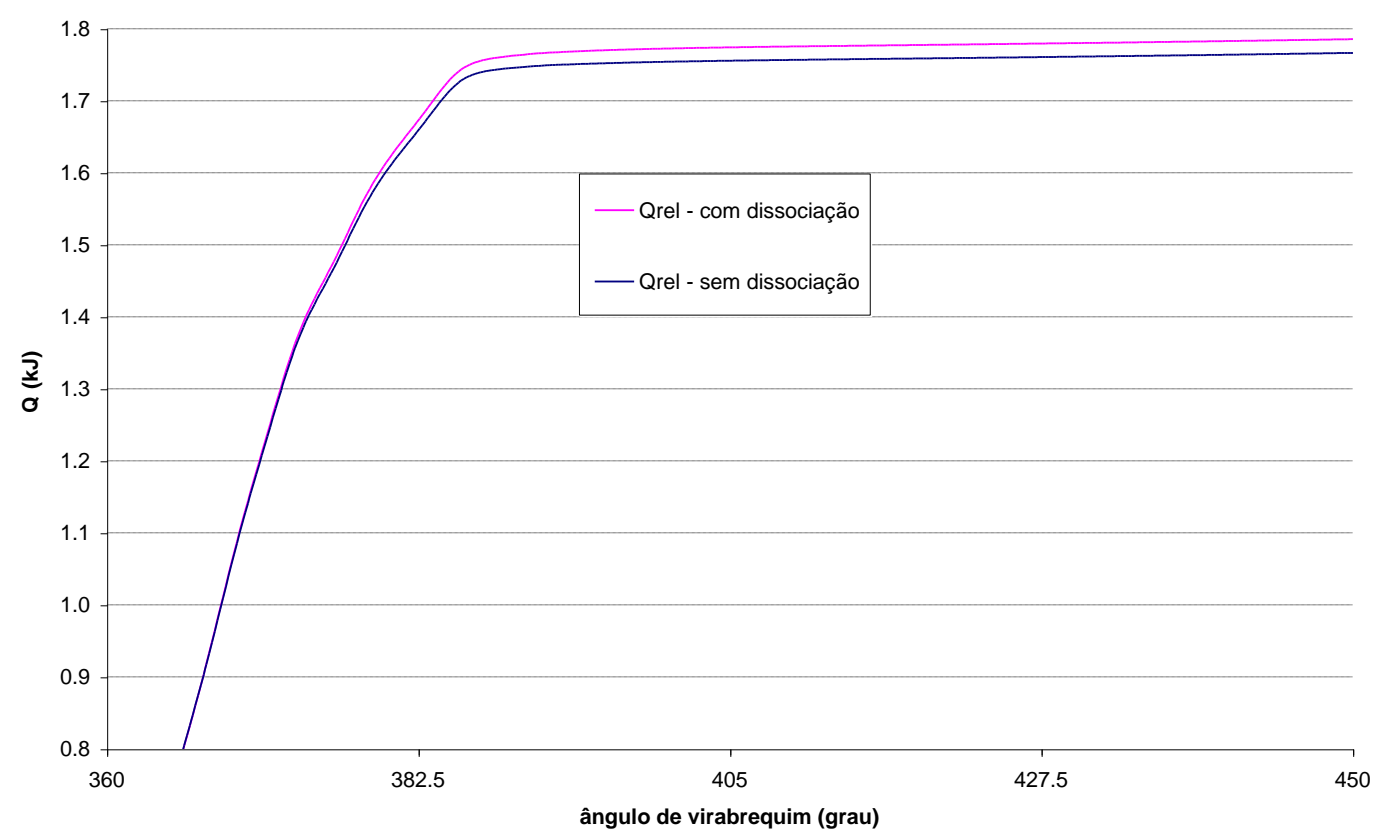

Figura 7.26 - Curvas de liberação de calor não se considerando a dissociação química.

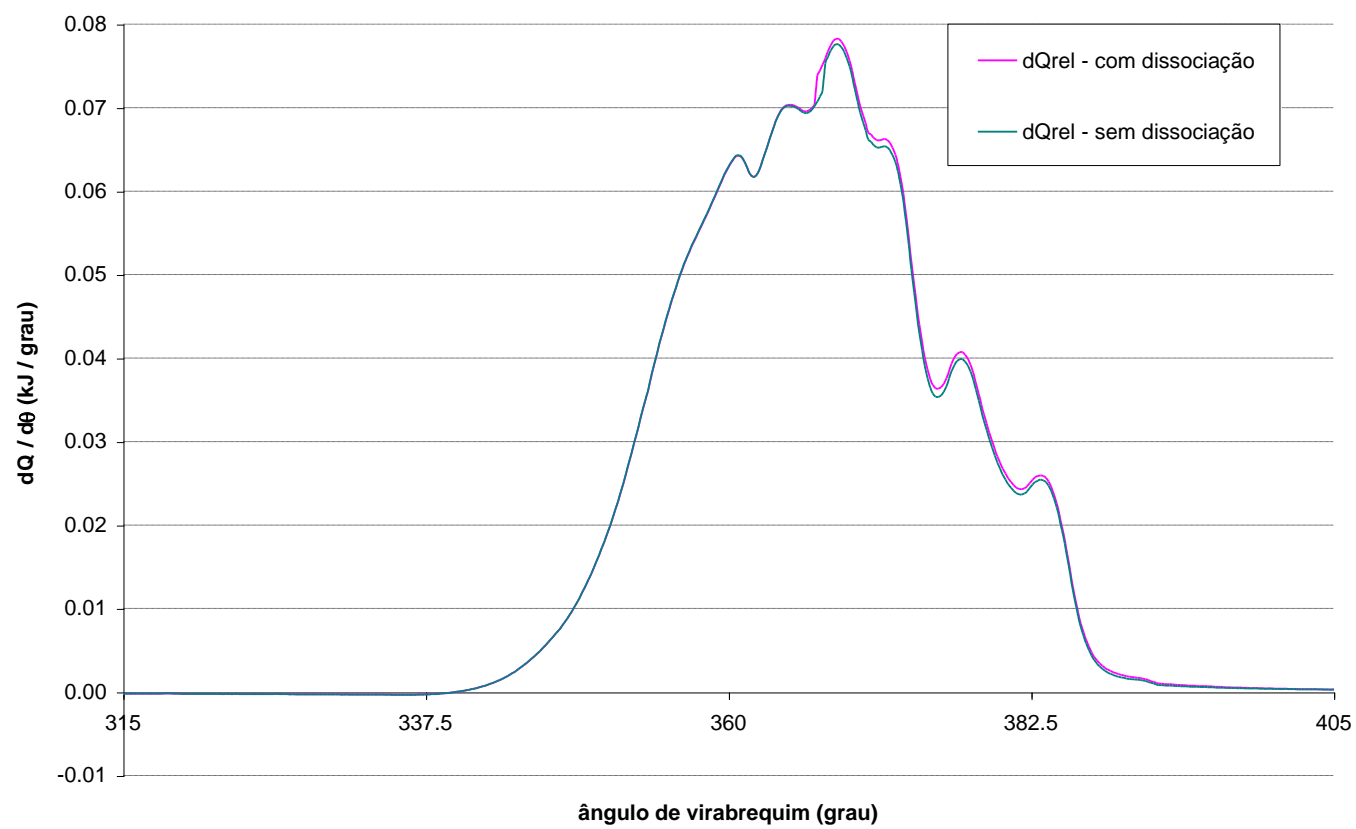

Figura 7.27 - Taxa de liberação de calor considerando-se ou não a dissociação.

O efeito das frestas também foi avaliado. Admitindo um volume equivalente constante de $1,0 \mathrm{~cm}^{3}$ para as frestas e uma temperatura de $470 \mathrm{~K}$ para os gases em seu interior (média da temperatura do pistão e cilindro), a fração de massa queimada foi 
calculada a partir da curva de pressão gerada pelo simulador (Figura 7.28). Embora este não contemple efeitos de frestas, o resultado da análise ilustra essa influência.

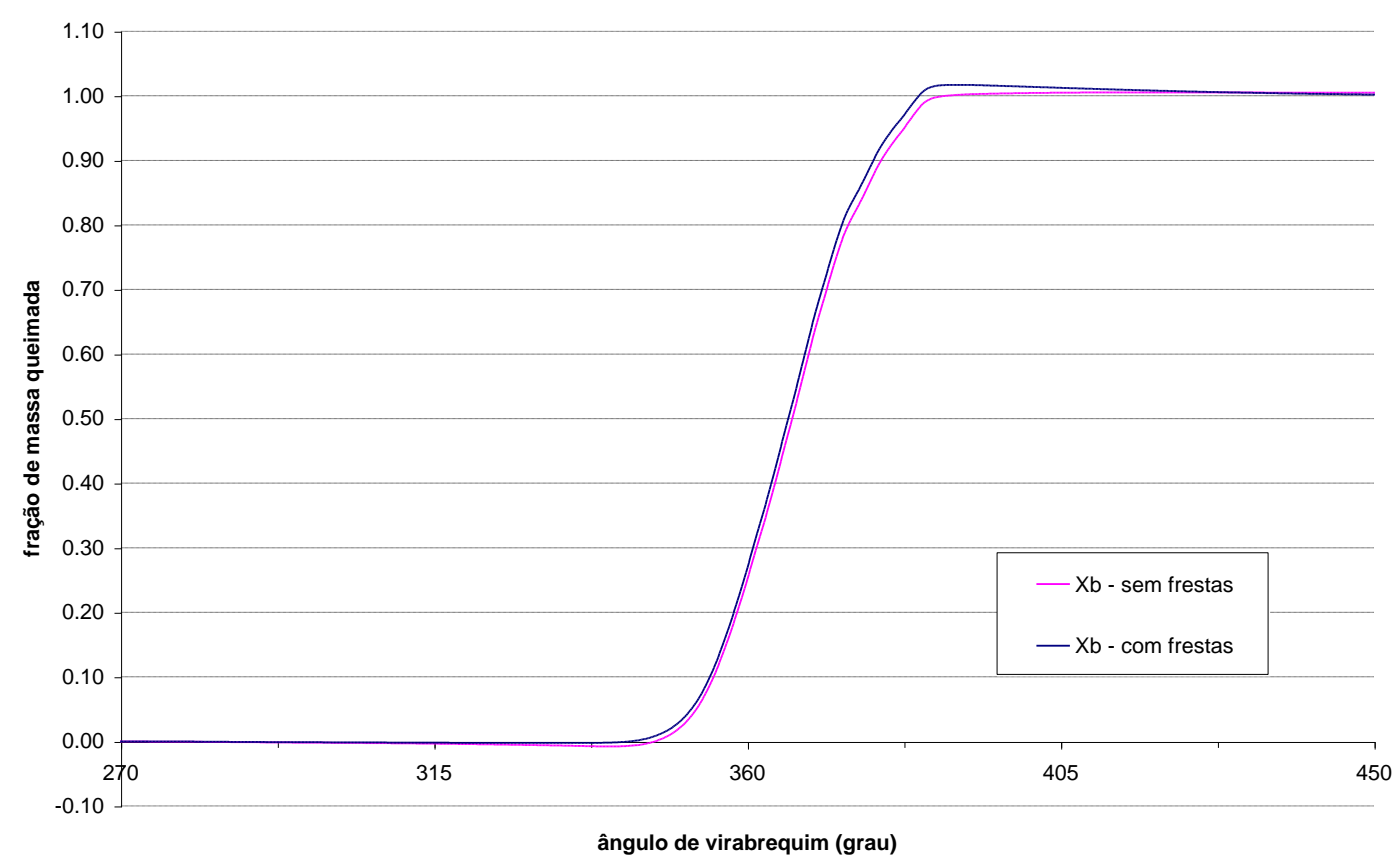

Figura 7.28 - Efeito das frestas na fração de massa queimada.

Pode-se perceber que as frestas exercem um papel muito importante no cálculo da fração de massa queimada. Um volume equivalente da ordem de 1,1\% do mínimo volume da câmara gera variação máxima da ordem de $1,0 \%$ na fração de massa queimada. É importante esclarecer que a fração de massa queimada está sempre sendo calculada neste trabalho como a massa do $\mathrm{VC}_{b}$ dividida pela massa total contida no cilindro no instante do fechamento da válvula de admissão.

Ressalte-se a importância das frestas na emissão de hidrocarbonetos não queimados. A diferença de 1,0\% na fração de massa queimada da Figura 7.28 está armazenada, de certa forma, nestes pequenos volumes e uma fração da massa neles contidos é combustível que não será queimado.

A Figura 7.29 traz a comparação entre as evoluções da frente de chama considerando-se ou não as frestas. Este gráfico mostra que a queima deveria se iniciar 
mais cedo para o caso com as frestas. Isto é explicado da seguinte forma: havendo uma "fuga" de mistura combustível para as frestas (e portanto um fluxo de entalpia saindo da câmara principal), a única maneira de o modelo obter o balanço de energia é "liberando calor" através da queima de combustível. O fato de se ter atingido a condição de parada para integração de $T_{u}\left(M_{u} \leq 0\right)$ faz com que a frente de chama não mais seja calculada, sendo que a combustão continua às custas da massa provinda das frestas.

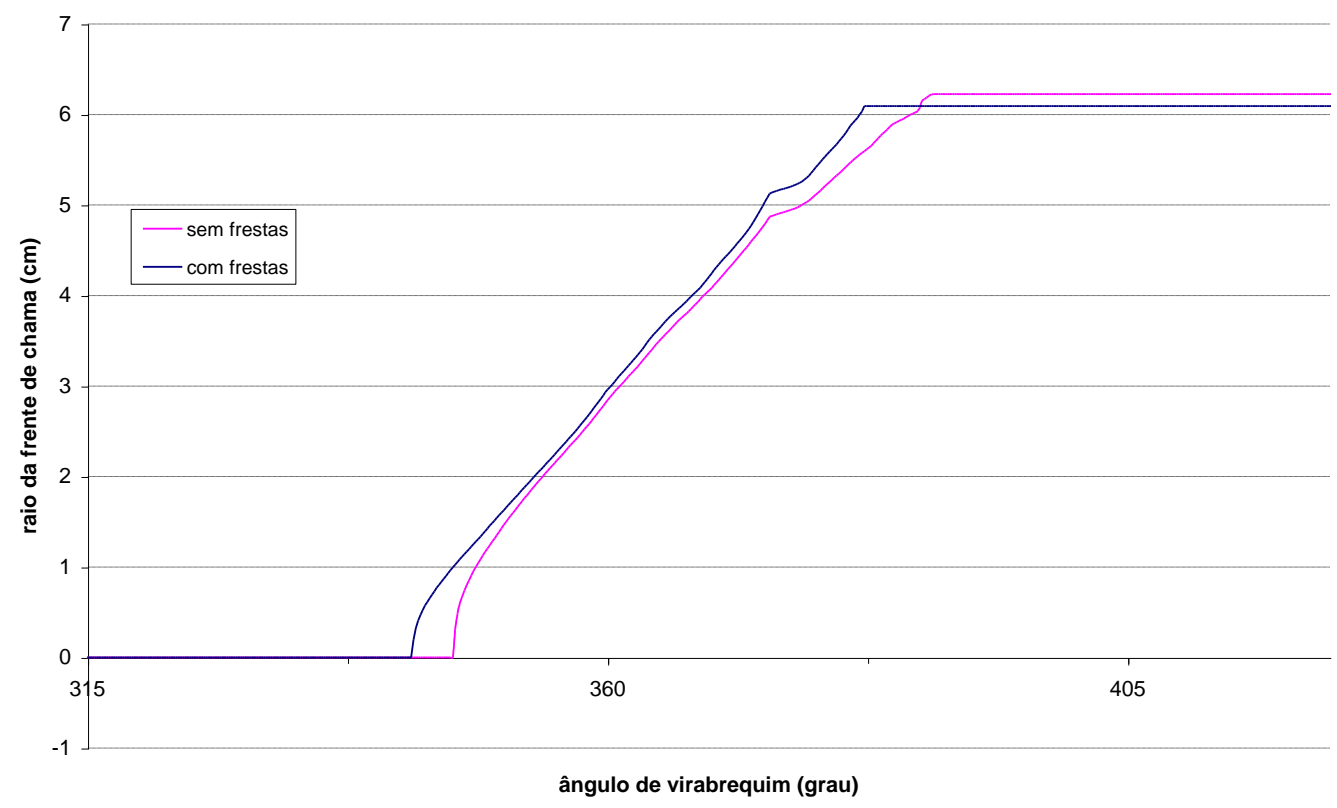

Figura 7.29 - Alteração na evolução da frente de chama devida às frestas.

A Figura 7.30 mostra a evolução da liberação de calor para os casos sem e com frestas. As curvas que se acham na parte superior deste gráfico representam as máximas quantidades de energia disponíveis na câmara $\left(\mathrm{VC}_{u}\right.$ e $\left.\mathrm{VC}_{b}\right)$, ou seja, a massa de combustível disponível multiplicada pelo seu poder calorífico inferior. A deflexão na curva correspondente ao caso com frestas é explicada pelo fluxo de uma parcela da massa de combustível do $\mathrm{VC}_{u}$ para as frestas. Ratifique-se a idéia de que estes resultados são ilustrativos, uma vez que partiu-se de uma curva de pressão que não traz consigo efeitos de frestas - o que explica então a liberação de calor calculada considerando-se as 
frestas ultrapassar a curva de máxima energia disponível (massa de combustível multiplicada pelo poder calorífico) na Figura 7.31.

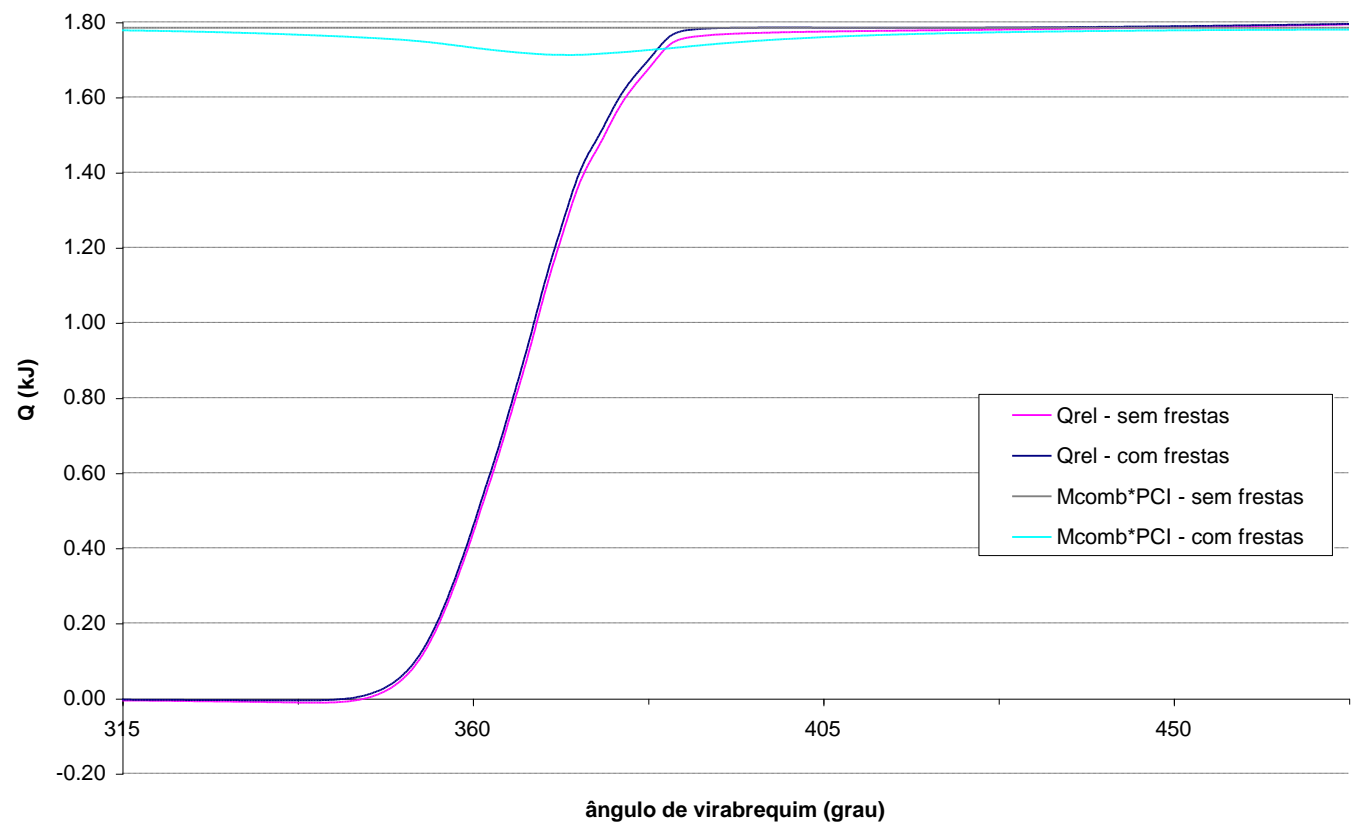

Figura 7.30 - Curvas comparativas de liberação de calor.

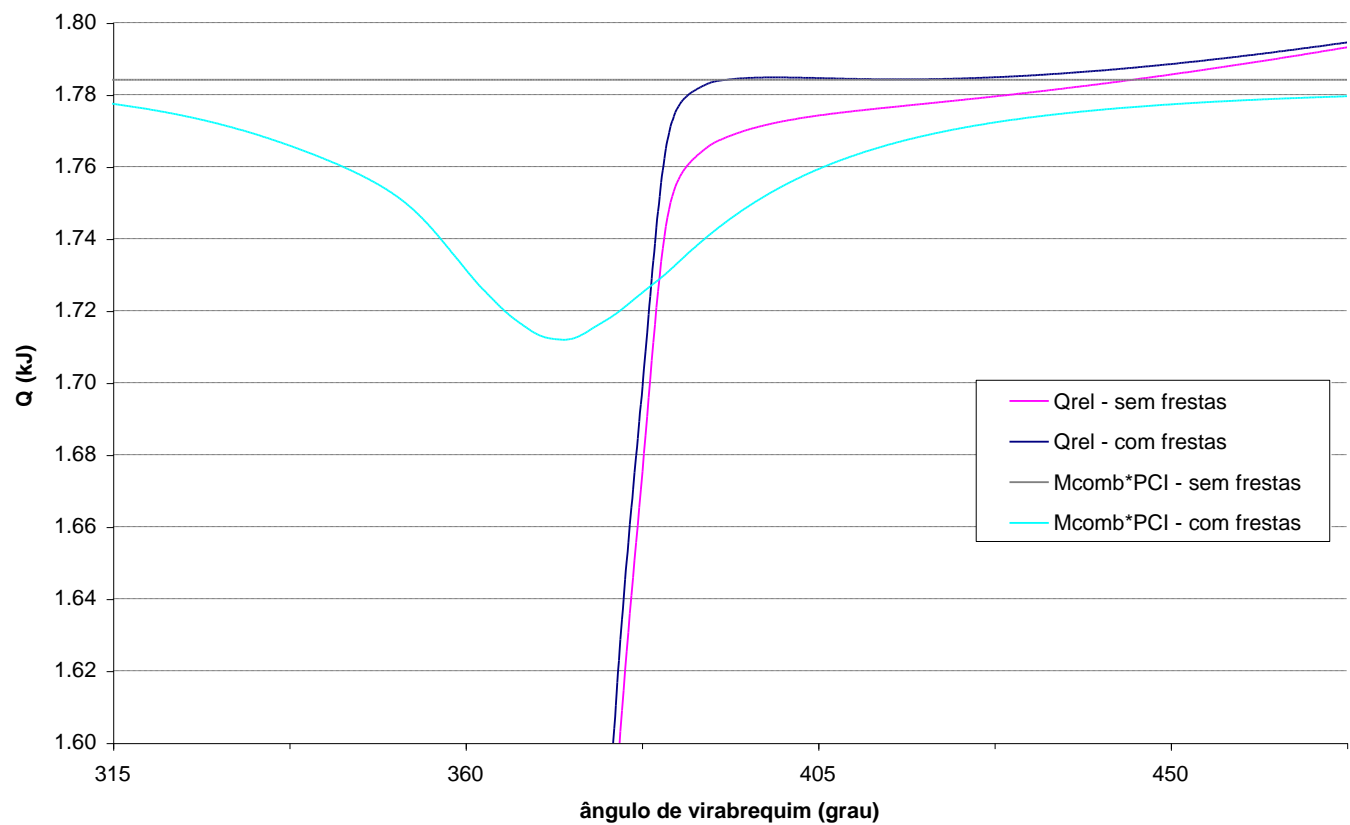

Figura 7.31 - Detalhe da Figura 7.30. 
O gráfico da Figura 7.32 mostra que o cálculo das temperaturas não é tão afetado pela inclusão dos efeitos das frestas. Já a Figura 7.33 reflete a elevação da taxa de liberação de calor quando se consideram as frestas, principalmente na região inicial da combustão, onde a fuga de massa para as frestas é maior, mas também no final da combustão, onde parte significativa dessa massa é liberada.

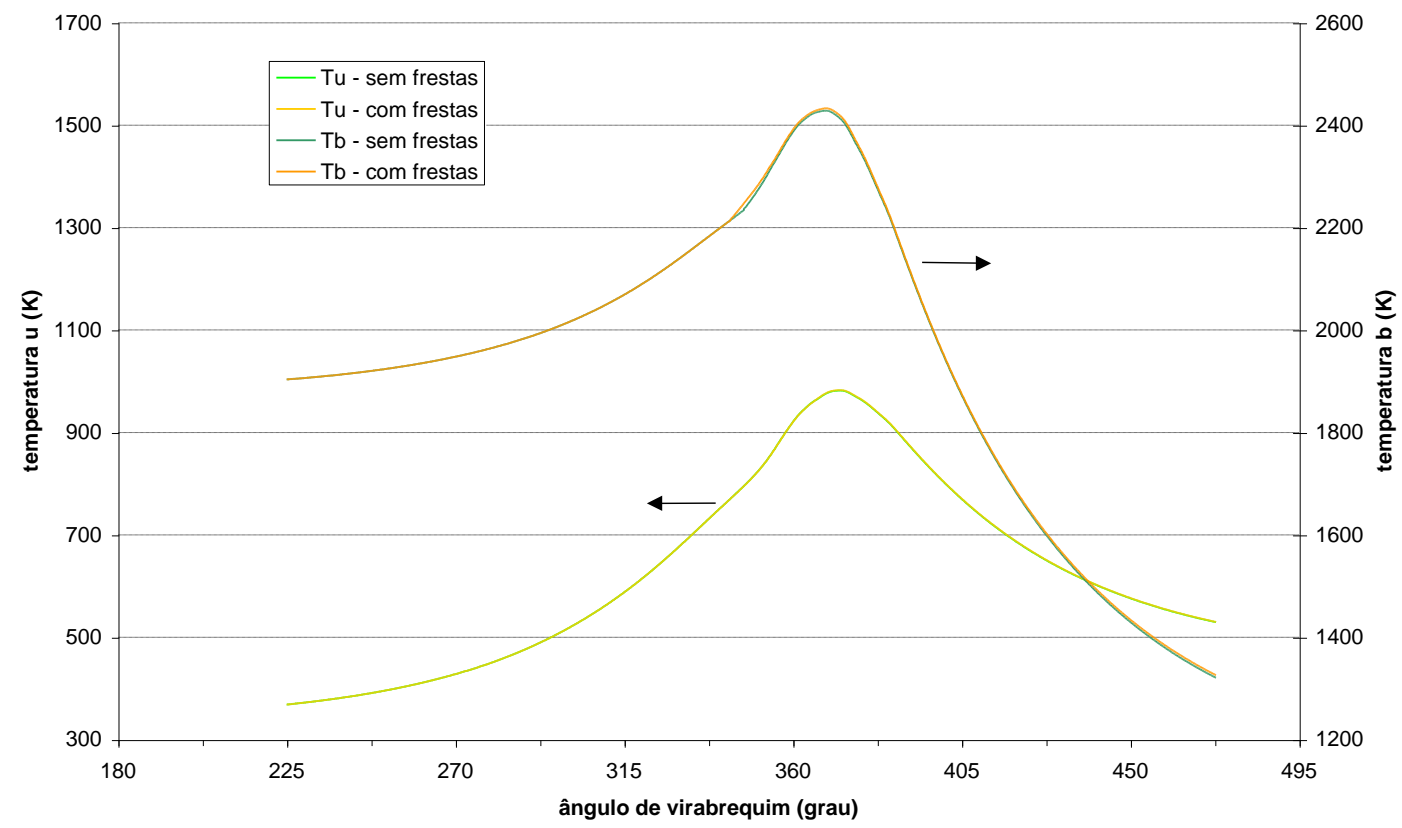

Figura 7.32 - Temperaturas calculadas considerando-se as frestas.

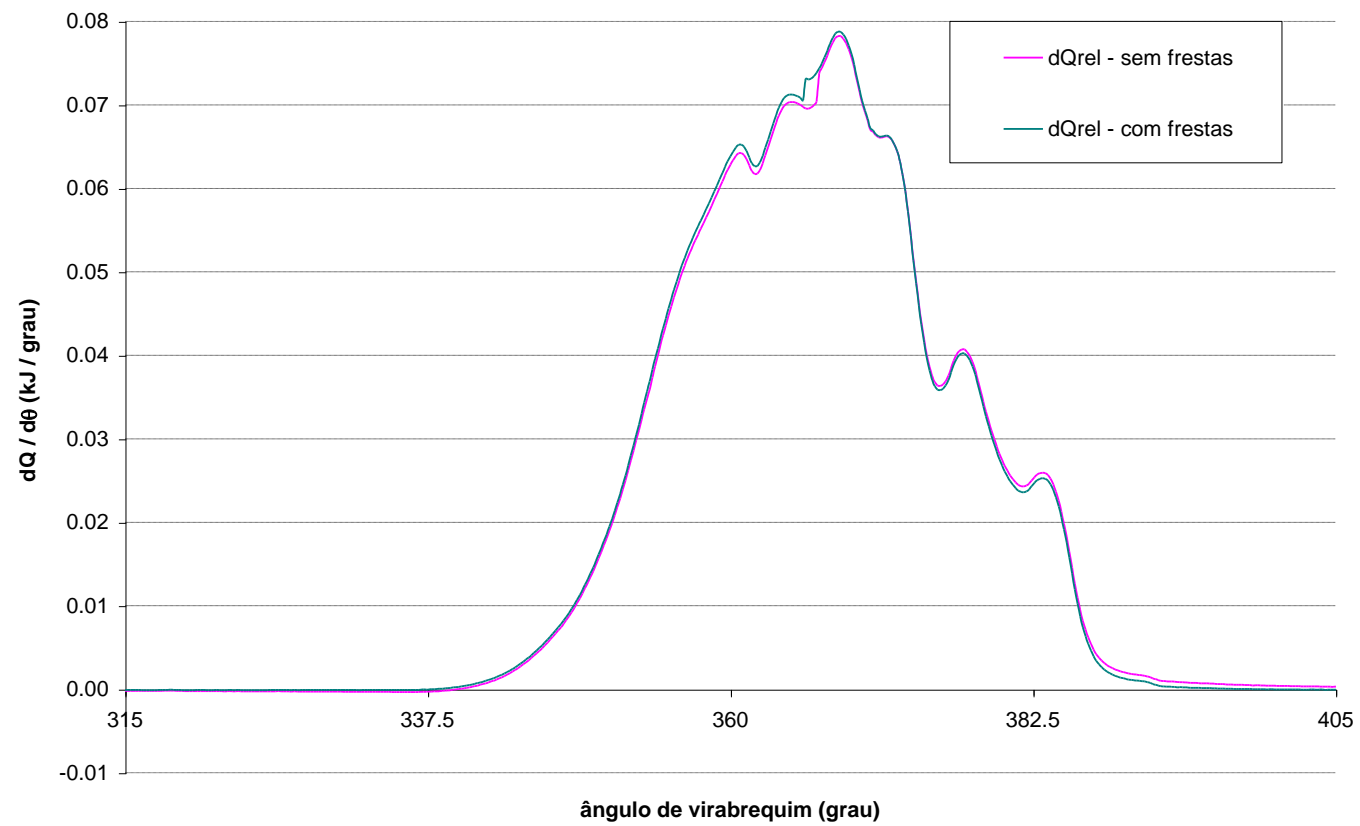

Figura 7.33 - Taxa de liberação de calor calculada com efeitos de frestas. 
Os efeitos dos vazamentos de gases para o cárter são parecidos com os efeitos das frestas. Dados experimentais mostram que para este motor, com o pacote de anéis utilizado nos ensaios, o vazamento (blow-by) é a da ordem de 0,7 a $0,8 \%$ do volume deslocado, medido à pressão atmosférica. Assim, a vazão de blow-by é aproximadamente 7,48 $\mathrm{cm}^{3} /$ ciclo por cilindro. Adotando-se como massa específica do ar atmosférico o valor de $1,08 \mathrm{~kg} / \mathrm{m}^{3}$ (no local de ensaio), tem-se uma vazão mássica de 0,0081 g/ciclo. Note-se que a maior parte desta vazão ocorre enquanto as válvulas de admissão e escapamento estão fechadas, pois fora deste intervalo a pressão na câmara é muito baixa (em motores normalmente aspirados, como é o caso).

Partindo-se então deste valor de vazamento, é possível ajustar-se a constante $K_{b b}$ que aparece na Eq. 4-11 de forma a igualar a massa total que vaza durante um ciclo à 0,0081 g. Para o caso até agora utilizado como referência, o valor de $K_{b b}$ é igual a 0,044 .

A Figura 7.34 traz a comparação entre as frações de massa queimada calculadas para os três casos: volume de frestas e $K_{b b}$ nulos, volume de frestas igual a $1,0 \mathrm{~cm}^{3}$ (com $T=470 K$ ) e sem blow-by, e o caso com frestas e blow-by considerados simultaneamente. Pode-se observar, através dos detalhes mostrados na Figura 7.35 e na Figura 7.36, que o efeito dos vazamentos acarreta um aumento na ordem de $0,2 \%$ na amplitude de variação da fração de massa queimada em relação ao caso que só considerava as frestas.

Este fato também se repete na liberação total de calor, mostrada na Figura 7.37 para os três casos. Há um ligeiro aumento da liberação total de calor em relação ao caso onde só se considerou o efeito das frestas. Estas pequenas alterações na fração de massa queimada e na liberação de calor não causam alterações perceptíveis nas temperaturas 
calculadas dos VC.

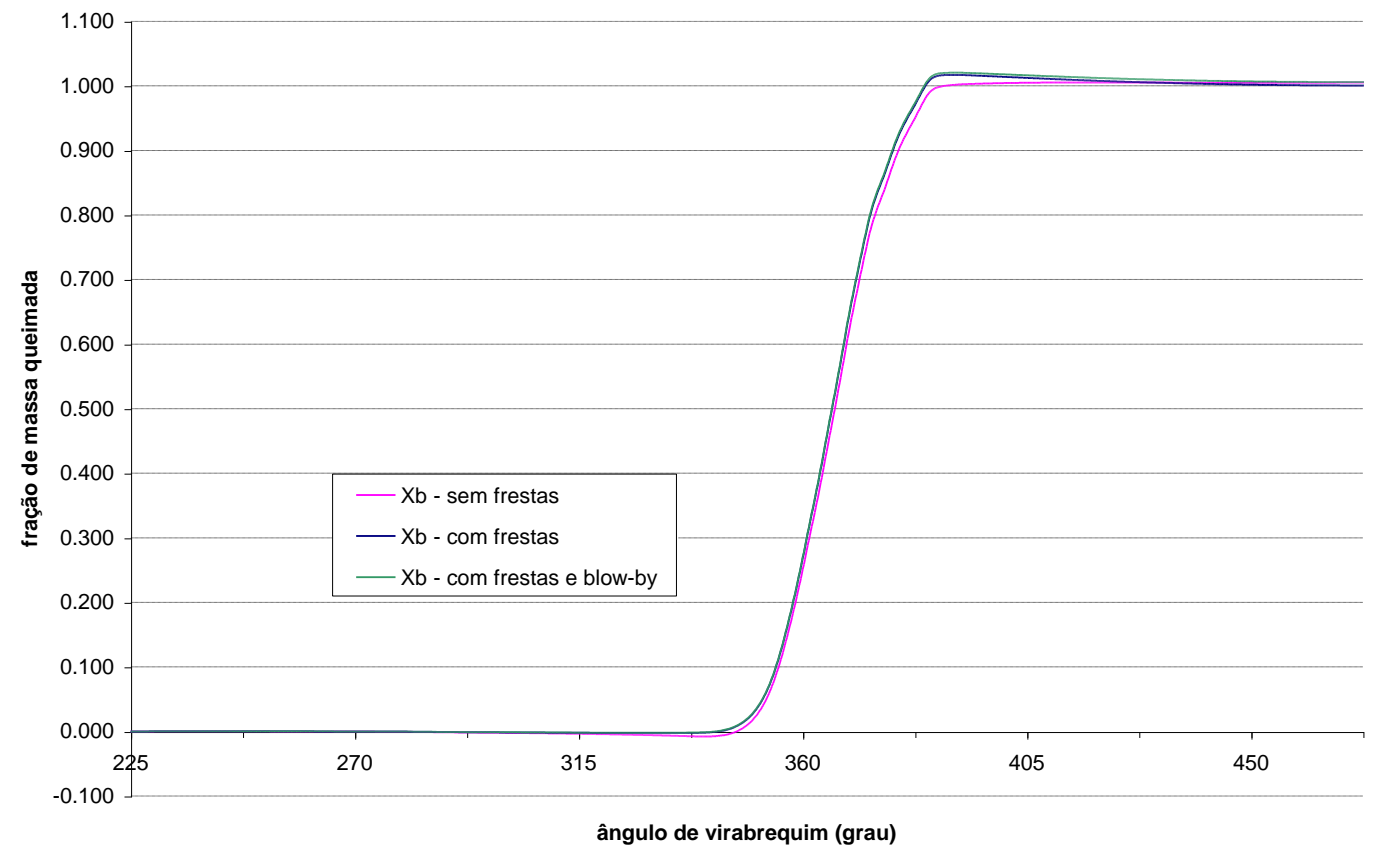

Figura 7.34 - Efeito dos vazamentos na fração de massa queimada.

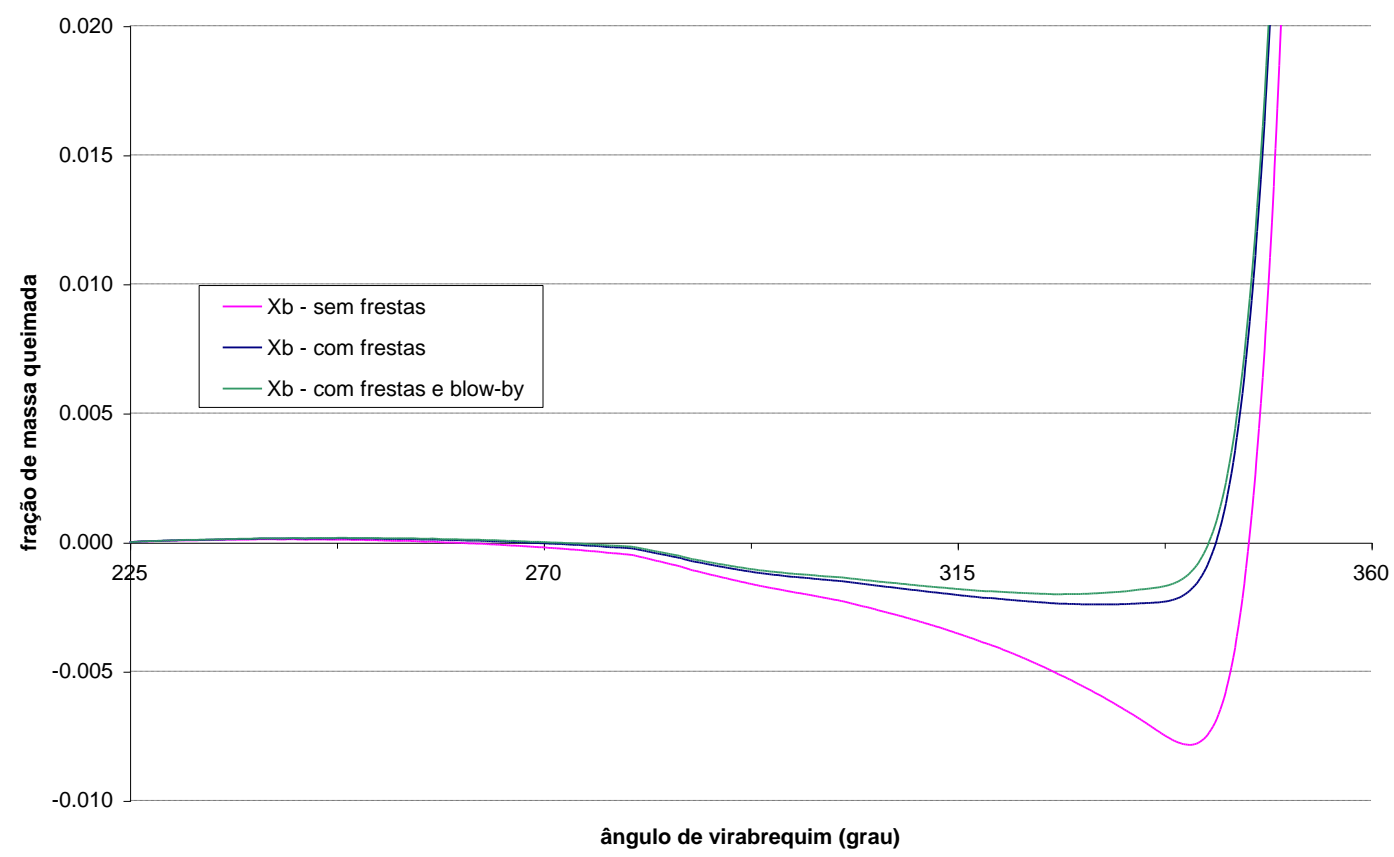

Figura 7.35 - Detalhe da Figura 7.34 na parte inicial da combustão. 


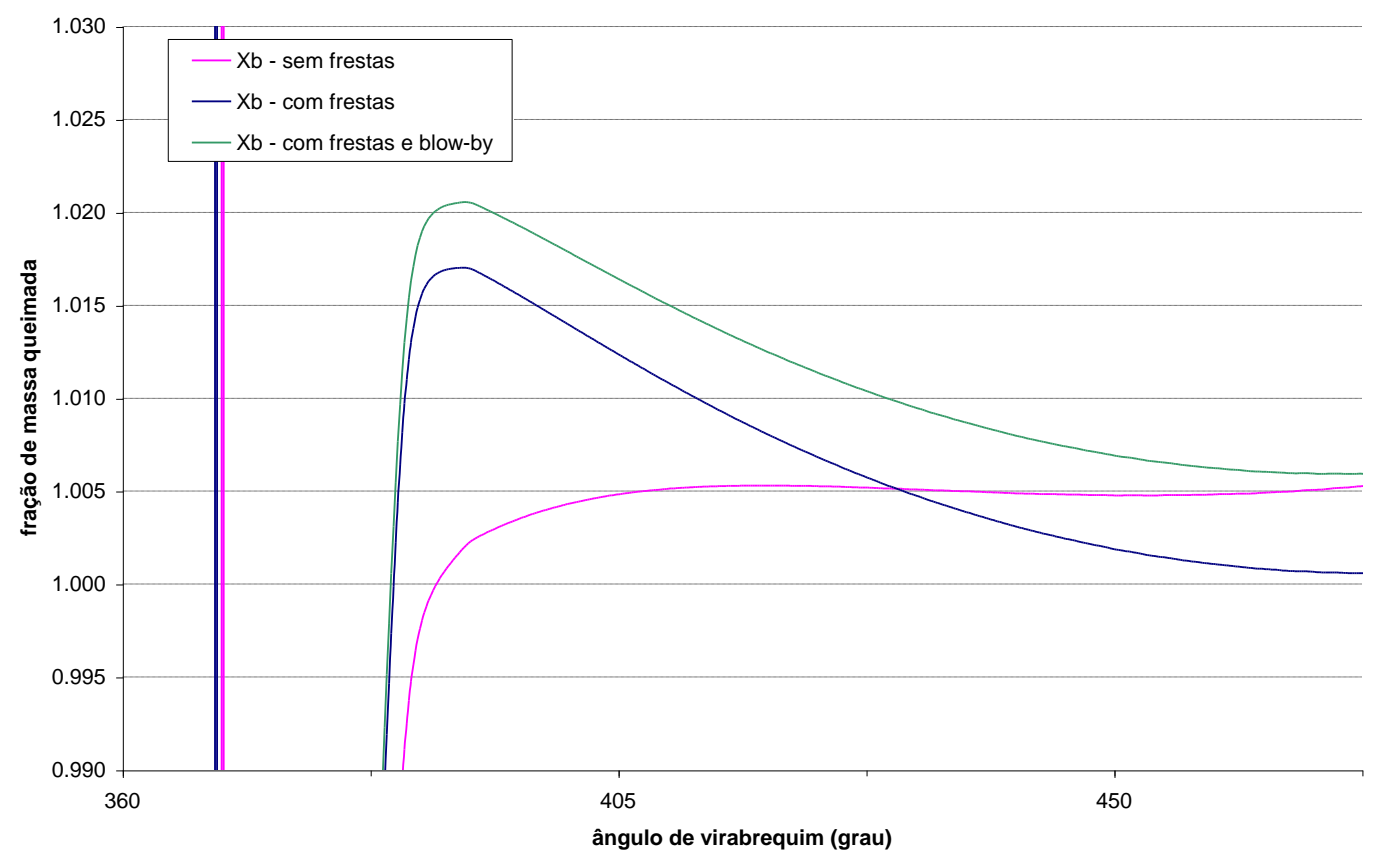

Figura 7.36 - Detalhe da Figura 7.34 na parte final da combustão.

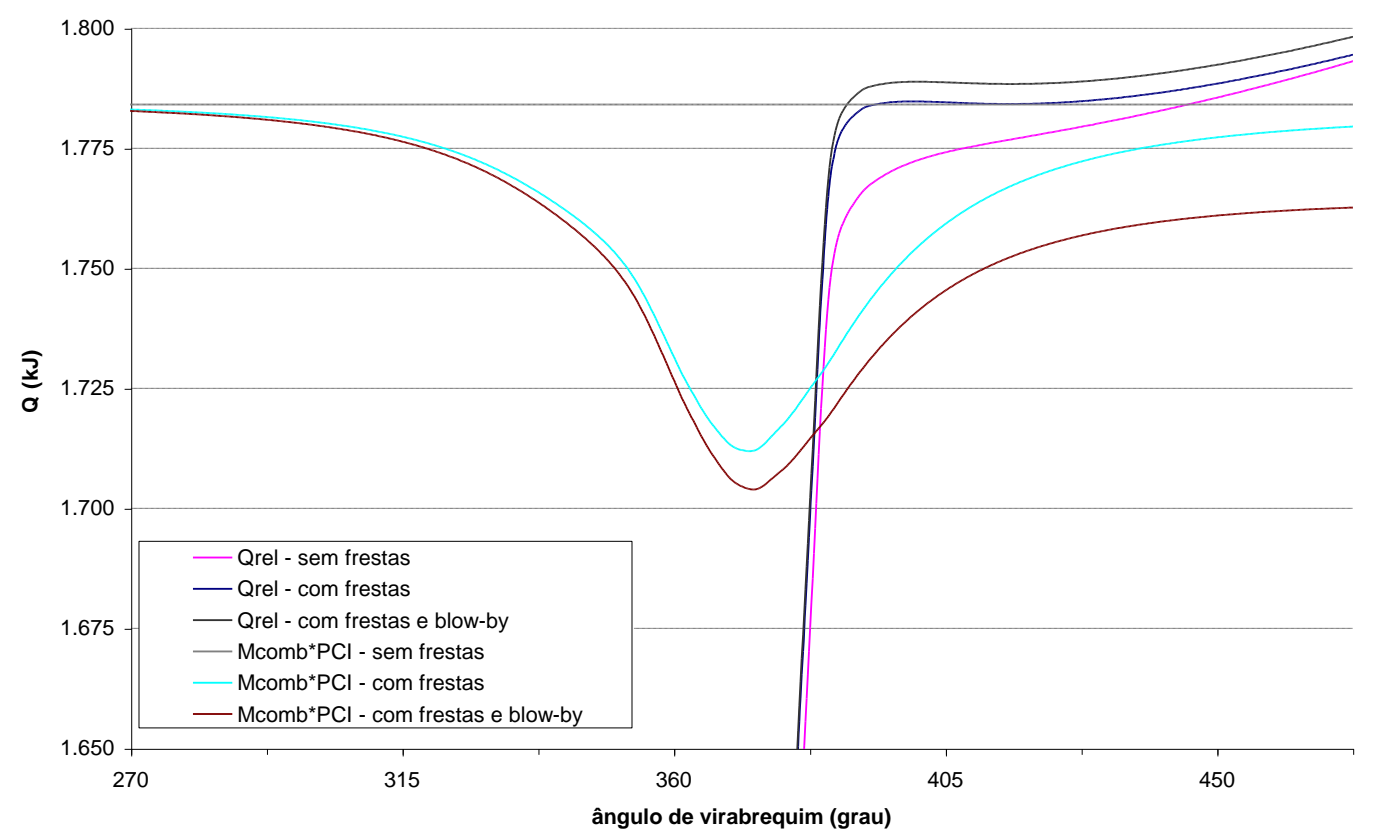

Figura 7.37 - Efeito dos vazamentos na liberação de calor.

Finalizando o estudo dos efeitos de blow-by, a Figura 7.38 traz a comparação entre as evoluções da frente de chama. Nota-se que, pelos mesmos motivos explicados anteriormente, o programa de análise prevê que o início da combustão deveria acontecer ainda mais cedo do que no caso que só considerava o efeito das frestas. 


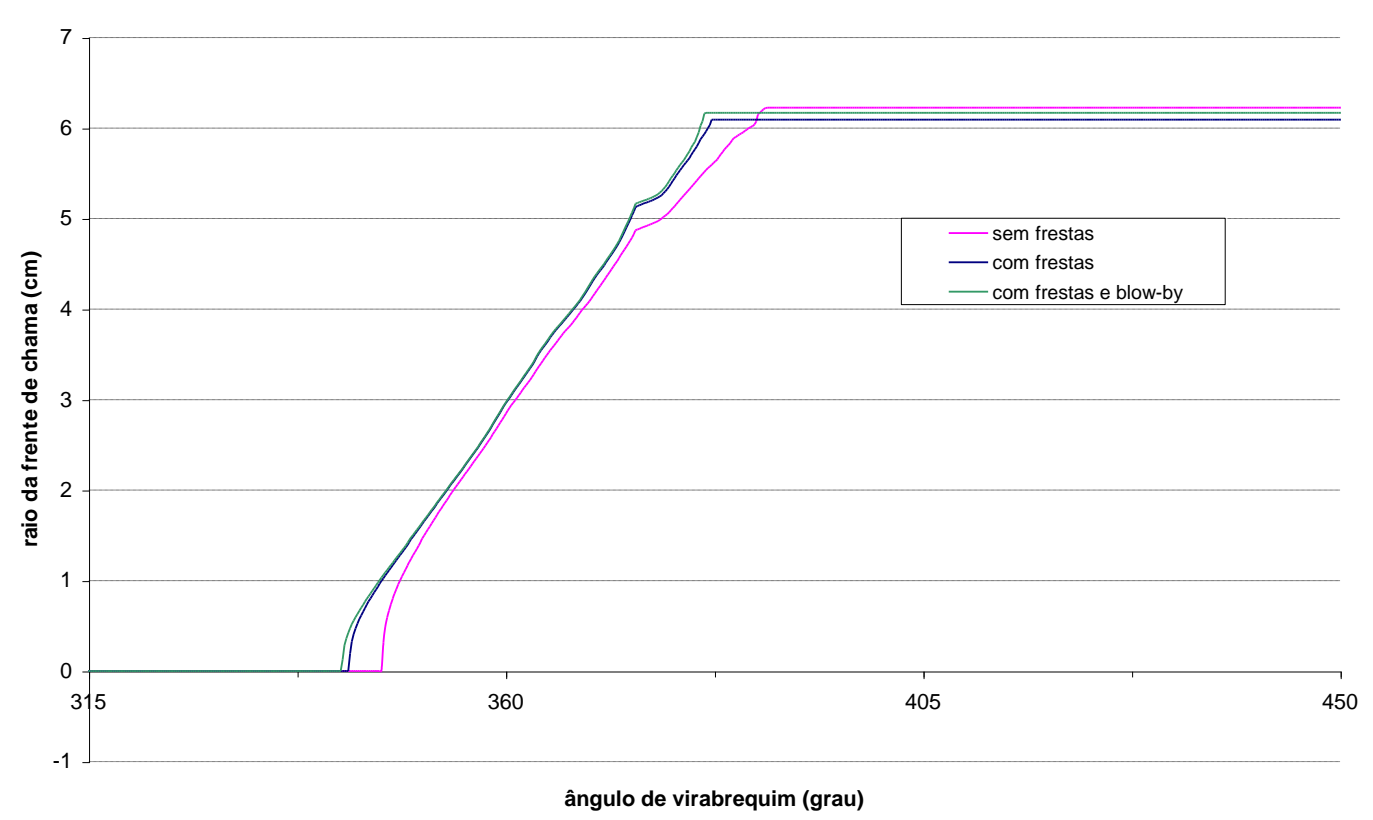

Figura 7.38 - Evolução da frente de chama considerando blow-by.

Pode-se confirmar que, para um vazamento da ordem de $1 \%$ da massa contida no cilindro no instante do fechamento da válvula de admissão (valor normalmente obtido em motores comerciais), os efeitos de blow-by são bem menores do que os demais apresentados até aqui.

A influência das temperaturas das paredes da câmara também foi estudada. $O$ conjunto de temperaturas utilizado no simulador e até agora adotado no programa de análise é o detalhado na Tabela 7.3. Uma redução de $40 K$ foi imposta a todas as temperaturas das paredes da câmara, de forma que as temperaturas utilizadas no programa de análise da combustão passaram a ser as constantes da Tabela 7.5.

\begin{tabular}{|c|c|}
\hline parede & temperatura $(K)$ \\
\hline topo do pistão & 480 \\
\hline cilindro & 420 \\
\hline cabeçote & 380 \\
\hline
\end{tabular}

Tabela 7.5 - Temperaturas das paredes reduzidas para efeito de análise de sensibilidade. 
A Figura 7.39 mostra o impacto desta alteração no cálculo da fração de massa queimada. Houve um aumento da ordem de 1,0\% na fração acumulada em relação ao calculado com as temperaturas originais. Esta diferença é causada pelo aumento do valor (absoluto) de calor trocado com as paredes, como pode ser visto na Figura 7.40. Note-se que esta diferença, entretanto, tem um efeito reduzido no cálculo das temperaturas dos gases contidos nos dois VC, como mostra a Figura 7.41, onde a maior diferença de temperatura ocorre no final da combustão para os gases não queimados $(\sim 8 K)$.

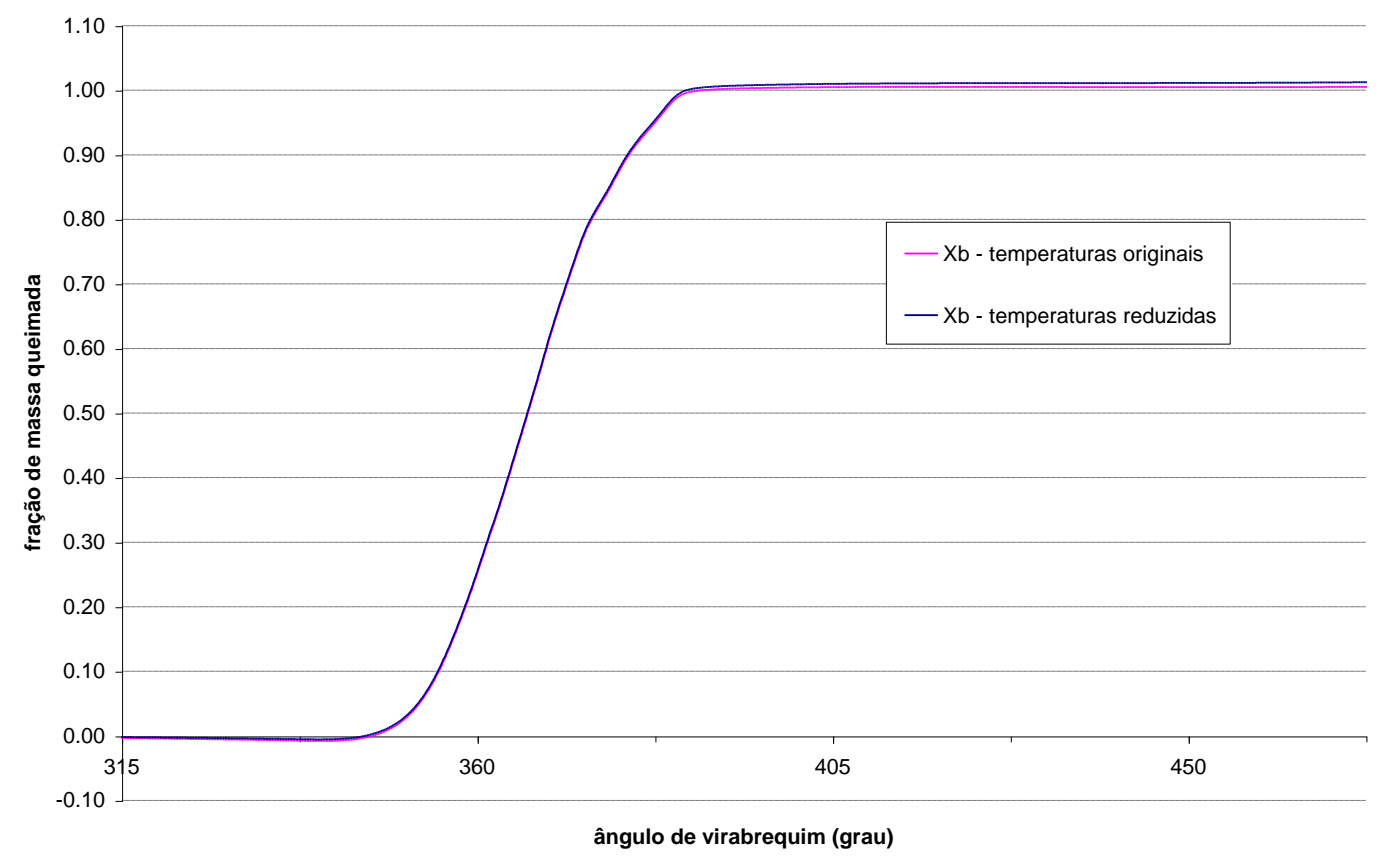

Figura 7.39 - Impacto da redução de temperaturas das paredes na fração de massa queimada.

Para complementação dos resultados, a Figura 7.42, a Figura 7.43 e a Figura 7.44 trazem as variações causadas na liberação de calor acumulada, na taxa de liberação de calor e na evolução do raio da frente de chama, respectivamente. Estes gráficos reforçam o fato de que uma incerteza da ordem de $40 K$ na determinação das temperaturas médias das paredes da câmara praticamente não altera a taxa de liberação 
de calor e causa uma diferença máxima de $1 \%$ na fração de massa queimada.

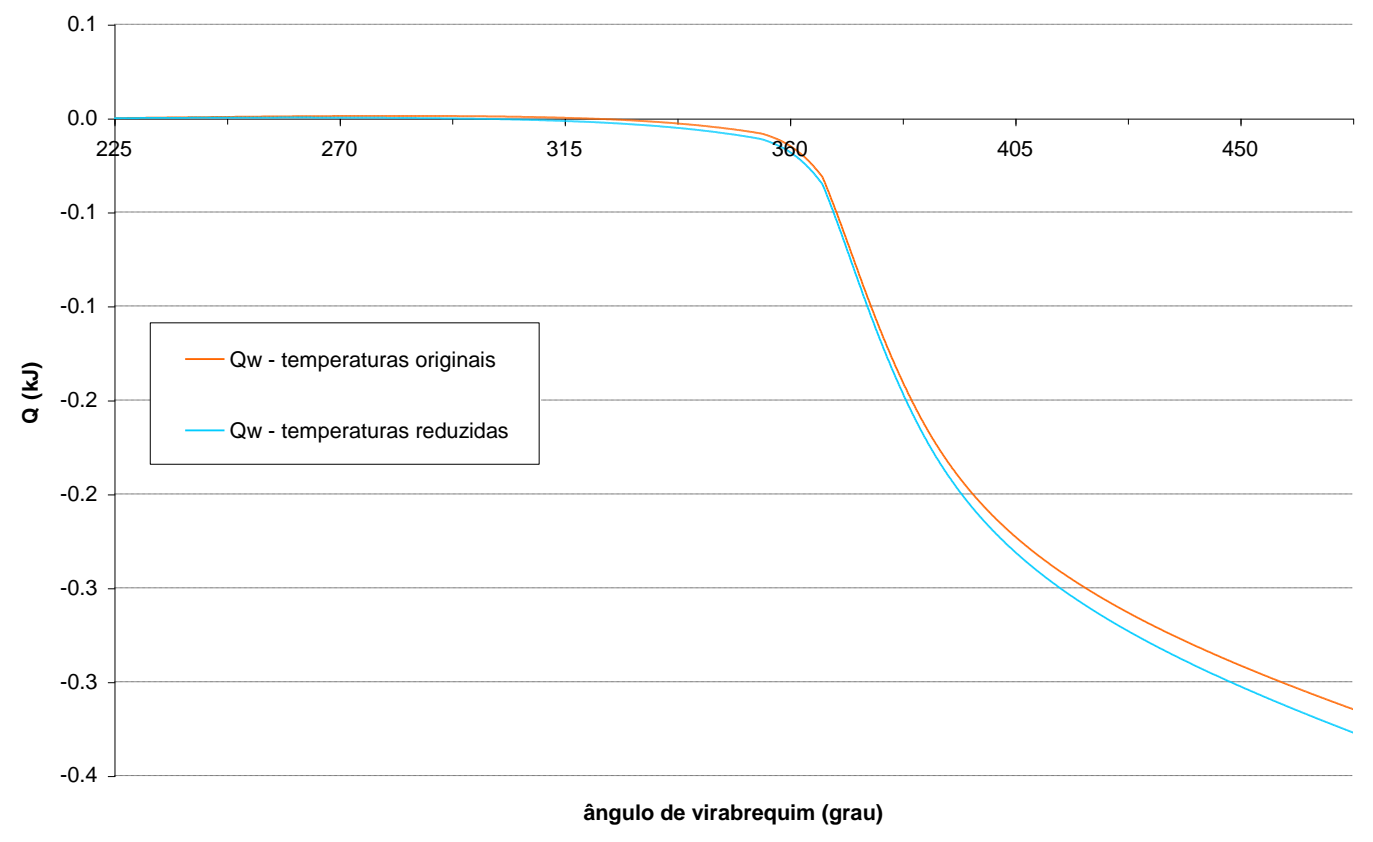

Figura 7.40 - Aumento na troca de calor devido à redução das temperaturas das paredes.

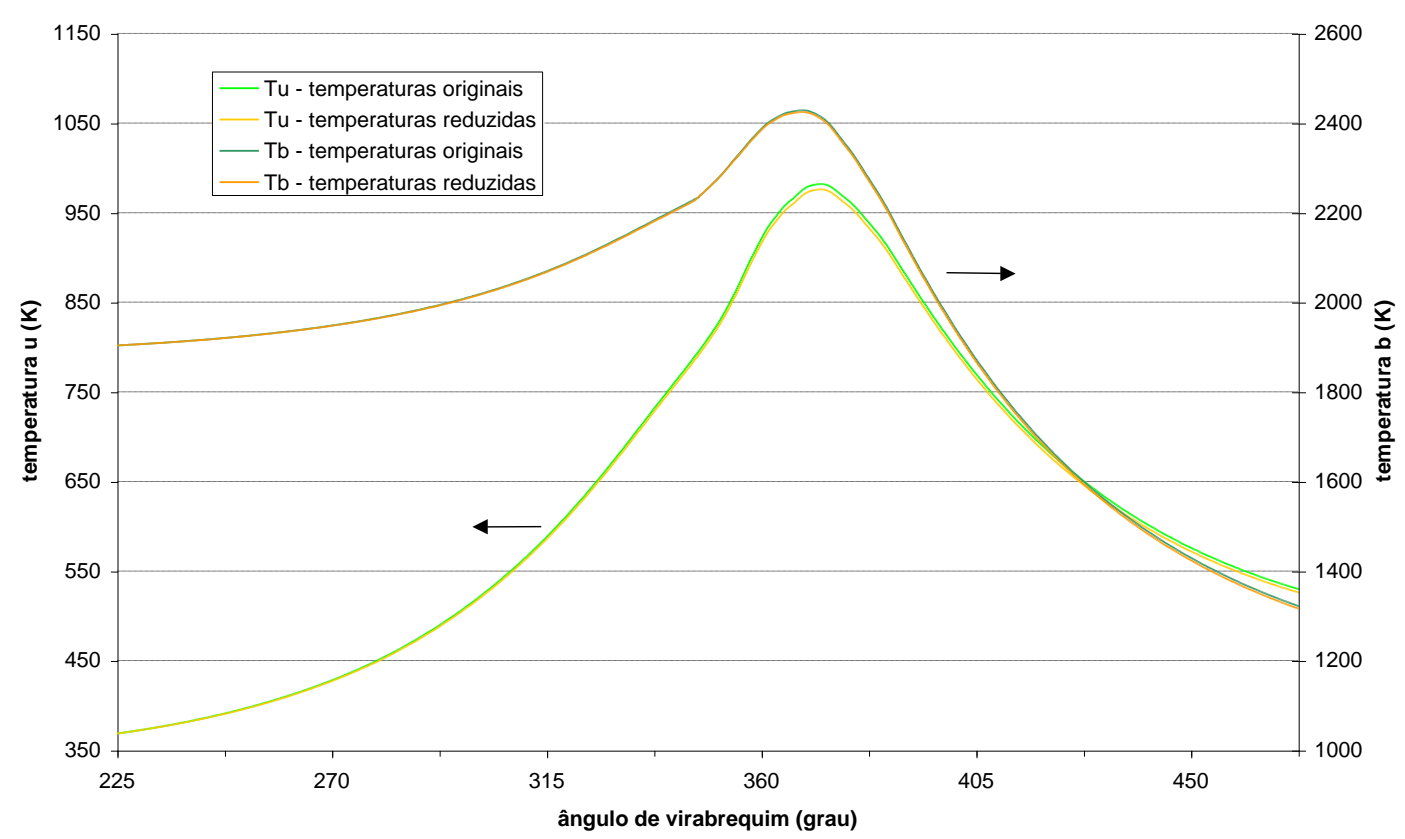

Figura 7.41 - Temperaturas dos VC calculadas com redução das temperaturas de paredes. 


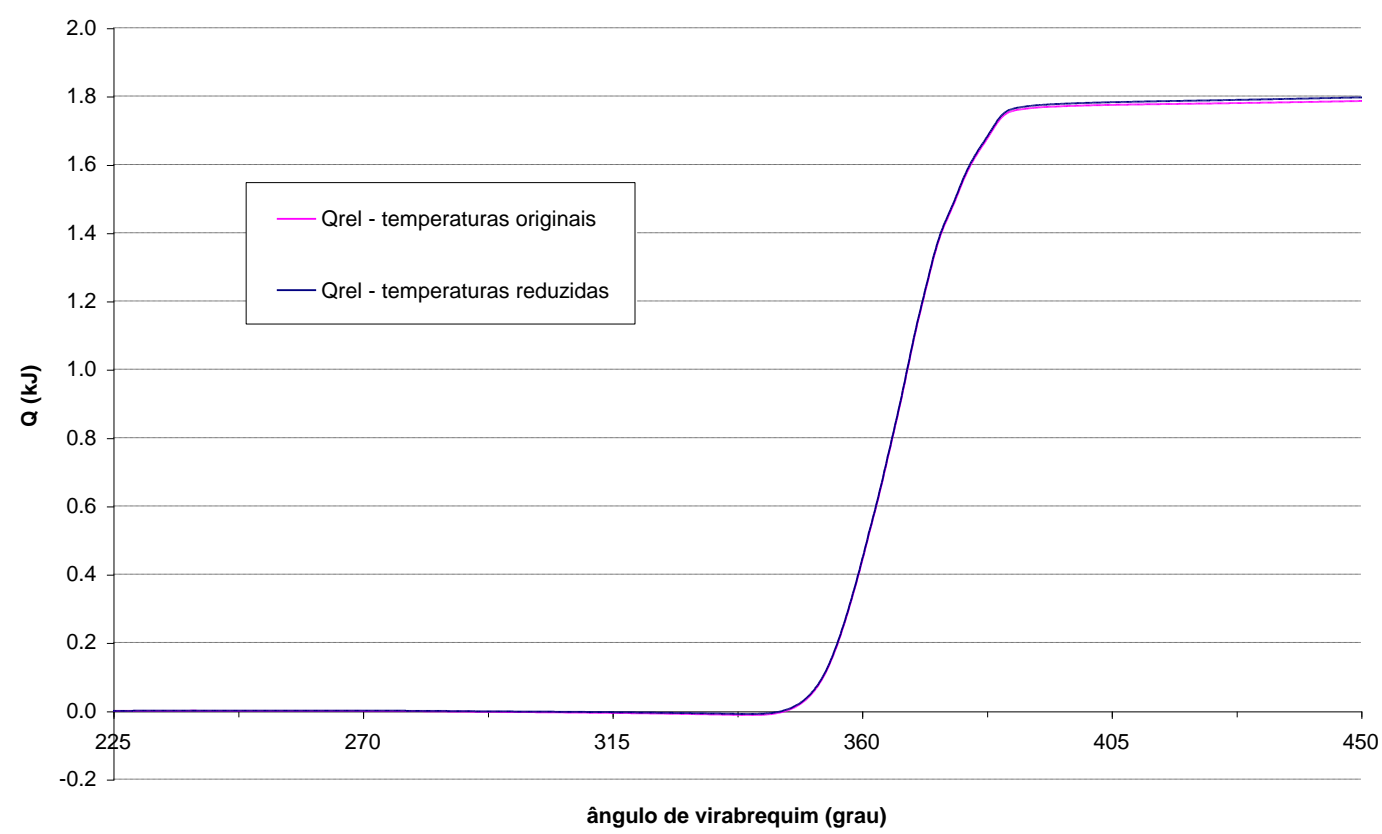

Figura 7.42 - Efeito da redução de temperaturas das paredes da câmara na liberação de calor.

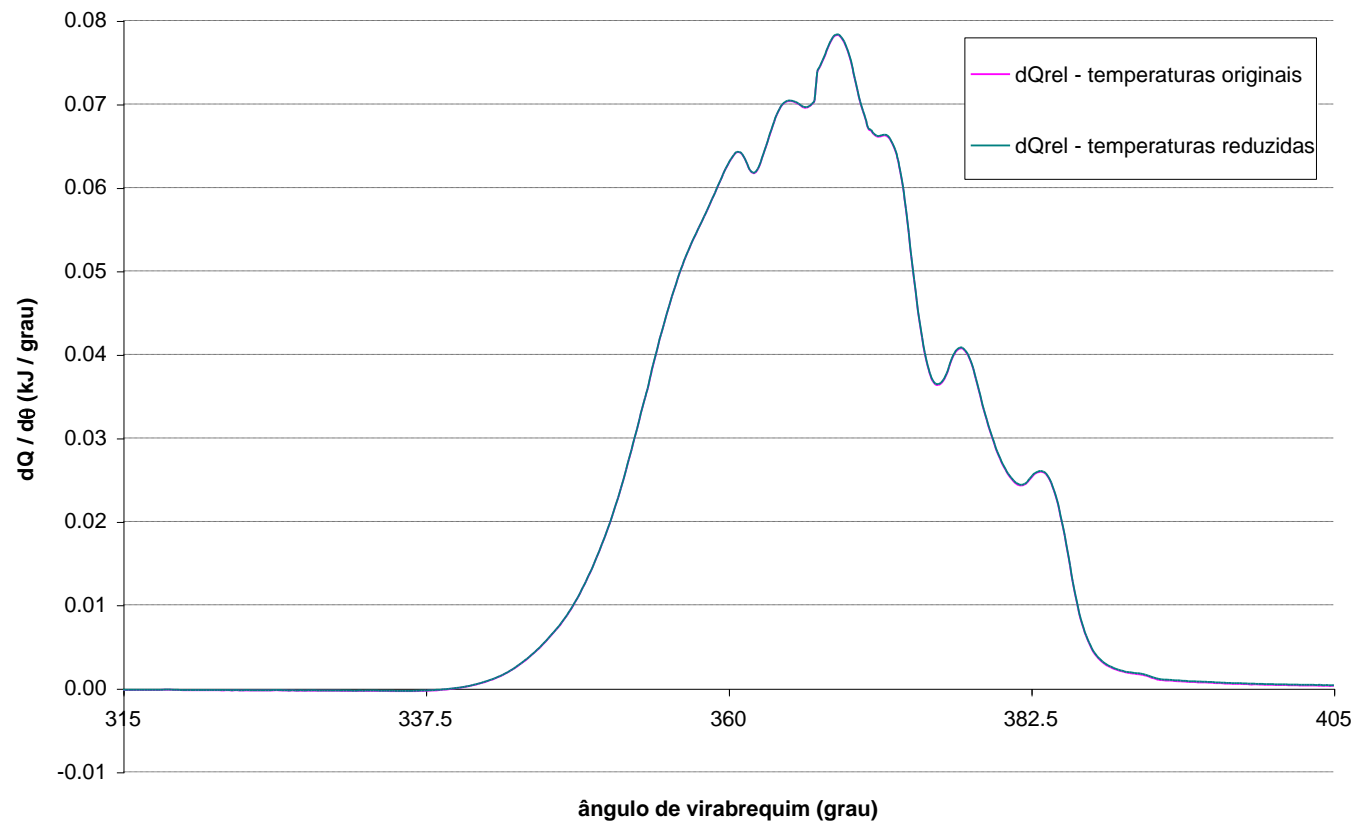

Figura 7.43 - Efeito da redução de temperaturas das paredes na taxa de liberação de calor. 


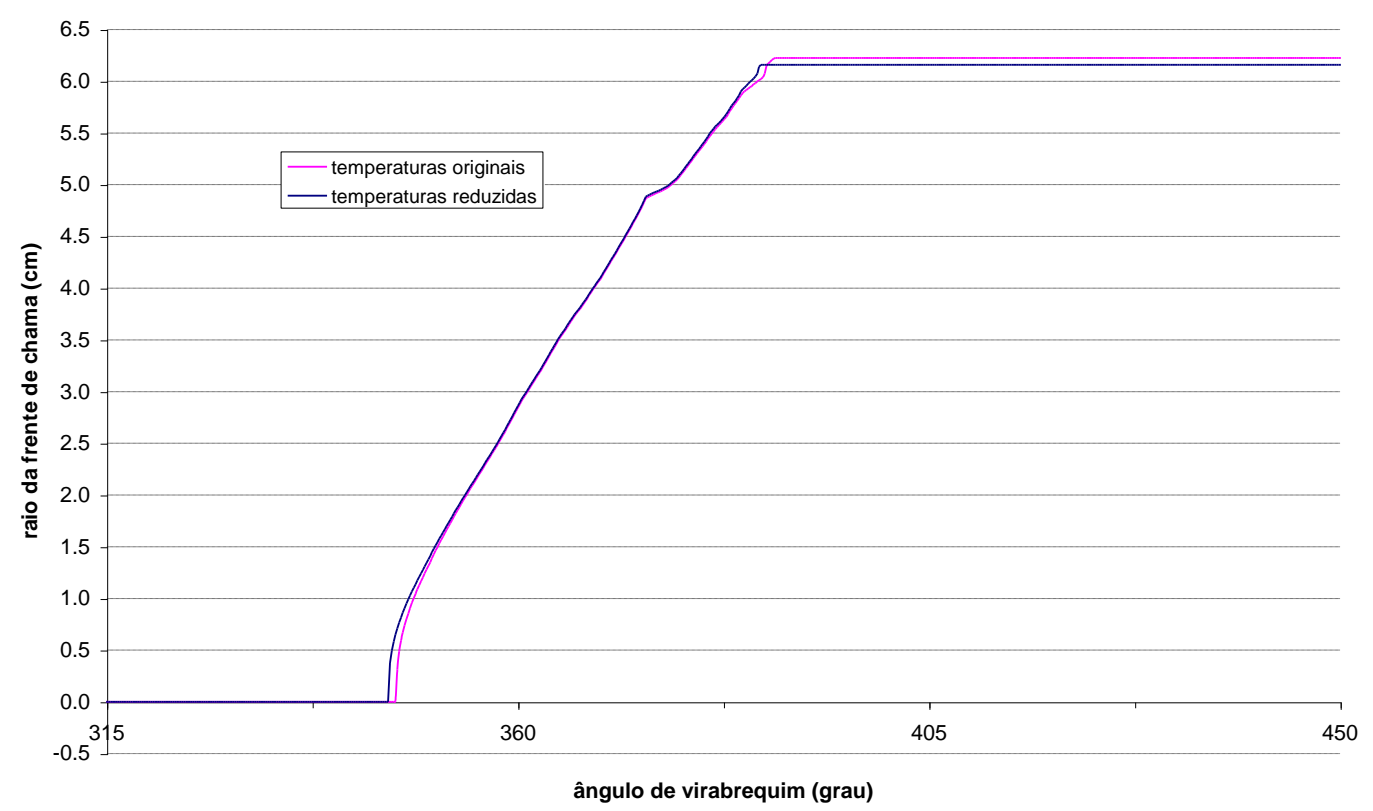

Figura 7.44 - Comparação entre as evoluções da frente de chama.

Tendo-se examinado a sensibilidade dos resultados à alteração dos principais parâmetros envolvidos na evolução da combustão e associados ao cálculo da liberação de calor, passa-se a reportar os resultados de análises efetuadas a partir de curvas de pressão medidas.

\subsection{Análise de dados experimentais}

O primeiro conjunto de dados a ser analisado foi aquele que continha a curva de pressão que serviu de base para a simulação no subcapítulo anterior (2800 rpm, plena carga). A composição do combustível utilizado é mostrada na Tabela 7.2 e os dados medidos na bancada podem ser vistos na Tabela 7.6. Estes dados foram coletados segundo o procedimento de ensaio descrito no subcapítulo 6.7 Dados coletados. 


\begin{tabular}{|l|c|c|c|l|}
\cline { 2 - 4 } \multicolumn{1}{c|}{} & $\mathrm{A}$ & $\mathrm{B}$ & $\mathrm{C}$ & \multirow{2}{*}{} \\
\hline rotação & 2800 & 2800 & 1680 & $\mathrm{rpm}$ \\
\hline \% carga & 100 & 50 & 100 & $\%$ \\
\hline umidade absoluta do ar de admissão & 0,0124 & 0,0121 & 0,0123 & $\mathrm{~kg}$ H2O $/ \mathrm{kg}_{\text {ar seco }}$ \\
\hline vazão mássica de combustível & 18,91 & 11,53 & 11,61 & $\mathrm{~kg} / \mathrm{h}$ \\
\hline vazão mássica de ar úmido & 406,8 & 248,3 & 252,2 & $\mathrm{~kg} / \mathrm{h}$ \\
\hline vazão mássica de vapor d'água & 4,98 & 2,98 & 3,07 & $\mathrm{~kg} / \mathrm{h}$ \\
\hline$\phi$ & 0,783 & 0,782 & 0,776 & - \\
\hline $\mathrm{P}_{\text {coletor admissão }}$ & 0,86 & 0,54 & 0,89 & bar \\
\hline $\mathrm{P}_{\text {coletor escapamento }}$ & 0,91 & 0,91 & 0,91 & bar \\
\hline $\mathrm{T}_{\text {admissão antes borboleta }}$ & 297 & 298 & 298 & $\mathrm{~K}$ \\
\hline $\mathrm{T}_{\text {escapamento }}$ & 970 & 937 & 910 & $\mathrm{~K}$ \\
\hline$\theta_{\text {centelha }}$ & 335,5 & 331,2 & 338,6 & graus \\
\hline
\end{tabular}

Tabela 7.6 - Valores medidos na bancada dinamométrica.

A partir destes dados, os consumos de ar, combustível e vapor d'água (médios entre os 6 cilindros) para cada condição foram calculados e são apresentados na Tabela 7.7 .

\begin{tabular}{|l|c|c|c|l|}
\cline { 2 - 4 } \multicolumn{1}{c|}{} & A & B & C & \\
\hline massa de combustível /ciclo & 0,0375 & 0,0229 & 0,0384 & g / ciclo \\
\hline massa de ar seco / ciclo & 0,797 & 0,487 & 0,824 & g / ciclo \\
\hline massa de vapor / ciclo & 0,0099 & 0,0059 & 0,0101 & g / ciclo \\
\hline massa total admitida / ciclo & 0,845 & 0,516 & 0,872 & g / ciclo \\
\hline
\end{tabular}

Tabela 7.7 - Consumos calculados a partir dos valores da Tabela 7.6.

As curvas médias de 25 ciclos adquiridas para as condições A, B e C da Tabela 7.6 são mostradas na Figura 7.45. É conveniente lembrar que a aquisição destas curvas de pressão foi realizada com um intervalo de $0,2^{\circ}$ de virabrequim.

Passando-se então à análise da condição A (2800 rpm, plena carga), a curva de pressão média adquirida foi fornecida como dado de entrada ao programa de cálculo, juntamente com os consumos correspondentes mostrados na Tabela 7.7, volume de frestas igual a $1 \mathrm{~cm}^{3}(\operatorname{com} T=470 \mathrm{~K})$ e constante de vazamento $K_{b b}$ igual a 0,044 . Utilizou-se ainda o valor de fração de gases residuais fornecido pelo simulador $(0,048)$. 


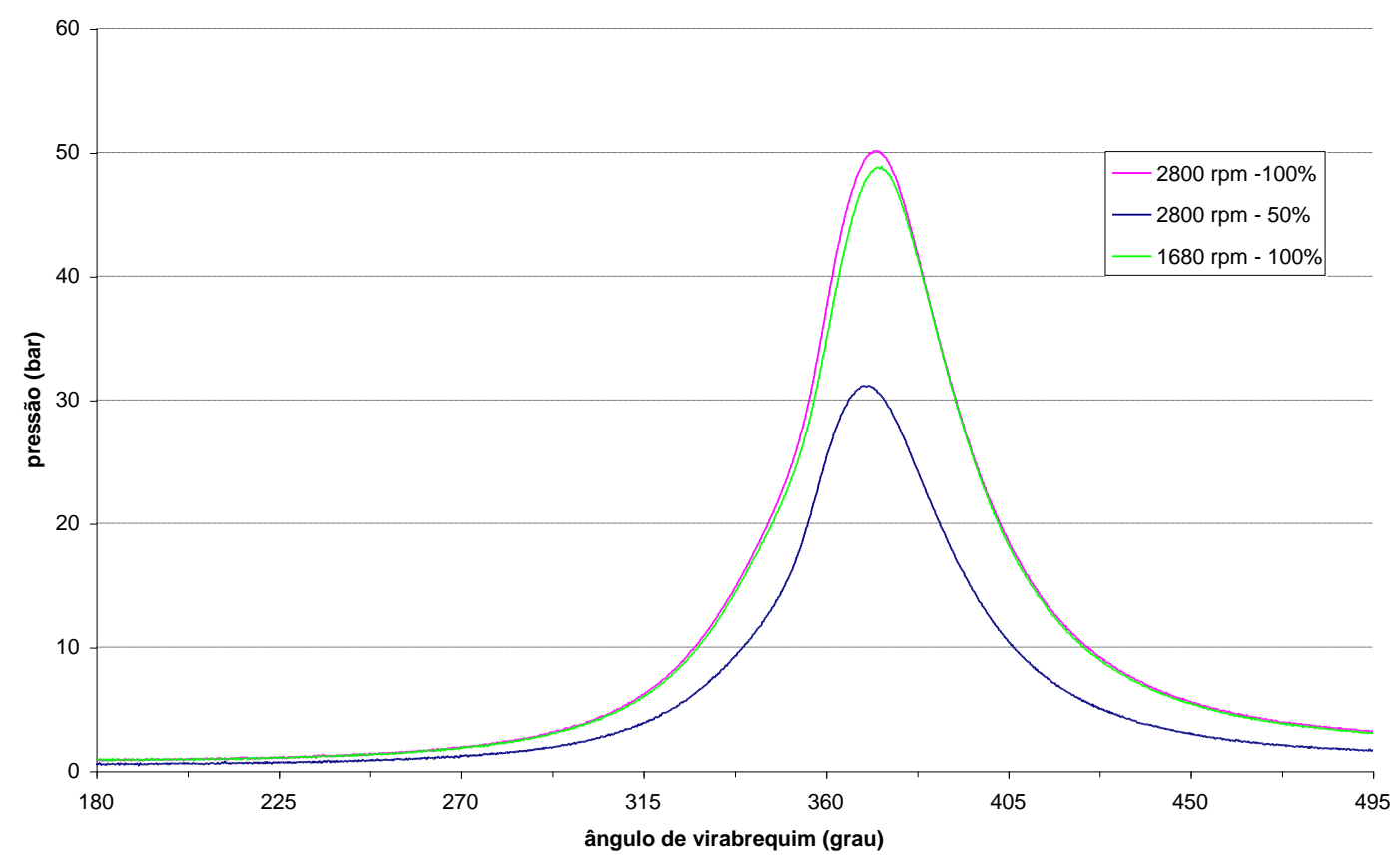

Figura 7.45 - Pressões médias de 25 ciclos.

Como resultado da análise, efetuada com passo de integração de $0,2^{\circ}$, as frações mássicas de gases queimados, de gases contidos nas frestas e de gases de blow-by são mostradas na Figura 7.46 e a liberação acumulada de calor é mostrada na Figura 7.47. Pelo fato de a massa específica dos gases não queimados ser da ordem de 2,5 vezes maior do que a massa específica dos queimados na região de pico de pressão e pela menor temperatura dos gases nas frestas, um volume das frestas de $1,1 \%$ do volume da câmara armazena cerca de $4 \%$ de massa em seu interior.

Também a evolução do raio da frente de chama e o volume contido em seu interior podem ser observados através da Figura 7.48. 


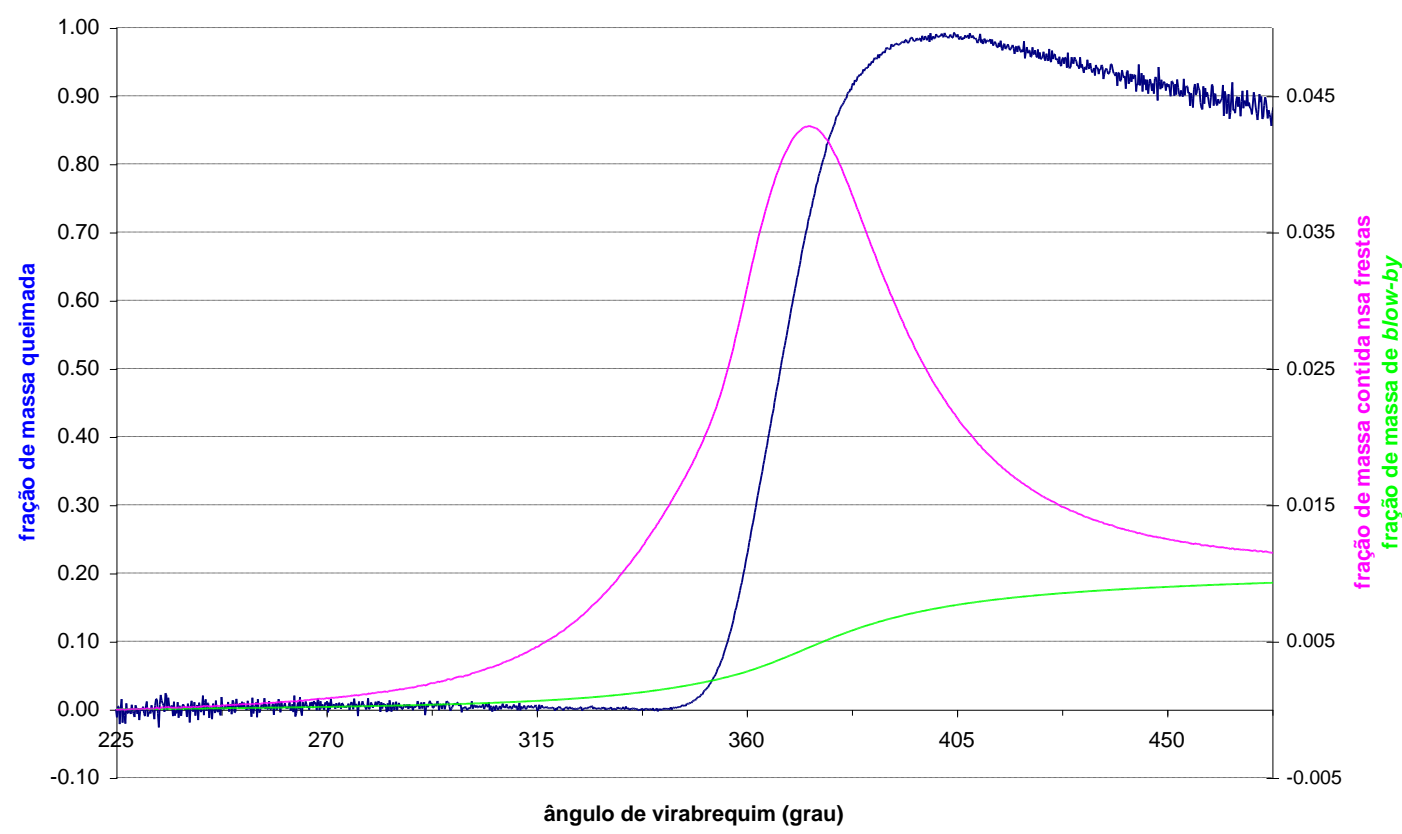

Figura 7.46 - Evoluções das frações mássicas (caso A).

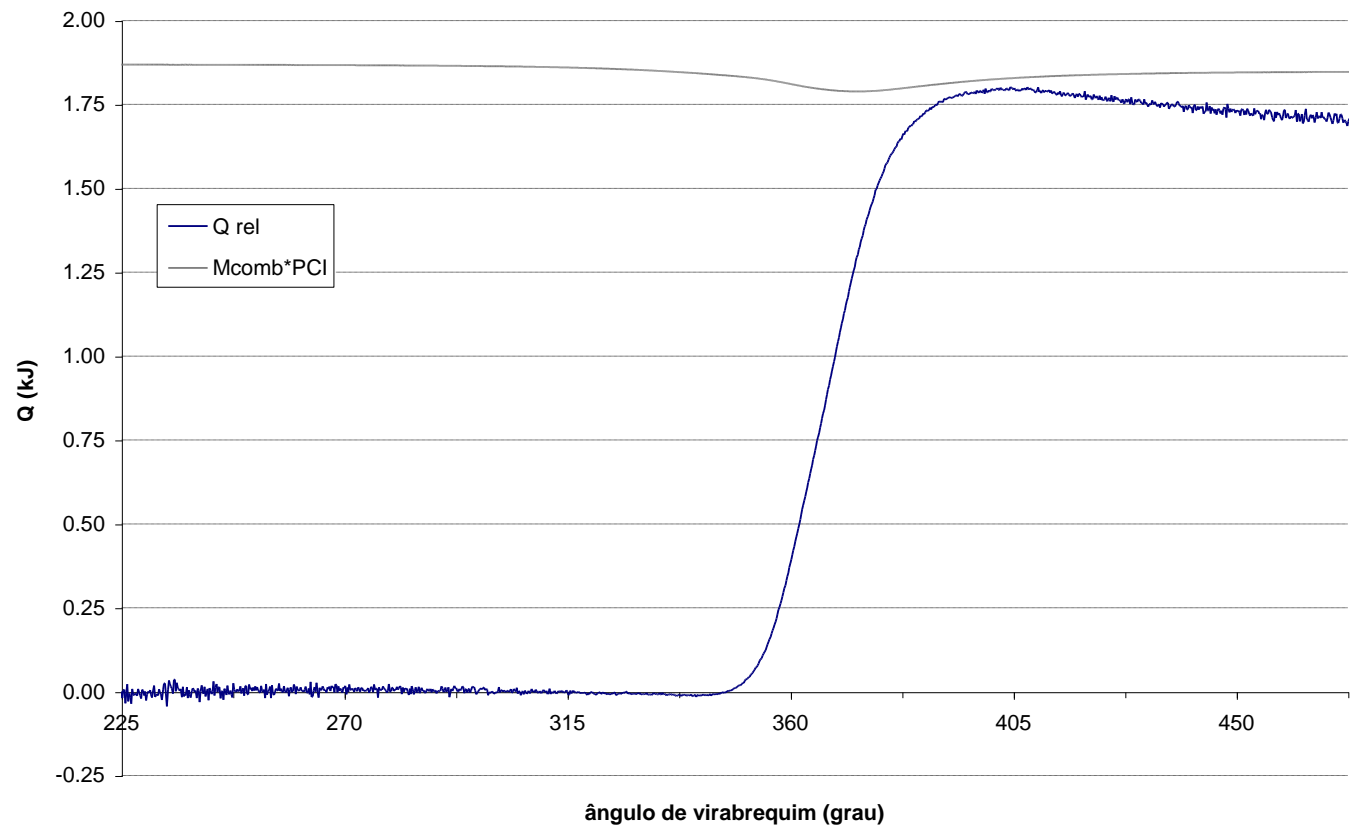

Figura 7.47 - Curva de liberação de calor (caso A).

Uma observação deve ser feita: as partes finais das curvas de fração de massa queimada e de liberação de calor são decrescentes em função do "short term drift" do transdutor, efeito este descrito anteriormente. A título de exemplificação, uma curva 
simples de correção de pressão análoga à mostrada na Figura 6.3 foi adicionada à curva de pressão medida, como mostra a Figura 7.49, e esta nova curva de pressão foi então fornecida ao programa de análise. As novas curvas de fração de massa queimada e liberação de calor são mostradas na Figura 7.50 e na Figura 7.51.

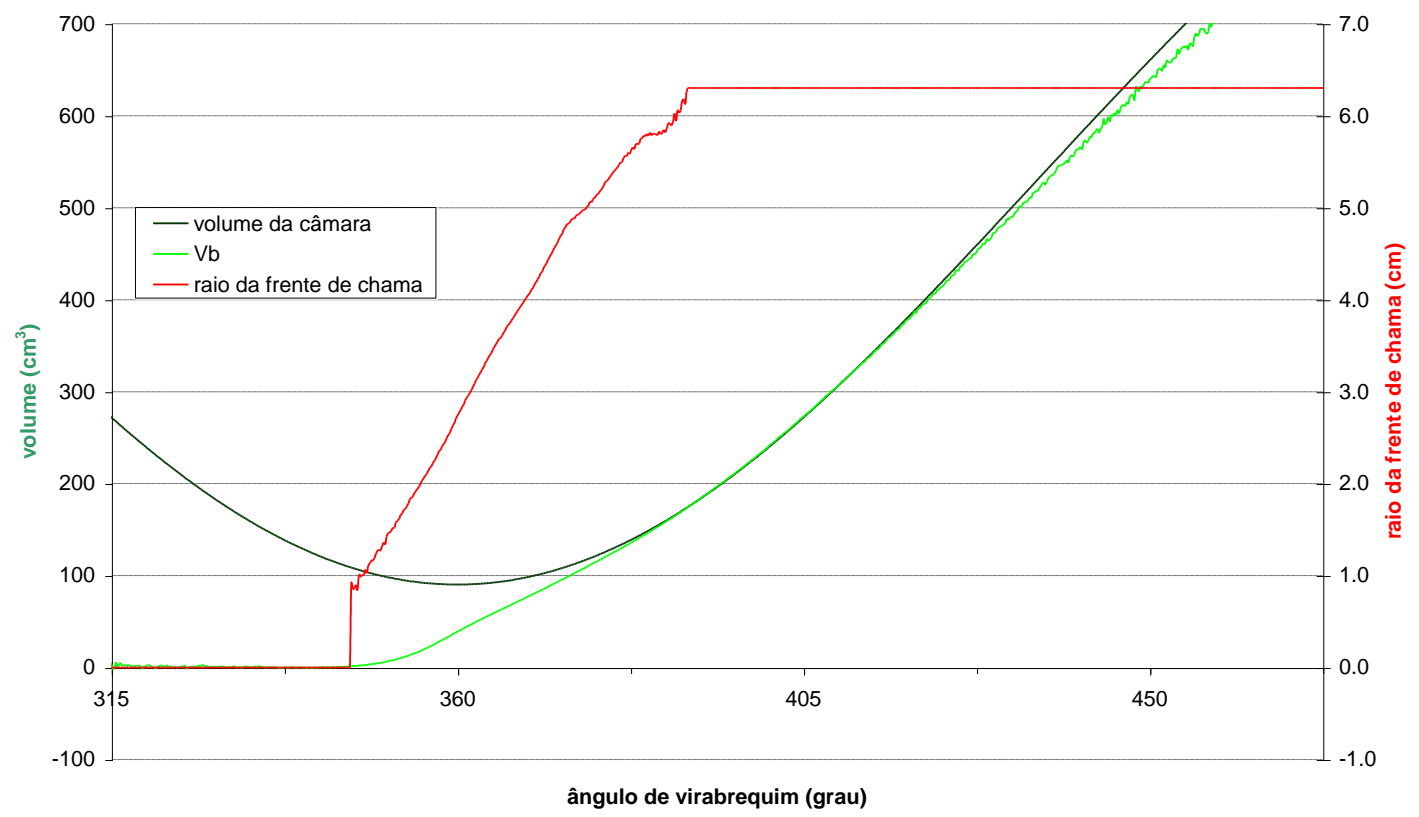

Figura 7.48 - Evolução do volume queimado e do raio da frente de chama (caso A).

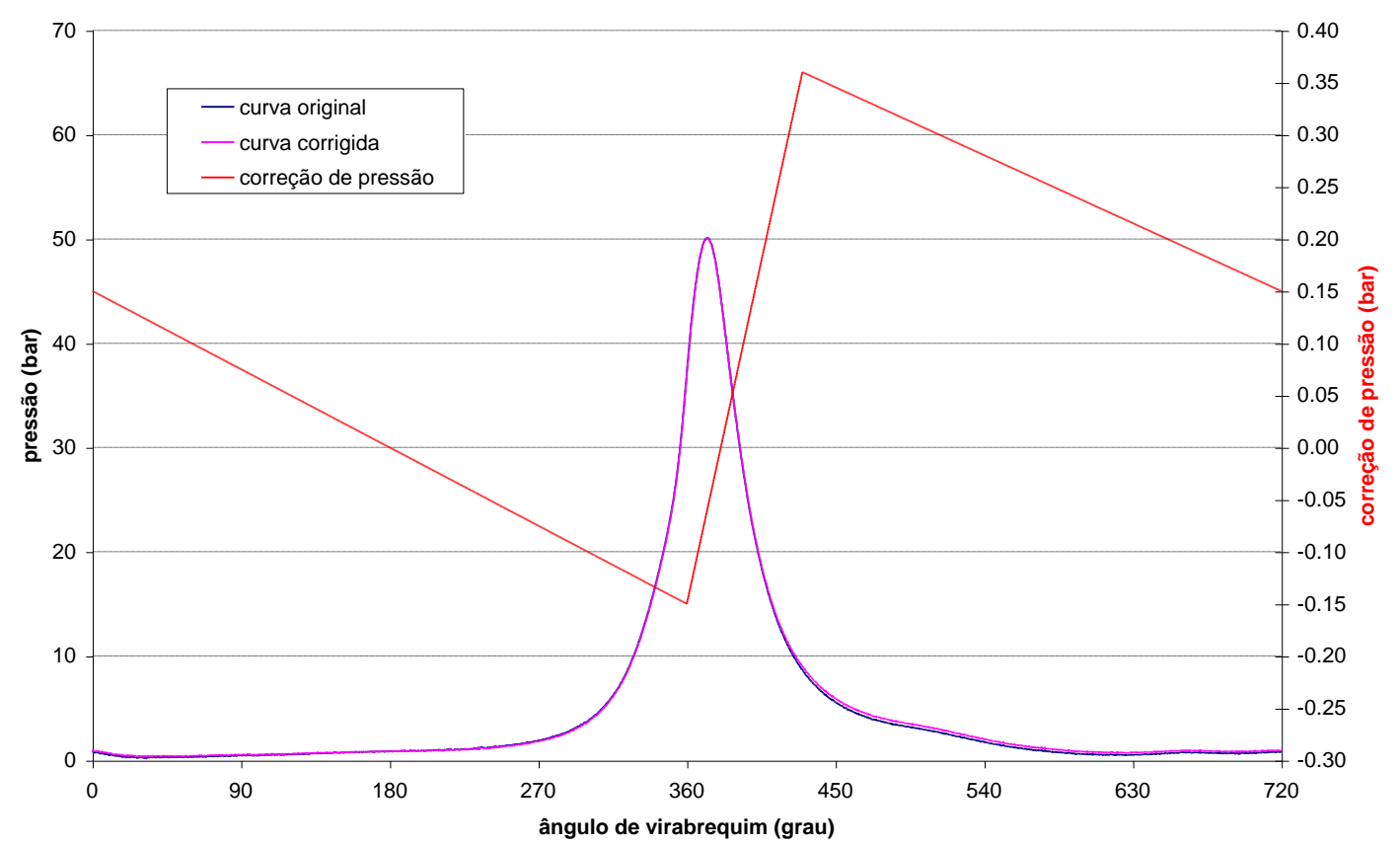

Figura 7.49 - Correção de pressão estimada devida ao drift do transdutor. 


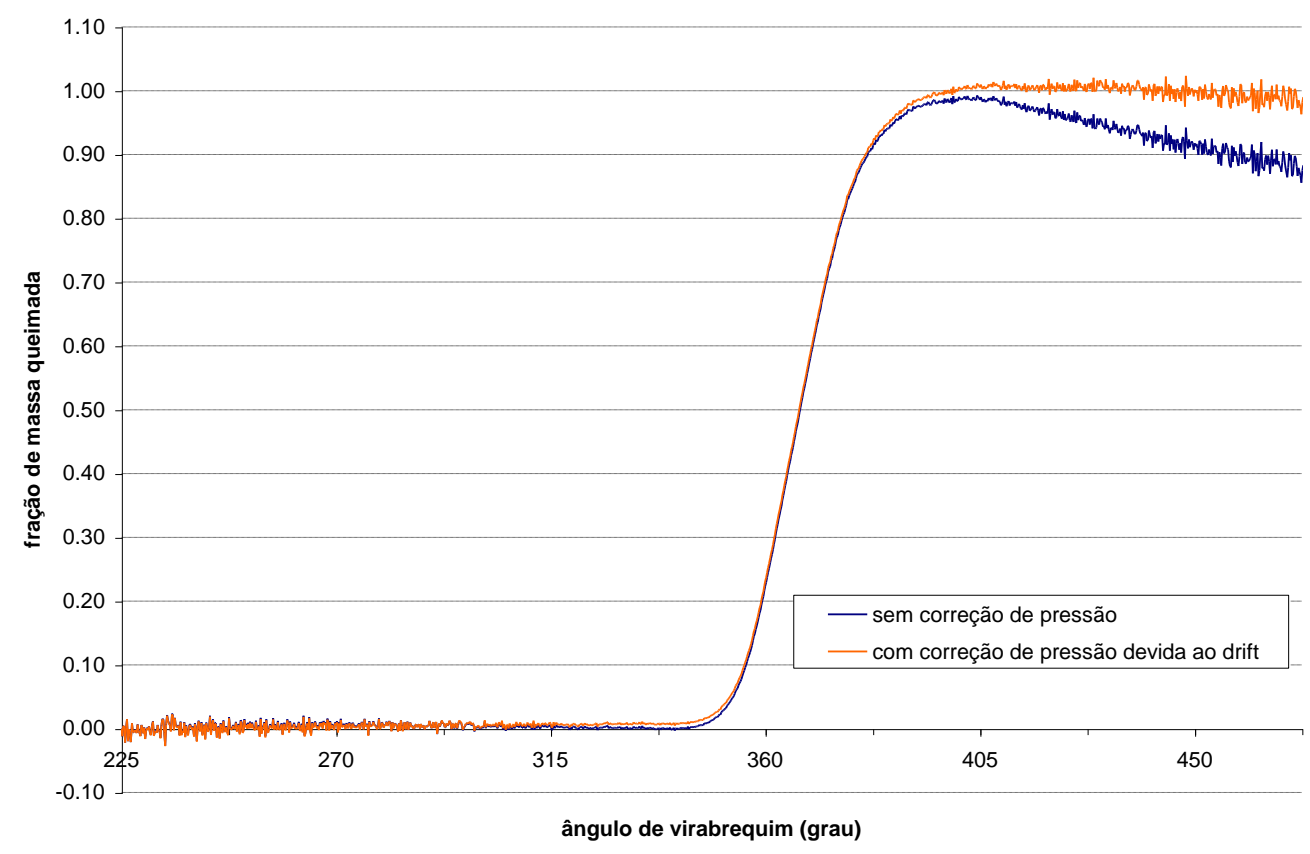

Figura 7.50 - Efeito da correção do drift na fração de massa queimada.

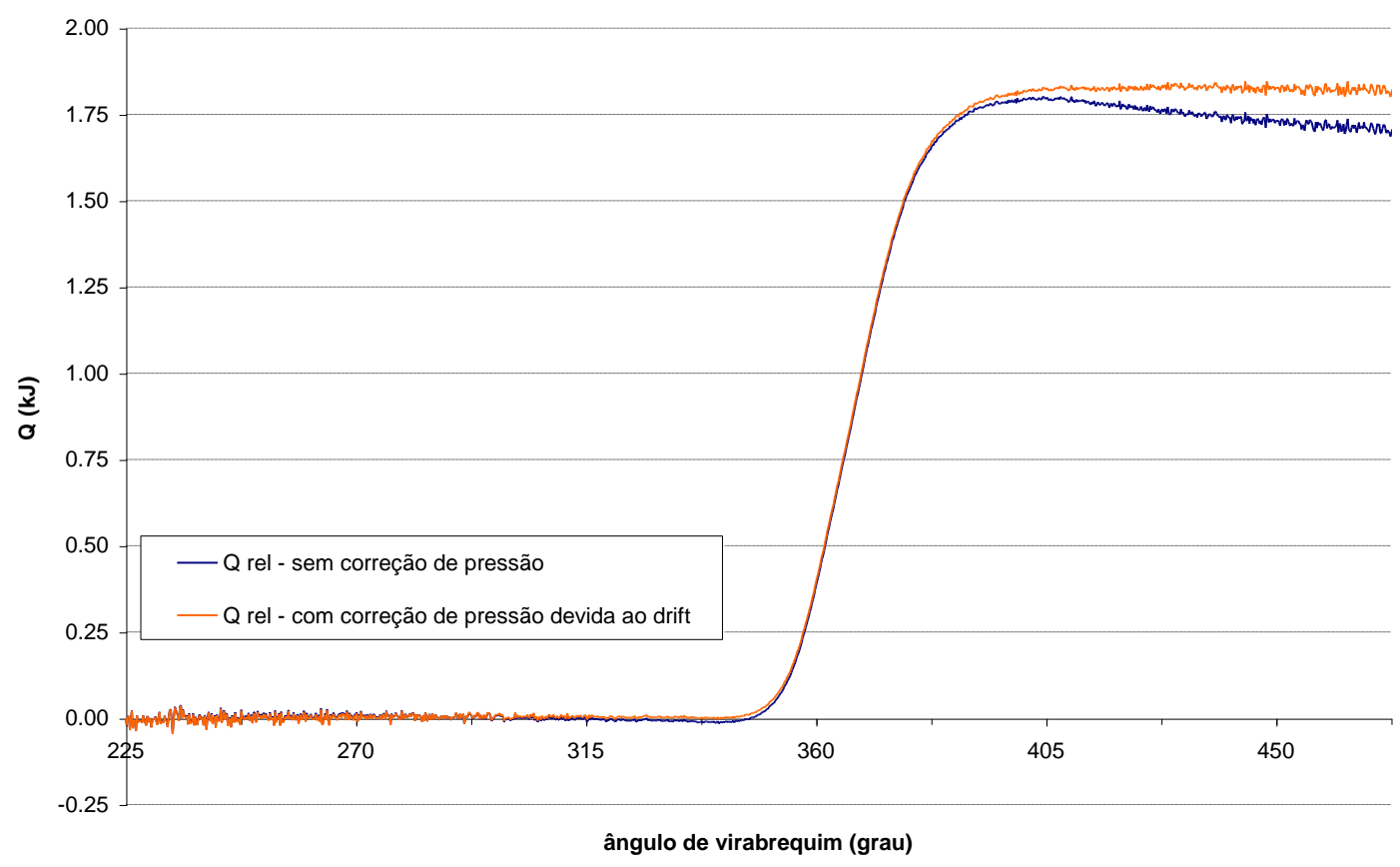

Figura 7.51 - Efeito da correção do drift na liberação de calor.

Note-se que uma correção de amplitude de 0,5 bar na região de combustão praticamente não altera as partes iniciais das curvas de massa queimada e liberação de calor, mas seu impacto nas partes finais destas mesmas curvas é sensível. Como, no 
entanto, na região de combustão a diferença entre as curvas é muito pequena, utilizar-seão as curvas de pressão originais nas análises a seguir.

Passando para a análise da taxa de liberação de calor, observa-se que o efeito dos ruídos e incertezas associados à aquisição de pressão exercem grande influência na curva da razão de liberação calculada, mesmo sendo a curva de pressão fornecida ao simulador uma média de 25 ciclos amostrados. A Figura 7.52 traz a curva de taxa de liberação calculada a partir da curva média amostrada a cada $0,2^{\circ}$ de virabrequim. A grande flutuação que pode ser vista é causada pela variação na derivada da pressão, como mostra a Figura 7.53, mesmo sendo esta calculada através de diferença finita centrada a cada $0,2^{\circ}$.

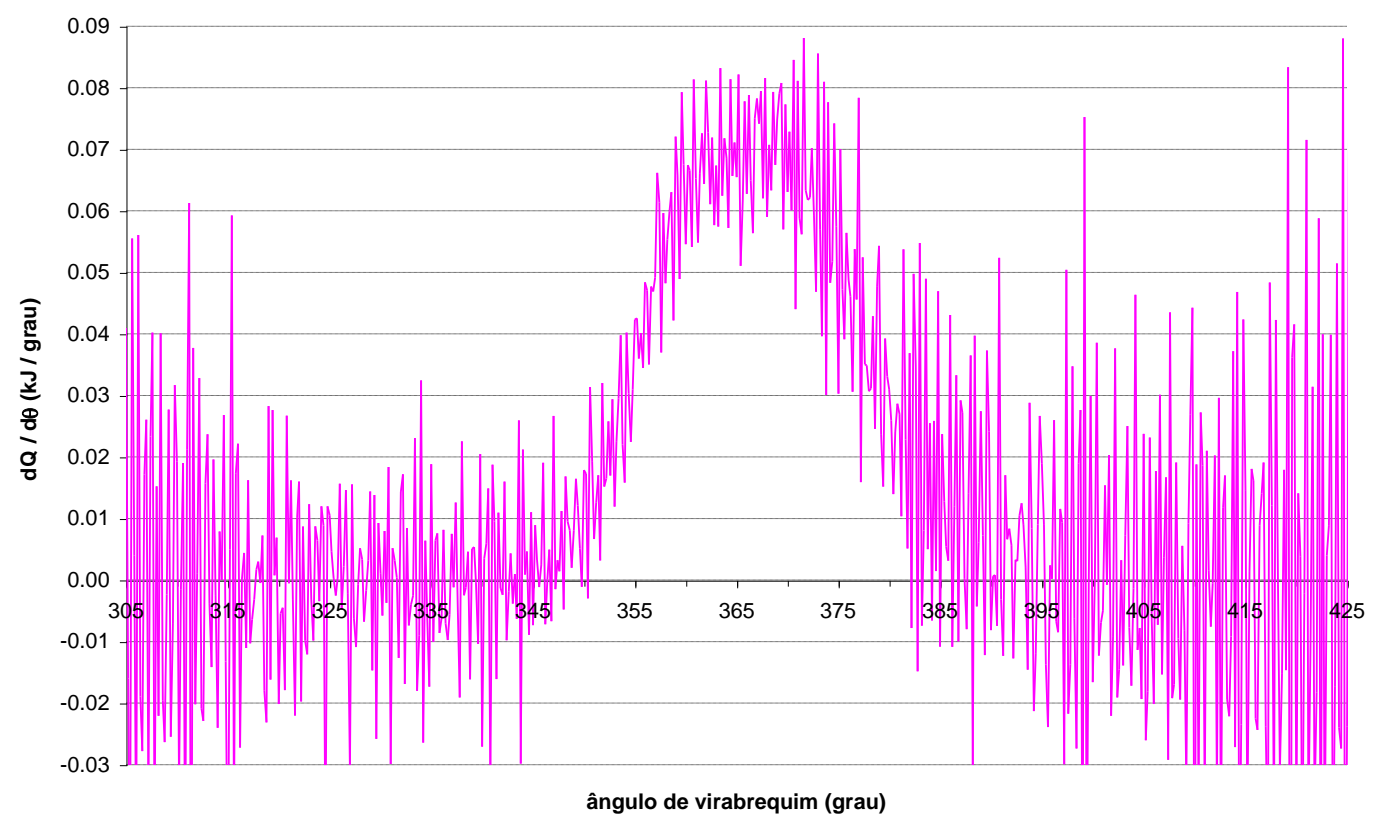

Figura 7.52 - Taxa de liberação de calor calculada a cada $0,2^{\circ}$ (caso A).

Estas flutuações dificultam a comparação entre curvas de taxa de liberação de calor calculadas em diversas condições. Uma forma de se atenuarem estas flutuações é utilizar um passo de integração de $1,0^{\circ}$ de virabrequim, mesmo sendo a curva de pressão 
amostrada a cada $0,2^{\circ}$ pois, como comentado na literatura, a determinação da correta posição de referência é muito mais importante do que o próprio passo de cálculo.

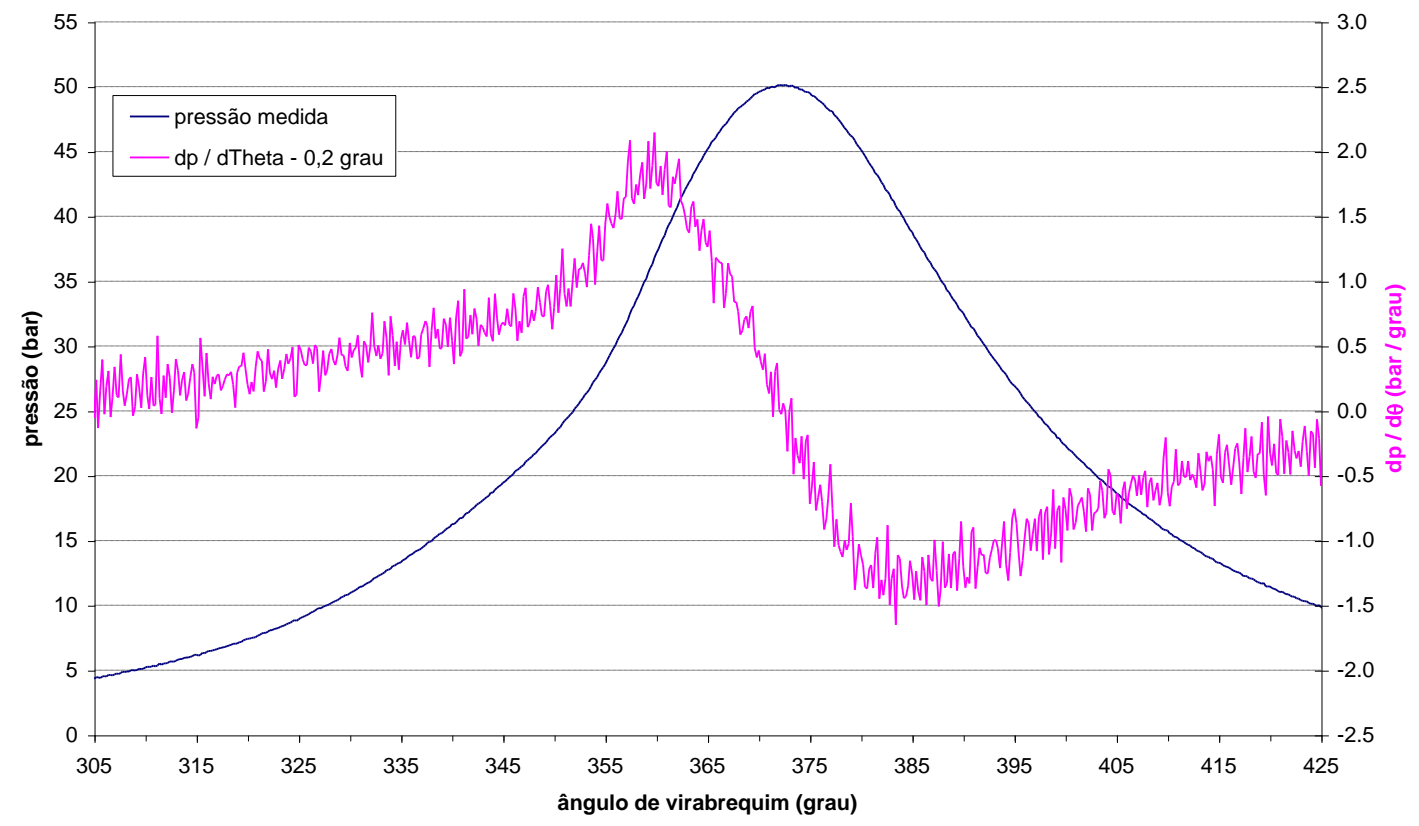

Figura 7.53 - Derivada da pressão calculada com diferenças finitas centradas $\left(0,2^{\circ}\right)$.

A Figura 7.54 mostra a comparação entre as derivadas da pressão calculadas a cada $0,2^{\circ}$ e a cada $1,0^{\circ}$ de virabrequim, enquanto a Figura 7.55 mostra a comparação entre as liberações acumuladas de calor calculadas utilizando-se estes dois passos de integração.

A Figura 7.56 mostra a comparação entre as taxas de liberação de calor calculadas para os dois passos de integração. Observa-se que a curva calculada com passo de integração igual a $1,0^{\circ}$ é mais fácil de ser visualizada sem, no entanto, se afastar demasiadamente da curva média calculada com passo igual a $0,2^{\circ}$. 


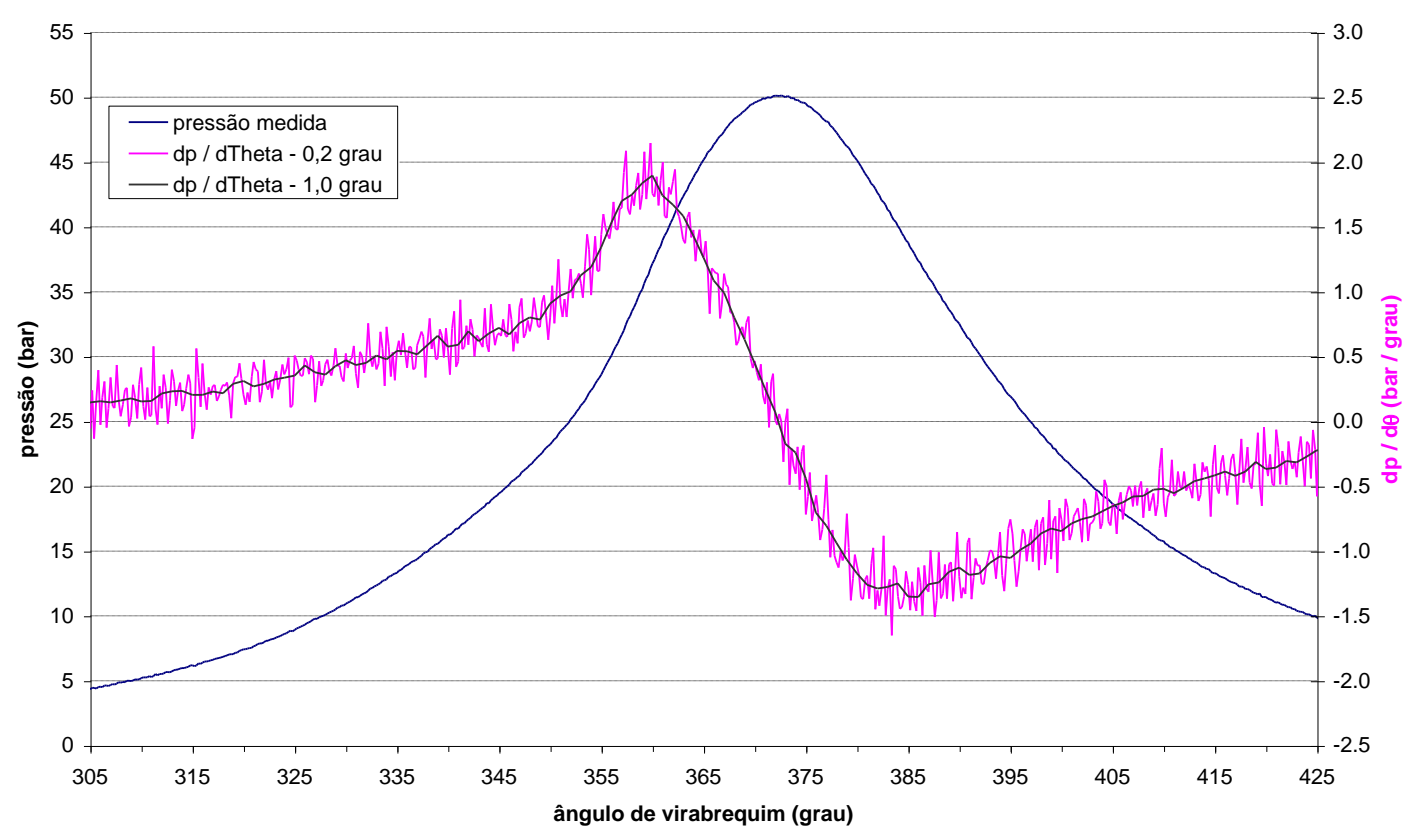

Figura 7.54 - Derivadas de pressão calculadas a cada $0,2^{\circ}$ e $1,0^{\circ}$.

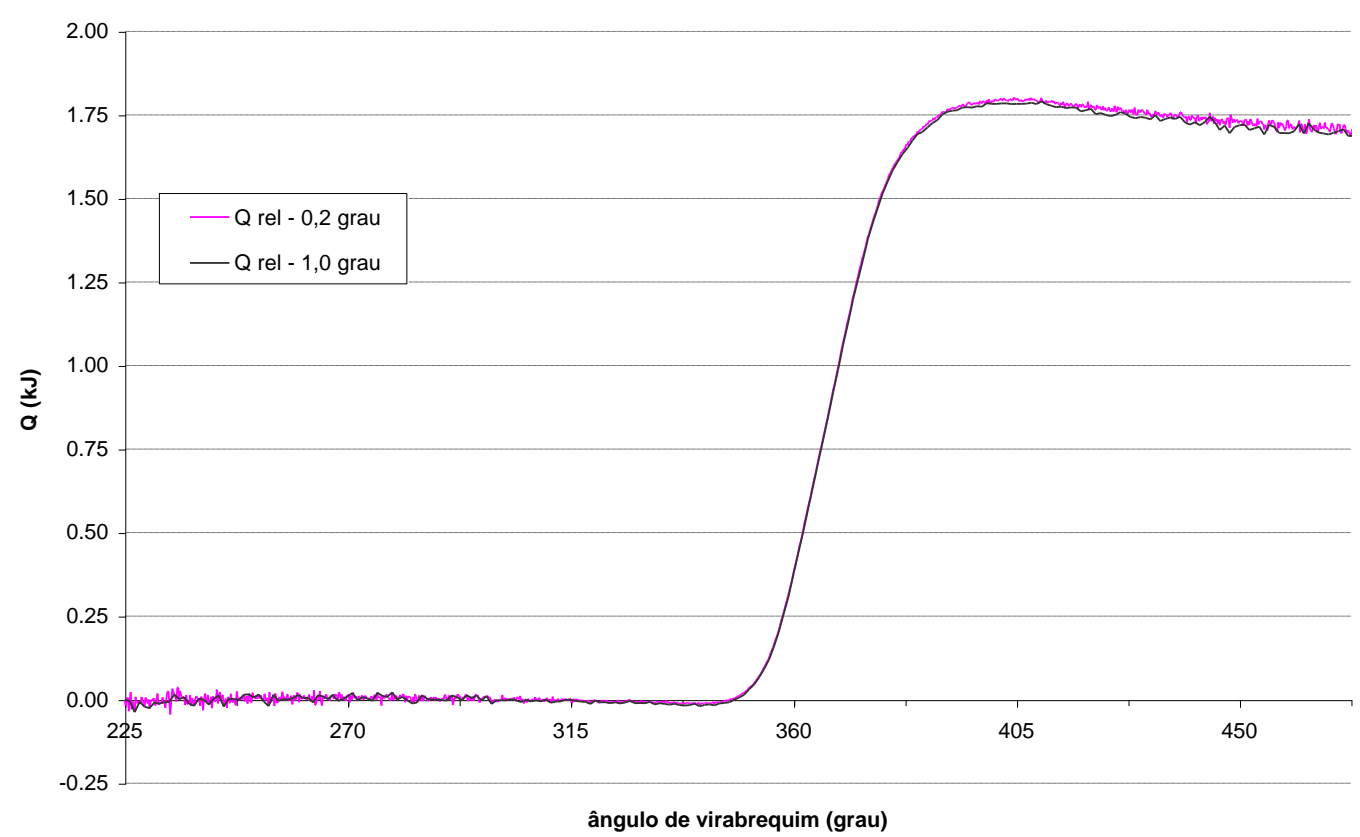

Figura 7.55 - Liberações de calor calculadas com passo de integração de $0,2^{\circ}$ e $1,0^{\circ}$.

A Figura 7.57 traz as alterações causadas no raio da frente de chama e no volume queimado em virtude da modificação do passo de integração. A curva que representa a evolução da frente de chama para o caso calculado com passo igual a $1,0^{\circ}$ indica que a 
combustão se inicia cerca de $2,0^{\circ}$ depois do instante calculado com passo de $0,2^{\circ}$. Mas pode-se notar que há uma grande aderência entre as curvas que representam os raios e os volumes para os dois casos.

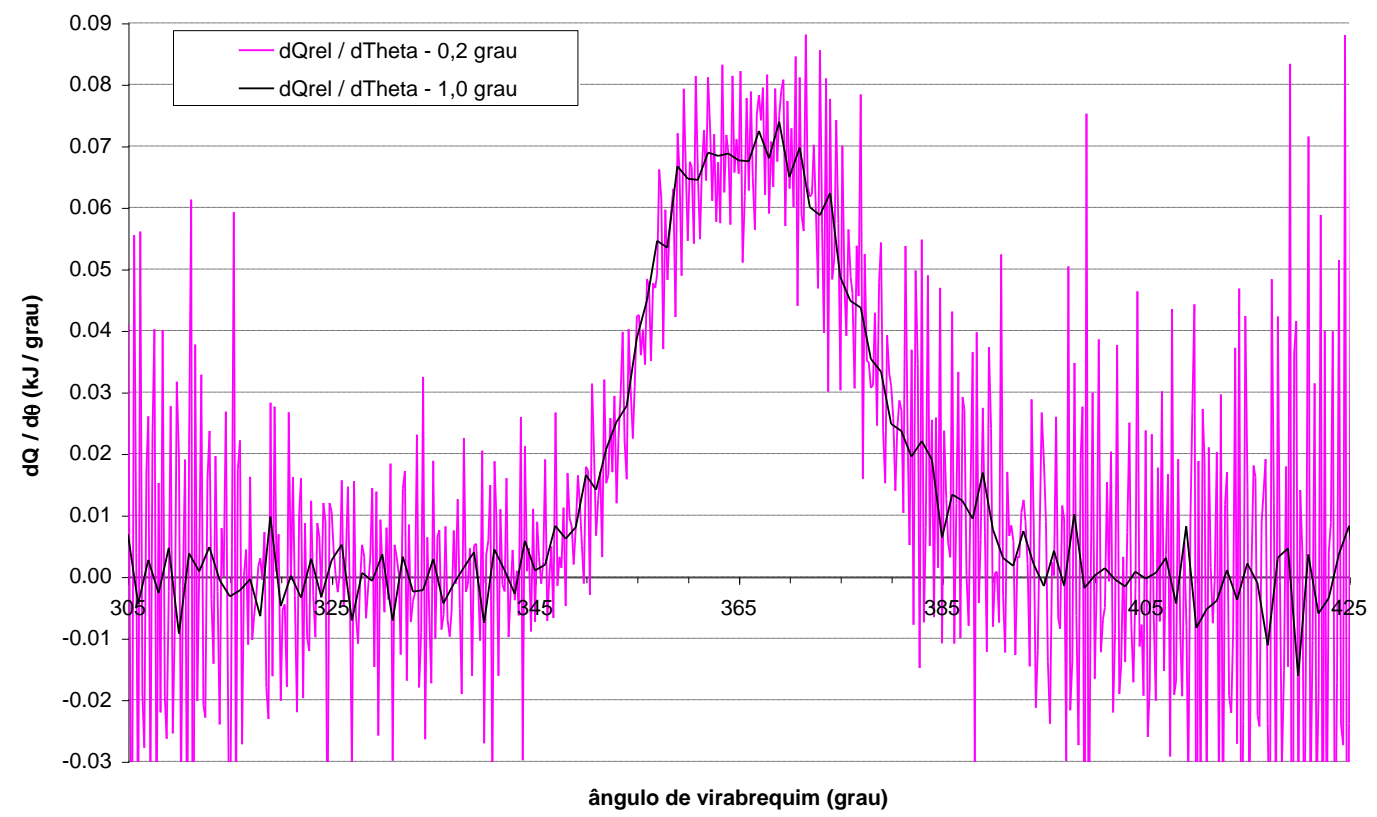

Figura 7.56 - Taxas de liberação de calor calculadas para os dois passos de integração.

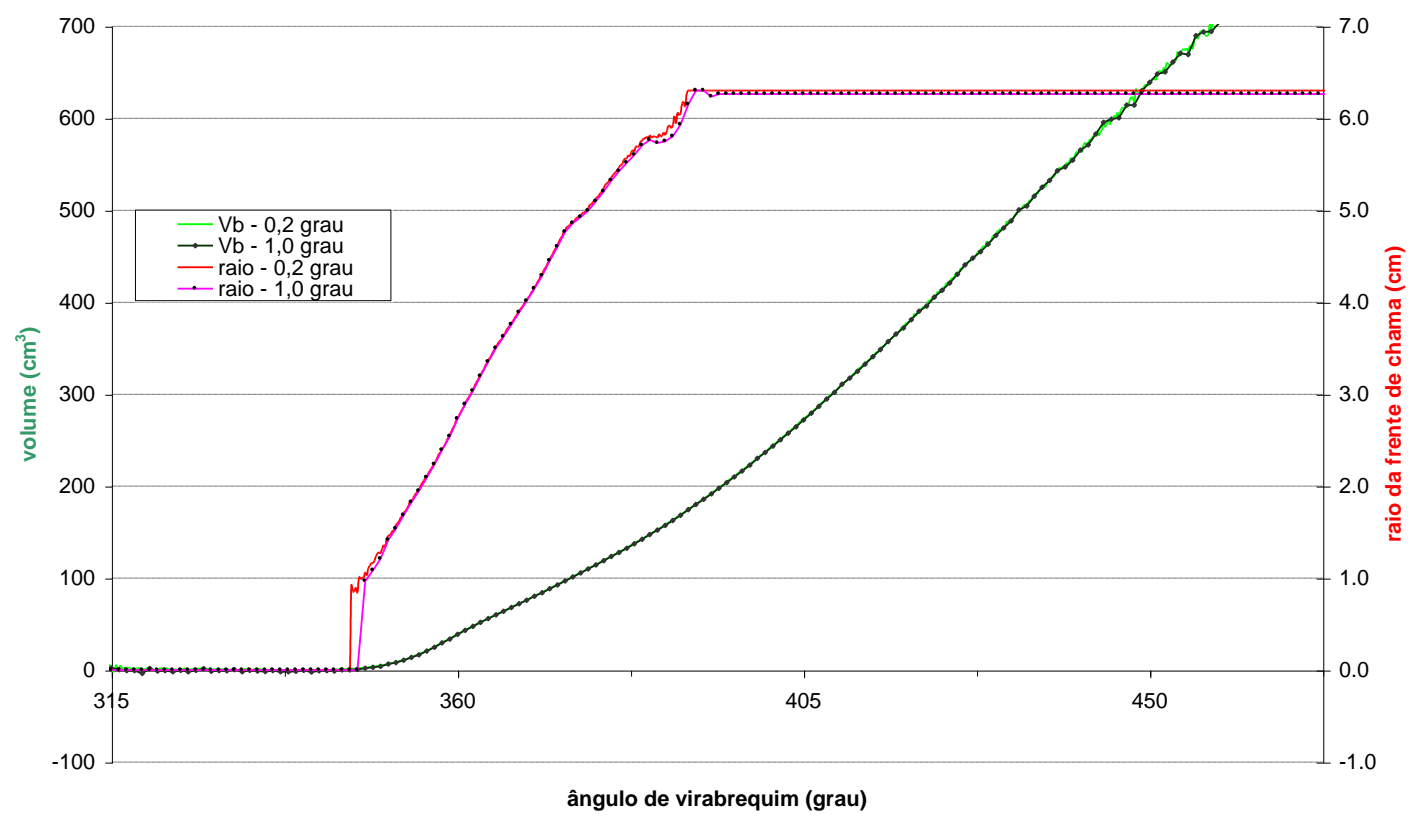

Figura 7.57 - Alterações no raio da frente de chama e volume queimado. 
O aumento do passo de integração não ocasionou alteração perceptível nas curvas de temperatura, como pode ser visto na Figura 7.58.

Todos estes fatos reforçam a tese de que muito mais importante do que o passo de integração é a posição de referência da curva de pressão, ao mesmo tempo em que mostram que o método de Euler utilizado na integração das equações diferenciais das temperaturas é adequado.

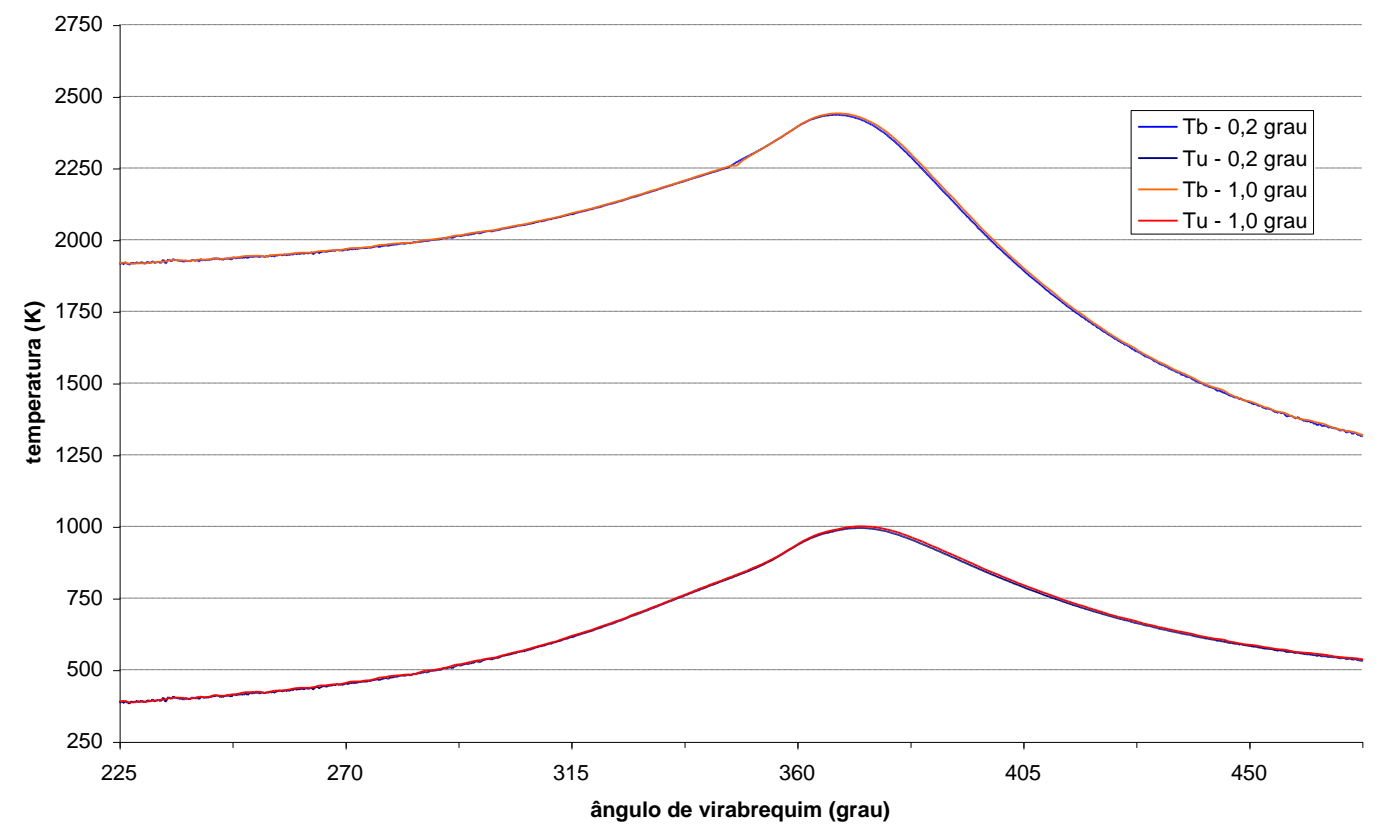

Figura 7.58 - Temperaturas calculadas com passos de integração iguais a $0,2^{\circ}$ e $1,0^{\circ}$.

Confirmando o que foi observado com a análise de sensibilidade, a Figura 7.59 traz as curvas de liberação de calor calculadas a partir dos valores de pressão medidos originais e adiantados $0,5^{\circ}$. Também a Figura 7.60 mostra o efeito destes parâmetros no cálculo da evolução da frente de chama. O raio da frente de chama calculado a partir da curva de pressão adiantada apresenta uma evolução sensivelmente diferente das demais. 


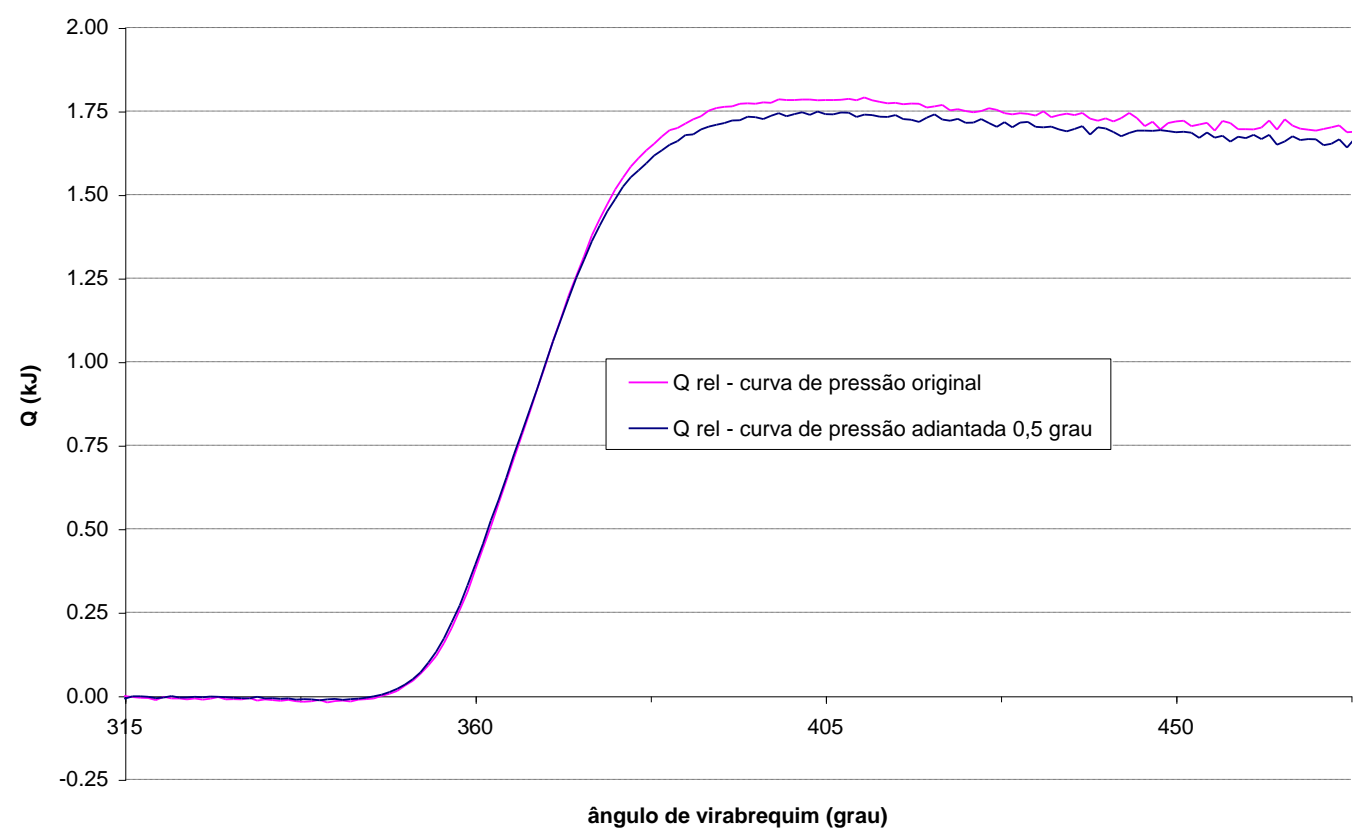

Figura 7.59 - Efeito da defasagem de $0,5^{\circ}$ na curva de pressão na liberação de calor.

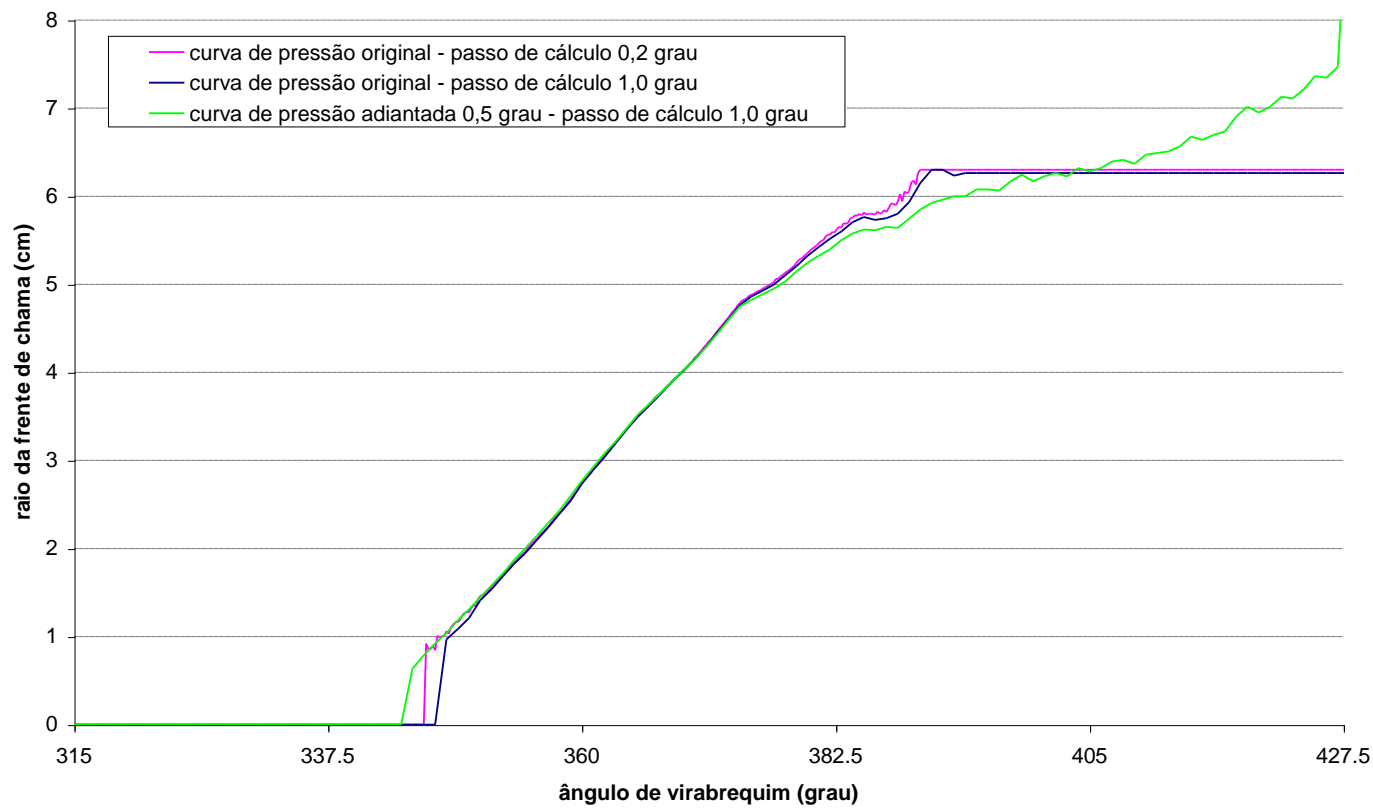

Figura 7.60 - Comparação entre as evoluções da frente de chama.

Entretanto, mesmo não se afastando muito das curvas calculadas com passo de integração $0,2^{\circ}$, as curvas geradas com passo de $1,0^{\circ}$ deixam de considerar valiosas informações contidas na curva de pressão. Uma maneira de não se desperdiçar esta 
informação e filtrar a curva de pressão de forma a gerar uma curva de taxa de liberação com menor nível de flutuação é executar uma média móvel com os valores de pressão medidos. Para efeito de comparação, uma média móvel centrada de 5 pontos (total $0,8^{\circ}$ ) foi efetuada sobre a curva original de pressão e os resultados da análise foram confrontados.

A Figura 7.61 traz as curvas de fração de massa queimada calculadas para a curva original de pressão com passos de $0,2^{\circ}$ e $1,0^{\circ}$ e a curva calculada a partir da curva de pressão filtrada por uma média móvel centrada de 5 pontos. Detalhes destas curvas na região de início da combustão (Figura 7.62) mostram que tanto a mudança de passo de integração como a filtragem pela média móvel trazem pequenas diferenças na fração de massa queimada. Já na região final da combustão (Figura 7.63), estas diferenças são mais pronunciadas, sendo que a média móvel traz resultados mais próximos daqueles calculados a partir da curva de pressão original.

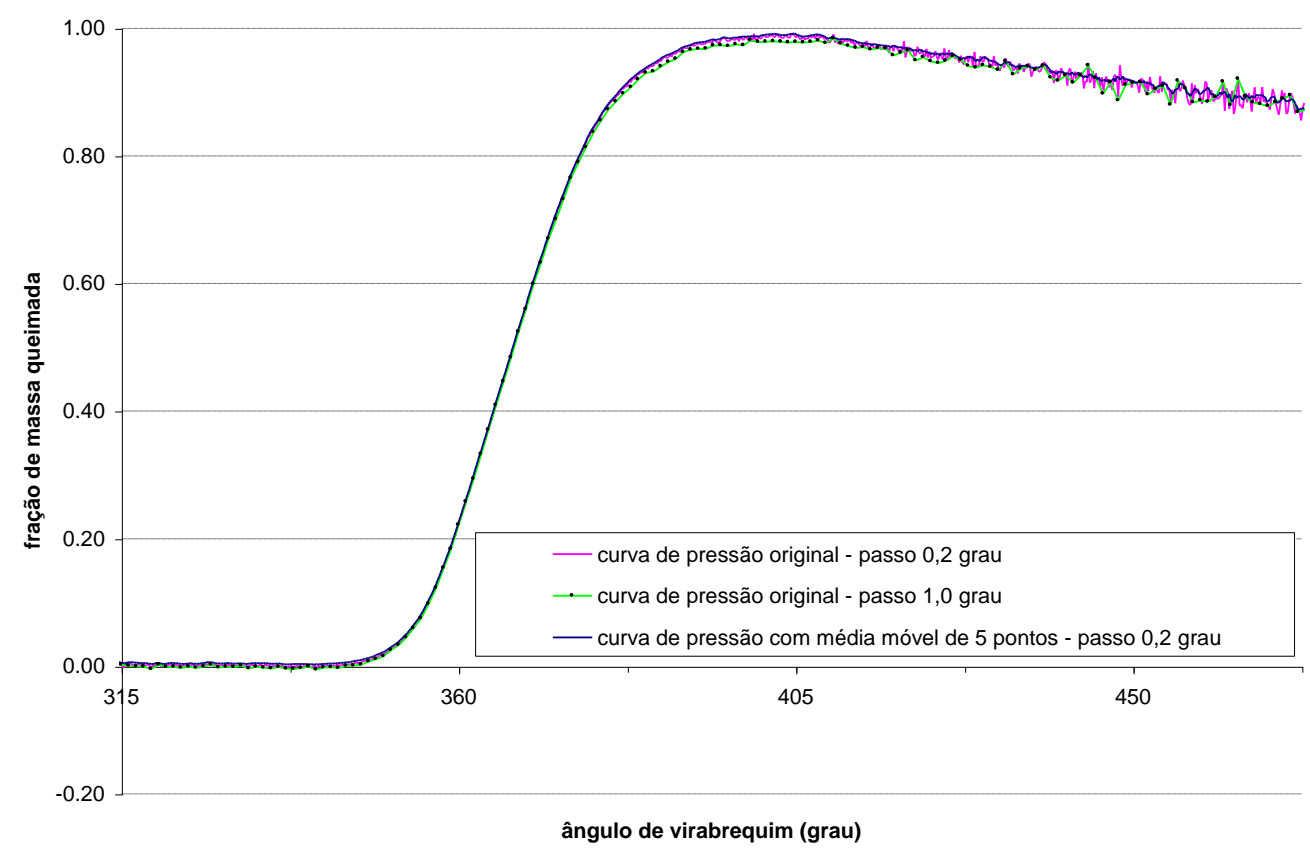

Figura 7.61 - Comparação entre efeitos da média móvel e passo de integração. 


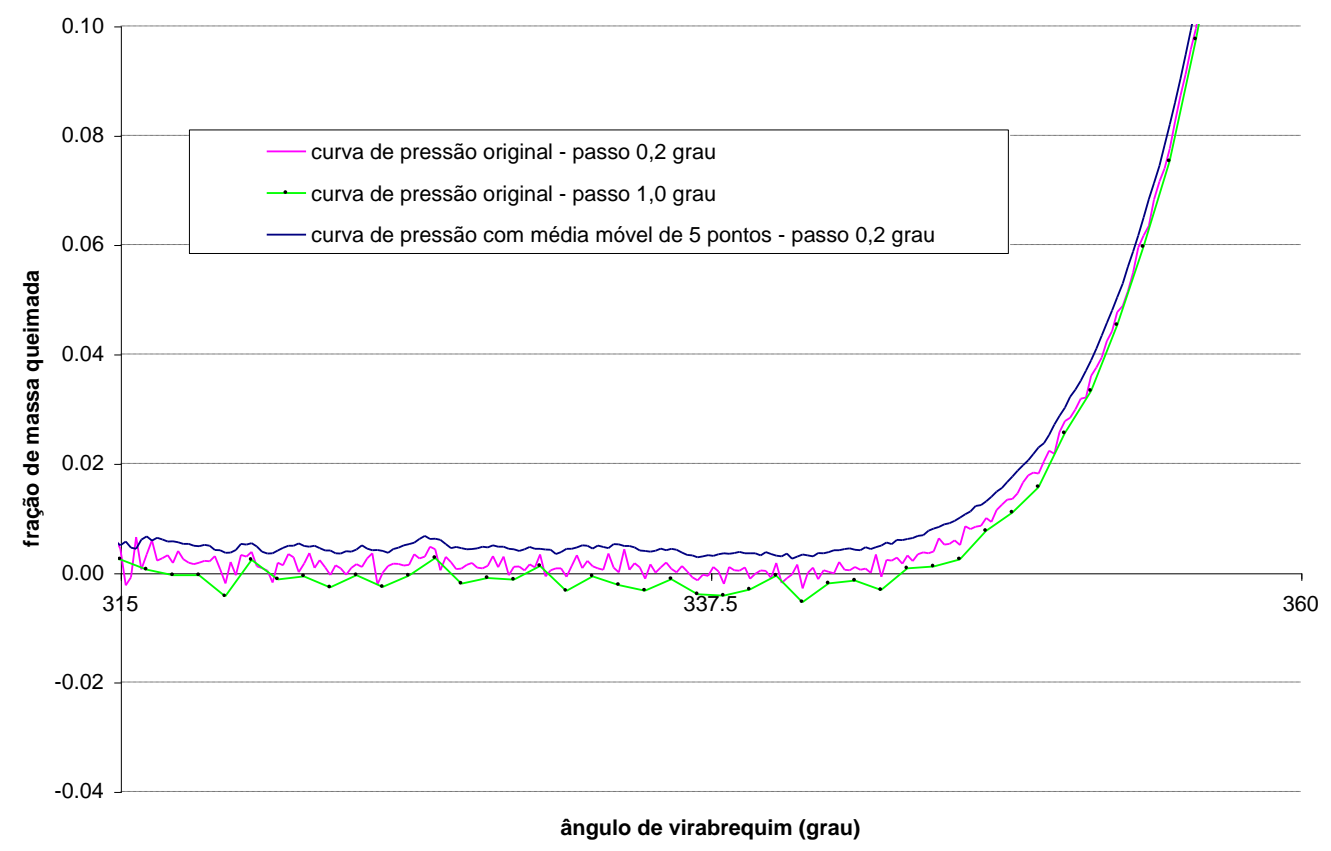

Figura 7.62 - Detalhe da Figura 7.61.

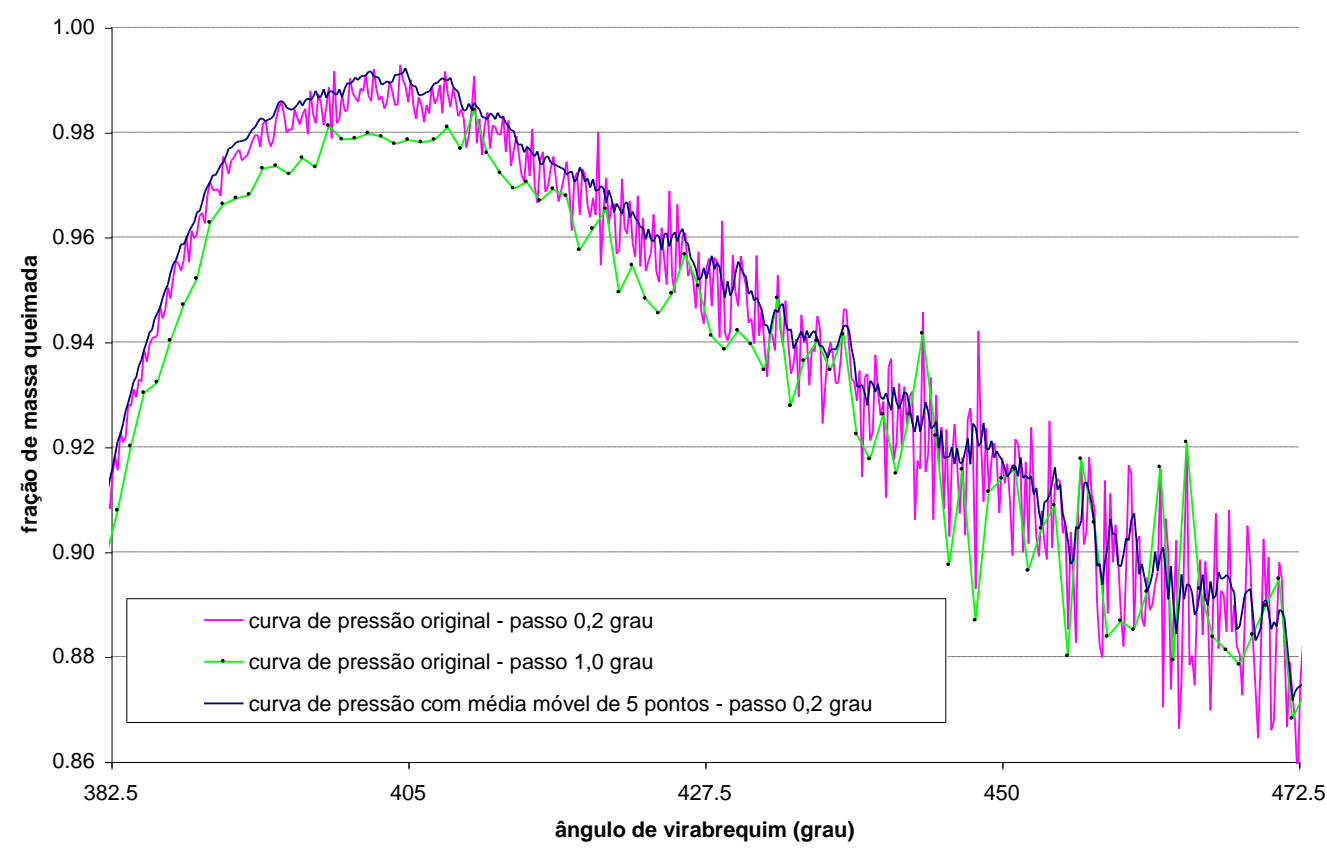

Figura 7.63 - Detalhe da Figura 7.61

O mesmo fato se repete para as curvas de liberação de calor calculadas. A região inicial é menos sensível à mudança de passo de integração ou à média móvel (Figura 7.64) do que a região final da combustão (Figura 7.65), onde a média móvel traz melhores resultados. 


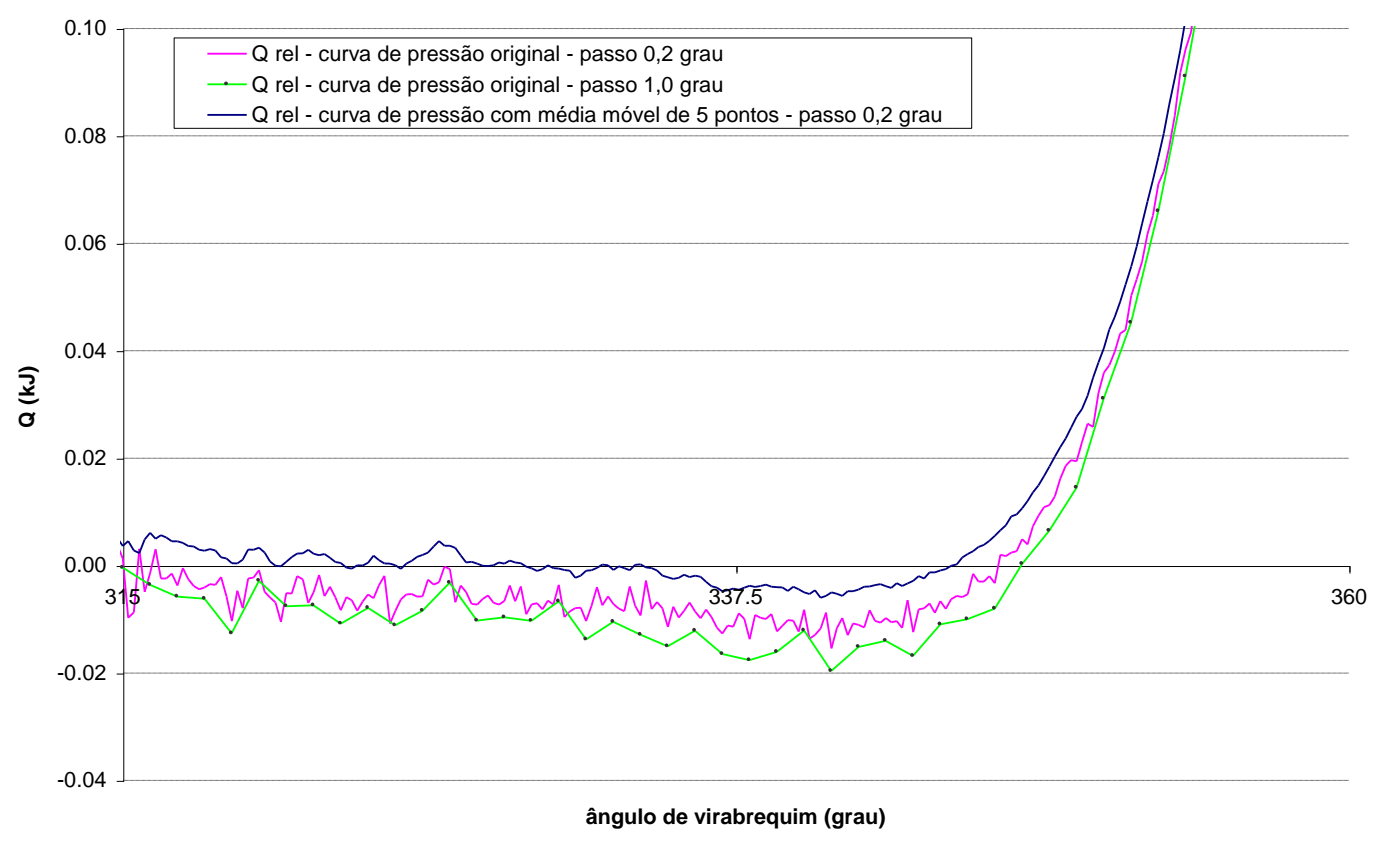

Figura 7.64 - Região inicial das curvas de liberação de calor calculadas.

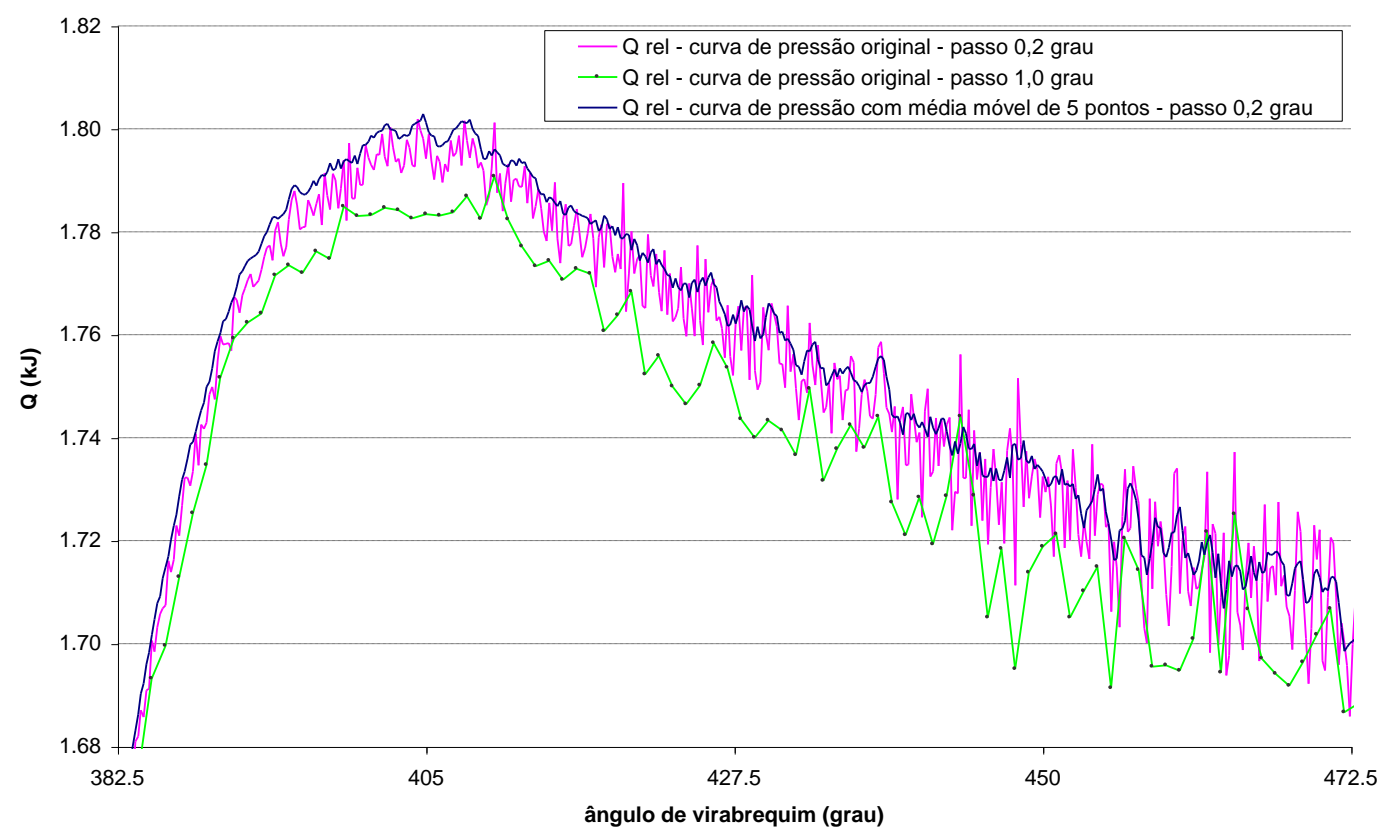

Figura 7.65 - Região final das curvas de liberação de calor calculadas.

A Figura 7.66 mostra a comparação entre as taxas de liberação de calor calculadas para os três casos. A média móvel ocasiona variações desta taxa mais 
próximas daquelas calculadas a partir da curva original com passo de $0,2^{\circ}$ do que quando o cálculo é feito com $1,0^{\circ}$ como passo de integração.

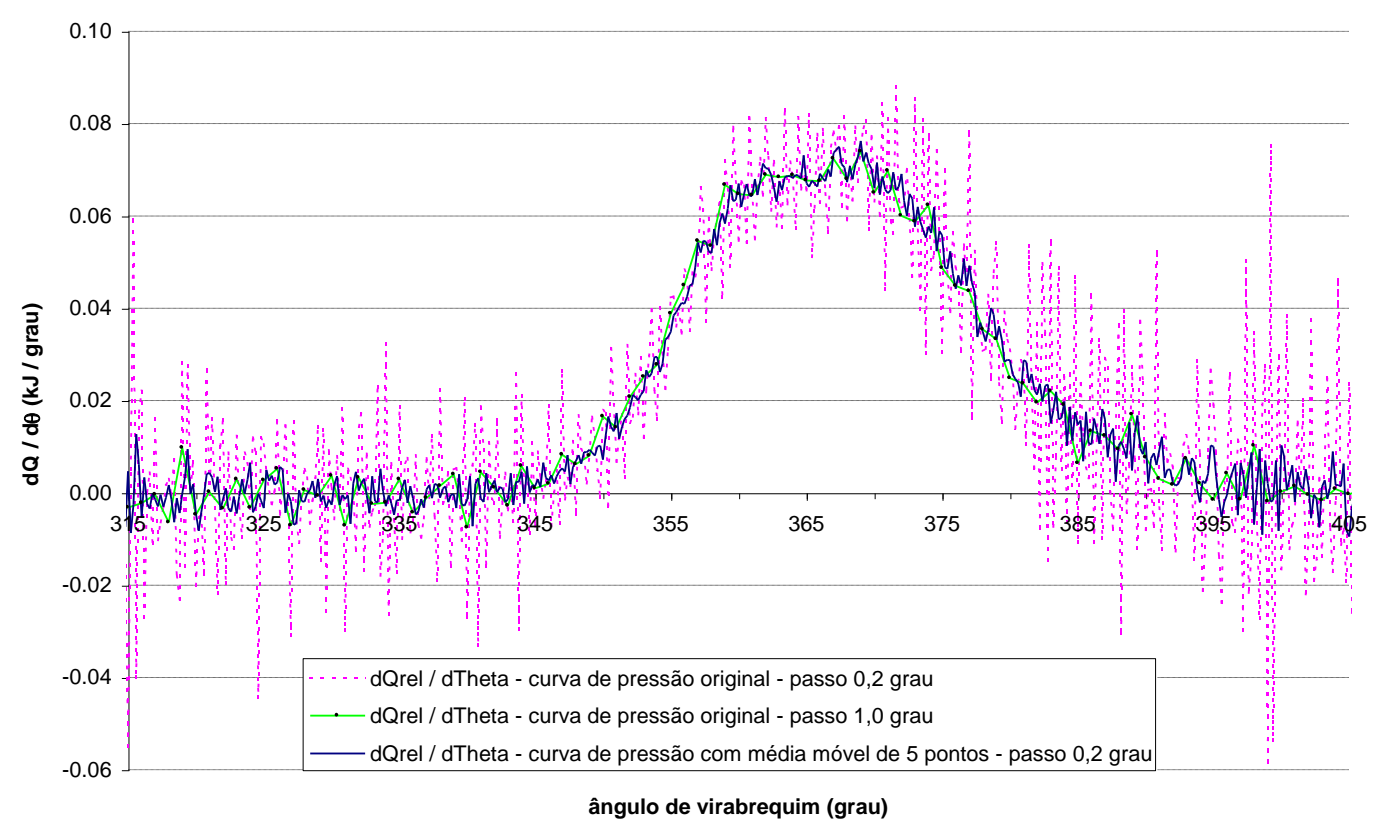

Figura 7.66 - Taxas de liberação de calor para diferentes passos de integração e média móvel.

Completando a comparação, a Figura 7.67 mostra as evoluções da frente de chama para os três casos sob inspeção. Pode-se notar que, a menos da região do início da combustão, onde a média móvel ocasiona um adiantamento do início da combustão e o maior passo de integração o atrasa, as curvas são bem aderentes entre si.

Após este estudo, optou-se por utilizar uma média móvel de 5 pontos (equivalente $\mathrm{a} \pm 0,4^{\circ}$ ) como forma de filtrar os ruídos embutidos na curva de pressão dos casos a serem analisados a seguir. 


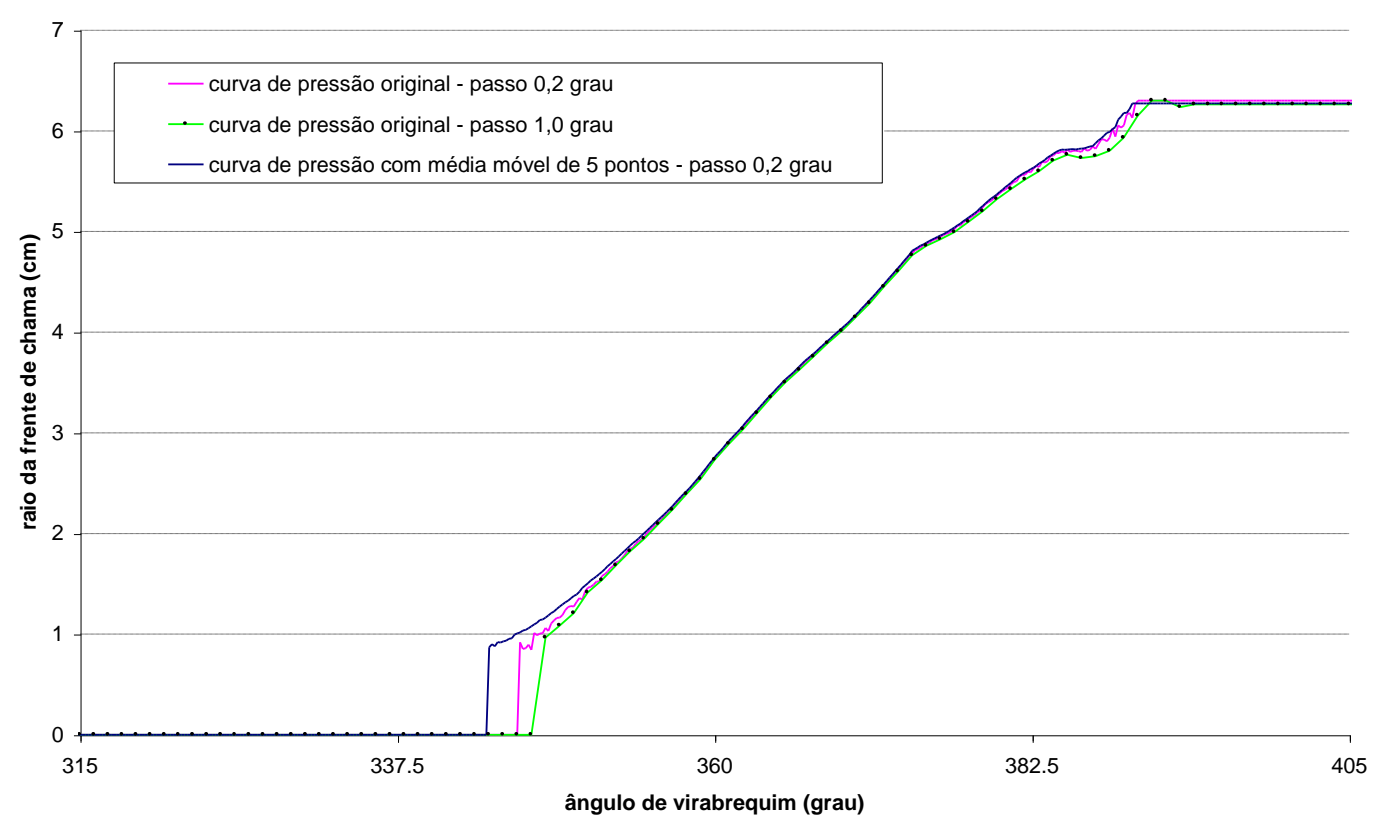

Figura 7.67 - Evoluções da frente de chama para diferentes passos de integração e média móvel.

A análise da combustão para os casos B e C referidos na Tabela 7.6 e na Tabela 7.7 também foi efetuada e as curvas correspondentes são mostradas a seguir. Utilizou-se o passo de integração de $0,2^{\circ}$, média móvel de 5 pontos sobre a curva de pressão e frações de gás residual oriundas do simulador, a saber: caso A - 4,8\%; caso B - 6,4\% e caso $\mathrm{C}-4,5 \%$. As temperaturas das paredes não foram alteradas, permanecendo então aquelas explicitadas na Tabela 7.3 pois, como foi mostrado, têm pequena influência na análise de liberação de calor. A temperatura das frestas também não foi alterada, permanecendo como a média das temperaturas do pistão e do cilindro.

Pode-se perceber na Figura 7.68 que o efeito do drift do transdutor é mais significativo diferente na condição de meia carga a 2800 rpm em relação às demais, pela menor pressão exercida em sua face nesta condição para um mesmo gradiente térmico, uma vez que as temperaturas dos gases queimados são próximas (Figura 7.69). 


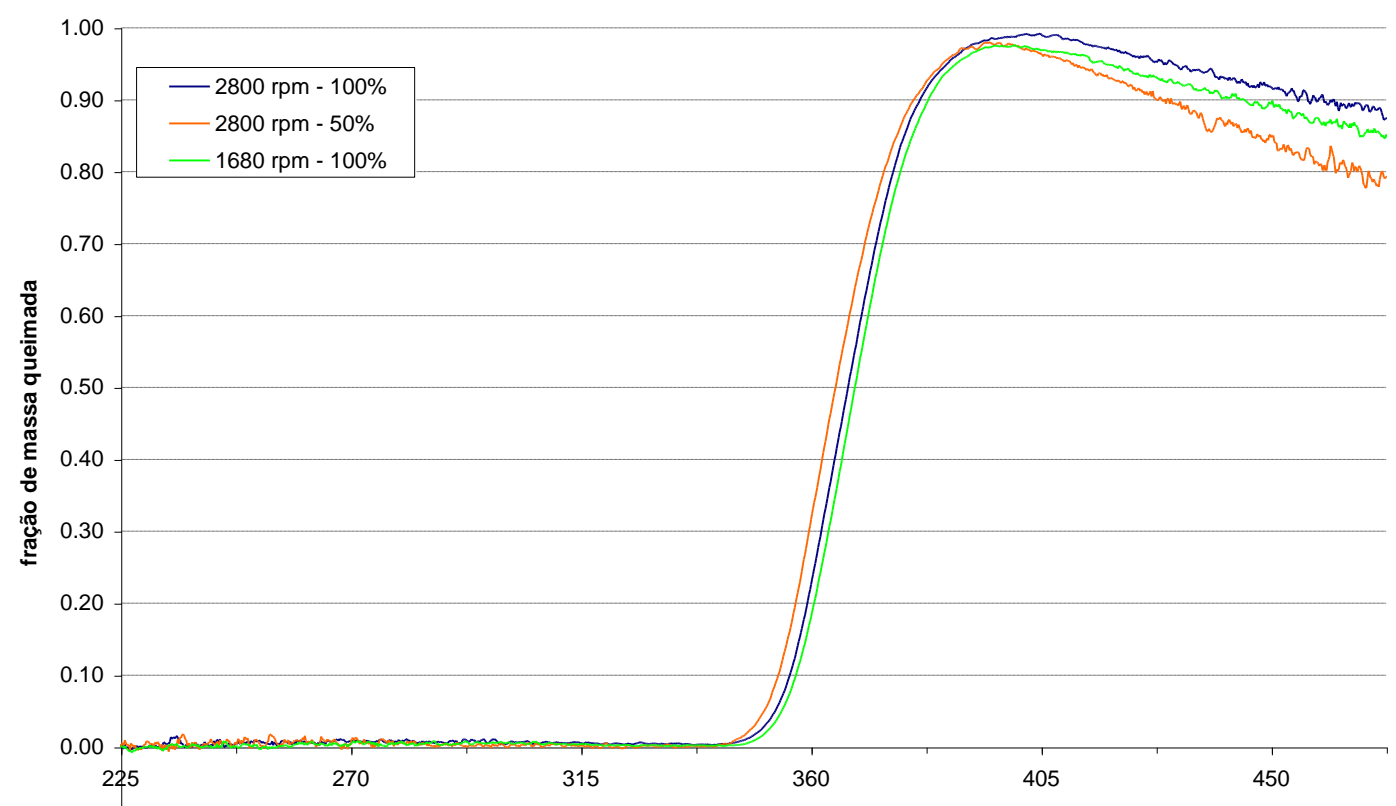
$-0.10$

ângulo de virabrequim (grau)

Figura 7.68 - Frações de massa queimada referentes às condições da Tabela 7.6.

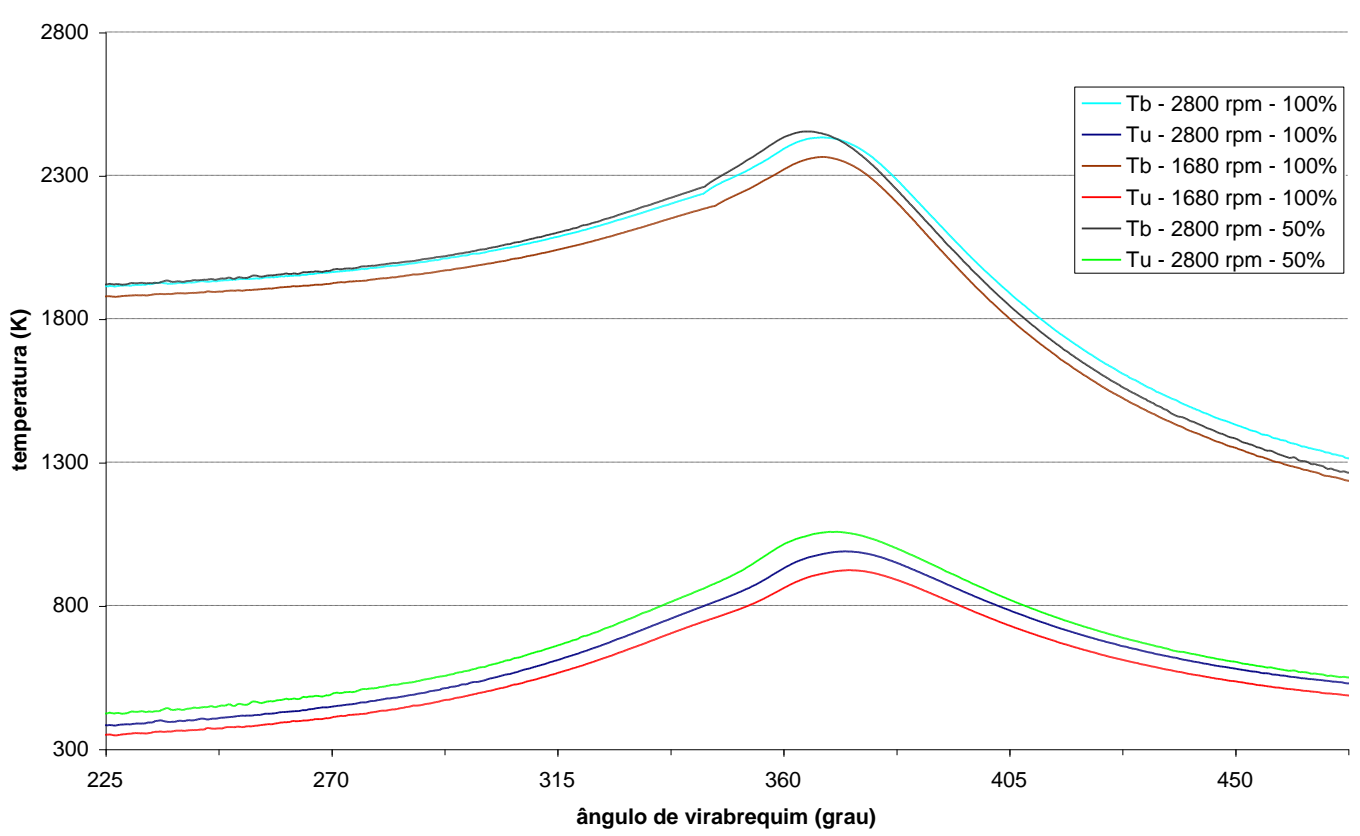

Figura 7.69 - Temperaturas calculadas para as condições A, B e C.

A Figura 7.70 traz as curvas de liberação de calor e as respectivas quantidades de energia química contidas na câmara de combustão $\left(\mathrm{Mcomb}{ }^{*} \mathrm{PCl}\right)$ para as três condições. 


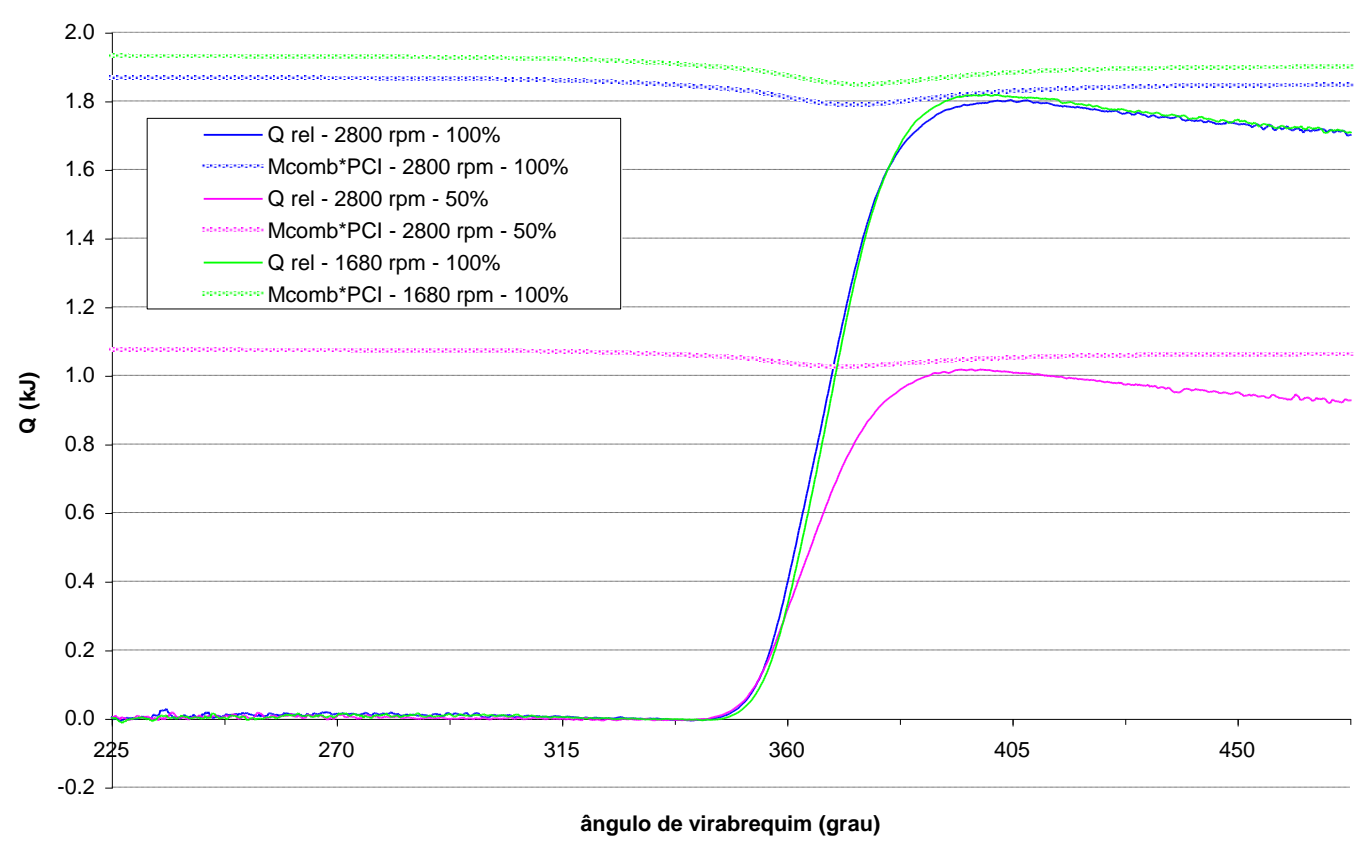

Figura 7.70 - Curvas de liberação de calor para as condições A, B e C.

Para que se possa comparar a progressão da frente de chama nos três casos, a Figura 7.71 mostra seu raio e o volume contido em seu interior calculados para as três condições. Nota-se que na condição de $1680 \mathrm{rpm}$, plena carga, o início da combustão ocorre mais tarde do que nas demais condições. Note-se que os avanços de ignição eram de $24,5^{\circ}, 28,8^{\circ}$ e $21,4^{\circ}$ para as condições de $2800 \mathrm{rpm}$ plena carga (A), $2800 \mathrm{rpm}$ meia carga (B) e 1680 rpm plena carga (C) respectivamente.

Finalizando a análise deste conjunto de dados, a Figura 7.72 traz as taxas de liberação de calor calculadas para as três condições A, B e C. Enquanto para as condições de plena carga o pico de liberação de calor ocorre em torno de $10^{\circ}$ após o PMS, para a condição de meia carga este ponto está localizado muito próximo do PMS. 


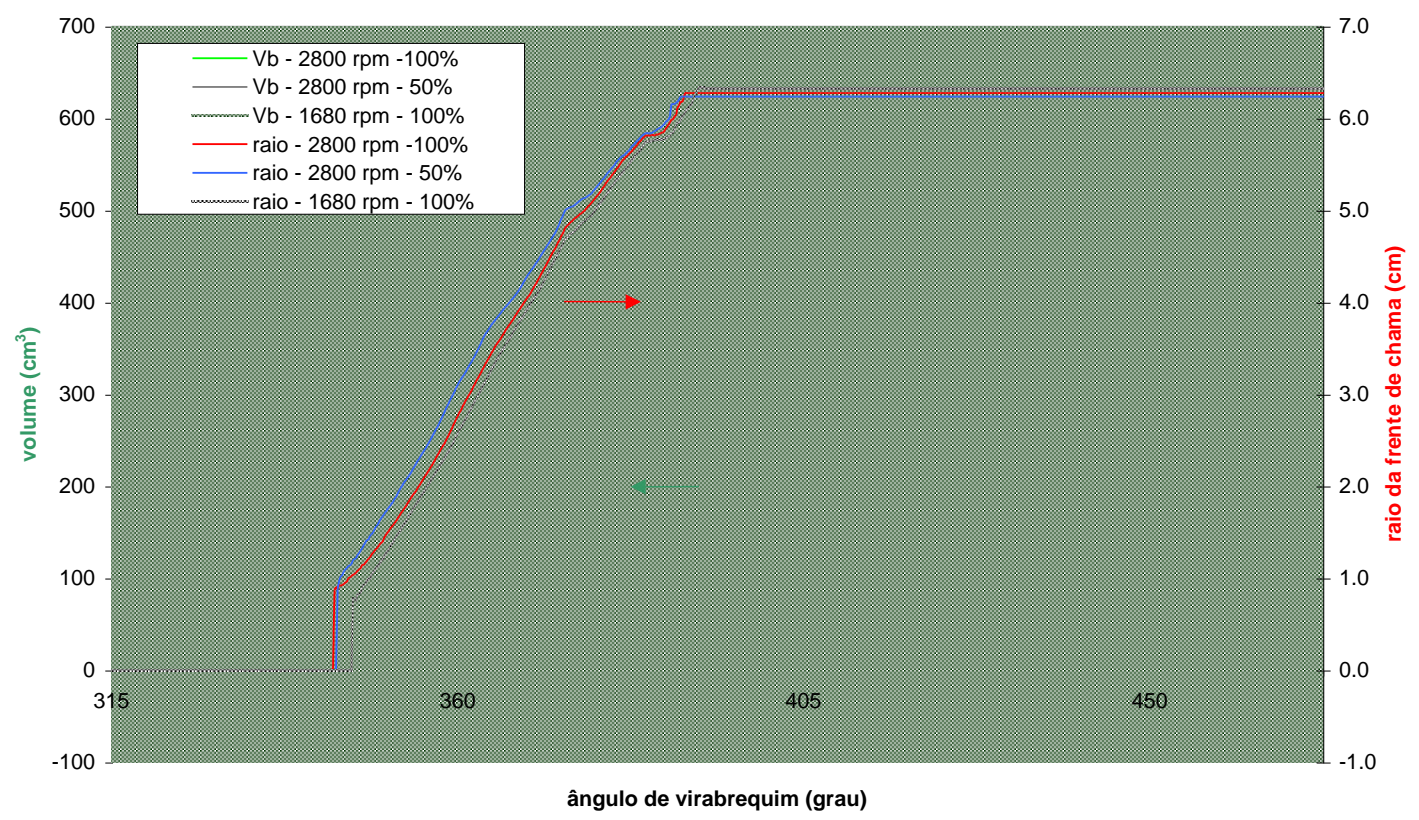

Figura 7.71 - Evolução da frente de chama para as condições A, B e C.

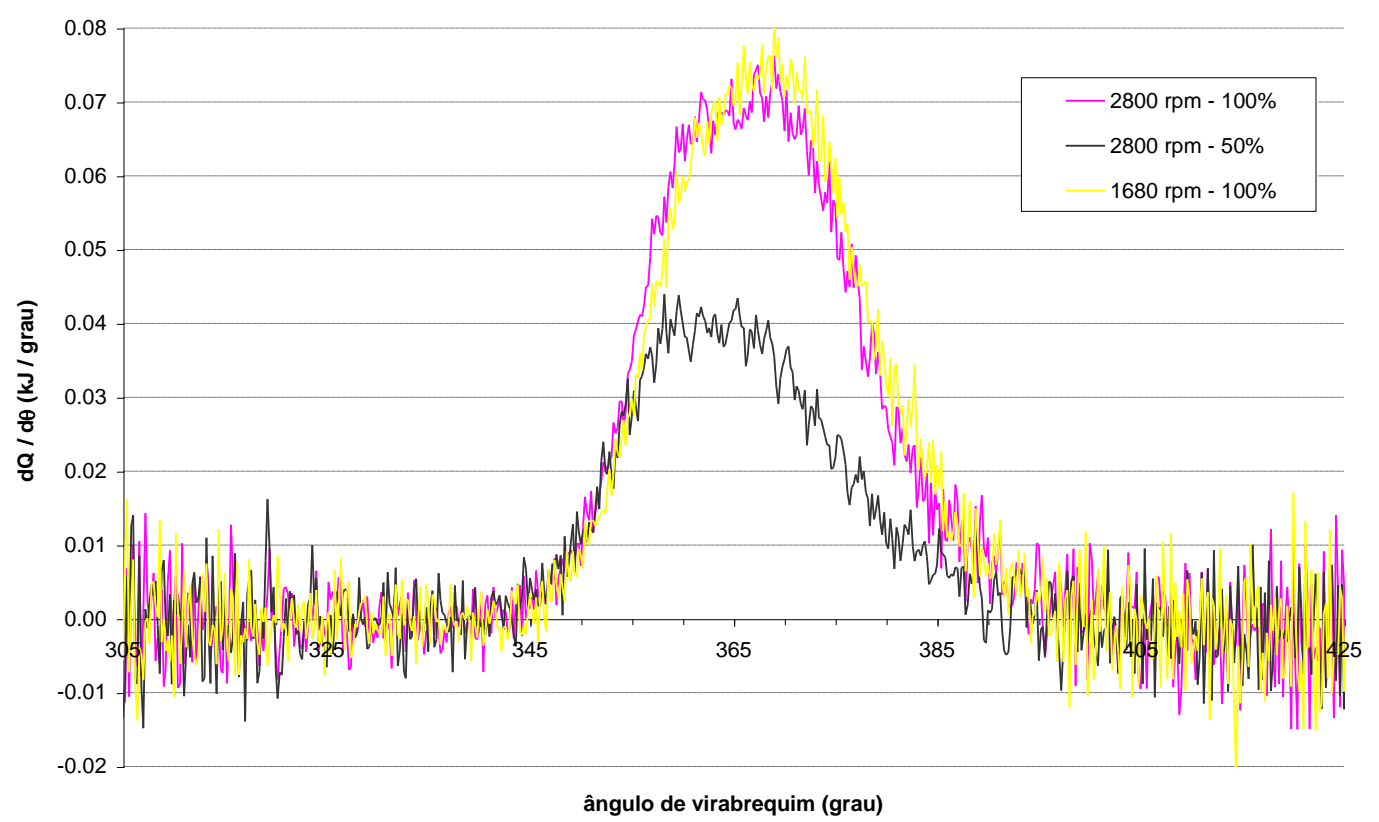

Figura 7.72 - Taxas de liberação de calor para as condições A, B e C.

A título de comparação, fez-se a análise da curva de pressão referente à operação em regime de máxima potência do motor com um combustível de maior conteúdo energético do que aquele descrito na Tabela 7.2. A composição deste combustível é 
mostrada na Tabela 7.8, convencionando-se denominá-lo doravante combustível II para diferenciá-lo do combustível I do caso anterior.

\begin{tabular}{|c|c|}
\hline espécie & fração volumétrica \\
\hline $\mathrm{CH}_{4}$ & $77,6 \%$ \\
\hline $\mathrm{C}_{2} \mathrm{H}_{6}$ & $14,4 \%$ \\
\hline $\mathrm{C}_{3} \mathrm{H}_{8}$ & $3,6 \%$ \\
\hline $\mathrm{C}_{4} \mathrm{H}_{10}$ e superiores & $2,8 \%$ \\
\hline $\mathrm{CO}_{2}$ & $0,3 \%$ \\
\hline $\mathrm{N}_{2}$ & $1,3 \%$ \\
\hline $\mathrm{H}_{2}$ & $0,0 \%$ \\
\hline
\end{tabular}

Tabela 7.8 - Composição do combustível de maior conteúdo energético.

\begin{tabular}{|l|c|l|}
\hline rotação & 2800 & $\mathrm{rpm}$ \\
\hline$\%$ carga & 100 & $\%$ \\
\hline umidade absoluta do ar de admissão & 0,0074 & $\mathrm{~kg}$ H2O $/ \mathrm{kg}_{\text {ar seco }}$ \\
\hline vazão mássica de combustível & 21,41 & $\mathrm{~kg} / \mathrm{h}$ \\
\hline vazão mássica de ar úmido & 404,7 & $\mathrm{~kg} / \mathrm{h}$ \\
\hline vazão mássica de vapor d'água & 2,96 & $\mathrm{~kg} / \mathrm{h}$ \\
\hline$\phi$ & 0,866 & - \\
\hline $\mathrm{P}_{\text {coletor admissão }}$ & 0,85 & $\mathrm{bar}$ \\
\hline $\mathrm{P}_{\text {coletor escapamento }}$ & 0,90 & bar \\
\hline $\mathrm{T}_{\text {admissão antes borboleta }}$ & 292 & $\mathrm{~K}$ \\
\hline $\mathrm{T}_{\text {escapamento }}$ & 1010 & $\mathrm{~K}$ \\
\hline$\theta_{\text {centelha }}$ & 335,8 & $\mathrm{graus}$ \\
\hline
\end{tabular}

Tabela 7.9 - Valores medidos na bancada dinamométrica.

O motor continuou operando segundo as especificações do fabricante, sendo que a única alteração foi a composição do combustível. Tanto o avanço de ignição como o sistema de alimentação de combustível não sofreram quaisquer modificações. Os dados medidos na bancada para a condição de potência máxima $(2800 \mathrm{rpm})$ podem ser vistos na Tabela 7.9. Estes dados, da mesma forma que os anteriores, foram coletados segundo o procedimento de ensaio descrito no subcapítulo 6.7 Dados coletados. 
A partir destes dados, os consumos de ar, combustível e vapor d'água (médios entre os 6 cilindros) para cada condição foram calculados e são apresentados na Tabela 7.10. A configuração do sistema de aquisição e o procedimento de coleta dos dados também foi o mesmo que o utilizado no caso anterior.

\begin{tabular}{|l|c|l|}
\hline massa de combustível /ciclo & 0,0425 & g / ciclo \\
\hline massa de ar seco / ciclo & 0,797 & g / ciclo \\
\hline massa de vapor / ciclo & 0,0059 & g / ciclo \\
\hline massa total admitida / ciclo & 0,845 & g / ciclo \\
\hline
\end{tabular}

Tabela 7.10 - Consumos calculados a partir dos valores da Tabela 7.9.

A Figura 7.73 traz a comparação entre as curvas médias de pressão e suas derivadas para a condição de potência máxima com o motor utilizando os combustíveis I e II.

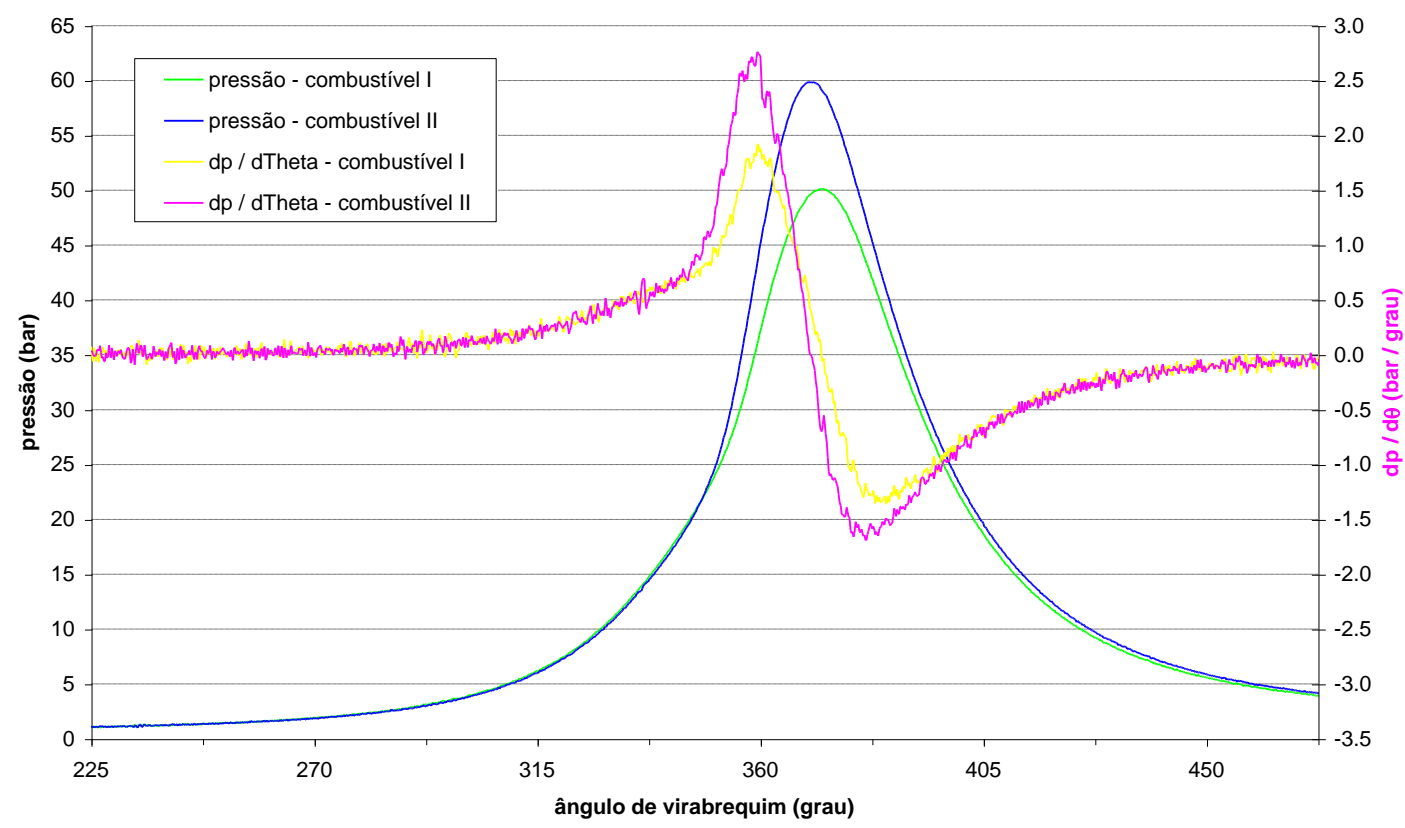

Figura 7.73 - Curvas de pressão e suas derivadas para combustíveis I e II.

Da mesma forma que nas análises até agora efetuadas, esta nova curva de pressão média foi fornecida como dado de entrada ao programa de cálculo, juntamente com os consumos correspondentes mostrados na Tabela 7.10, volume de frestas igual a $1 \mathrm{~cm}^{3}$ (com $T=470 K$ ) e constante de vazamento $K_{b b}$ igual a 0,044. Utilizou-se ainda o 
mesmo valor de fração de gases residuais $(0,048)$, passo de integração de $0,2^{\circ}$ e média móvel sobre a curva de pressão de 5 pontos.

As frações mássicas de gases queimados, de gases contidos nas frestas e de gases de blow-by são mostradas na Figura 7.74. Pode-se observar que, pelo fato de a pressão de pico na câmara com o combustível II ser superior à pressão de pico com o combustível I para massas admitidas praticamente idênticas, uma maior fração máxima de gases nas frestas (Xcrev) é causada no caso II, da mesma forma que a fração de blowby $(\mathrm{Xbb})$.

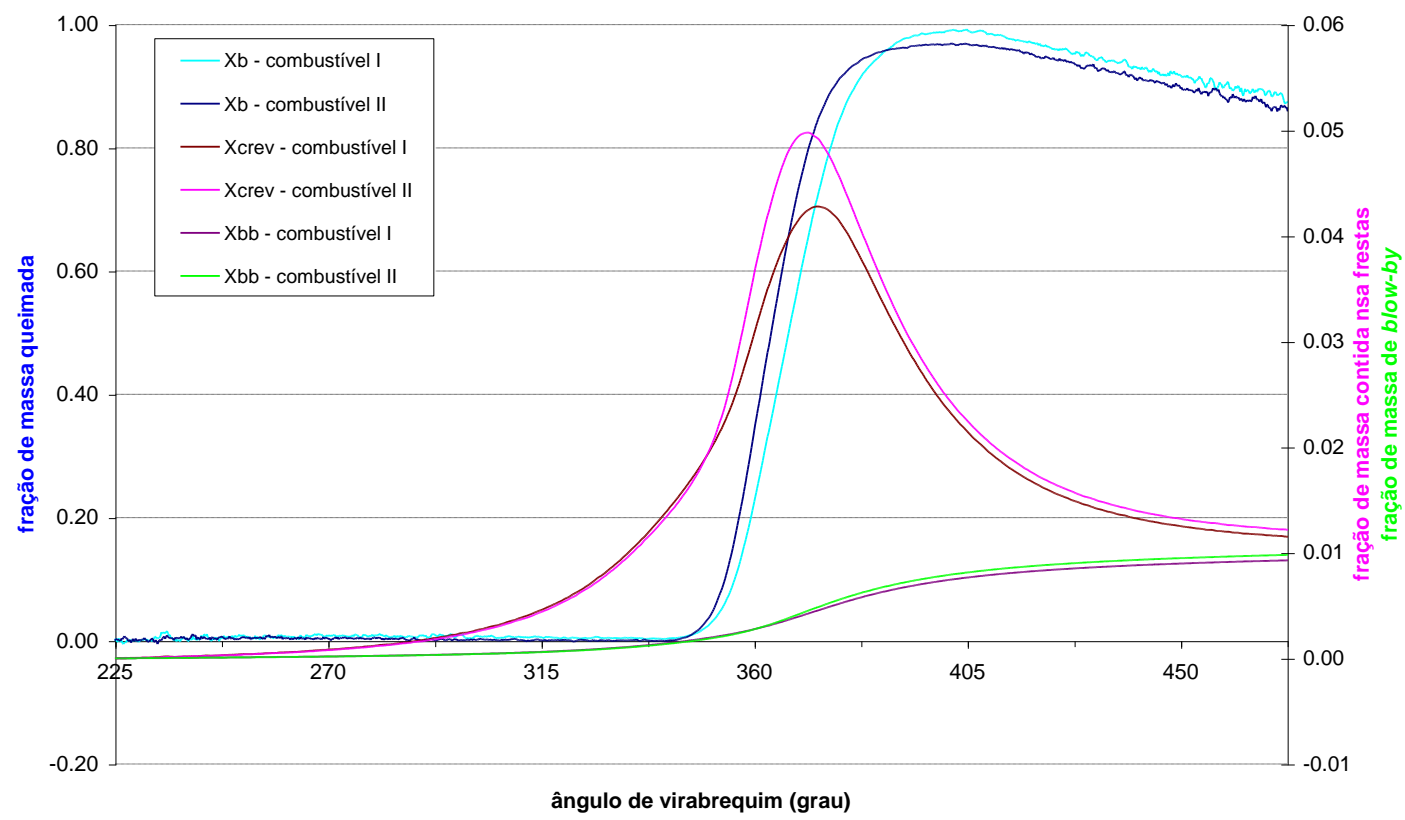

Figura 7.74 - Comparação entre as frações mássicas para os combustíveis I e II.

A inclinação das curvas de fração de massa queimada já indica que o combustível II está "queimando" mais rapidamente do que o combustível I. Isto pode ser confirmado pela evolução da frente de chama e volume queimado mostrados na Figura 7.75. 


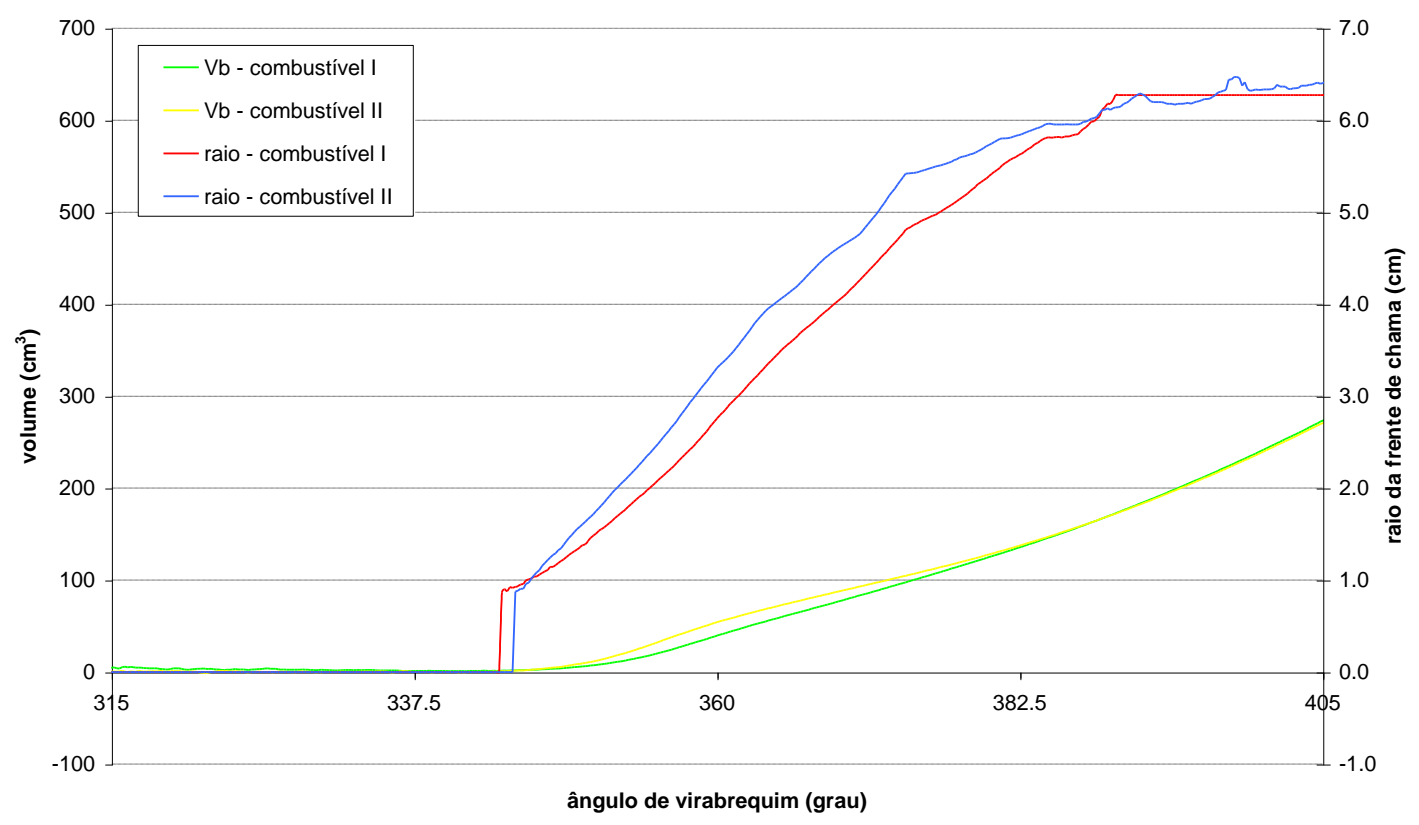

Figura 7.75 - Evolução das frentes de chama e volumes queimados para os combustíveis I e II.

Esta maior taxa de queima é mais visível através da observação das curvas de taxa de liberação de calor na Figura 7.76. O pico de liberação de calor para o combustível II é cerca de $25 \%$ maior do que para o combustível I. Deve-se ressaltar, entretanto, que esta maior taxa de queima não é exclusivamente causada pela diferente composição do combustível, mas também pela maior razão de equivalência com a qual o motor operava nesta condição. Este fato, por sua vez, era ocasionado pelo sistema de dosagem de gás empregado neste motor: um sistema de dosagem volumétrico sem realimentação.

A Figura 7.77 compara as curvas integrais de liberação de calor para o motor operando com os dois combustíveis e mostra as quantidades de energia disponíveis na câmara de combustão por ciclo, sob a forma de PCI.

Finalizando a análise, a Figura 7.78 traz as temperaturas calculadas dos gases queimados e não queimados em função da posição angular do virabrequim para os dois 
combustíveis. Vê-se que os gases queimados sofrem um acréscimo máximo da ordem de $150 \mathrm{~K}$ quando da alteração do combustível I para o II, enquanto a temperatura dos gases não queimados sofre pouca influência pela mudança do combustível.

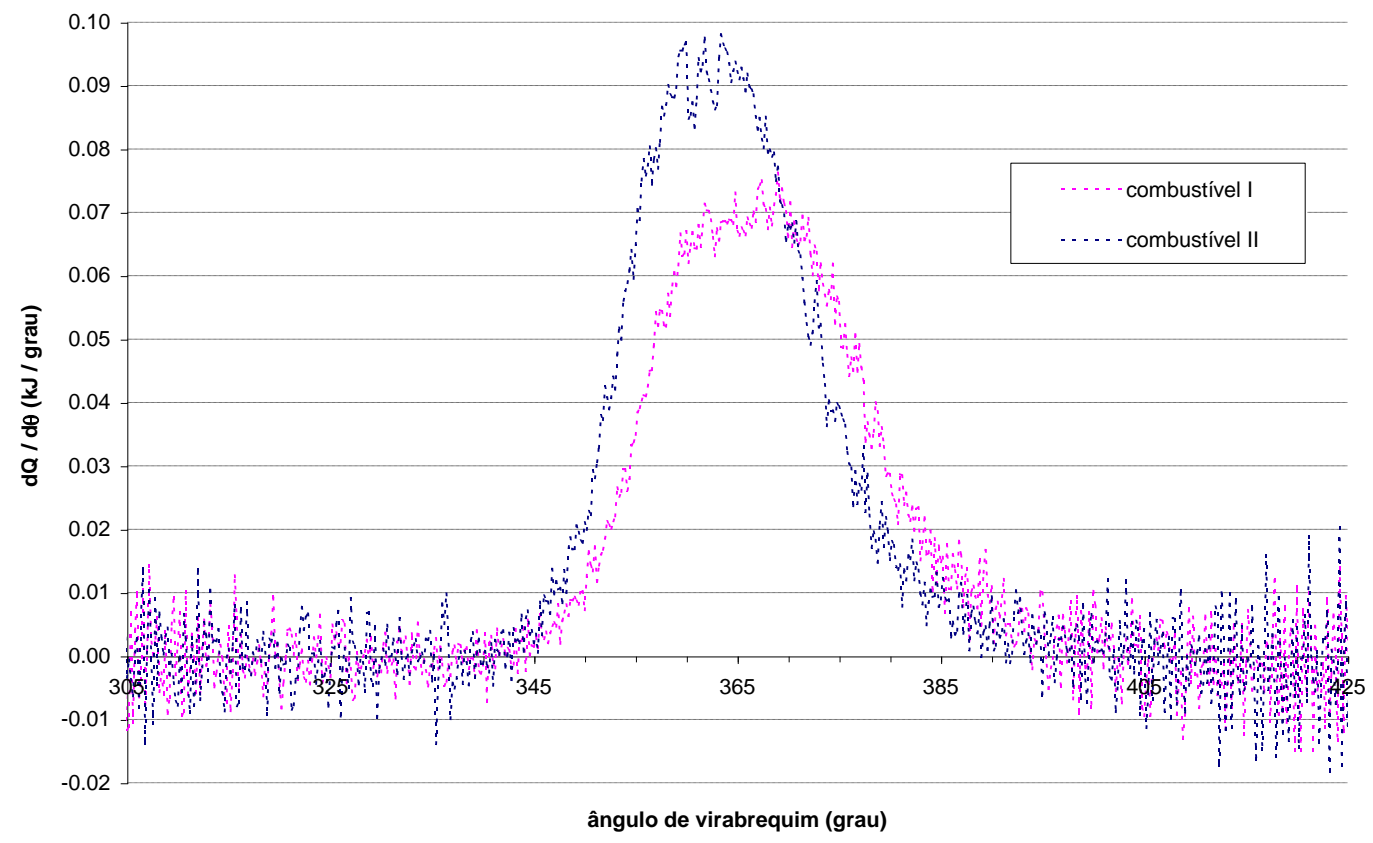

Figura 7.76 - Taxas de liberação de calor calculada para os combustíveis I e II.

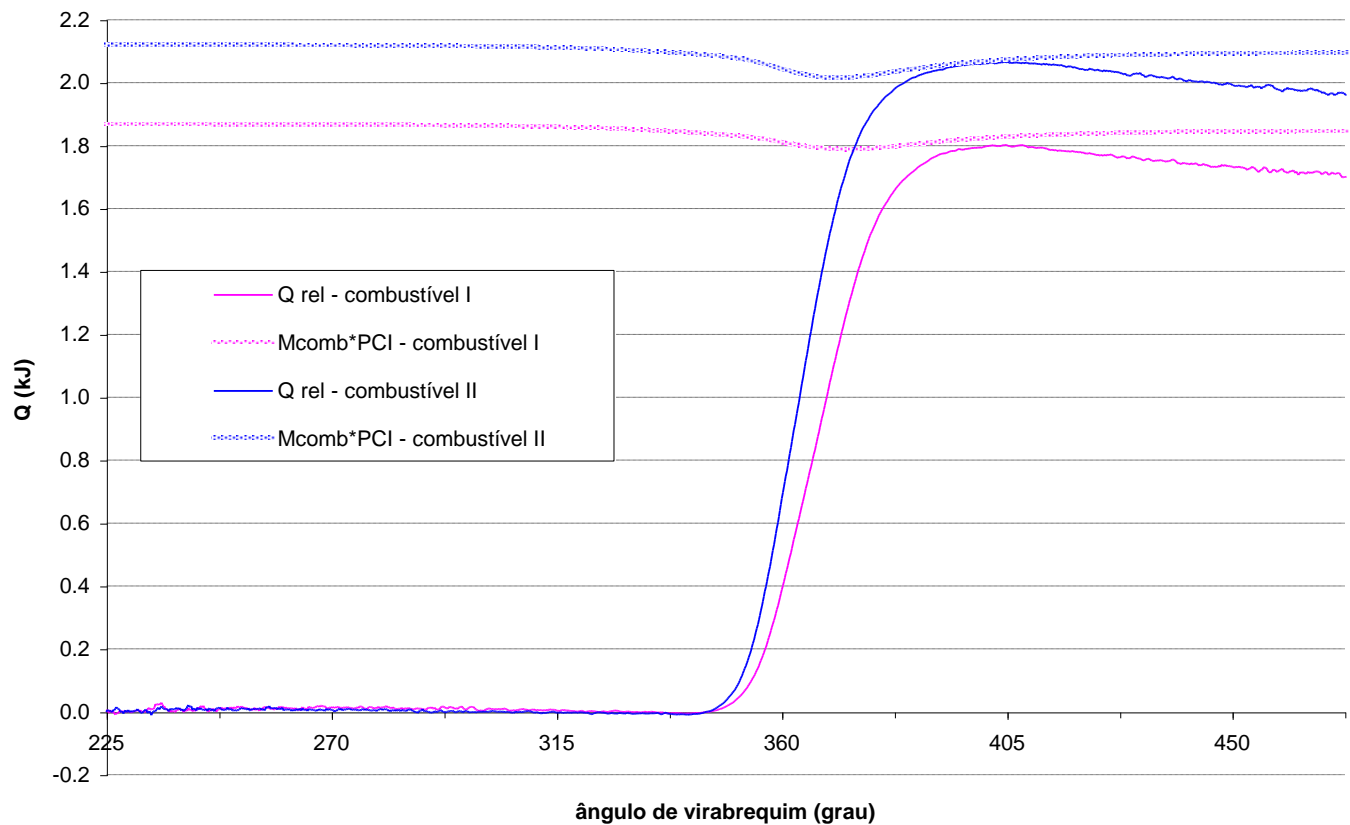

Figura 7.77 - Curvas de liberação de calor para os combustíveis I e II. 


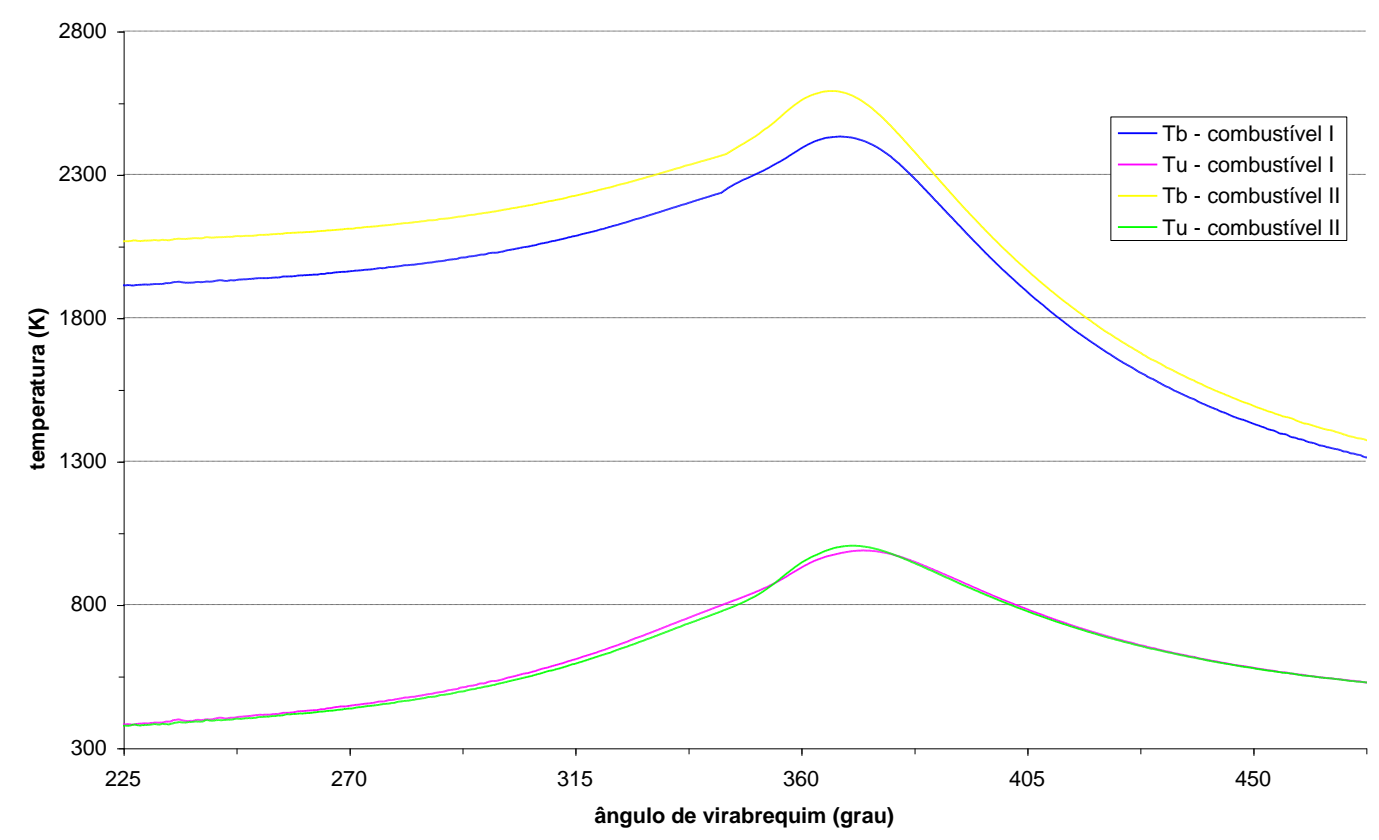

Figura 7.78 - Curvas de temperaturas dos VC para os combustíveis I e II.

Como se observa, a aplicação do sistema de análise da combustão a dados determinados experimentalmente forneceu resultados coerentes em termos de balanços de massa e energia, permitindo avaliar a influência de parâmetros de projeto e operação do motor na evolução da combustão. 


\section{CONCLUSÕES E RECOMENDAÇÕES}

O presente trabalho demonstrou a viabilidade da implementação de um modelo para determinação da evolução da combustão a partir da pressão medida na câmara, considerando-se, além das duas zonas principais contendo gases queimados e não queimados, mais uma terceira representando as frestas, os efeitos de vazamento de gases para o cárter e dissociação química dos produtos da combustão a altas temperaturas. $\mathrm{O}$ equacionamento empregado, explicitando as derivadas das temperaturas dos gases contidos nos volumes de controle em função da posição angular do virabrequim, permitiu a construção de um código numérico que torna sua resolução extremamente rápida e simples, sem necessidade de reiterações. Este programa computacional, aliado ao sistema de aquisição de pressão na câmara de combustão desenvolvido, constitui uma ferramenta adequada para aplicação em pesquisa e desenvolvimento de motores.

O sistema de análise da combustão fornece não só valores de fração de massa queimada em função da posição angular do virabrequim como também temperaturas, fluxos de calor para as paredes, interação da frente de chama com as paredes da câmara, e influência das frestas e vazamentos na evolução da combustão. Indiretamente, também permite avaliar a influência de parâmetros operacionais e de projeto na progressão da combustão e, portanto, no rendimento indicado do motor. Todos estes aspectos são fundamentais não só no desenvolvimento de motores mas também no projeto e otimização de componentes como pistões, válvulas, anéis, etc.

A aplicação do sistema de análise a uma curva de pressão gerada numericamente por um simulador de ciclo termodinâmico bastante fidedigno permitiu obter curvas de evolução da combustão similares às previstas pelo simulador, confirmando a coerência e 
confiabilidade do modelo desenvolvido. Em particular, o modelo de troca de calor empregado trouxe melhores resultados do que o modelo empregado no simulador, fato comprovado pela obtenção de valores de liberação de calor (ou fração de massa queimada) nulos no período de compressão a partir das análises de curvas de pressão obtidas experimentalmente.

A análise de sensibilidade dos resultados à variação dos parâmetros de entrada do modelo proposto confirma a importância da determinação precisa da posição angular de referência na curva de pressão. Uma incerteza na fração de massa queimada menor do que $1,5 \%$ requer que a incerteza na determinação desta posição angular seja menor do que $0,2^{\circ}$. Também foi observado que a não consideração da dissociação química dos produtos da combustão ocasionou diferenças da ordem de 3,5\% no cálculo da massa queimada, para o motor considerado em regime de plena potência. Pôde-se avaliar também a influência das frestas no cálculo da liberação de calor, onde um volume da ordem de 1,1\% do mínimo volume da câmara gerou uma diferença máxima de até 1,0 \% na fração de massa queimada e 1,2 \% na liberação acumulada de calor. Os efeitos de vazamentos na fração de massa queimada, para o motor considerado, são no mesmo sentido do que aqueles gerados pelas frestas, acrescentando a estes últimos uma alteração de cerca de 0,2\% na amplitude de variação. Constatou-se que a influência das temperaturas admitidas para as paredes da câmara e da pressão de referência na massa queimada é menos importante do que a dos parâmetros anteriores.

Em relação à forma de integração numérica das equações diferenciais obtidas no modelamento, constatou-se não ser necessário empregar métodos mais sofisticados do que o método de Euler, pois mesmo para um passo de integração de $1,0^{\circ}$, os resultados se mostraram apropriados. 
A aplicação do sistema de análise desenvolvido a casos reais mostrou a eficácia da ferramenta, na medida em que os balanços de massa e energia foram atingidos dentro da faixa de $1,0 \%$ e em que alterações das condições de funcionamento se refletiram coerentemente nas curvas calculadas.

Há que se ressaltar a importância da precisão na medição de pressão para a analise da combustão. A minimização de ruídos associados à aquisição de pressão através do emprego de filtros (físicos ou numéricos) e aterramento comum a todos os componentes envolvidos, incluindo o próprio motor, são medidas necessárias caso se queira uma análise mais acurada. Paralelamente, a escolha de um transdutor de pressão com características térmico-mecânicas adequadas reduz o efeito de drifts causados por tensões térmicas na face de medição.

Propõe-se, a título de aprimoramento do presente trabalho, a elaboração de um modelo adicional capaz de fornecer a fração do volume de frestas que, a cada instante, possa estar contendo gases queimados, uma vez que aqui se adotou a hipótese de que somente gases não queimados poderiam entrar nestas frestas. Para o motor analisado, esta hipótese é bem razoável por ser a vela de ignição relativamente centrada. Mas para câmaras em forma de cunha, esta hipótese não mais poderia ser validada. Também se pode, a partir de conhecimento mais detalhado das características construtivas do transdutor de pressão, elaborar um modelo de correção do drift devido a tensões térmicas, uma vez que se conhece a evolução da temperatura na câmara.

Um tratamento mais sofisticado dos valores de pressão medidos certamente trará melhoria aos resultados da análise. A implementação de filtros digitais, ou mesmo físicos, que não descaracterizem a curva média de pressão como faz a média móvel, é algo a ser estudado e aprimorado. 


\section{REFERÊNCIAS BIBLIOGRÁFICAS}

[1] RASSWIELER, G. M.; WITHROW L. "Motion Pictures of Engine Flame Propagation Model for S.I. Engines”. SAE Journal (Transactions). 1938. Vol. 42, pp. $185-204$.

[2] SHAYLER, P. J.; WISEMAN, M. W.; MA, T. "Improving the Determination of Mass Fraction Burnt”. SAE paper \# 900351. 1990.

[3] KRIEGER, R. B.; BORMAN, G. L. "The Computation of Apparent Heat Release for Internal Combustion Engines”. ASME paper 66-WA/DGP-4. 1966.

[4] EICHELBERG, G. "Some New Investigation on Old Combustion Engine Problems”. Engineer, Londres, Inglaterra. 1939. Vol. 148, pp. 463-466, 547, 560.

[5] BORMAN, G.; NISHIWAKI, K. "Internal Combustion Engine Heat Transfer”. Prog. Energy Comb. Sci. 1987. Vol. 13, pp. 1-46.

[6] GATOWSKI, J. A.; BALleS, E. N.; CHUN, K. M.; NELSON, F. E.; EKCHIAN, J. A.; HEYWOOD, J. B. "Heat Release Analysis of Engine Pressure Data”. SAE paper \# 841359. 1984.

[7] WOSCHNI, G. "A Universally Applicable Equation for the Instantaneous Heat Transfer Coefficient in the Internal Combustion Engine". SAE paper \# 670931. 1967.

[8] BOWMAN, C. T. "Kinetics of Pollutant Formation and Destruction in Combustion". In: HEYWOOD, J. B. Internal Combustion Engine Fundamentals. McGraw-Hill, 1988. pp 572-574.

[9] CHUN, K. M.; HEYWOOD, J. B. "Estimating Heat-Release and Mass-ofMixture Burned from Spark-Ignition Engine Pressure Data". Combustion Science and Technology. 1987. Vol. 54, pp. 133-143.

[10] CHEUNG, H. M.; HEYWOOD, J. B. "Evaluation of a One-Zone BurnRate Analysis Procedure Using Production SI Engine Pressure Data”. SAE paper \# 932749. 1993. 
[11] NIGRO, F. E. B.; TRIELLI, M. A. "Determinação da Razão de Liberação de Calor durante a Combustão de Ésteres de Óleos Vegetais em Motores Diesel”. In: I Simpósio de Engenharia Automotiva. Anais. Brasília, 1983.

[12] MUELlER, R. P.; LI, C.; TSAO, K. C. "Modeling for Mass Burning Rate and Combustion Duration in Spark Ignition Engines Using Gasohol Fuels". SAE paper \# 831677. 1983.

[13] POULOS, S. G.; HEYWOOD, J.B. "The Effect of Chamber Geometry on Spark-Ignition Engine Combustion”. SAE paper \# 830334. 1983.

[14] NIGRO, R. B.; PIMENTA, M. M. Análise de um Simulador de Motor de Combustão Interna de Ignição por Centelha. São Paulo, 1994. 193p. Trabalho de formatura - Escola Politécnica, Universidade de São Paulo.

[15] BLIZARD, N. C.; KECK, J. C. "Experimental and Theoretical Investigation of Turbulent Burning Model for Internal Combustion Engines”. SAE paper \# 740191. 1974.

[16] TABACZYNSKI, R. J.; FERGUSON, C. R.; RADHAKRISHNAN, K. “A Turbulent Entrainment Model for Spark-Ignition Engine Combustion”. SAE paper \# 770647. 1977.

[17] HIRES, S. D.; EKCHIAN A.; HEYWOOD, J. B.; TABACZYNSKI, R. J.; WALL, J. C. "Performance and $\mathrm{NO}_{\mathrm{x}}$ Emissions Modeling of a Jet Ignition Prechamber Stratified Charge Engine”. SAE paper \# 760161. 1976.

[18] MARTIN, M. K.; HEYWOOD, J. B. "Approximate Relationships for the Thermodynamic Properties of Hydrocarbon-Air Combustion Products". Combustion Science and Technology. 1977. Vol. 15, pp. 1-10.

[19] VAN WYlen, G. J.; SONNTAG, R. E. Fundamentos da Termodinâmica Clássica Tradução da $2^{\circ}$ edição americana Editora Edgard Blücher. 1976.

[20] HEYWOOD, J. B. Internal Combustion Engine Fundamentals. McGraw-Hill, 1988.

[21] HOLMAN, J. P. Transferência de Calor. McGraw-Hill, 1983. 
[22] KYOUNGDOUG, M.; CHENG, W. K.; HEYWOOD, J. B. "The Effects of Crevices on the Engine-Out Hydrocarbon Emissions in SI Engines". SAE paper \# 940306. 1994.

[23] YUN, H. J.; MIRSKY, W. "Schlieren Streak Measurements of Instantaneous Gas Velocities from a Spark Ignition Engine”. SAE paper \# 741015. 1974.

[24] KURATLE, R. H.; MÄRKI, B. "Influencing Parameters and Error Sources During Indication on Internal Combustion Engines”. SAE paper \# 920233. 1992.

[25] ASSOCIAÇÃO BRASILEIRA DE NORMAS TÉCNICAS “Determinação da emissão do gás de escapamento emitido por motor Diesel” - NBR10813. Rio de Janeiro. 1993.

[26] SCHRAMM, J.; SORENSON, S. C. "Effects of Lubricating Oil on Hydrocarbon Emissions in an SI Engine”. SAE paper \# 890622. 1989.

[27] KAISER, E. W.; SIEGL, W. O.; RUSS, S. G. "Fuel Composition Effects on Hydrocarbon Emissions from a Spark-Ignited Engine - Is Fuel Absorption in Oil Significant?”. SAE paper \# 952542. 1995.

[28] NAMAZIAN, M.; HEYWOOD, J. B. "Flow in the Piston-Cylinder-Ring Crevices of a Spark-Ignition Engine: Effect on Hydrocarbon Emissions, Efficiency and Power”. SAE paper \# 820088. 1982.

[29] GRIMM, B. M.; JOHNSON, R. T. "Review of Simple Heat Release Computations". SAE paper \# 900445. 1990.

[30] SHAYLER, P. J.; MAY, S. A. "Heat Transfer to the Combustion Chamber Walls in Spark Ignition Engines”. SAE paper \# 950686. 1995.

[31] OLIKARA, C.; BORMAN, G. L. "A Computer Program for Calculating Properties of Equilibrium Combustion with Some Applications to I.C. Engines”. SAE paper \# 750468. 1975.

[32] WAY, R. J. B. "Methods for Determination of Composition and Thermodynamic Properties of Combustion Products for Internal Combustion Engine Calculations". Instn. Mech. Engrs. Proceedings. 1977. Vol. 190 60/76, pp. 687- 
697.

[33] TAYLOR, F. T. Análise dos Motores de Combustão Interna vol 1. Editora Edgard Blücher. 1968

[34] TAYLOR, F. T. Análise dos Motores de Combustão Interna vol 2. Editora Edgard Blücher. 1968

[35] BRANCO, G. M. Curso de motores - apostila do curso. EPUSP/CETESB. 1990.

[36] DOMSCHKE, A. G.; LANDI, F. R. Motores de Combustão Interna de Êmbolo. EPUSP. 1963.

[37] CARNAHAN, B.; LUTHER, H. A.; WILKES, J. O. Applied Numerical Methods. New York. John Wiley \& Sons. 1969. 604p.

[38] OBERT, E. F. Internal Combustion Engines vol 1. International Textbook Company. Pennsylvania, 1968.

[39] OBERT, E. F. Internal Combustion Engines vol 2. International Textbook Company. Pennsylvania, 1968. 


\section{APÊNDICE A}

\section{MAPA DE GEOMETRIA DO MOTOR}

Os gráficos a seguir trazem a evolução das áreas do pistão, cabeçote e cilindro englobadas pela frente de chama em função de seu raio adimensionalizado pelo diâmetro do cilindro do motor M 366 G. Podem ser vistas também as evoluções dos volumes contidos em seu interior. Estas curvas foram geradas para raios de frente de chama a cada $1 \%$ do diâmetro do cilindro e a cada $3,5^{\circ}$ de virabrequim, a partir do PMS até $66,5^{\circ}$.

Estes mapas são utilizados na determinação do raio da frente de chama e das áreas supra citadas uma vez dado o volume queimado em uma determinada posição angular do virabrequim, através de interpolações lineares.

Na parte superior de cada gráfico acham-se a posição angular do virabrequim e a respectiva distância do pistão ao cabeçote para as quais a evolução das áreas e volumes foi calculada. 

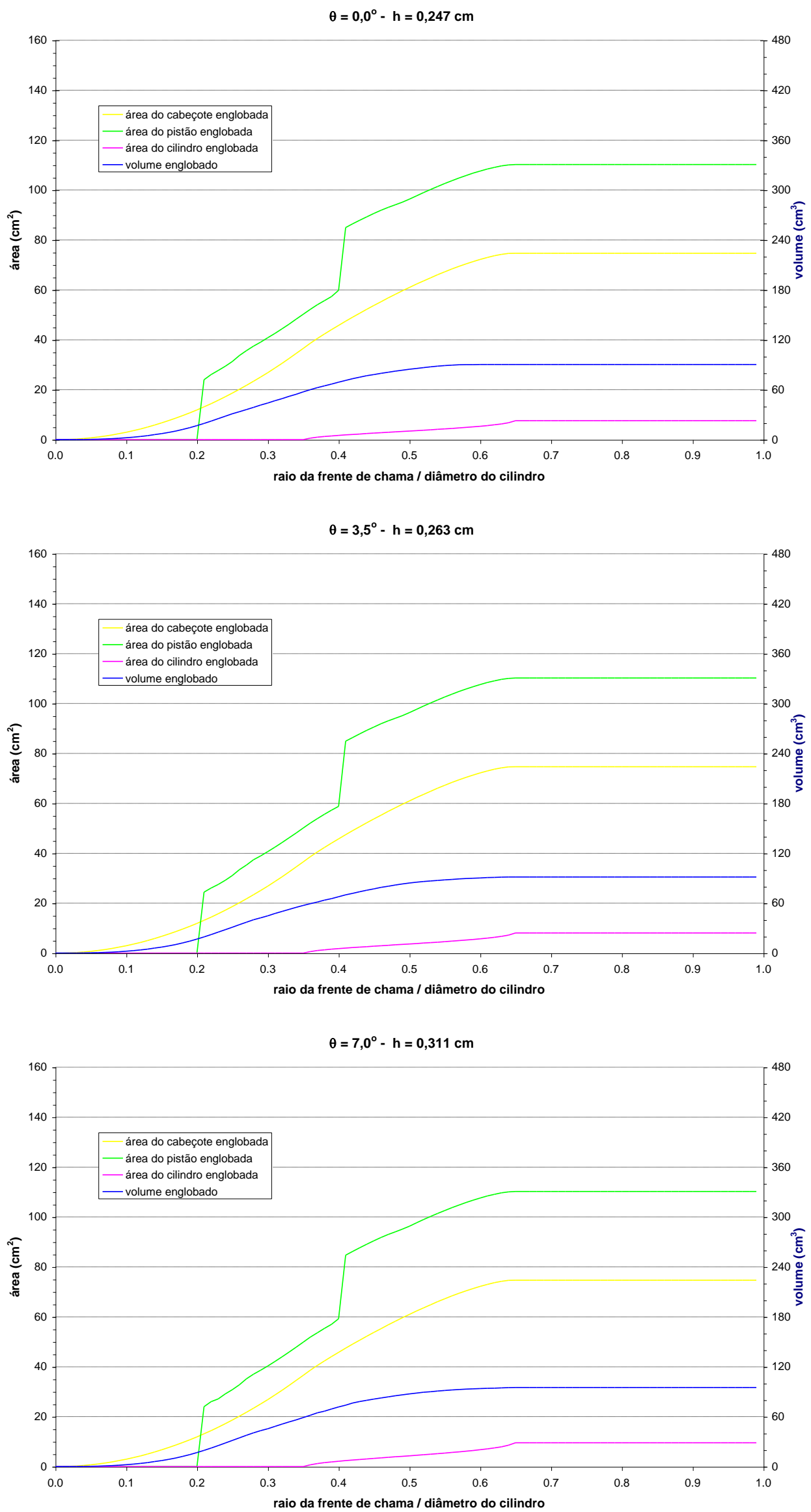

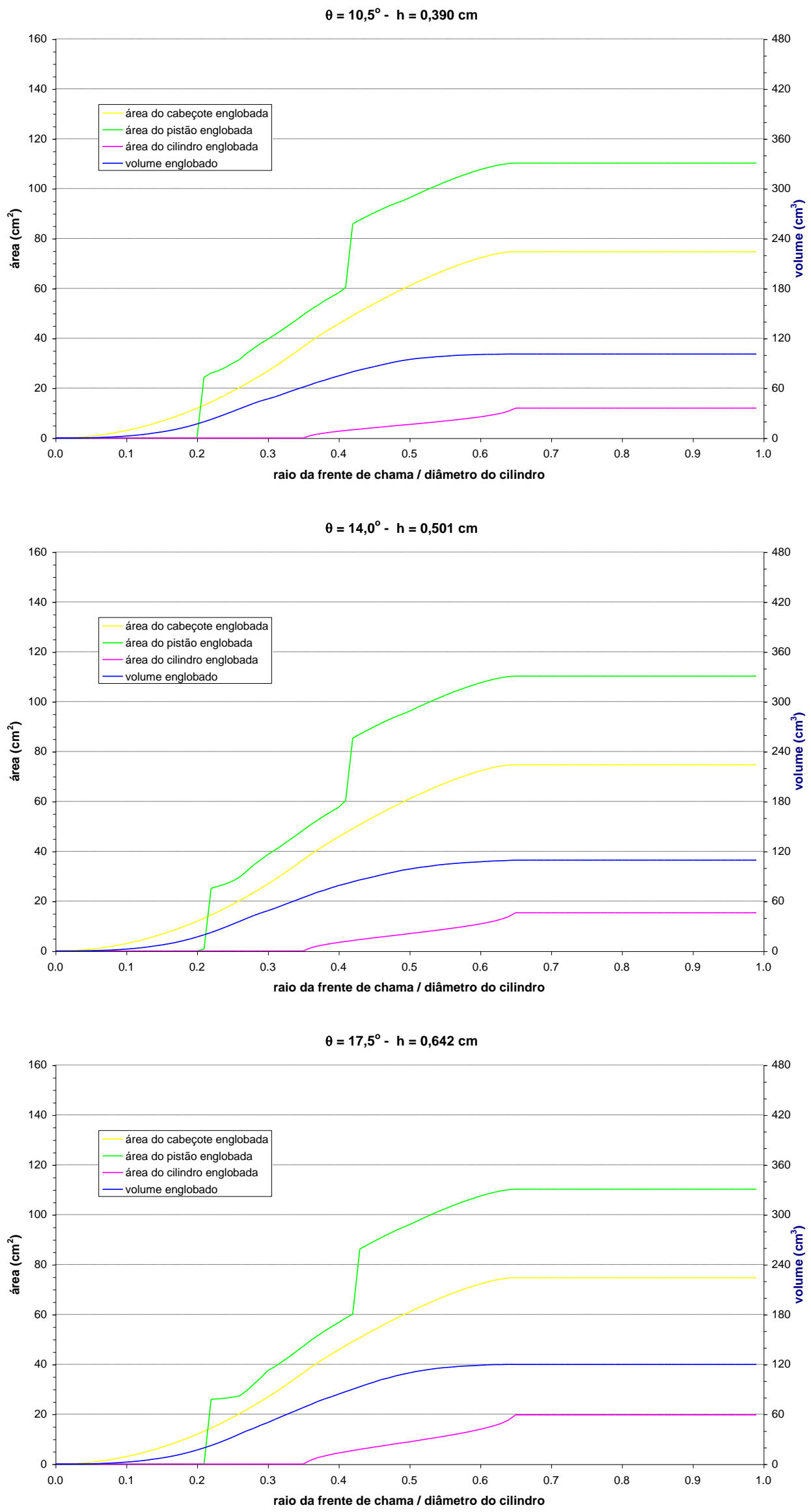


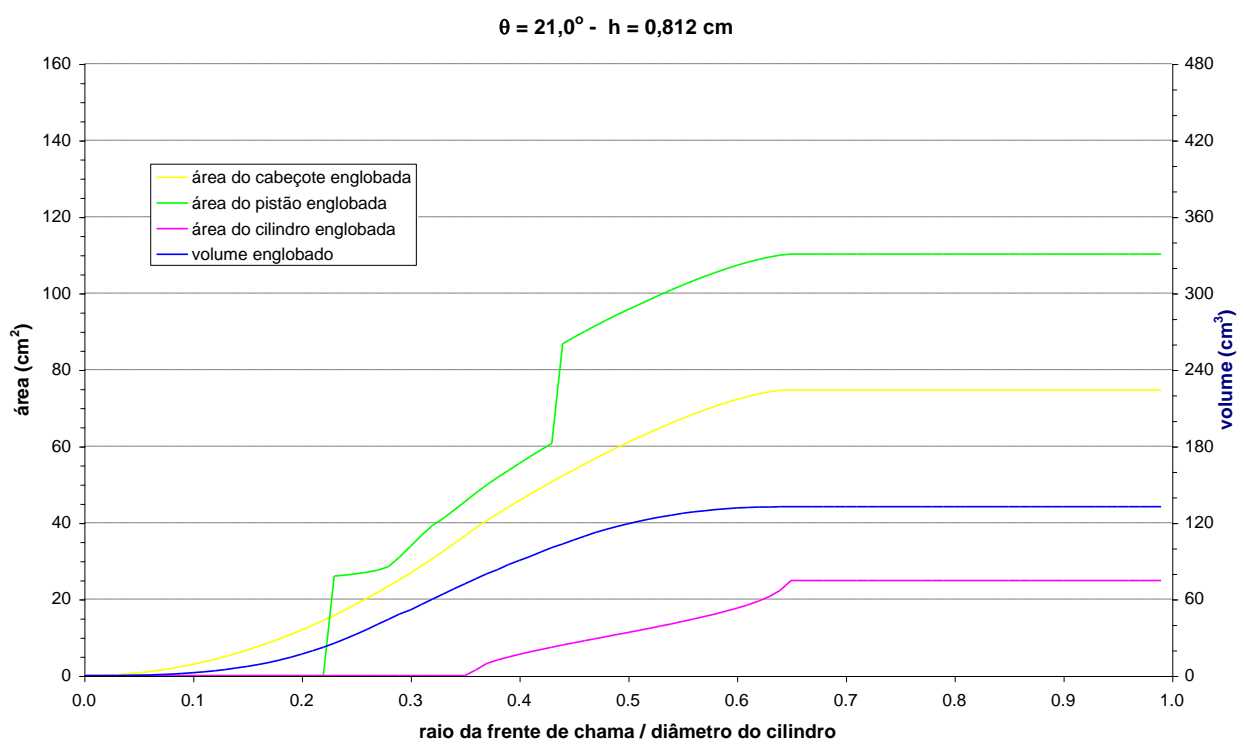

$\theta=24,5^{\circ}-\mathrm{h}=1,012 \mathrm{~cm}$

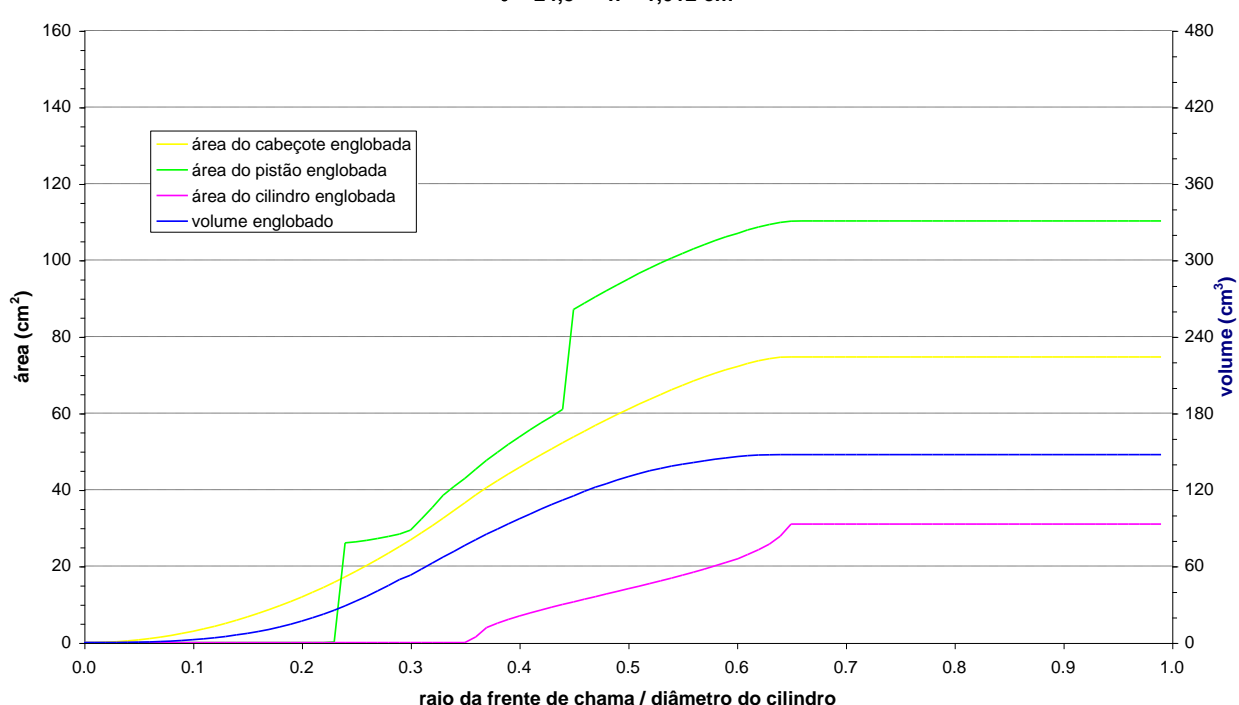

$\theta=28,0^{\circ}-h=1,238 \mathrm{~cm}$

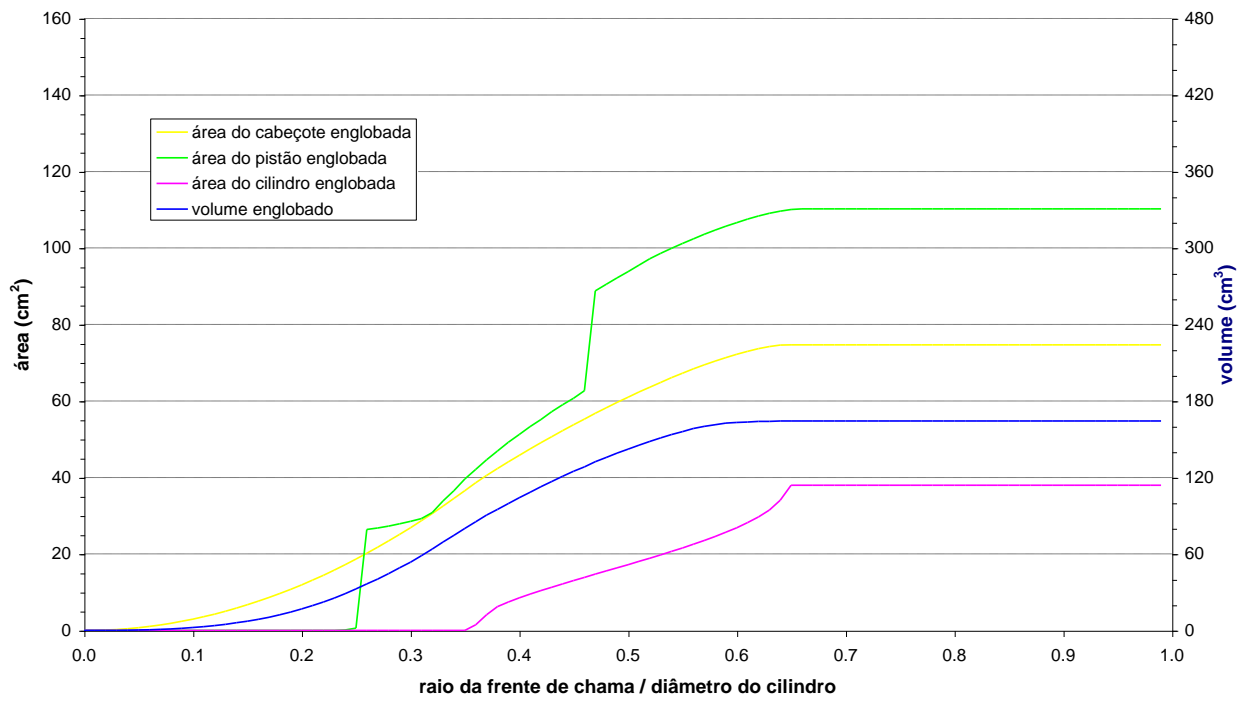




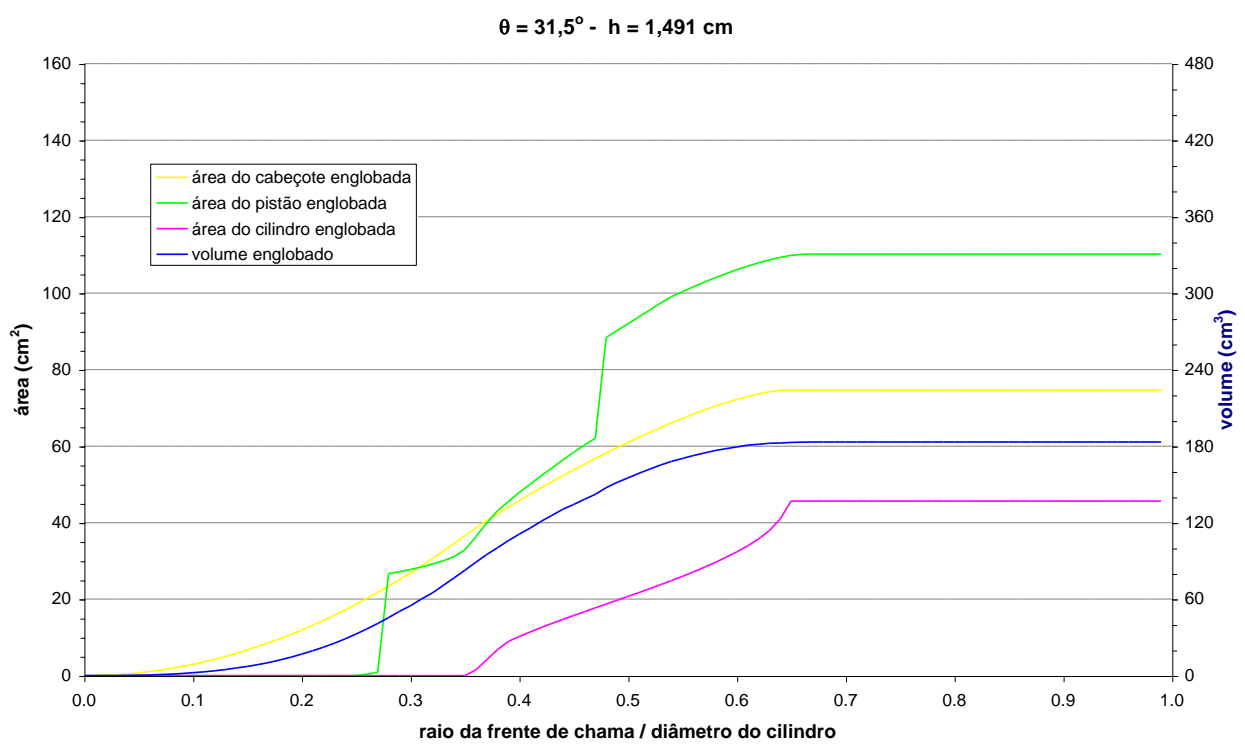

$\theta=35,0^{\circ}-h=1,768 \mathrm{~cm}$

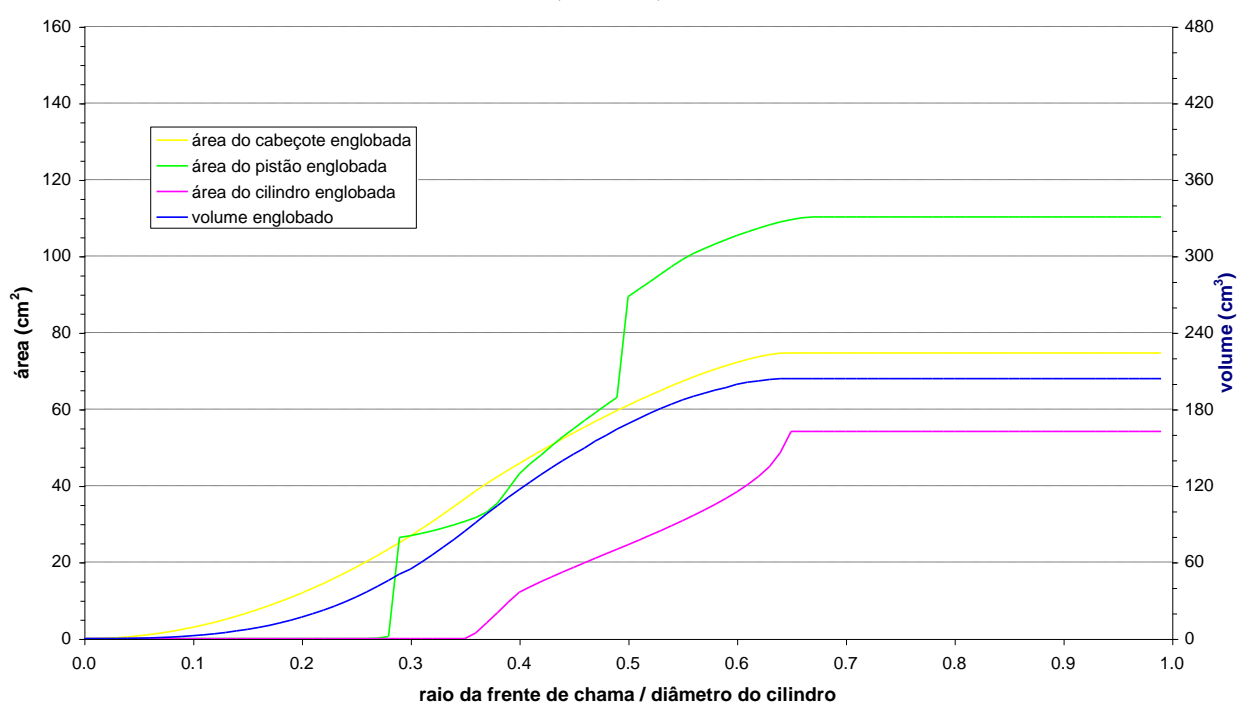

$\theta=38,5^{\circ}-h=2,068 \mathrm{~cm}$

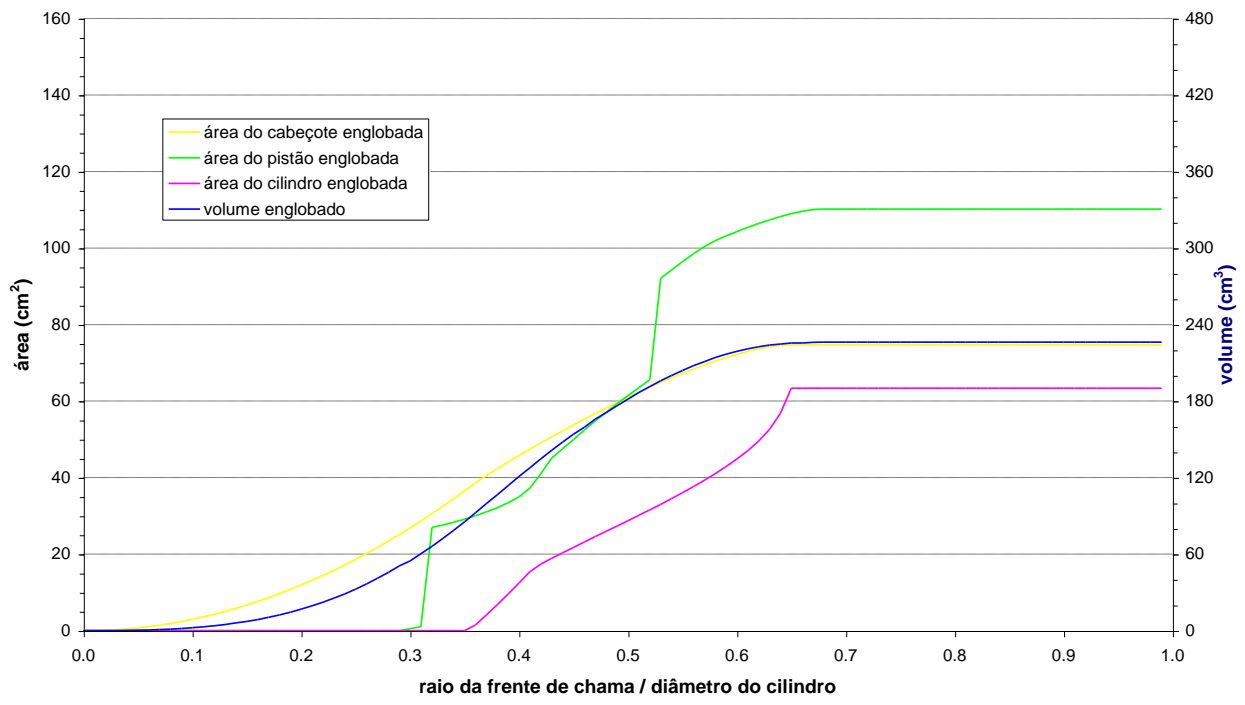




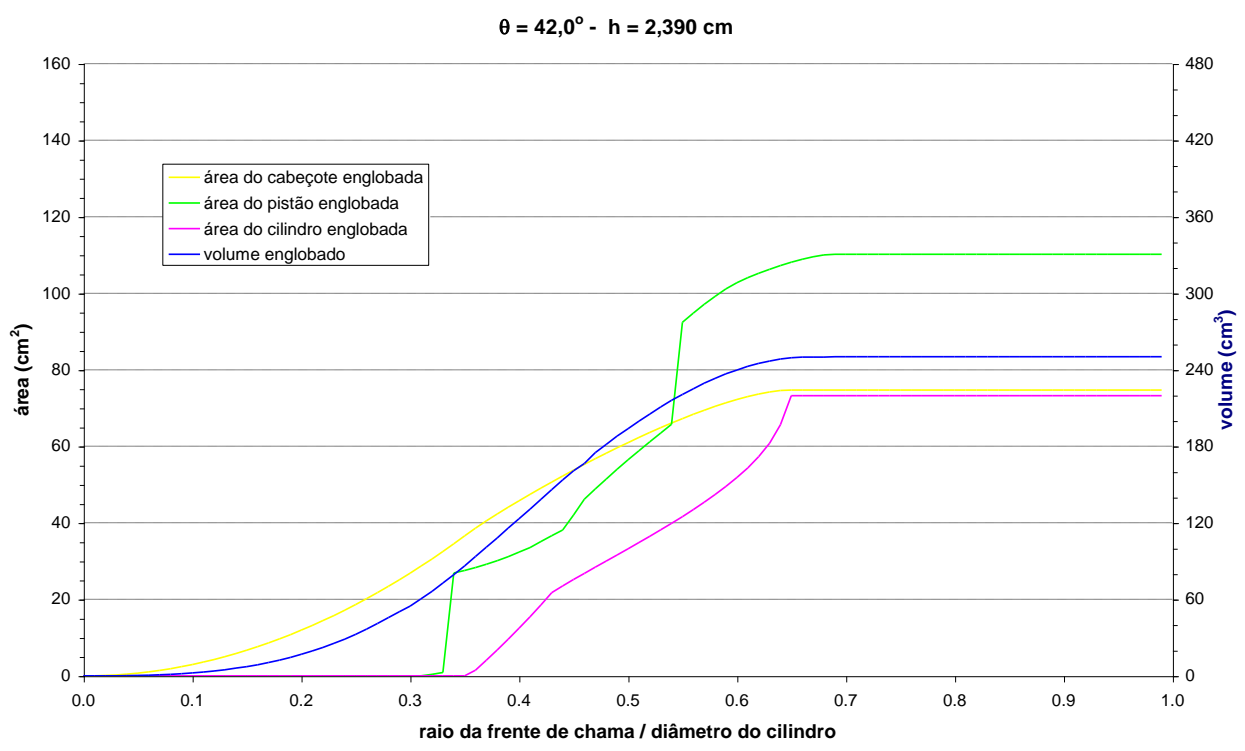

$\theta=45,5^{\circ}-\mathrm{h}=2,730 \mathrm{~cm}$

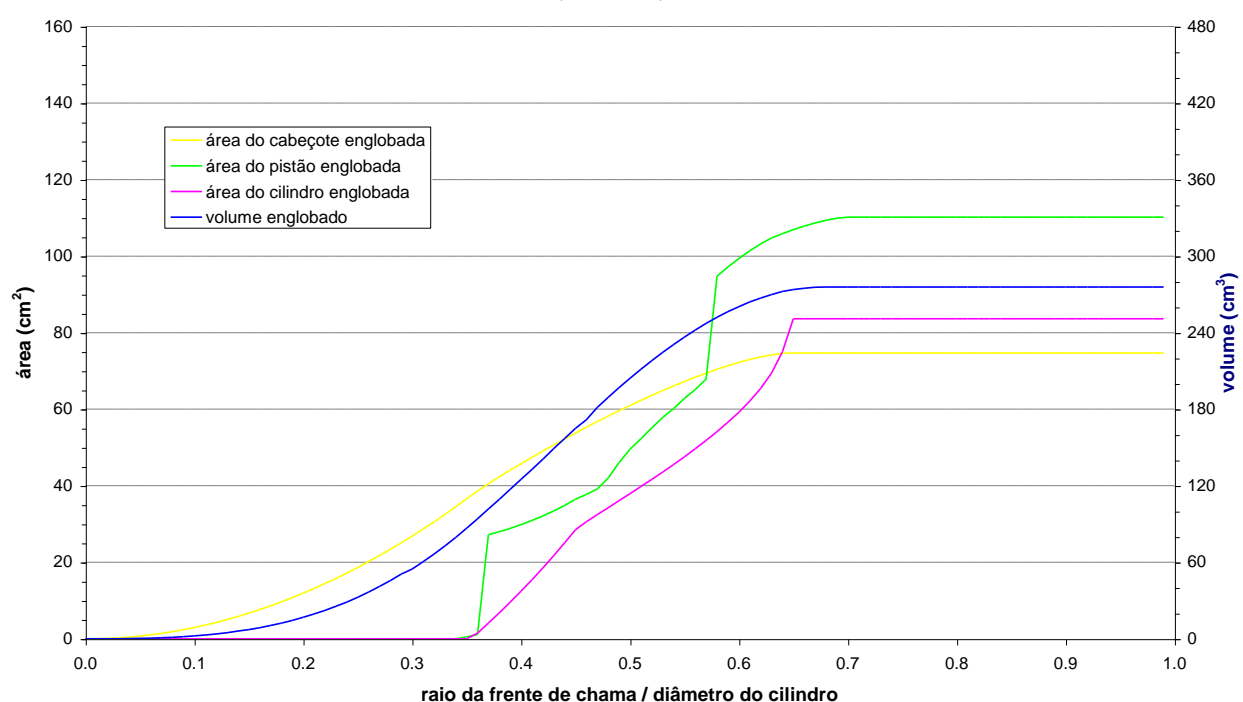

$\theta=49,0^{\circ}-h=3,088 \mathrm{~cm}$

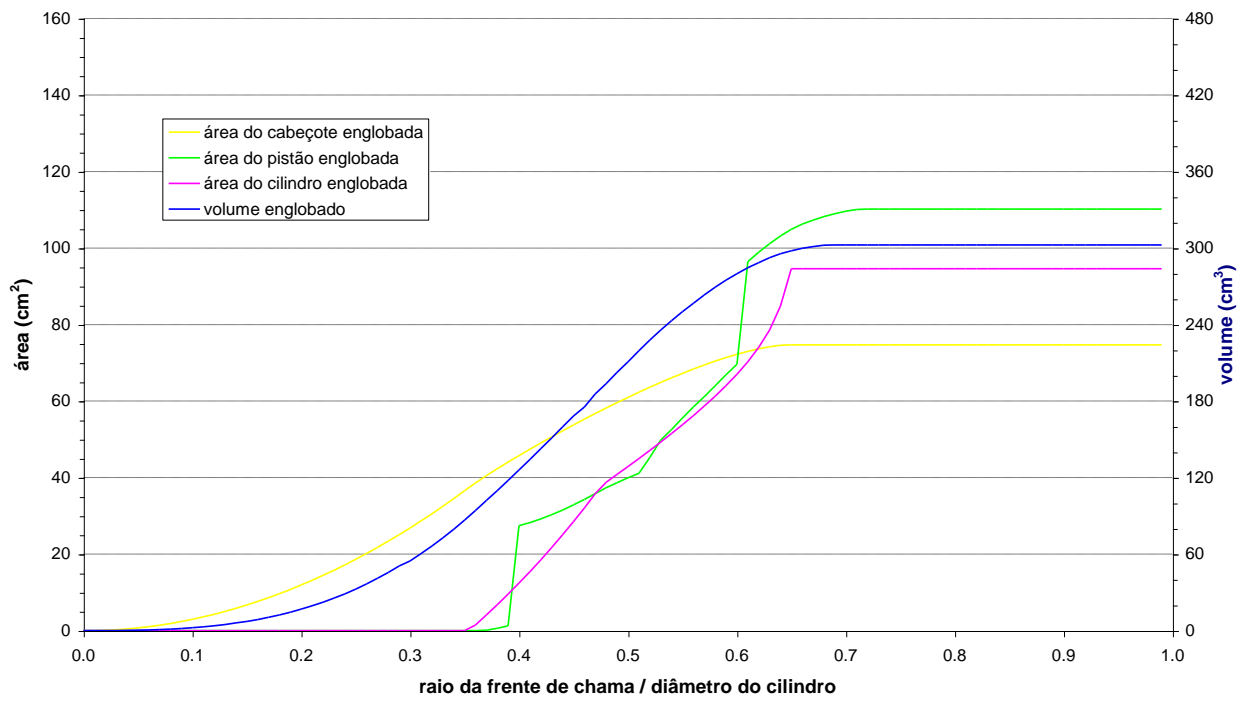




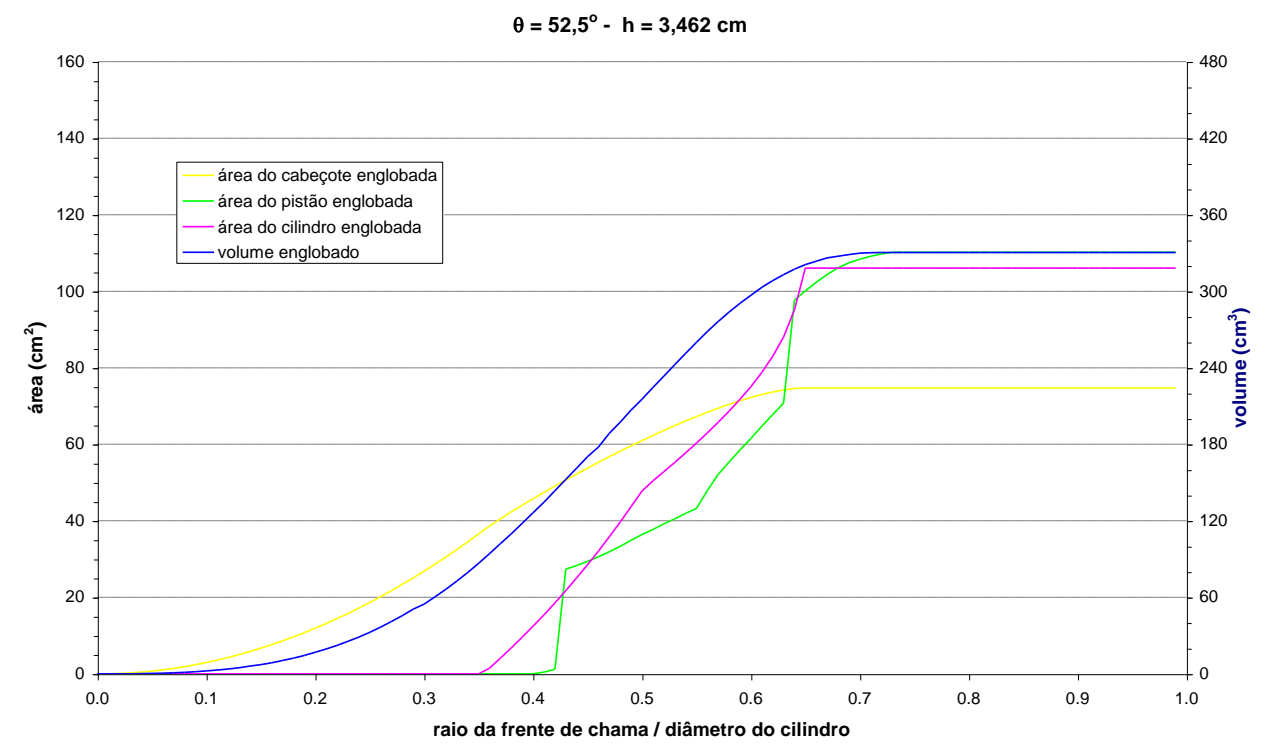

$\theta=56,0^{\circ}-\mathrm{h}=3,849 \mathrm{~cm}$

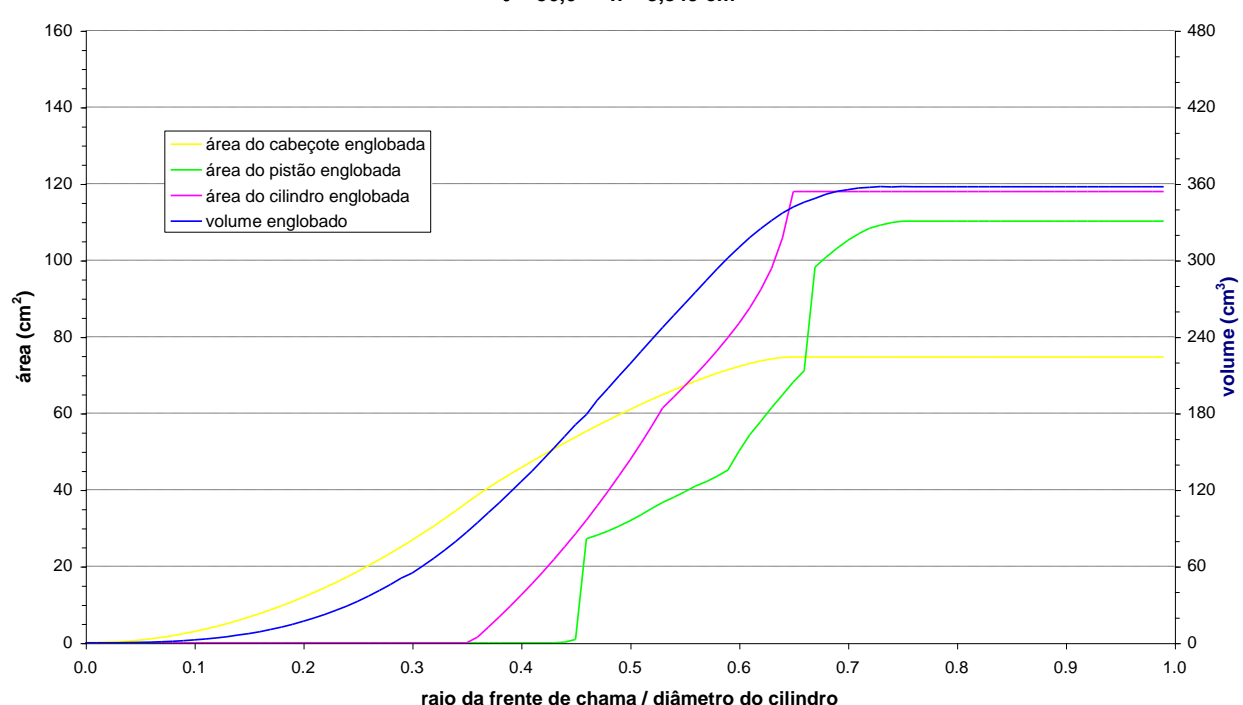

$\theta=59,5^{\circ}-h=4,247 \mathrm{~cm}$

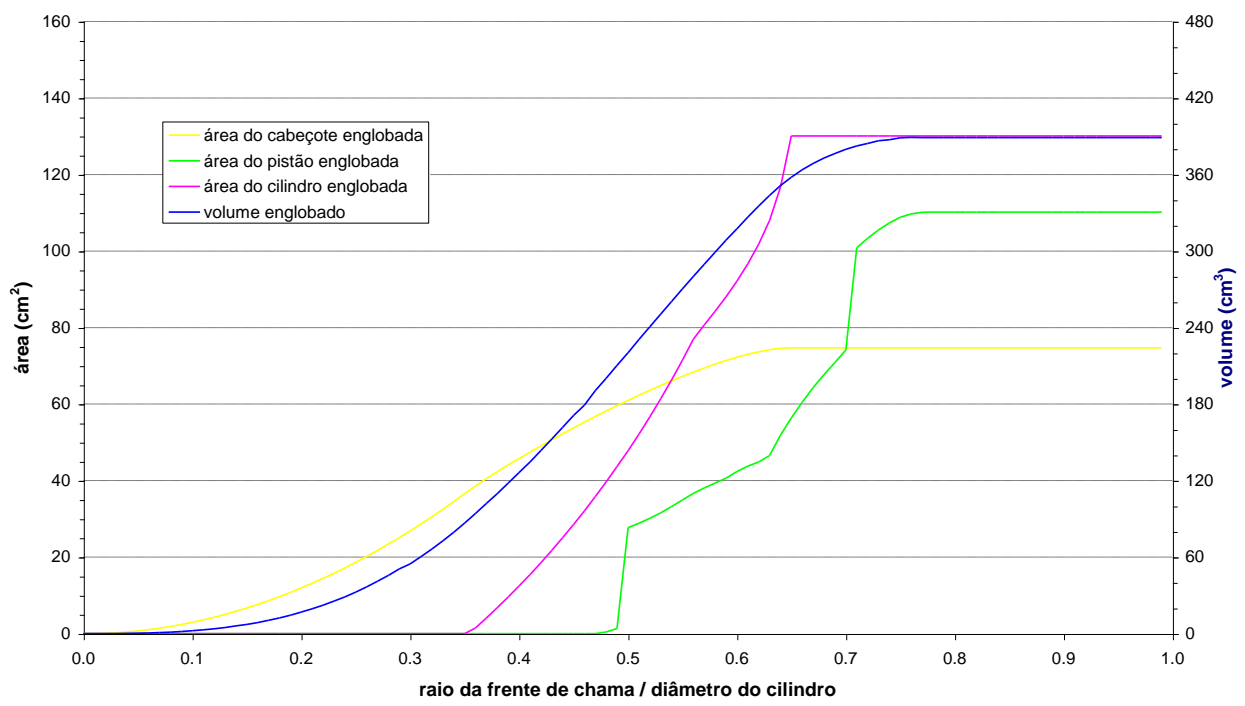




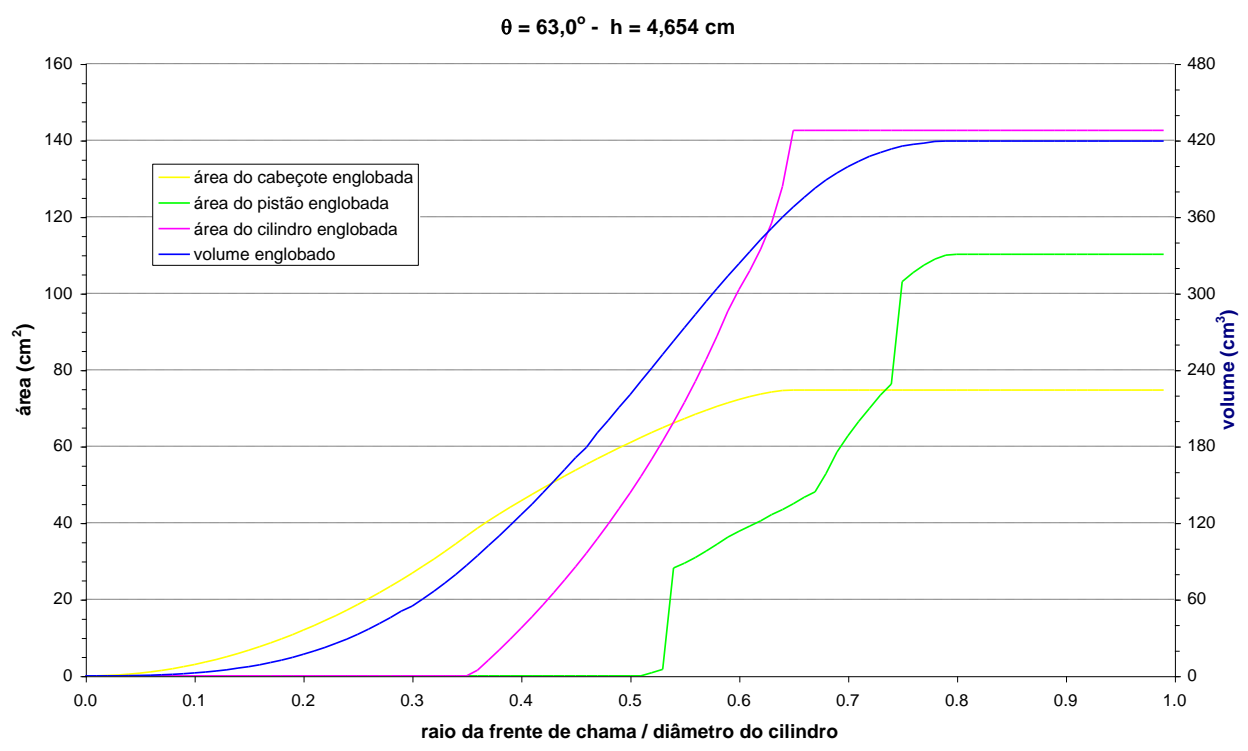

$\theta=66,5^{\circ}-\mathrm{h}=5,069 \mathrm{~cm}$

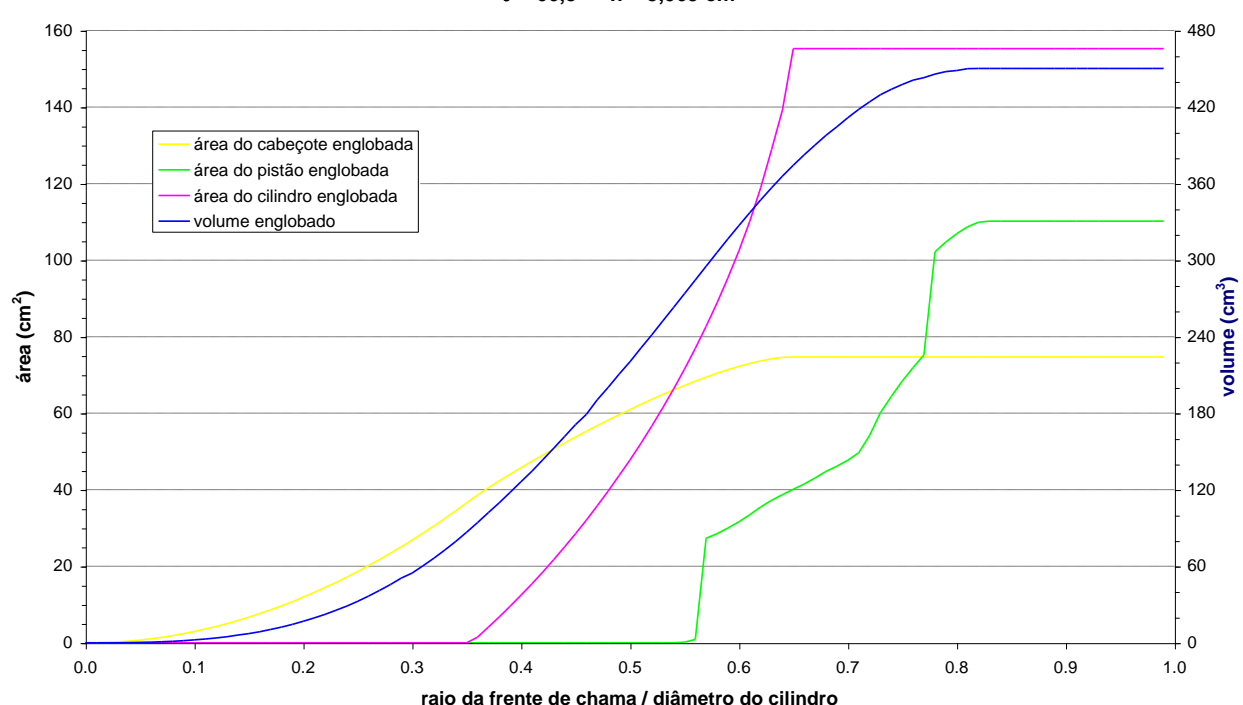




\section{APÊNDICE B}

\section{RESULTADOS DOS ENSAIOS}

A seguir são relacionadas as planilhas de dados de ensaio do motor M 366 G referentes às composições de combustível I e II descritas na Tabela 7.2 e na Tabela 7.8. Estes dados propiciaram a obtenção, entre outros, dos valores de consumos relacionados na Tabela 7.6 e na Tabela 7.9. 


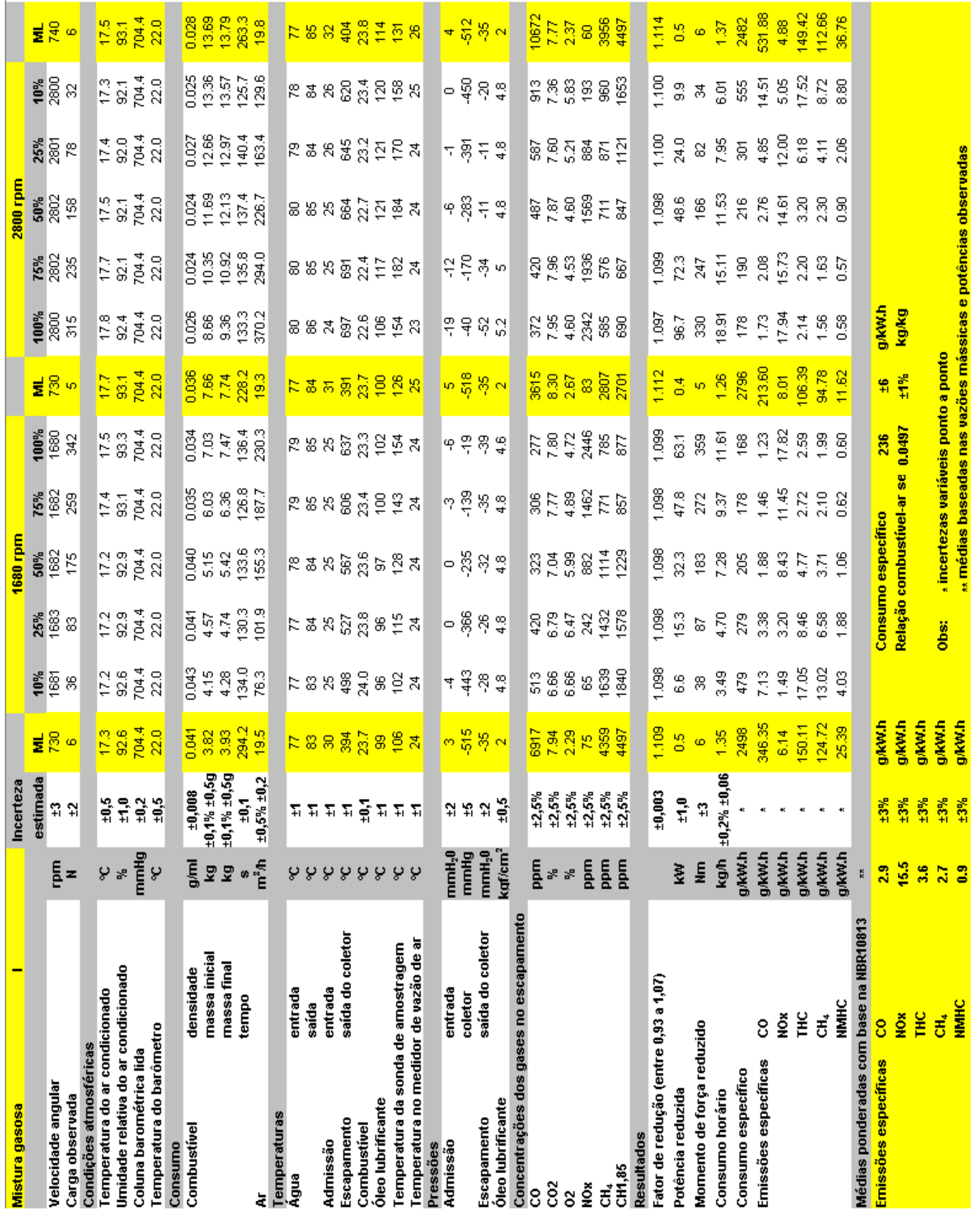




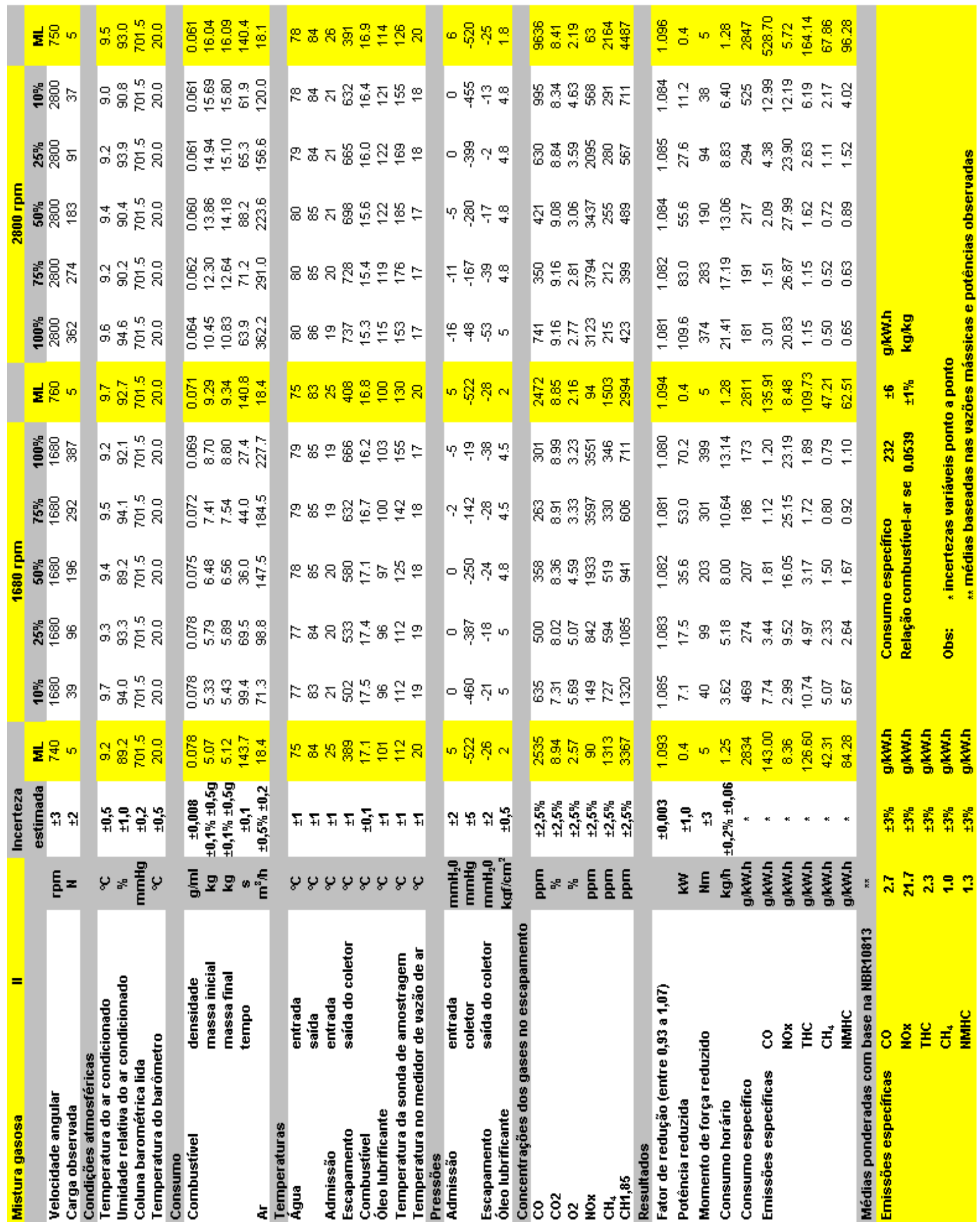

